ANL-MGR-GS-000001 REV 02

October 2004

\title{
Characterize Framework for Igneous Activity at Yucca Mountain, Nevada
}

Prepared for:

U.S. Department of Energy

Office of Civilian Radioactive Waste Management

Office of Repository Development

1551 Hillshire Drive

Las Vegas, Nevada 89134-6321

Prepared by:

Bechtel SAIC Company, LLC

1180 Town Center Drive

Las Vegas, Nevada 89144

Under Contract Number

DE-AC28-01RW12101 


\section{DISCLAIMER}

This report was prepared as an account of work sponsored by an agency of the United States Government. Neither the United States Government nor any agency thereof, nor any of their employees, nor any of their contractors, subcontractors or their employees, makes any warranty, express or implied, or assumes any legal liability or responsibility for the accuracy, completeness, or any third party's use or the results of such use of any information, apparatus, product, or process disclosed, or represents that its use would not infringe privately owned rights. Reference herein to any specific commercial product, process, or service by trade name, trademark, manufacturer, or otherwise, does not necessarily constitute or imply its endorsement, recommendation, or favoring by the United States Government or any agency thereof or its contractors or subcontractors. The views and opinions of authors expressed herein do not necessarily state or reflect those of the United States Government or any agency thereof. 
QA: QA

Characterize Framework for Igneous Activity at Yucca Mountain Nevada

ANL-MGR-GS-000001 REV 02

October 2004 


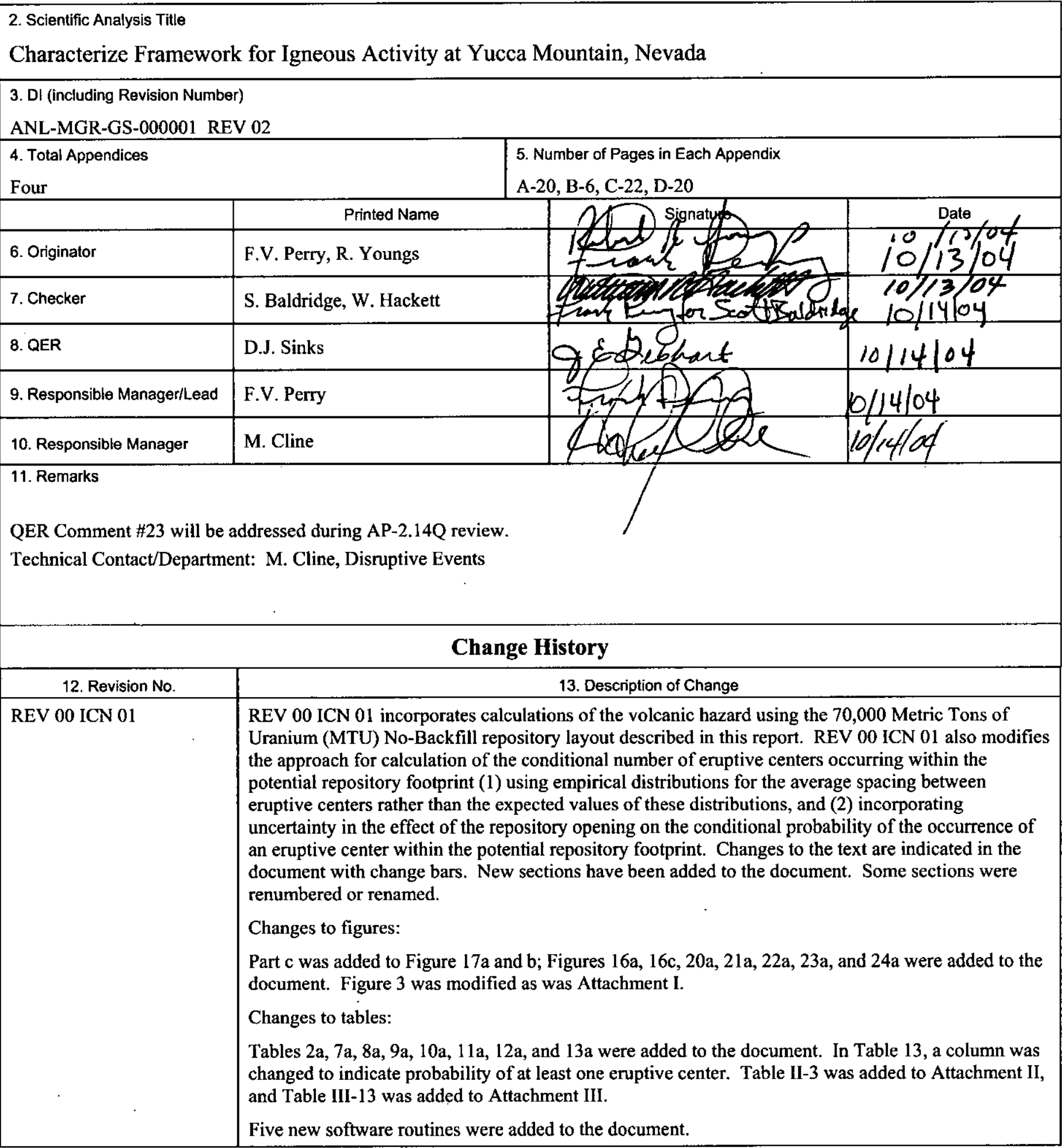




\begin{tabular}{|c|l|}
\hline 12. Revision No. & \multicolumn{1}{c|}{ 13. Description of Change } \\
\hline REV 01 & $\begin{array}{l}\text { REV 01 recalculated the frequency of intersection based on the new License Application footprint } \\
\text { (Section 6.5.3); documented sensitivity of the 1999 USGS aeromagnetic data (Section 6.5.4); and } \\
\text { documented the alternative conceptual model of the hot spot beneath the Yucca Mountain region } \\
\text { (Section 6.3.3).. Change bars were not used because revisions were extensive due to the change in the } \\
\text { repository footprint. }\end{array}$ \\
\hline REV 02 & $\begin{array}{l}\text { REV 02 presents sensitivity studies (Section 6.5.4) for alternative conceptual models to the PVHA. } \\
\text { editorial corrections are included in this revision. Three new sections (6.1.1, 6.1.3, 6.5.4.2) were added } \\
\text { to the report, and Sections 6.5.1, 6.5.2, and 6.5.3 were rewritten to improve transparency. The } \\
\text { mathematical formulations previously presented in these sections were moved to a new appendix } \\
\text { (Appendix A). Tables and figures were renumbered to reflect the report section in which they occur. } \\
\text { This revision was a complete rewrite, therefore no change bars were used. }\end{array}$ \\
\hline
\end{tabular}




\section{CONTENTS}

Page

ACRONYMS AND ABBREVIATIONS XV

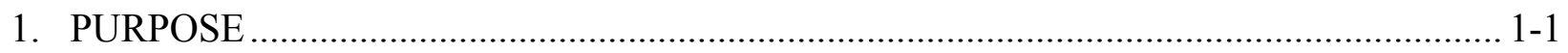

2. QUALITY ASSURANCE ................................................................................. 2-1

3. USE OF SOFTWARE ............................................................................................. $3-1$

3.1 SOFTWARE TRACKED BY CONFIGURATION MANAGEMENT ...................... 3-1

3.2 EXEMPT SOFTWARE ......................................................................... $3-7$

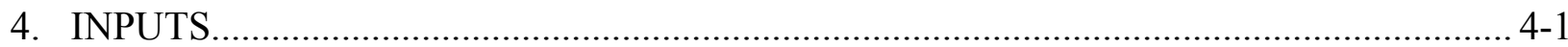

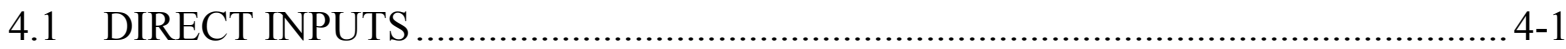

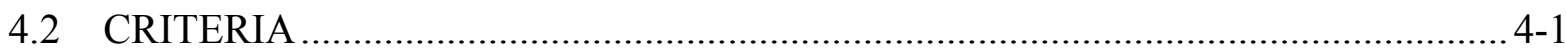

4.3 CODES, STANDARDS, AND REGULATIONS ............................................. 4-2

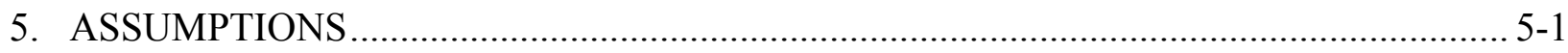

5.1 USE OF QUATERNARY VOLCANOES ....................................................... 5-1

5.2 ALL VOLCANIC EVENTS PRODUCE AT LEAST ONE ERUPTIVE CENTER ....................................................................................................... $5-2$

5.3 LOCATION OF ERUPTIVE CENTERS ALONG THE LENGTH OF A DIKE OR DIKE SEGMENT ............................................................................... $5-2$

6. SCIENTIFIC ANALYSIS ................................................................................ $6-1$

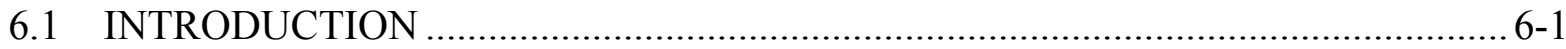

6.1.1 Summary of Conceptual Model for Igneous Activity................................... 6-2

6.1.1.1 Igneous Framework .......................................................... 6-2

6.1.1.2 Igneous Processes .................................................................... 6-6

6.1.1.3 Post-Igneous Processes......................................................... 6-8

6.1.2 Features, Events, and Processes..................................................................... 6-9

6.1.3 Summary of Output Data ........................................................................... 6-9

6.2 VOLCANIC HISTORY OF THE YUCCA MOUNTAIN REGION...................... 6-10

6.3 THE PROBABILISTIC VOLCANIC HAZARD ANALYSIS .............................. 6-13

6.3.1 The Probabilistic Volcanic Hazard Analysis Process .................................... 6-13

6.3.1.1 Selecting the Expert Panel Members............................................. 6-13

6.3.1.2 Identifying Technical Issues.................................................... 6-13

6.3.1.3 Temporal and Spatial Aspects of Probability Models ................... 6-14

6.3.1.4 Eliciting the Experts' Judgments............................................. 6-15

6.3.1.5 Probabilistic Volcanic Hazard Analysis Results and Uncertainty ....................................................................... 6-15

6.3.1.6 Consideration of Alternative Conceptual Models .......................... 6-16

6.3.1.7 Significance of Buried Volcanic Centers on Probabilistic Volcanic Hazard Analysis Results ............................................... 6-17

6.3.1.8 Alternative Estimates of the Intersection Probability................... 6-20 


\section{CONTENTS (Continued)}

Page

6.3.2 Definitions and Parameters of a Volcanic Event and Implications for Alternative Probability Calculations 6-21

6.3.2.1 Intrusive Versus Extrusive Events: Evidence from Analogue Sites .....

6.3.2.2 Alternative Event Lengths ....................................................... 6-26

6.3.3 Conceptual Models of Volcanism and Formulation of Probability Models ... 6-27

6.4 THE CRATER FLAT STRUCTURAL DOMAIN .............................................. 6-32

6.4.1 Internal Structure and Boundaries of the Crater Flat Basin .......................... 6-34

6.4.1.1 Fault Orientations, Dip Directions, and Displacements ................ 6-34

6.4.1.2 Rotation of Faults .................................................................. 6-36

6.4.1.3 Quaternary Slip Rate ........................................................ 6-36

6.4.1.4 Basin Subsidence and Fault Displacement................................. 6-37

6.4.1.5 Correlation with Volcanism .................................................. 6-38

6.4.2 Probabilistic Volcanic Hazard Analysis Volcanic Source Zones: Relationship to

Crater Flat Structural Features and the Probability of Dike Intersection........ 6-38

6.5 PROBABILISTIC VOLCANIC HAZARD ANALYSIS FOR THE

REPOSITORY FOOTPRINT ....................................................................... $6-42$

6.5.1 Description of the PVHA Volcanic Hazard Model Formulation.................... 6-42

6.5.1.1 Frequency of Intersection of the Repository Footprint by a

Dike .......................................................................................... 6-43

6.5.1.2 Conditional Distribution for Length and Azimuth of an

Intersecting Dike ............................................................. 6-50

6.5.1.3 Conditional Distribution for the Number of Eruptive Centers....... 6-51

6.5.2 Description of Probabilistic Volcanic Hazard Calculation ............................ 6-62

6.5.2.1 Computation of Frequency of Intersection of the Repository

Footprint by a Dike............................................................. 6-62

6.5.2.2 Computation of Distributions for Length, Azimuth, and

Number of Eruptive Centers................................................. 6-65

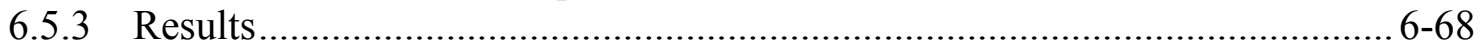

6.5.3.1 Frequency of Dike Intersection of the Repository Footprint ........ 6-68

6.5.3.2 Conditional Distributions for Intersection Length, Azimuth, and Number of Eruptive Centers within the Repository

Footprint

6.5.4 Sensitivity Studies

6.5.4.1 Impact of 1999 Aeromagnetic Data on Frequency of

Intersection ......................................................................... 6-8

6.5.4.2 Impact of Potential Undetected Volcanic Events on Frequency

of Intersection......................................................................... 6-84

6.5.4.2.1 Scenario Development .......................................... 6-87

6.5.4.2.2 Impact of Scenario on Frequency of Intersection ....... 6-88 


\section{CONTENTS (Continued)}

Page

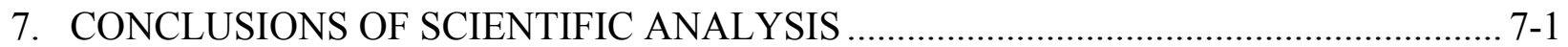

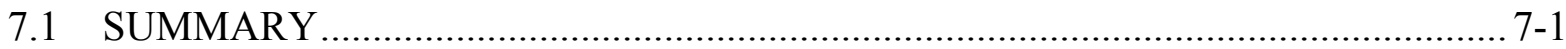

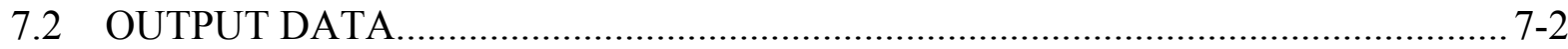

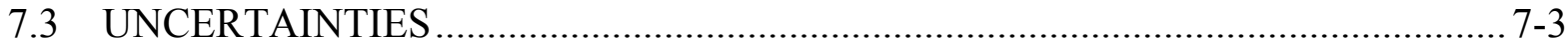

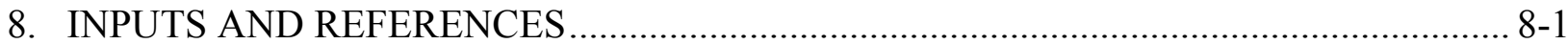

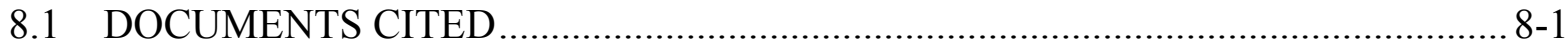

8.2 CODES, STANDARDS, REGULATIONS, AND PROCEDURES............................. 8-8

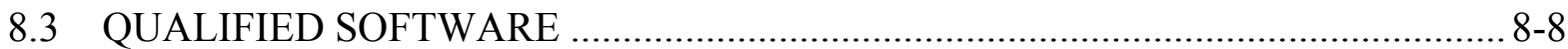

8.4 INPUT DATA AND OTHER REFERENCED DTNS …………….................... 8-10

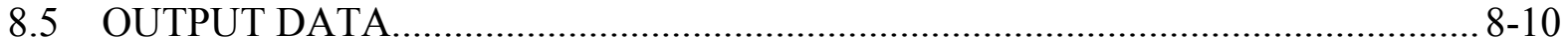

APPENDIX A - DESCRIPTION OF MATHEMATICAL FORMULATION AND IMPLEMENTATION OF PROBABILISTIC VOLCANIC HAZARD ANALYSIS

APPENDIX B - DEVELOPMENT OF FOOTPRINT POLYGON FOR THE PROPOSED REPOSITORY

APPENDIX C - DEVELOPMENT OF DISTRIBUTIONS FOR NUMBER OF ERUPTIVE CENTERS PER VOLCANIC EVENT AND AVERAGE SPACING BETWEEN ERUPTIVE CENTERS

APPENDIX D - ADDRESSING YUCCA MOUNTAIN REVIEW PLAN, FINAL REPORT ACCEPTANCE CRITERIA RELATED TO SITE CHARACTERIZATION, IDENTIFICATION OF EVENTS WITH PROBABILITIES GREATER THAN $10^{-8}$ PER YEAR, AND VOLCANIC DISRUPTION OF WASTE PACKAGES D-1 
INTENTIONALLY LEFT BLANK 


\section{FIGURES}

Page

3-1. Flowchart for Computation of Frequency of Intersection of Proposed Repository by a Dike.

3-2. Flowchart for Computation of Conditional Distributions for Length and Azimuth of Intersecting Dike and Number of Eruptive Centers within the Repository Given Intersection of Repository Footprint by a Dike

6-1. Location and Age of Post-Miocene (less than 5.3 million years (m.y.)) Volcanoes (or Clusters Where Multiple Volcanoes Have Indistinguishable Ages) in the Yucca Mountain Region.

6-2. Composite Distribution for Dike Length Averaged Across All 10 Probabilistic Volcanic Hazard Analysis Experts

6-3. Conceptual Diagram Comparing Event Definitions from the Probabilistic Volcanic Hazard Analysis and Reamer: Implications for Eruption and Intrusion Probabilities Based on Different Event Definitions

6-4. Composite Distribution for the Distance from the Point Volcanic Event to the End of the Dike Averaged Across All 10 PVHA Experts

6-5. Local Structural Domains and Domain Boundaries of the Yucca Mountain Region and Internal Structures of the Crater Flat Basin and Selected Parts of Adjacent Domains

6-6. Schematic Cross Section of the Crater Flat Basin, from Seismic Reflection, Surficial Geology, and Borehole Information

6-7a. Local Structural Domains and Domain Boundaries of the Yucca Mountain Region and Internal Structures of the Crater Flat Basin and Selected Parts of Adjacent Domains

6-7b. Local Structural Domains and Domain Boundaries of the Yucca Mountain Region and Internal Structures of the Crater Flat Basin and Selected Parts of Adjacent Domains

6-8. Schematic Illustrating Procedure for Computing the Frequency of Intersection of the Proposed Repository by a Volcanic Event .

6-9. Illustration of the Process Used to Compute the Conditional Probability of Intersection of the Proposed Repository by a Volcanic Event

6-10. Example Distributions for Dike Length, L, (part a); Normalized Location of the Point Volcanic Event Relative to the Total Length of the Dike, EL, (part b); and the Resulting Distribution for Distance from the Point Volcanic Event to the End of the Dike, d (part c)

6-11. Spatial Distribution of Volcanic Hazard Defined by the Probabilistic Volcanic Hazard Analysis Expert Panel: (a) Spatial distribution of Expected Volcanic Event Frequency and (b) Spatial Distribution of Expected Intersection Frequency ...... 6-47

6-12a. Logic Tree Structure Used to Characterize Uncertainty in Volcanic Hazard................ 6-48

6-12b. Logic Tree Structure for Sub-trees Addressing Uncertainty in Volcanic Hazard from Specific Sources. $6-48$

6-13. Distributions for Number of Eruptive Centers per Volcanic Event Derived from the Probabilistic Volcanic Hazard Analysis Experts' Interpretations 6-52 


\section{FIGURES (Continued)}

Page

6-14. Example Simulations of the Distribution of Eruptive Centers along the Length of a Dike for: (a) the Independent, Uniformly Distributed (IUD) Spatial Distribution and (b) the Uniformly Spaced, Randomly Distributed (USRD) Spatial Distribution .... 6-55

6-15a. Probability for the Number of Eruptive Centers Within the Repository Footprint, $\mathrm{r}^{\mathrm{EC}}$, as a Function of Dike Length, L, for the Length of Intersection Equal to $1 \mathrm{~km}$ and the Number of Eruptive Centers Associated with the Volcanic Event Equal to 2

6-15b. Probability for the Number of Eruptive Centers Within the Repository Footprint, $\mathrm{r}^{\mathrm{EC}}$, as a Function of Dike Length, L, for the Length of Intersection Equal to $1 \mathrm{~km}$ and the Number of Eruptive Centers Associated with the Volcanic Event Equal to 3

6-16. Example Probabilities for the Number of Eruptive Centers within the Repository Footprint, $\mathrm{r}^{\mathrm{EC}}$, Computed with the Total Number of Eruptive Centers Defined by an Average Spacing of $2.5 \mathrm{~km}$ between Eruptive Centers Compared to Probabilities Computed Using a Fixed Total Number of 2 Eruptive Centers

6-17a. Repository Emplacement Drifts and Footprint Polygon Encompassing the Emplacement Panels

6-17b. Location of 2003 Repository Footprint (BSC 2003 [DIRS 162289]) Compared to Repository Footprint Used in the Probabilistic Volcanic Hazard Analysis 6-65

6-18. Annual Frequency of Intersecting the Repository Footprint

6-19. Marginal Distributions for Dike Intersection Length, $L^{I}$, for the 5th Percentile, Mean, and 95th Percentile Frequency of Intersection

6-20. Marginal Distributions for Dike Intersection Azimuth, $\phi$, for the 5th Percentile, Mean, and 95th Percentile Frequency of Intersection for the Repository Footprint

6-21. Marginal Distributions for the Number of Eruptive Centers within the Repository Footprint, $r^{E C}$, for the 5th Percentile, Mean, and 95th Percentile Frequency of Intersection

6-22. Locations of Potential Buried Basalt Inferred from Aeromagnetic Data

6-23. Composite Annual Frequency of Intersection of the Repository Footprint for Sensitivity Cases for the Primary-plus-Contingency Block Case of the 70,000 Metric Tons of Uranium No-Backfill Layout

6-24. Individual Expert Results for Annual Frequency of Intersection of the Repository Footprint for Sensitivity Cases for the Primary-plus-Contingency Block Case of the 70,000 Metric Tons of Uranium No-Backfill Layout.......................................... 6-86

6-25. Areas Used to Define the Hidden-Events Scenario.

6-26. Simulated Hidden-Event Locations in Crater Flat and Jackass Flats Used in Scenario Calculation 


\section{FIGURES (Continued)}

Page

6-27. Example of Effect of Hidden-Event Scenario on the Spatial Density of Volcanic Events Computed Using the 2-D Gaussian Parametric Field Shape Model

6-28. Example of Effect of Hidden-Event Scenario on the Spatial Density of Volcanic Events Computed Using the Kernel Density Spatial Model

C-1. Distributions for Number of Eruptive Centers per Volcanic Event, $\mathrm{n}^{\mathrm{EC}}$, Derived from the Probabilistic Volcanic Hazard Analysis Experts' Interpretations 


\section{INTENTIONALLY LEFT BLANK}




\section{TABLES}

Page

3-1. Software Routines Used to Compute Frequency of Intersection of the Proposed Repository by a Dike.

3-2 Software Routines Used to Compute Conditional Distributions for Dike Length, Azimuth, and Number of Eruptive Centers within the Proposed Repository .................. 3-4

3-3. Software Used to Convert Emplacement Drift End Points for the Repository Footprint from Nevada State Plane Coordinates to Universal Transverse Mercator ....... 3-7

3-4. Exempt Software ................................................................................................ 3-7

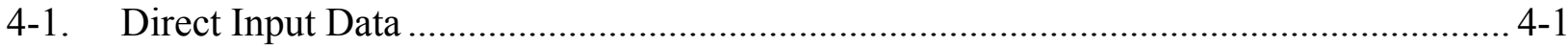

4-2. Other Direct Input to This Scientific Analysis ........................................................ 4-1

6-1. Included Features, Events, and Processes for This Scientific Analysis Report ............. 6-9

6-2. Estimated Volume and ${ }^{40} \mathrm{Ar} /{ }^{39} \mathrm{Ar} \mathrm{Age}^{\mathrm{a}}$ of Quaternary Volcanoes in the Yucca

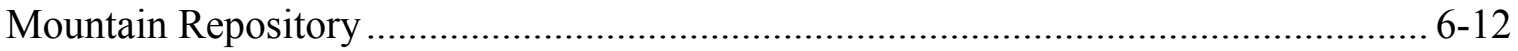

6-3. Probabilistic Volcanic Hazard Analysis Panel Members ............................................ 6-13

6-4. Alternative Conceptual Models Not Considered in the Probabilistic Volcanic Hazard Analysis................................................................................................... 6-16

6-5. Published Estimates of the Probability of Intersection of the Proposed Repository at Yucca Mountain by a Volcanic Event .................................................................... 6-20

6-6. Empirical Distribution for Average Spacing between Eruptive Centers Calculation

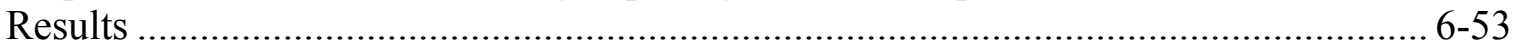

6-7. Expected Value for Average Eruptive Center Spacing ............................................. 6-54

6-8. Frequency of Intersection for the Repository Footprint ......................................... 6-68

6-9. Marginal Distributions for Dike Intersection Length for the 5th Percentile, Mean, and 95th Percentile Frequency of Intersection of the Repository Footprint ................. 6-75

6-10. Marginal Distribution for Intersecting Dike Azimuth for the 5th Percentile, Mean, and 95th Percentile Frequency of Intersection of the Repository Footprint

6-11. Marginal Distribution for Number of Eruptive Centers within the Proposed Repository for the 5th Percentile, Mean, and 95th Percentile Frequency of Intersection of the Repository Footprint.

6-12. Comparison of Mean Number of Volcanic Events for 1996 Probabilistic Volcanic Hazard Analysis Assessment with Sensitivity Analysis Values

6-13. Summary of Computed Frequency of Intersection for 70,000-Metric Tons of Uranium No-Backfill Repository Layout (primary + contingency blocks) from Sensitivity Cases

6-14. Summary of Computed Frequency of Intersection for 70,000 Metric Tons of Uranium No-Backfill Repository Layout (primary + contingency blocks) from Hidden-Events Scenario Cases.... 


\section{TABLES (Continued)}

Page

7-1. Summary Frequencies of Disruptive Volcanic Events for the License Application Footprint

B-1. Repository Drift Coordinates for 2003 Repository Design ...............................................

C-1. Assessments from Alex McBirney's Volcanic Hazard Model............................................ -3

C-2. Assessments from Bruce Crowe's Volcanic Hazard Model ..............................................

C-3. Assessments from George Thompson's Volcanic Hazard Model....................................... -5

C-4. Assessments from George Walker's Volcanic Hazard Model ............................................6

C-5. Assessments from Mel Kuntz's Volcanic Hazard Model ................................................

C-6. Assessments from Michael Sheridan's Volcanic Hazard Model ........................................ -8

C-7. Assessments from Richard Carlson's Volcanic Hazard Model .........................................

C-8. Assessments from Richard Fisher's Volcanic Hazard Model ...........................................

C-9. Assessments from Wendell Duffield's Volcanic Hazard Model ....................................11

C-10. Assessments from William Hackett's Volcanic Hazard Model ....................................... -12

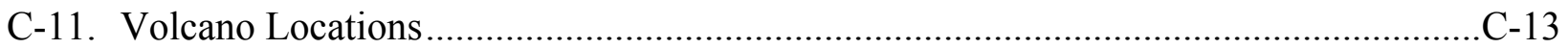

C-12. Summary of Expected Average Spacing Between Eruptive Centers Calculation

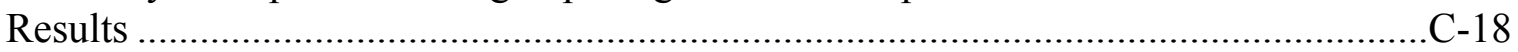

C-13. Empirical Distribution for Average Spacing Between Eruptive Centers Calculation Results C-19 


\section{ACRONYMS AND ABBREVIATIONS}

CDF cumulative probability density function

DOE U.S. Department of Energy

DTN data tracking number

FEPs features, events, and processes

IUD-C Independent, Uniformly Distributed, Correlated

IUD-UC Independent, Uniformly Distributed, Uncorrelated

ka thousand years ago

k.y. thousand years

LA License Application

MTU metric tons of uranium

m.y. million years

NRC U.S. Nuclear Regulatory Commission

PA performance assessment

PVHA Probabilistic Volcanic Hazard Analysis

RMEI reasonably maximally exposed individual

TSPA total system performance assessment

TSPA-LA total system performance assessment for license application

TWP technical work plan

USGS U.S. Geological Survey

USRD-C Uniformly Spaced, Randomly Distributed, Correlated

USRD-FD Uniformly Spaced, Randomly Distributed Fixed Density

USRD-UC Uniformly Spaced, Randomly Distributed, Uncorrelated

UTM Universal Transverse Mercator

YMR Yucca Mountain region 


\section{INTENTIONALLY LEFT BLANK}




\section{PURPOSE}

The purpose of this scientific analysis report is threefold:

- Present a conceptual framework of igneous activity in the Yucca Mountain region (YMR) consistent with the volcanic and tectonic history of this region and the assessment of this history by experts who participated in the probabilistic volcanic hazard analysis (PVHA) (CRWMS M\&O 1996 [DIRS 100116] $\left.{ }^{1}\right)$. Conceptual models presented in the PVHA are summarized and applied in areas in which new information has been presented. Alternative conceptual models are discussed, as well as their impact on probability models. The relationship between volcanic source zones defined in the PVHA and structural features of the YMR are described based on discussions in the PVHA and studies presented since the PVHA.

- Present revised probability calculations based on PVHA outputs for a repository footprint proposed in 2003 (BSC 2003 [DIRS 162289]), rather than the footprint used at the time of the PVHA. This analysis report also calculates the probability of an eruptive center(s) forming within the repository footprint using information developed in the PVHA. Probability distributions are presented for the length and orientation of volcanic dikes located within the repository footprint and for the number of eruptive centers (conditional on a dike intersecting the repository) located within the repository footprint.

- Document sensitivity studies that analyze how the presence of potentially buried basaltic volcanoes may affect the computed frequency of intersection of the repository footprint by a basaltic dike. These sensitivity studies are prompted by aeromagnetic data collected in 1999, indicating the possible presence of previously unrecognized buried volcanoes in the YMR (Blakely et al. 2000 [DIRS 151881]; O'Leary et al. 2002 [DIRS 158468]). The results of the sensitivity studies are for informational purposes only and are not to be used for purposes of assessing repository performance.

The U.S. Department of Energy (DOE) considers volcanism to be a potentially disruptive event in the total system performance assessment (TSPA) analysis supporting the License Application (LA) for the proposed Yucca Mountain repository (DOE 1998 [DIRS 100550]). The two volcanic scenarios (with individual probabilities and consequences) modeled by the TSPA-LA are:

- Ascent of a basaltic dike or dike system (i.e., a set or swarm of multiple dikes comprising a single intrusive event) to repository level where it intersects drifts

- Development of volcanoes within the repository footprint with one or more conduits that intersect waste packages.

\footnotetext{
${ }^{1}$ In this report, a unique six-digit numerical identifier (the Document Input Reference System [DIRS] number) is placed in the text following the reference callout (e.g., BSC 2002 [DIRS 156605]), the purpose of which is to assist the reader in locating a specific reference in the DIRS database. Within the reference list (Section 8), multiple sources by the same author and date (e.g., BSC 2002) are sorted alphabetically by title.
} 
As a consequence of the first event, which is non-eruptive, waste from breached packages may provide a source of radionuclides when groundwater moves through the damaged packages at some time in the future (igneous intrusion groundwater release). The potential consequence of the second event is that waste packages entrained within a conduit may be breached, releasing radionuclides to the erupting ash plume where they can be dispersed downwind to a reasonably maximally exposed individual (RMEI) (10 CFR 63 [DIRS 156605], Section 63.2; 66 FR 55794) in the accessible environment at the controlled area boundary (10 CFR 63 [DIRS 156605], Section 63.302; 66 FR 55813). According to 10 CFR Part 63 this location is to be approximately $18 \mathrm{~km}$ from the southern boundary of the repository.

This report, Characterize Framework for Igneous Activity at Yucca Mountain, Nevada, Revision (REV) 02, describes the conceptual framework for volcanism near Yucca Mountain and how the conceptual framework provides the basis for probability calculations. This report also presents the probability results and associated uncertainties for intersection of the proposed repository by a volcanic event and the probability of an eruption through the repository, conditional on a dike intersection. In the context of the PVHA, a volcanic event is a spatially and temporally distinct batch of magma ascending from the mantle through the crust as a dike or system of dikes (CRWMS M\&O 1996 [DIRS 100116], Appendix E). For the purposes of the probability models discussed in this report, a volcanic event is defined as a point $(x, y)$ in space representing the expected midpoint of the dike system involved in the magma ascent. The dike system associated with the volcanic event is represented in a probability model by a line element defined in terms of a length, azimuth, and location relative to the point event (Figure 6-8 and Figure 6-10). The term "dike length" used in the PVHA and in this report when discussing volcanic events, refers to the total length of the dike system associated with the volcanic event. The phrase "intersection of the repository footprint by a dike" refers to intersection of the emplacement area of the repository by the line element representing the dike system associated with the volcanic event. The possibility that a dike system (e.g., multiple dikes) has width or consists of multiple parallel dikes is not part of the calculations in this report. Both the width of the dikes and the number of parallel dikes affect the consequences of an intersection and are included in Number of Waste Packages Hit by Igneous Intrusion (BSC 2004 [DIRS 170001]).

The probability results documented in this report provide the basis for all further igneous consequences analysis. These probability results remain unchanged from those presented in REV 01 of this report (BSC 2003 [DIRS 163769]) and no new output data were generated in this version. The output data tracking numbers (DTNs) carried forward as output from this revision are listed in Section 7.2. The results of this report provide direct input into the Number of Waste Packages Hit by Igneous Intrusion scientific analysis report and direct input to the TSPA-LA. This document uses information on conduit size developed in Characterize Eruptive Processes at Yucca Mountain, Nevada, to define a buffer zone around the repository footprint.

The following documents also use information developed in this analysis report:

Screening Analysis of Criticality Features, Events, and Processes for License Application

Features, Events, and Processes: System Level

Features, Events, and Processes in UZ Flow and Transport

Features, Events, and Processes: Disruptive Events. 
Consideration of the number of volcanic events that have occurred during selected periods of time in the YMR was one of the key parameters the PVHA used to calculate the probability of a basaltic dike intersecting the repository footprint. Volcanic features counted as volcanic events included individual volcanoes, alignments of volcanoes, and aeromagnetic anomalies in the region that are known (by drilling) or inferred to be buried volcanoes. In 1999, three years after the PVHA was completed, a new aeromagnetic survey of the YMR was completed under the direction of the U.S. Geological Survey (USGS) (Blakely et al. 2000 [DIRS 151881], O'Leary et al. 2002 [DIRS 158468]). REV 01 of this report (BSC 2003 [DIRS 163769]) presented sensitivity studies addressing the potential impact of the new aeromagnetic survey results. This report documents an additional sensitivity analysis that uses alternative conceptual models to assess the potential impact of undetected (buried) volcanic events on the probability of intersection of the repository footprint by a basaltic dike. This scientific analysis report is governed by the Technical Work Plan For: Igneous Activity Assessment for Disruptive Events (TWP) (BSC 2004 [DIRS 171403]). The TWP specifies the activities to be carried out in updating information in the revision of this report. The activities documented in this report do not deviate from those specified in the TWP. 


\section{INTENTIONALLY LEFT BLANK}




\section{QUALITY ASSURANCE}

Development of this scientific analysis report and the supporting analyses was subject to the Office of Civilian Radioactive Waste Management quality assurance program (BSC 2003 [DIRS 171403], Section 8.1). Approved quality assurance procedures identified in the TWP (BSC 2004 [DIRS 171403], Section 4) were used to conduct and document the activities described in this report. The TWP also identifies the methods used to control the electronic management of data (BSC 2004 [DIRS 171403], Section 8.4). The TWP also described the methods to be used for the electronic management of information, as identified in AP-SV.1Q, Control of the Electronic Management of Information. These methods were followed in developing this report.

This report documents the volcanic history of the YMR, recalculates the frequency of intersection and development of distributions for length and orientation of dikes, and recalculates the number of eruptive centers within the repository footprint (subsurface facilities). The subsurface facilities are classified on the Q-List (BSC 2004 [DIRS 168361], Appendix A) as a Safety Category because of their importance to waste isolation, as defined in AP-2.22Q, Classification Analyses and Maintenance of the Q-List. The results of this report are important to the demonstration of compliance with the postclosure performance objectives prescribed in 10 CFR 63.113 [DIRS 156605]. This report contributes to the analysis and modeling data used to support performance assessment; the conclusions do not directly impact engineered features important to safety, as defined in AP-2.22Q. 


\section{INTENTIONALLY LEFT BLANK}




\section{USE OF SOFTWARE}

\subsection{SOFTWARE TRACKED BY CONFIGURATION MANAGEMENT}

The calculations presented in this scientific analysis report were performed with the set of software routines described below. This software was qualified and placed on the Software Baseline under AP-SI.1Q, Software Management, in 2000. The qualified calculations presented in this report were conducted in REV 01 (BSC 2003 [DIRS 163769]) in 2003, again under the software procedures active at that time. Although those software procedures have been superseded by a more recent procedure (LP-SI.11Q-BSC), the software used in this analysis has not been modified from the original baseline software. The software and routines used in support of this work are appropriate for this application and are used within their range of validation as described in the qualification documentation. The software is written in FORTRAN77 and operates on a personal computer equipped with a 486 or Pentium processor under a disk operating system or in a Microsoft Windows operating system window. The computations were performed using the software routines acquired from Software Configuration Management. The software used was selected because it was designed to perform the calculations defined by the PVHA (CRWMS M\&O 1996 [DIRS 100116]), and it was used within the parameter limits defined by the PVHA. There are no limitations on the use of the results due to use of the selected software.

The software routine titles are listed with the standard FORTRAN .FOR extension in the Software Configuration Management database, the DIRS database, and in Section 8.3 of this report. The routines are listed by their titles without the .FOR extension in Table 3-1 and Table 3-2, Figure 3-1 and Figure 3-2, and in the text of this report.

Table 3-1 lists the software routines used to compute the frequency of intersection of the repository footprint by a volcanic event through full enumeration of the PVHA experts' logic trees. Figure 3-1 shows the data flow through the routines in Table 3-1. The software routines listed in Table 3-1 are qualified versions of the routines used in the PVHA calculation (CRWMS M\&O 1996 [DIRS 100116]).

Table 3-2 lists the software routines used to compute the conditional distributions for the length and azimuth of an intersecting dike within the repository footprint and the number of eruptive centers within this footprint. The data flow through the software routines for this calculation is shown in Figure 3-2.

In addition, the software routine COMBDELD.FOR V1.0 (LANL 2000 [DIRS 148617]) was used to calculate aggregate dike length and event length distributions across all 10 PVHA experts for display in Figures 6-2 and 6-4.

Software used to convert Nevada State Plane coordinates to Universal Transverse Mercator (UTM) coordinates for the repository footprint is listed in Table 3-3. 
Table 3-1. Software Routines Used to Compute Frequency of Intersection of the Proposed Repository by a Dike

\begin{tabular}{|c|c|}
\hline $\begin{array}{l}\text { Software Routine } \\
\text { (Software Tracking } \\
\text { Number) }\end{array}$ & Function \\
\hline $\begin{array}{l}\text { FITCD V1.0 } \\
(10262-1.0-00)[D I R S \\
148532]\end{array}$ & $\begin{array}{l}\text { Computes discrete cumulative probability distributions for dike length from cumulative } \\
\text { probabilities specified at selected values of length. }\end{array}$ \\
\hline $\begin{array}{l}\text { SFCD V1.0 } \\
(10275-1.0-00)[D I R S \\
148533]\end{array}$ & $\begin{array}{l}\text { Computes discrete cumulative probability distributions for dike length using user- } \\
\text { specified distribution forms. }\end{array}$ \\
\hline $\begin{array}{l}\text { DCPELD V1.0 } \\
(10258-1.0-00)[D I R S \\
148534]\end{array}$ & $\begin{array}{l}\text { Computes discrete probability distribution for dike length from expert-specified } \\
\text { distributions (output of FITCD). }\end{array}$ \\
\hline $\begin{array}{l}\text { CPDI V1.0 } \\
(10257-1.0-00)[D I R S \\
148535]\end{array}$ & $\begin{array}{l}\text { Computes conditional probability of intersection from volcanic events on an } x, y \text { grid } \\
\text { using output of DCPELD and expert-specified azimuth distributions. }\end{array}$ \\
\hline $\begin{array}{l}\text { UZVH V1.0 } \\
(10277-1.0-00) \text { [DIRS } \\
148536]\end{array}$ & Computes frequency of intersection from volcanic source zones using output of CPDI. \\
\hline $\begin{array}{l}\text { FKVH V1.0 } \\
(10265-1.0-00)[D I R S \\
148567]\end{array}$ & $\begin{array}{l}\text { Computes frequency of intersection using kernel density estimation with specified } h \\
\text { and output of CPDI. }\end{array}$ \\
\hline $\begin{array}{l}\text { UZVPVH V1.0 } \\
(10279-1.0-00)[D I R S \\
148537]\end{array}$ & $\begin{array}{l}\text { Computes frequency of intersection from volcanic source zones using volume } \\
\text { predictable volcanic event rate model and output of CPDI. }\end{array}$ \\
\hline $\begin{array}{l}\text { FKVPVH V1.0 } \\
(10267-1.0-00) \text { [DIRS } \\
148538]\end{array}$ & $\begin{array}{l}\text { Computes frequency of intersection using kernel density estimation using volume } \\
\text { predictable volcanic event rate model and output of CPDI. }\end{array}$ \\
\hline $\begin{array}{l}\text { ZBCKVH V1.0 } \\
(10283-1.0-00) \text { [DIRS } \\
148539]\end{array}$ & $\begin{array}{l}\text { Computes frequency of intersection using kernel density estimation with } h \text { constrained } \\
\text { by a source zone boundary and output of CPDI. }\end{array}$ \\
\hline $\begin{array}{l}\text { FITFIELD V1.0 } \\
(10263-1.0-00)[D I R S \\
148540]\end{array}$ & $\begin{array}{l}\text { Computes parameters of a bivariate Gaussian distribution that approximates } \\
\text { boundaries of a defined polygon. }\end{array}$ \\
\hline $\begin{array}{l}\text { FIT2CNTR V1.0 } \\
(10261-1.0-00)[\text { DIRS } \\
148541]\end{array}$ & $\begin{array}{l}\text { Computes parameters of a bivariate Gaussian distribution from locations of volcanic } \\
\text { events. }\end{array}$ \\
\hline $\begin{array}{l}\text { PFGVH V1.0 } \\
(10273-1.0-00)[D I R S \\
148542]\end{array}$ & $\begin{array}{l}\text { Computes frequency of intersection using a bivariate Gaussian distribution with } \\
\text { specified field parameters and output of CPDI. Bivariate Gaussian distribution } \\
\text { parameters obtained from programs FIT2CNTR or FITFIELD. }\end{array}$ \\
\hline $\begin{array}{l}\text { FPFGVH V1.0 } \\
(10269-1.0-00) \text { [DIRS } \\
148543]\end{array}$ & $\begin{array}{l}\text { Computes frequency of intersection using a bivariate Gaussian distribution with } \\
\text { parameters fit to volcanic event locations and output of CPDI. }\end{array}$ \\
\hline $\begin{array}{l}\text { VHTREE V1.0 } \\
(10282-1.0-00)[D I R S \\
148544]\end{array}$ & $\begin{array}{l}\text { Computes mean and fractiles of frequency of intersection over an individual expert's } \\
\text { volcanic hazard logic tree and aggregate over all experts using outputs of UZVH, } \\
\text { UZVHB, FKVH, UZVPVH, FKVPVH, ZBCLVH, PFGVH, and FPFGVH. }\end{array}$ \\
\hline
\end{tabular}


Table 3-2 Software Routines Used to Compute Conditional Distributions for Dike Length, Azimuth, and Number of Eruptive Centers within the Proposed Repository

\begin{tabular}{|c|c|}
\hline $\begin{array}{c}\text { Software Routine } \\
\text { (Software Tracking Number) }\end{array}$ & Function \\
\hline $\begin{array}{l}\text { FITCD V1.0 } \\
(10262-1.0-00) \text { [DIRS 148532] }\end{array}$ & $\begin{array}{l}\text { Computes discrete cumulative probability distributions for dike length from } \\
\text { cumulative probabilities specified at selected values of length. }\end{array}$ \\
\hline $\begin{array}{l}\text { SFCD V1.0 } \\
(10275-1.0-00) \text { [DIRS 148533] }\end{array}$ & $\begin{array}{l}\text { Computes discrete cumulative probability distributions for dike length using user- } \\
\text { specified distribution forms. }\end{array}$ \\
\hline $\begin{array}{l}\text { DCPELD V1.0 } \\
(10258-1.0-00) \text { [DIRS 148534] }\end{array}$ & $\begin{array}{l}\text { Computes discrete probability distribution for dike length from expert-specified } \\
\text { distributions (output of FITCD). }\end{array}$ \\
\hline $\begin{array}{l}\text { CPDI V1.0 } \\
(10257-1.0-00)[D I R S 148535]\end{array}$ & $\begin{array}{l}\text { Computes conditional probability of intersection from volcanic events on an } x, y \\
\text { grid using output of DCPELD and expert-specified azimuth distributions. }\end{array}$ \\
\hline $\begin{array}{l}\text { UZVHLH V1.0 } \\
(10278-1.0-00) \text { [DIRS 148545] }\end{array}$ & $\begin{array}{l}\text { Computes simulations of contributions to frequency of intersection on an } x, y \text { grid } \\
\text { from volcanic source zones using Latin Hypercube sampling and output from } \\
\text { CPDI. }\end{array}$ \\
\hline $\begin{array}{l}\text { FKVHLH V1.0 } \\
(10266-1.0-00)[D I R S 148546]\end{array}$ & $\begin{array}{l}\text { Computes simulations of contributions to frequency of intersection on an } x, y \text { grid } \\
\text { using kernel density estimation with specified } h \text {, Latin Hypercube sampling, and } \\
\text { output from CPDI. }\end{array}$ \\
\hline $\begin{array}{l}\text { UZVPVHLH V1.0 } \\
(10280-1.0-00)[\text { [DIRS 148547] }\end{array}$ & $\begin{array}{l}\text { Computes simulations of contributions to frequency of intersection on an } x, y \text { grid } \\
\text { from volcanic source zones using volume predictable volcanic event rate model, } \\
\text { Latin Hypercube sampling, and output from CPDI. }\end{array}$ \\
\hline $\begin{array}{l}\text { FKVPVHLH V1.0 } \\
(10268-1.0-00)[\text { DIRS 148551] }\end{array}$ & $\begin{array}{l}\text { Computes simulations of contributions to frequency of intersection on an } x, y \text { grid } \\
\text { with kernel density estimation using volume predictable volcanic event rate } \\
\text { model, Latin Hypercube sampling, and output from CPDI. }\end{array}$ \\
\hline $\begin{array}{l}\text { ZBCKVHLH V1.0 } \\
(10284-1.0-00)[D I R S 148550]\end{array}$ & $\begin{array}{l}\text { Computes simulations of contributions to frequency of intersection on an } x, y \text { grid } \\
\text { using kernel density estimation with } h \text { constrained by a source zone boundary, } \\
\text { Latin Hypercube sampling, and output from CPDI. }\end{array}$ \\
\hline $\begin{array}{l}\text { FITFIELD V1.0 } \\
(10263-1.0-00) \text { [DIRS 148540] }\end{array}$ & $\begin{array}{l}\text { Computes parameters of a bivariate Gaussian distribution that approximates } \\
\text { boundaries of a defined polygon. }\end{array}$ \\
\hline $\begin{array}{l}\text { FIT2CNTR V1.0 } \\
(10261-1.0-00)[D I R S 148541]\end{array}$ & $\begin{array}{l}\text { Computes parameters of a bivariate Gaussian distribution from locations of } \\
\text { volcanic events. }\end{array}$ \\
\hline $\begin{array}{l}\text { PFGVHLH V1.0 } \\
(10274-1.0-00)[D I R S 148552]\end{array}$ & $\begin{array}{l}\text { Computes simulations of contributions to frequency of intersection on an } x, y \text { grid } \\
\text { using a 2D-Gaussian distribution with specified parameters, Latin Hypercube } \\
\text { sampling, and output from CPDI. Gaussian distribution parameters obtained } \\
\text { from programs FIT2CNTR or FITFIELD. }\end{array}$ \\
\hline $\begin{array}{l}\text { FPFGVHLH V1.0 } \\
(10270-1.0-00)[\text { DIRS 148553] }\end{array}$ & $\begin{array}{l}\text { Computes simulations of contributions to frequency of intersection on an } x, y \text { grid } \\
\text { using a } 2 D-G a u s s i a n \text { distribution with parameters fit to volcanic event locations, } \\
\text { Latin Hypercube sampling, and output from CPDI. }\end{array}$ \\
\hline $\begin{array}{l}\text { VHTIELHS V1.0 } \\
(10281-1.0-00)[\text { DIRS 148554] }\end{array}$ & $\begin{array}{l}\text { Computes mean and fractiles of simulations of contributions to frequency of } \\
\text { intersection on an } x, y \text { grid over an individual expert's volcanic hazard logic tree } \\
\text { using Latin Hypercube sampling and output from UZVHLH, FKVHLH, } \\
\text { UZVPVHLH, FKVPVHLH, ZBCLVHLH, PFGVHLH, and FPFGVHLH. }\end{array}$ \\
\hline $\begin{array}{l}\text { NECPDS V1.1 } \\
(10272-1.1-00) \text { [DIRS 168238] }\end{array}$ & $\begin{array}{l}\text { Computes distributions for number of eruptive centers per volcanic event and } \\
\text { average spacing between eruptive centers. }\end{array}$ \\
\hline $\begin{array}{l}\text { FITIDSR V1.0 } \\
(10264-1.0-00) \text { [DIRS 148557] }\end{array}$ & $\begin{array}{l}\text { Computes discrete incremental probability distributions for dike length using } \\
\text { input to FITCD. }\end{array}$ \\
\hline $\begin{array}{l}\text { SFIDSR V1.0 } \\
(10276-1.0-00) \text { [DIRS 148571] }\end{array}$ & $\begin{array}{l}\text { Computes discrete incremental probability distributions for dike length using } \\
\text { input to SFCD. }\end{array}$ \\
\hline $\begin{array}{l}\text { DLECD V1.0 } \\
(10260-1.0-00) \text { [DIRS 148558] }\end{array}$ & $\begin{array}{l}\text { Computes joint discrete probability distributions for dike length and number of } \\
\text { eruptive centers per volcanic event using output from FITIDSR. }\end{array}$ \\
\hline
\end{tabular}


Table 3-2 Software Routines Used to Compute Conditional Distributions for Dike Length, Azimuth, and Number of Eruptive Centers within the Proposed Repository (Continued)

\begin{tabular}{|l|l|}
\hline $\begin{array}{c}\text { Software Routine } \\
\text { (Software Tracking Number) }\end{array}$ & \multicolumn{1}{c|}{ Function } \\
\hline $\begin{array}{l}\text { DILECDLH V1.1 } \\
\text { (10259-1.1-00) [DIRS 168221] }\end{array}$ & $\begin{array}{l}\text { Computes joint conditional distribution of dike intersection length, dike azimuth, } \\
\text { and number of eruptive centers within the repository footprint from outputs of } \\
\text { program VHTIELHS using Latin hypercube sampling of dike length and volcanic } \\
\text { event location distributions from DIECDIST. }\end{array}$ \\
\hline $\begin{array}{l}\text { CFRAC V1.0 } \\
(10254-1.0-00) \text { [DIRS 148560] }\end{array}$ & $\begin{array}{l}\text { Locates individual expert's simulation results that represent specified percentiles } \\
\text { of the composite distribution for frequency of intersection from outputs of } \\
\text { VHTIELHS. }\end{array}$ \\
\hline $\begin{array}{l}\text { COMBSM V1.1 } \\
(10256-1.1-00) \text { [DIRS 168220] }\end{array}$ & $\begin{array}{l}\text { Computes composite joint distribution of dike intersection length, dike azimuth, } \\
\text { and number of eruptive centers within the repository footprint across experts } \\
\text { from outputs of DILECDLH and VHTIELHS for mean hazard. }\end{array}$ \\
\hline $\begin{array}{l}\text { COMBSF V1.1 } \\
(10255-1.1-00) \text { [DIRS 168218] }\end{array}$ & $\begin{array}{l}\text { Computes composite joint distribution of dike intersection length, dike azimuth, } \\
\text { and number of eruptive centers within the repository footprint across experts } \\
\text { from outputs of DILECDLH for selected percentiles of the hazard. }\end{array}$ \\
\hline $\begin{array}{l}\text { MARGIN V1.1 } \\
\text { (10271-1.1-00) [DIRS 168223] }\end{array}$ & $\begin{array}{l}\text { Computes marginal distributions for dike intersection length, dike azimuth, and } \\
\text { number of eruptive centers within the repository footprint from output of } \\
\text { COMBSM and COMBSF. }\end{array}$ \\
\hline
\end{tabular}

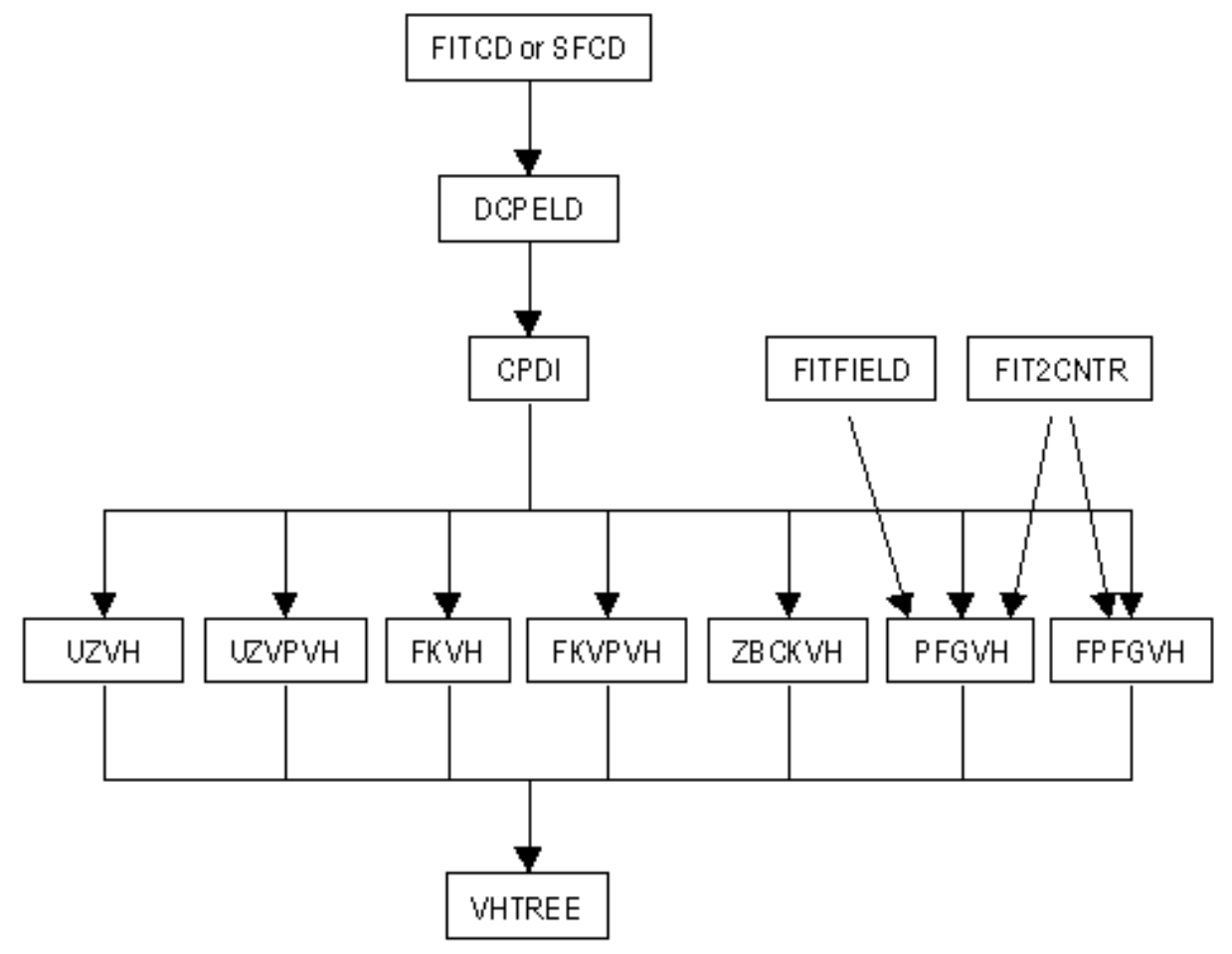

For Information Only

NOTE: Names in the boxes denote software routines listed in Table 3-1.

Figure 3-1. Flowchart for Computation of Frequency of Intersection of Proposed Repository by a Dike 


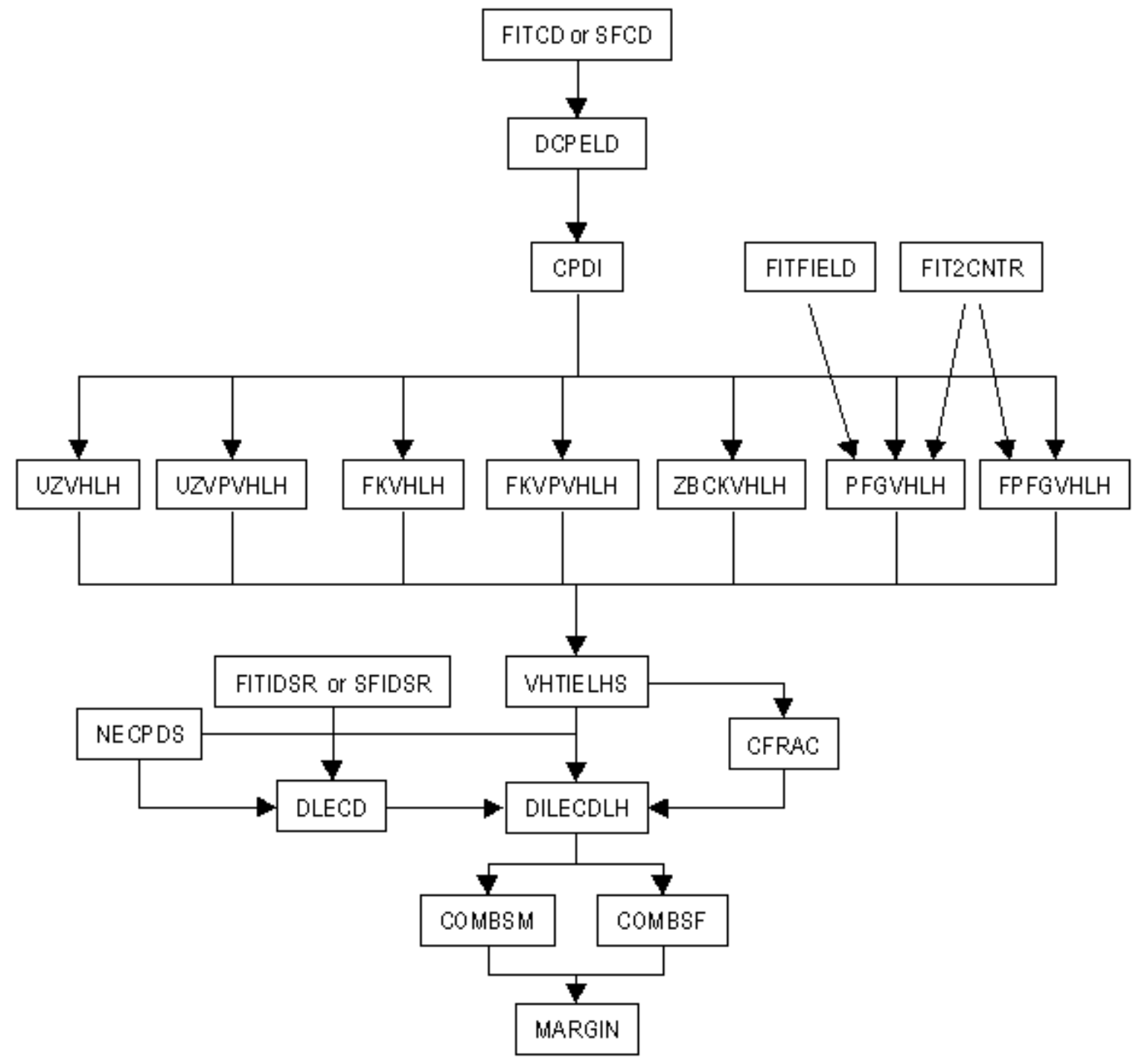

For information only

NOTE: Names in boxes denote software routines listed in Table 3-2.

Figure 3-2. Flowchart for Computation of Conditional Distributions for Length and Azimuth of Intersecting Dike and Number of Eruptive Centers within the Repository Given Intersection of Repository Footprint by a Dike 
Table 3-3. Software Used to Convert Emplacement Drift End Points for the Repository Footprint from Nevada State Plane Coordinates to Universal Transverse Mercator

\begin{tabular}{|l|l|l|l|}
\hline $\begin{array}{c}\text { Software Name } \\
\text { and Version (V) }\end{array}$ & $\begin{array}{c}\text { Software Tracking } \\
\text { Number }\end{array}$ & \multicolumn{1}{|c|}{ Description } & $\begin{array}{c}\text { Computer and Platform } \\
\text { Identification }\end{array}$ \\
\hline $\begin{array}{l}\text { EarthVision 5.1 } \\
\text { [DIRS 167994] }\end{array}$ & $10174-5.1-00$ & $\begin{array}{l}\text { Commercial GIS software used for } \\
\text { coordinate conversion. }\end{array}$ & $\begin{array}{l}\text { Silicon Graphics/ } \\
\text { IRIX 6.5 }\end{array}$ \\
\hline
\end{tabular}

\subsection{EXEMPT SOFTWARE}

Commercial, off-the-shelf software used in support of this scientific analysis is listed in Table 3-4. This software is exempt from the requirements of LP-SI.11Q-BSC, Software Management.

Table 3-4. Exempt Software

\begin{tabular}{|c|c|c|c|}
\hline $\begin{array}{c}\text { Software Name and } \\
\text { Version } \\
\text { (V) }\end{array}$ & $\begin{array}{l}\text { Software } \\
\text { Tracking } \\
\text { Number }\end{array}$ & Description & $\begin{array}{c}\text { Computer and } \\
\text { Platform } \\
\text { Identification }\end{array}$ \\
\hline Microsoft Excel, 97 & $\mathrm{~N} / \mathrm{A}$ & $\begin{array}{l}\text { The commercial software, Microsoft Excel, } 97 \text { was } \\
\text { used for plotting graphs and preparing tables. No } \\
\text { software routines or macros were used with this } \\
\text { software to prepare this report. The output was } \\
\text { visually checked for correctness. }\end{array}$ & PC, Windows 98 \\
\hline
\end{tabular}




\section{INPUTS}

\subsection{DIRECT INPUTS}

The location, a brief description, and the data tracking number (DTN) used as input for this scientific analysis report are listed in Table 4-1. The qualification status of data input is provided in the Technical Data Management System and listed in the Document Input Reference System (DIRS) database.

Table 4-1. Direct Input Data

\begin{tabular}{|l|l|l|}
\hline \multicolumn{1}{|c|}{ Data Name } & \multicolumn{1}{c|}{ Data Source } & \multicolumn{1}{c|}{ DTN } \\
\hline $\begin{array}{l}\text { PVHA (CRWMS M\&O 1996 } \\
\text { [DIRS 100116]): Expert Assessment of } \\
\text { Volcanic Hazard in the YMR }\end{array}$ & CRWMS M\&O 1996 [DIRS 100116] & $\begin{array}{l}\text { MO0002PVHA0082.000 } \\
\text { [DIRS 148234] }\end{array}$ \\
\hline Conduit Diameter & BSC 2004 [DIRS 169980] & $\begin{array}{l}\text { LA0407DK831811.001 } \\
\text { [DIRS 170768] }\end{array}$ \\
\hline
\end{tabular}

The primary source of input data for this analysis is the PVHA expert interpretations presented in Probabilistic Volcanic Hazard Analysis for Yucca Mountain, Nevada (CRWMS M\&O 1996 [DIRS 100116]). Because this report is an analysis of the PVHA (CRWMS M\&O 1996 [DIRS 100116]), the use of the PVHA as input to this report is appropriate. The PVHA expert interpretations are used as inputs to the calculations described in Section 6.5 and Appendix C. Interpretations and inputs provided by the PVHA to perform the calculations described in Section 6.5 are discussed in Section 6.5.1. The interpretations are also discussed in the conceptual framework described in Sections 6.1 through 6.4. The distribution of conduit diameters is used in Appendix B to develop a buffer zone surrounding the repository footprint that is used to account for the effect of conduit size on the calculation of the frequency of dike intersection and the distribution for number of eruptive centers within the repository footprint.

Other input to this analysis is listed in Table 4-2.

Table 4-2. Other Direct Input to This Scientific Analysis

\begin{tabular}{|c|l|c|}
\hline \multicolumn{1}{|c|}{ Name } & \multicolumn{1}{|c|}{ Description } & DTN \\
\hline Repository footprint & $\begin{array}{l}\text { Repository footprint determined from information described } \\
\text { in BSC 2003 [DIRS 162289] }\end{array}$ & N/A \\
\hline
\end{tabular}

All other DTNs presented in this scientific analysis report are not used as direct input to this report and are used as reference only.

\subsection{CRITERIA}

The general requirements to be satisfied by the TSPA are stated in 10 CFR 63.114 [DIRS 156605]. Technical requirements to be satisfied by the TSPA are identified in the Yucca Mountain Project Requirements Document (Canori and Leitner 2003 [DIRS 166275]). The acceptance criteria that will be used by the Nuclear Regulatory Commission (NRC) to determine whether the technical requirements have been met are identified in the Yucca Mountain Review 
Plan, Final Report (NRC 2003 [DIRS 163274]). Criteria that are applicable to this scientific analysis report, and details of how the criteria have been addressed, are described in Appendix D.

The Yucca Mountain Review Plan, Final Report (NRC 2003 [DIRS 163274]) lists acceptance criteria pertaining to the above requirements. Criteria that are applicable to this scientific analysis report are described in Appendix D.

The Yucca Mountain Review Plan, Final Report Acceptance Criteria are intended to ensure that the requirements of 10 CFR 63.114(a)-(c) and (e)-(g) [DIRS 156605] are met.

\subsection{CODES, STANDARDS, AND REGULATIONS}

No specific formally established codes, standards, or regulations have been identified as applying to this activity, except for those discussed in Section 4.2. This activity does not directly support LA design. 


\section{ASSUMPTIONS}

This section describes the assumptions used for the analyses in Section 6.5 and Appendix C.

The calculation of the updated distribution for frequency of intersection of the repository footprint by a basaltic dike requires no assumptions because it uses the outputs defined by the PVHA (CRWMS M\&O 1996 [DIRS 100116]) without modification. The update involves only a change in the repository footprint.

The calculation of conditional distributions for the length and azimuth of intersecting dikes within the proposed repository requires no assumptions because it involves only a modification of the software to output an intermediate step of the "frequency of intersection of the repository footprint by a dike" calculation.

The calculation of conditional distributions for the number of eruptive centers within the repository footprint requires an assessment of the number of eruptive centers associated with a volcanic event and the spatial distribution for eruptive centers along the length of the dike. As explained in Section 6.5.2.2, this analysis uses the PVHA experts' assessment of volcanic event counts and the number of separate eruptive centers to develop a distribution for the number of eruptive centers per volcanic event. The number of eruptive centers associated with a volcanic event is derived using the following assumptions.

\subsection{USE OF QUATERNARY VOLCANOES}

Assumption: The mapped Quaternary volcanoes in the YMR are representative of the type of volcanoes characterized for calculation of the consequences of an eruptive event through the proposed repository. For the purposes of this analysis report and for performance assessment (PA) calculations, each eruptive center or vent equates to one subsurface conduit.

Basis: As stated by the Igneous Consequences Peer Review Panel, “...the history of volcanism and eruptive styles of Pliocene to Quaternary volcanoes in the Crater Flat Volcanic Zone (CFVZ) represents the best guide to possible future activity at the YMR" (Detournay et al. 2003 [DIRS 169660], Section 2.1.1). Therefore, the characteristics of Quaternary volcanoes in the YMR are used to define the distributions for the characteristics of future volcanic events (BSC 2004 [DIRS 169980]). The assumption that each volcano is associated with a conduit is consistent with the description of the eruptive process for YMR volcanoes described in the scientific analysis report Characterize Eruptive Processes at Yucca Mountain, Nevada (BSC 2004 [DIRS 169980]). Volcanoes were also used by the PVHA experts as indicators of the occurrence of past volcanic events.

Use in the Analysis: This assumption is used in Appendix $C$ to derive distributions for the number of eruptive centers per volcanic event and the average spacing between eruptive centers.

Confirmation Status: This assumption needs no further confirmation. 


\subsection{ALL VOLCANIC EVENTS PRODUCE AT LEAST ONE ERUPTIVE CENTER}

Assumption: Each hypothetical volcanic event for which the associated dike intersects the repository has at least one eruptive center located somewhere along the length of the dike.

Basis: This assumption is reasonable on the basis of the PVHA expert panel's general belief that magma that ascends to within a few hundred meters of the surface will produce a surface manifestation of the volcanic event (CRWMS M\&O 1996 [DIRS 100116], Appendix E, pp. RC-10, BC-6, WD-6, WH-6, MK-12). The assumption is conservative because the PVHA experts allowed for the possibility that not all past volcanic events reached the surface in assessing the rate of volcanic events. The rate of volcanic events used to compute the frequency of intersection of the repository footprint by a dike was obtained by multiplying the rate based on past volcanic events with observed surface manifestations by a hidden events factor greater than or equal to 1.0. The hidden events factor was used by the PVHA experts to account for past volcanic events that may not have reached the surface, but did ascend high enough in the crust to reach the level of the repository. The hidden event factors assessed by the PVHA experts ranged from 1.0 to 5.0 with a composite mean value of approximately 1.4. Assuming all future volcanic events will produce an eruptive center produces the maximum rate of eruptive center occurrence.

Use in the Analysis: This assumption is used in Appendix $\mathrm{C}$ to develop distributions for the number of eruptive centers per volcanic event and in Section 6.5.2.2 in the computation of the conditional distribution for number of eruptive centers within the repository.

Confirmation Status: The assumption is consistent with the expert panel's general consideration that magma ascending to within a few hundred meters of the surface would erupt and need not be confirmed.

\subsection{LOCATION OF ERUPTIVE CENTERS ALONG THE LENGTH OF A DIKE OR DIKE SEGMENT}

Assumption: The location of an eruptive center (a volcanic cone and associated conduit) along the length of a dike or dike segment is defined by a uniform probability distribution.

Basis: A distribution for the location of eruptive centers along the length of the dike system associated with a volcanic event was not assessed as part of the PVHA. Therefore, an assumption about the form of this distribution is needed in order to complete the calculations in this analysis report. The assumption of a uniform distribution is justified on the basis that it is the minimum information assumption that maximizes the uncertainty in location of the eruptive centers. Any other form of a probability distribution requires more information than the range of possible locations (in this case, the end points of a dike or dike segment). The assumption is conservative because it maximizes the probability for the occurrence of multiple eruptive centers within the repository footprint (i.e., no clustering of eruptive centers on a dike segment falling partly outside the repository footprint). The PVHA experts did assess the location of the dike with respect to the volcanic event, typically specifying that the dike was most likely to be centered on the volcanic event. An alternative for Assumption 5.3 would be to assume that the assessed location of dikes relative to the volcanic event also applies to the location of eruptive 
centers along the length of a dike; i.e., that eruptive centers are most likely to occur at the center of the dike. However, this alternative assumption imposes more information on the process than the assumption of a uniform distribution and is expected to produce slightly lower hazard. In addition, applying this alternative to the case of multiple eruptive centers during a single event is not straightforward. Therefore, the assumption of a uniform distribution is considered to be more appropriate.

Use in the Analysis: This assumption is used in Section 6.5.2.2 in the computation of the conditional distribution for number of eruptive centers within the proposed repository.

Confirmation Status: The assumption does not need to be confirmed because it does not impose any additional information beyond the length of the dike, which is obtained from the PVHA experts' interpretations. Furthermore, in this report an alternative assumption is used in which the presence of the repository induces, with a probability of 1.0, the formation of at least one eruptive center within the repository footprint, given an intersection by a volcanic event. 


\section{INTENTIONALLY LEFT BLANK}




\section{SCIENTIFIC ANALYSIS}

\subsection{INTRODUCTION}

In this report, a conceptual framework for volcanism at Yucca Mountain consistent with output and results of the PVHA is described. This report describes how this framework and alternative conceptual frameworks influence the results of estimations of the probability of dike intersection and volcanic eruption at the proposed geologic repository at Yucca Mountain.

This report summarizes and extends the findings of the PVHA (CRWMS M\&O 1996 [DIRS 100116]). For the PVHA, an expert panel was convened in 1995 to review all pertinent data relating to volcanism at Yucca Mountain and based on these data, to quantify both the annual probability and associated uncertainty of a volcanic event intersecting a proposed repository sited at Yucca Mountain. The data the experts reviewed was comprehensive, consisting of two decades of data collected by volcanologists who conducted studies to quantify the probability that a future volcanic eruption would disrupt the proposed repository (e.g., CRWMS M\&O 1998 [DIRS 105347] and references therein). This report also describes the relationship between volcanic source zones defined in the PVHA and the current understanding of structural controls on volcanism in the YMR.

The results of the PVHA are a set of alternative models for assessing the volcanic hazard at Yucca Mountain, probabilities that each model is the appropriate model, and probability distributions for the parameters of the models. As such, the PVHA defines the scientific uncertainty in applying models to assess the volcanic hazard. The PVHA experts documented the basis for their assessments of the validity of the alternative models in Probabilistic Volcanic Hazard Analysis for Yucca Mountain, Nevada (CRWMS M\&O 1996 [DIRS 100116], Appendix E). Therefore, the results of the PVHA are considered valid for assessing the uncertainty in the volcanic hazard at Yucca Mountain.

In the context of the PVHA, the volcanic hazard is defined as the annual frequency of intersection of the repository by a volcanic event. A volcanic event was defined in the PVHA to be a spatially and temporally distinct batch of magma ascending from the mantle through the crust as a dike or system of dikes (CRWMS M\&O 1996 [DIRS 100116], Appendix E). For the purposes of the probability models developed in the PVHA and discussed in this report, a volcanic event is defined as a point $(x, y)$ in space representing the expected midpoint of the dike system involved in the magma ascent. The dike system associated with the volcanic event is represented in probability model by a line element defined in terms of a length, azimuth, and location relative to the point event. The term "dike length" used in the PVHA and in this report when discussing volcanic events, refers to the total length of the dike system associated with the volcanic event. The phrase "intersection of the repository footprint by a dike" refers to intersection of the emplacement area of the repository by the line element representing the dike system associated with the volcanic event. The possibility that a dike system (e.g., multiple dikes) has width or consists of multiple parallel dikes does not significantly affect the intersection probability and is not part of the calculations in this report. Both the width of the dikes and the number of parallel dikes affect the consequences of an intersection and are included in the consequence analyses presented in Number of Waste Packages Hit by Igneous Intrusion (BSC 2004 [DIRS 170001]). 
Based on the PVHA outputs and assumptions in Section 5 of this report, probability distributions are developed for the length and orientation of intersecting dikes within the repository footprint and for the number of eruptive centers located within the repository footprint (conditional on a dike intersecting the repository). Lastly, the probability of dike intersection is recalculated based on the 2003 repository footprint (BSC 2003 [DIRS 162289]) and the probability of an eruptive center(s) forming within the repository footprint is calculated (the latter is a calculation that was not included in the PVHA).

The analysis presented in this report is based on the volcanic hazard model developed in the PVHA (CRWMS M\&O 1996 [DIRS 100116]). Therefore, the computational methods and software used to perform the analysis are based on the original software developed to implement the PVHA hazard model. Other software to implement the 1996 PVHA volcanic hazard model does not exist.

\subsubsection{Summary of Conceptual Model for Igneous Activity}

This section provides a summary of the conceptual model for igneous activity near Yucca Mountain. The conceptual model consists of three components, each related to an aspect of igneous processes that may impact the repository. The three components are:

Igneous Framework-describes the igneous and tectonic history and features of the Yucca Mountain region, and the assessment of the history and features by PVHA experts as a basis to determine the probability of intersection of the repository by a volcanic event (this report).

Igneous Processes-describes the physical processes expected to occur during a potential future volcanic event (BSC 2004 [DIRS 169980]; BSC 2004 [DIRS 170001]; BSC 2003 [DIRS 168960]; BSC 2004 [DIRS 170028]; BSC 2004 [DIRS 170026]; BSC 2004 [DIRS 168504]).

Post-Igneous Processes-describes the surficial processes of erosion and deposition expected to occur when a contaminated tephra sheet covers the landscape and is redistributed following a potential future volcanic eruption through the repository (BSC 2004 [DIRS 170026]).

\subsubsection{Igneous Framework}

Basaltic volcanism is the most common form of volcanism on earth and has occurred repeatedly throughout the western United States over the past 5 million years (Perry et al. 1998 [DIRS 144335], Figure 4.1). Basaltic volcanoes, primarily scoria cones, generally form in clusters of several, to several hundred volcanoes that define a volcanic field. In the western United States, the largest basaltic volcanic fields erupted approximately 100 to 300 cubic kilometers of lava, generally over periods of less than a few million years (Perry et al. 1998 [DIRS 144335], Figure 4.2). The larger volcanic fields tend to occur along the margins of major physiographic provinces, such as the Colorado Plateau and Great Basin. Smaller-volume volcanic fields of less than tens of cubic kilometers tend to occur within the interior of the Basin and Range Province, including the interior of the Great Basin where Yucca Mountain is located. Basaltic volcanism in the western United States is generally correlated with regions of 
extensional tectonics. It is not uncommon for relatively large-volume basaltic volcanism to be spatially and temporally associated with regions of relatively high extension rate (Section 6.2 of this report).

The earliest volcanism in the Yucca Mountain region was dominated by a major episode of caldera-forming, silicic volcanism that occurred primarily between about 15 and 11 million years ago, forming the southwestern Nevada volcanic field (Sawyer et al. 1994 [DIRS 100075]). Silicic volcanism was approximately synchronous with a major period of extension, which occurred primarily between 13 and 9 million years ago (Sawyer et al. 1994 [DIRS 100075], Figure 4). Silicic volcanism has not occurred in the Yucca Mountain region in the last 7 or 8 million years and is not included as part of the igneous conceptual model. The commencement of basaltic volcanism occurred during the latter part of the silicic caldera-forming phase as extension rates waned. Small-volume basaltic volcanism has continued into the Quaternary as part of a general decline in eruption volume over the past 11 million years (Perry et al. 1998 [DIRS 144335], Chapter 2).

Post-Miocene volcanism (younger than 5 million years) has occurred in six episodes in the Yucca Mountain region, at approximately 4.8, 3.7, 3.1, 1.0, 0.4, and 0.08 million years ago, as summarized in Figure 6-1 and Table 6-2 (Perry et al. 1998 [DIRS 144335] Table 2.B; Heizler et al. 1999 [DIRS 107255]). The total eruption volume of the post-Miocene basalts is about $6 \mathrm{~km}^{3}$. The volume of individual episodes has decreased progressively through time, with the three Pliocene episodes having volumes of approximately 1 to $3 \mathrm{~km}^{3}$ each and the three Quaternary episodes having a total volume of only about $0.5 \mathrm{~km}^{3}$ (Perry et al. 1998 [DIRS 144335], Table 3.1). The Quaternary volcanoes are of small volume (about $0.1 \mathrm{~km}^{3}$ or less) and typically consist of a single main scoria cone surrounded by a small field of $a a$ basalt flows, which commonly extend about $1 \mathrm{~km}$ from the scoria cone (Section 6.2 of this report).

In addition to surface exposures of basaltic volcanism, several magnetic anomalies in the Amargosa Desert identified in aeromagnetic surveys conducted in the early 1990s have characteristics that indicate buried basaltic volcanic centers (Langenheim et al. 1993 [DIRS 148622], p. 1840). One of these anomalies ([DIRS 148622], Anomaly B of Langenheim et al. 1993), was drilled and basalt cuttings were dated at 3.85 million years using the ${ }^{40} \mathrm{Ar} /{ }^{39} \mathrm{Ar}$ method (CRWMS M\&O 1998 [DIRS 105347], Chapter 2, Table 2.B). A more recent survey conducted by the USGS in 1999 (O'Leary et al. 2002 [DIRS 158468]) suggests the possibility of additional buried volcanic centers. Results of sensitivity studies indicate these data do not significantly impact the results of the PVHA (Section 6.5.4.1 of this report).

The decreased eruptive volume through time, together with geochemical evidence (Perry et al. 1998 [DIRS 144335], p. 4-8), indicates that the intensity of mantle melting processes that produce basaltic magma beneath the Yucca Mountain region has waned over the past 5 million years (Perry and Crowe 1992 [DIRS 106488], p. 2359). Considered in terms of total eruption volume, frequency of eruptions, and duration of volcanism, basaltic volcanic activity in the Yucca Mountain region in the past 5 million years defines one of the least active basaltic volcanic fields in the western United States (CRWMS M\&O 1998 [DIRS 105347], Figure 4-2). 
The probability of intersection of the repository footprint by a volcanic event depends on the recurrence rate of volcanic events multiplied by the likelihood that a volcanic event will intersect the repository (CRWMS M\&O 1996 [DIRS 100116], Section 3.1.1). Because volcanic events have occurred very infrequently on average in the past 5 million years (every few hundred thousand years), recurrence rates for volcanic events are proportionally low $\left(10^{-5}\right.$ to $10^{-6}$ events per year). The low recurrence rate of volcanism in the Yucca Mountain region is the primary reason that the probability of intersection is extremely low, with a mean of $1.7 \times 10^{-8}$ intersections per year (Section 6.5.3.1 of this report), or approximately one in 6,000 over the 10,000 -year performance period of the repository. The probability that a volcano will erupt through the repository is conditional on dike intersection and is slightly less than the probability of dike intersection (mean of $1.3 \times 10^{-8}$ eruptions per year) (Section 6.5.3.2 of this report), because a volcano may not necessarily erupt at a location along the length of an intersecting dike that lies within the repository footprint (Section 6.5.1.3 of this report).

Post-Miocene volcanoes of different ages in the Yucca Mountain region are spatially clustered (Figure 6-1). Clustering of volcanism is potentially significant to probability models because it indicates spatial control on location of past volcanism that may predict the location of future volcanism. The most significant clustering of post-Miocene volcanism occurs in the Crater Flat structural domain (Fridrich et al. 1999 [DIRS 107333), both in terms of number of episodes (three of six post-Miocene episodes) and proximity to Yucca Mountain (Figure 6-1). Two of the three episodes of Quaternary volcanism, including the youngest episode at Lathrop Wells, occur within the Crater Flat structural domain, as does the repository. The structural and geophysical features of the domain and the extent to which they influence the location of volcanism within the domain were key factors in conceptual models of volcanism and assessments of the probability of volcanic disruption of the repository.

Structural data indicate that the southwestern part of the Crater Flat domain is more extended than the northeastern part of the domain (Fridrich 1999 [DIRS 118942]; Fridrich et al. 1999 [DIRS 107333]). Post-Miocene basaltic centers of the Crater Flat domain lie within the extended southwestern part of the domain. The youngest volcano in the Crater Flat domain, the 80 thousand years ago (ka) Lathrop Wells volcano, lies within the most active site of late Quaternary faulting in the Crater Flat domain (Fridrich et al. 1999 [DIRS 107333], p. 211). Thus, a close spatial and temporal relationship exists between sites of extension and volcanism throughout the Crater Flat domain (Fridrich et al. 1999 [DIRS 107333], p. 211). The restriction of three episodes of post-Miocene volcanism to the more extended part of the Crater Flat domain suggests that volcanism is less likely to occur at Yucca Mountain, which lies outside of the more extended part in an area where no post-Miocene volcanism has occurred (Fridrich et al. 1999 [DIRS 107333], p. 210, Figure 17a). The PVHA experts recognized the close association between volcanism and areas of maximum extension in the Yucca Mountain region (CRWMS M\&O 1996 [DIRS 100116], pp. RC-5, BC-12, AM-5, MS-2, GT-2). Subsequent geologic and geophysical studies provide corroborative evidence that areas of maximum extension in the Crater Flat domain correspond closely to volcanic source zones defined in the PVHA (Stamatakos et al. 1997 [DIRS 138819]; Brocher et al. 1998 [DIRS 100022]; Fridrich et al. 1999 [DIRS 107333]). 


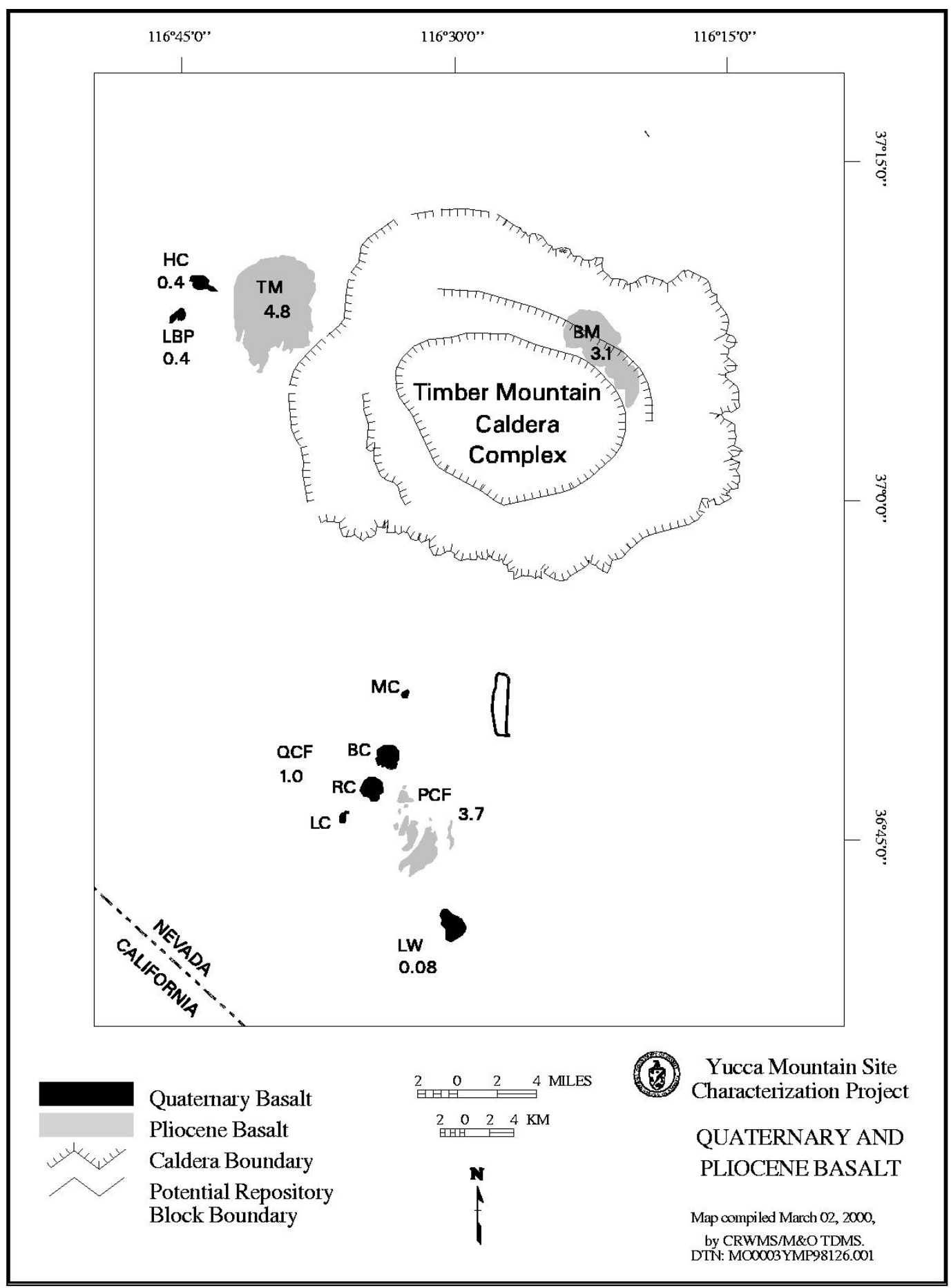

DTNs: LAFP831811AQ97.001 [DIRS 144279]; MO0003YMP98126.001 [DIRS 149605] (both are reference only).

Source: Numbers by each volcano indicate approximate age in millions of years (CRWMS M\&O 1998 [DIRS 105347], Chapter 2, Tables 2.B and 2.C; DTN: LAFP831811AQ97.001).

$\mathrm{TM}=$ Thirsty Mesa; PCF = Pliocene Crater Flat; BM = Buckboard Mesa; QCF = Quaternary Crater Flat; $(\mathrm{MC}=$ Makani Cone; $\mathrm{BC}=$ Black Cone; RC = Red Cone; LC = Little Cones); HC = Hidden Cone; LBP = Little Black Peak; LW = Lathrop Wells

Figure 6-1. Location and Age of Post-Miocene (less than 5.3 million years (m.y.)) Volcanoes (or Clusters Where Multiple Volcanoes Have Indistinguishable Ages) in the Yucca Mountain Region 


\subsubsection{Igneous Processes}

The formation of a volcanic event in the Yucca Mountain region begins with ascent of magma from the mantle source as a dike (magma-filled crack). During magma ascent and decompression, volatile gases, such as $\mathrm{H}_{2} \mathrm{O}$ and $\mathrm{CO}_{2}$, escape, increasing the volume of the magma. This resulting volume expansion drives the basaltic magma upward through the upper few kilometers of crust. Because volatiles are concentrated near the crack tip of the ascending magma, the start of volcanism is typically characterized by pyroclastic eruptions (volcanic explosions and aerial expulsion of clastic rock from a volcanic vent) of gas-rich magma. Based on analogue studies, the concentration of volatile species in basalts of the Yucca Mountain region is likely to range from 1 to $3 \mathrm{wt} \%$, or more (BSC 2004, [DIRS 169980], Section 7). This range is higher than in most alkali (sodium or potassium-rich) basalt magmas, possibly because the volatile species originated in small percentages of partial melt of a hydrous lithospheric mantle source. The incompatible-element-enriched nature of these alkali basalts relative to other alkali basalts in the western United States is consistent with this conclusion (BSC 2004 [DIRS 169980], Sections 6.3.2 and 6.3.3).

Basaltic magma is transported from a region of melting in the mantle to the surface through dikes. In the Yucca Mountain region, dikes are typically 1 to $2 \mathrm{~m}$ in width and have an average length of $4 \mathrm{~km}$ (CRWMS M\&O 1996 [DIRS 100116]). The longest expected dike length in the Yucca Mountain region is about $10 \mathrm{~km}$. Based on the regional stress field of the upper crust, dikes are expected to have an orientation that centers on $\mathrm{N} 30^{\circ} \mathrm{E}$, although other orientations are possible and are observed within the region (BSC 2004, [DIRS 169980], Section 6.3).

Although an ascending dike could be influenced by topographic or thermal-mechanically induced stress, the model described here assumes that the dike propagates through the repository (BSC 2004 [DIRS 170028], Section 6.3.9.2.2.2). As the dike approaches the level of the drifts, the crack tip advances ahead of the magma front and will intersect the repository drifts first. When the magma front within the dike reaches the level of the repository, magma will be available to flow into drifts. There are two possibilities for the behavior of the magma as it approaches the drifts. One is that the magma steadily releases gas into the host rock as it approaches the drifts so that a relatively gas-poor magma flows effusively into the drifts. A more likely scenario, based on analogue studies of historic eruptions, is that the initial magma encountering the drifts will be gas-rich, resulting in pyroclastic flow into the drifts. In either case, the dike tip will precede the magma by several seconds to a few hours. Because the entry of magma from the dike into the drift is not necessarily instantaneous with intersection, it is unlikely that dike intersection will result in an abrupt explosion into the drift (BSC 2004 [DIRS 170028]). At the analogue Parícutin volcano, the initial crack broke the surface several hours before the first manifestation of weak pyroclastic eruptions began (BSC 2004 [DIRS 170028]).

The most likely scenario following dike intersection of repository drifts is that the dike continues to follow the path established by the dike tip and erupts to the surface without being influenced by the presence of the repository. An alternative scenario is that the lateral diversion of magma into drifts results in sufficient pressurization of drifts to propagate a dike to the surface at a location some distance from the site of the initial dike intersection. This scenario could potentially lead to more waste entrained during an eruption compared to the case of conduits 
developed only above the site of initial dike intersection. The amount of waste potentially entrained in this scenario would depend on the length of drifts that transport magma to the site of the down-drift dike, assuming the magma is able to incorporate and transport waste.

The rate and degree to which an intersected drift fills with magma depends on variables, such as magma rise rate, magma viscosity, and the nature (effusive or pyroclastic) of the flow into the drifts (BSC 2004 [DIRS 170028]). Magma rise rates are assumed to range between 1 and $10 \mathrm{~m} / \mathrm{s}$, while viscosities are assumed to range between 10 and $100 \mathrm{~Pa} \cdot \mathrm{s}$ (BSC 2004 [DIRS 169980]).

The potential ascent of dikes and the formation of conduits at Yucca Mountain has been analyzed relative to the configuration of the repository, which consists of approximately one hundred waste-emplacement drifts of 5-m diameter, spaced about $80 \mathrm{~m}$ apart and encompassing a total area of approximately $5 \mathrm{~km}^{2}$. The number of waste-emplacement drifts intersected would depend on the orientation of a dike system intersecting the repository, the number of dikes in a dike swarm, and the lengths of the dikes lying within the repository footprint.

Formation of a volcano begins with a fissure eruption as a dike or dike swarm intersects the surface (BSC 2004 [DIRS 169980]). The formation of a basaltic volcano is complex with total eruption durations typically ranging from weeks to months and possibly years. During the eruption, activity includes effusion of gas-poor lava flows and explosive, gas-rich pyroclastic eruptions. Both types of eruptions can occur simultaneously or in alternating cycles that include periods of inactivity (BSC 2004 [DIRS 169980], Section 6.4). Intrusive processes simultaneously occur in the subsurface. Analogue studies of shallowly eroded volcanoes in the Yucca Mountain region demonstrate that subsurface intrusive processes may include the formation of multiple dikes (dike swarm) and sills (horizontal emplacement of magma into the host rock). Evolution of the intrusion beneath an erupting volcano can also lead to changes in the location or migration of eruptive vents during the period of eruption (BSC 2004 [DIRS 169980], Sections 6.3.1 and 6.3.3).

At a relatively early stage of the eruption, the fissure eruption localizes to one or more conduits that transport magma to the surface for the remainder of the eruption. Conduit formation provides a mechanism to transport waste to the surface. The physical processes that would influence the exact location of a conduit within the repository (e.g., at drifts or within pillars) depend on multiple complex factors. Conduit localization is assumed to be random along the length of a given dike (BSC 2004 [DIRS 169980], Section 6.3.1.1). Conduit diameters are typically a few tens of meters. A value of $150 \mathrm{~m}$ is used in the TSPA-LA as an upper bound for conduit diameter. Basalt conduit depths probably reach several hundred meters and are assumed in this model to reach the depth of the repository to allow interaction with waste emplacement drifts (BSC 2004 [DIRS 169980], Sections 6.3.3 and 6.3.1).

Magma flux through the conduit during explosive phases of the eruption typically varies from approximately $10^{4} \mathrm{~kg} / \mathrm{s}$ for normal Strombolian (eruption of ballistic magma fragments) activity to approximately $10^{6} \mathrm{~kg} / \mathrm{s}$ for violent Strombolian (sustained eruption column producing an ash plume) activity (BSC 2004 [DIRS 169980], Section 6.3). Commonly, high magma flux and explosive eruptions occur during the early stage of the eruption, with an increase in effusive 
(lava flows) activity as the eruption proceeds. At Lathrop Wells, however, field observations indicate that early volcanism was Strombolian, followed by violent Strombolian eruptions.

Lathrop Wells is one of eight small-volume (about $0.01 \mathrm{~km}^{3}$ to $0.1 \mathrm{~km}^{3}$ ) basaltic volcanoes that formed during the Quaternary within $50 \mathrm{~km}$ of Yucca Mountain (Figure 6-1). Based on observations of preserved eruptive deposits, these volcanoes share a similar eruptive history of a pyroclastic phase that led to the formation of a main scoria cone and effusion of aa lava flows. The scoria cone and lava flow deposits, excluding tephra fall from violent eruptions, typically cover a few square kilometers. The fundamental similarity of all Quaternary volcanoes in the YMR suggests that a future volcano that could potentially disrupt the repository will share these same characteristics (BSC 2004 [DIRS 169980], Section 6.3.3).

A violent Strombolian eruption is the most energetic eruption expected in the Yucca Mountain region (BSC 2004 [DIRS 169980]; BSC 2004 [DIRS 170026]). These eruptions involve a sustained, vertical eruption column (a gas-particle jet) that propels the tephra to heights of several kilometers above the scoria cone. The tephra plume eventually reaches a level of neutral buoyancy in the atmosphere, spreads laterally as an anvil cloud, and is transported downwind. Tephra particles fall out of the vertical eruption column and the anvil-shaped cloud. The atmospheric dispersal and deposition of the fine tephra forms a sheet-like deposit of volcanic ash characterized by decreasing thickness and grain size with distance from the volcano. Tephra deposits might extend $10 \mathrm{~km}$ or more from the volcano and cover several hundred square kilometers (BSC 2004 [DIRS 169980], Section 6.3.3). In the TSPA-LA, only the violent Strombolian phase of volcanism is modeled for atmospheric dispersal because this is the only mechanism for the ash column to reach the heights necessary to deposit ash $18 \mathrm{~km}$ downwind from the volcano to the location of the RMEI (BSC 2004 [DIRS 169980], Sections 6.3.3.4.1 and 6.3.3.4.3).

If a dike intersects the repository, waste packages can be disrupted by magma entering the emplacement drifts and contacting the waste packages (intrusion case), or by direct entrainment of waste packages within conduits to the surface (eruption case). In the intrusion case, the number of packages disrupted depends on the number of emplacement drifts filled by magma, which is conditional on the number of drifts intersected by dikes. For the eruption case, the number of packages disrupted depends on the diameter and number of conduits that form within the repository footprint (BSC 2004 [DIRS 170001], Section 6.4).

If magma fills a drift, post-emplacement processes become important (BSC 2004 [DIRS 170028]). Magmatic volatiles are expected to degas from the cooling magma within the intruded drift and infiltrate the tuff host rock. Thermal energy from the cooling magma would also be transferred into the host rock (BSC 2004 [DIRS 170028], Section 6.9).

\subsubsection{Post-Igneous Processes}

After the deposition of a violent Strombolian tephra sheet, volcanic ash is subject to redistribution by normal sedimentary processes (erosion and deposition) (BSC 2004 [DIRS 170026]). A hypothetical violent Strombolian eruption through the repository would produce tephra dispersed to the northeast, blanketing part of the Fortymile Wash drainage system with particles less than $2 \mathrm{~mm}$ in size (BSC 2004 [DIRS 170026], Section 6). Redistribution of 
the tephra would be dominated by southward fluvial transport in Fortymile Wash. Tephra deposited on slopes would be moved downslope as small debris flows, eventually reaching a distributary channel at the base of a slope. The general result is downstream movement of tephra-bearing sediment that is progressively diluted and dispersed. This mixing and dilution of the sedimentary components from the drainage system occurs in environments where sediment is transported by water or wind. Such mechanisms might transport contaminated ash to the RMEI, even if the original volcanic eruption did not deposit tephra at the reasonably maximally exposed location.

\subsubsection{Features, Events, and Processes}

Table 6-1 describes the features, events, and processes (FEPs) that are included in the TSPA-LA through the use of the results of the analysis described in this document. The complete set of FEPs is contained in DTN: MO0407SEPFEPLA.000 [DIRS 170760]. This analysis report addresses the annual frequency (essentially equivalent to annual probability) of the events addressed by the FEPs. The effects of these events are addressed by the reports described in Section 6.1.1.2.

Table 6-1. Included Features, Events, and Processes for This Scientific Analysis Report

\begin{tabular}{|l|l|l|}
\hline FEP Number & \multicolumn{1}{|c|}{ FEP Name } & \multicolumn{1}{c|}{ Relevant Section } \\
\hline $1.2 .04 .03 .0 \mathrm{~A}$ & $\begin{array}{l}\text { Igneous intrusion into } \\
\text { repository }\end{array}$ & $\begin{array}{l}\text { Section } 6.5 \text { describes the } \\
\text { calculation of the annual } \\
\text { frequency of igneous } \\
\text { intrusion into the repository }\end{array}$ \\
\hline $1.2 .04 .06 .0 \mathrm{~A}$ & $\begin{array}{l}\text { Eruptive conduit to surface } \\
\text { intersects repository }\end{array}$ & $\begin{array}{l}\text { Section } 6.5 \text { describes the } \\
\text { calculation of the annual } \\
\text { frequency of intersection of } \\
\text { the repository by an } \\
\text { eruptive conduit }\end{array}$ \\
\hline
\end{tabular}

\subsubsection{Summary of Output Data}

The primary output data of this analysis are contained in the following two data sets:

- Output DTN: LA0302BY831811.001 contains the computed distribution for frequency of intersection of the repository footprint by a basaltic dike and the conditional distributions for the length and azimuth of intersecting dikes within the repository footprint and conditional distributions for the number of eruptive centers. These outputs are described in Section 6.5.3.1 and 6.5.3.2.

- Output DTN: LA0307BY831811.001 contains the distribution for the frequency of intersection of the repository in a modified format appropriate for submittal to TSPA. File PVHA-4P.DST (Output DTN: LA0302BY831811.001) was modified by adding a zero point and by eliminating a few intermediate points that did not result in a perceptible increase in the cumulative probability distribution. The resulting modified file, PVHA-4PA.DST in Output DTN: LA0307BY831811.001, conforms to the TSPA requirement for a monotonic increase in an input discrete probability distribution. 
Output DTN: LA0307BY831811.001 also contains data presented in summary tables in Section 6.5 .3 and 7.1.

The output data in these two output DTNs are based on the 2003 repository footprint (BSC 2003 [DIRS 162289]) and are to be used as input to revisions of the Number of Waste Packages Hit by Igneous Intrusion report (BSC 2004 [DIRS 170001]), and as inputs to the TSPA-LA. These data were computed during REV 01 of this report (BSC 2003 [DIRS 163769]) and have not changed from that revision.

In addition, there are three other data sets associated with this analysis report:

- Output DTN: LA0303BY831811.001 contains the repository footprint polygon developed in Appendix B and data used to generate figures and tables in Section 6 of this report. The data files are referenced by the figure and table numbers in REV 01 of this report (BSC 2003 [DIRS 163769]).

- Output DTN: LA0009FP831811.001 contains the data files for the PVHA 1996 volcanic hazard model used as input to the calculations and data used to generate some figures in Section 6 and Appendix C. This DTN also contains output files from Rev 0 of this report based on earlier repository designs.

- Output DTN: LA0009FP831811.004 contains additional data from Appendix C and output files from Rev 0 of this report based on earlier repository designs.

Section 6.5.4 presents sensitivity analyses conducted to assess the impact of recent data and proposed models for volcanic event locations. The results of these sensitivity studies are for information only and are not to be used for purposes of assessing repository performance. They were conducted with non-qualified input data and non-qualified software.

\subsection{VOLCANIC HISTORY OF THE YUCCA MOUNTAIN REGION}

Because several Quaternary basaltic volcanoes exist within $20 \mathrm{~km}$ of the proposed Yucca Mountain repository (Figure 6-1), volcanism must be assessed as a possible future disruptive event in TSPA. Two major types of volcanism have occurred in the YMR: an early phase of Miocene silicic volcanism, the recurrence of which is considered extremely unlikely in the next million years, and a more recent phase of Miocene and post-Miocene basaltic volcanism that indicates recurrence of volcanism somewhere in the YMR is likely (Reamer 1999 [DIRS 119693], p. 5).

The earliest volcanism in the YMR was dominated by a major episode of caldera-forming, silicic volcanism that occurred primarily between approximately 15 and $11 \mathrm{~m} . \mathrm{y}$., forming the southwestern Nevada volcanic field (Sawyer et al. 1994 [DIRS 100075]). Silicic volcanism was approximately coincident with a major period of extension, which occurred primarily between 13 and 9 m.y. (Sawyer et al. 1994 [DIRS 100075], Figure 4). Yucca Mountain is an uplifted, erosional remnant of voluminous ash-flow tuff deposits formed during the early phase of silicic volcanism. 
The commencement of basaltic volcanism occurred during the latter part of the caldera-forming phase, as extension rates waned, and small-volume basaltic volcanism has continued into the Quaternary. In terms of eruption volume, the $15 \mathrm{~m} . \mathrm{y}$. history of volcanism in the YMR is viewed as a magmatic system that peaked between 13 and $11 \mathrm{~m} . \mathrm{y}$. with the eruption of over $5000 \mathrm{~km}^{3}$ of ash flow tuffs and has been in decline since, with relatively minor volumes of basalt erupted since 11 m.y. ago (CRWMS M\&O 1998 [DIRS 100129], Figure 3.9-2). Approximately 99.9 percent of the volume of the southwestern Nevada volcanic field erupted by about 7.5 m.y. ago with the eruption of tuffs from the Stonewall Mountain volcanic center, which is the last active caldera system of the southwestern Nevada volcanic field. The last 0.1 percent of eruptive volume of the volcanic field consists entirely of basalt erupted since 7.5 m.y. ago (CRWMS M\&O 1998 [DIRS 100129], Figure 3.9-5). Considered in terms of total eruption volume, frequency of eruptions, and duration of volcanism, basaltic volcanic activity in the YMR defines one of the least active basaltic volcanic fields in the western United States (e.g., CRWMS M\&O 1998 [DIRS 105347], Chapter 4, Figure 4-2, for post-Miocene basalts of Crater Flat).

Post-caldera basalts in the YMR can be divided into two episodes: Miocene (eruptions between approximately 9 and 7.3 m.y.) and post-Miocene (eruptions between approximately 4.8 and 0.08 m.y.). The time interval of about 2.5 m.y. between these episodes is the longest eruptive hiatus of basalt in the YMR during the last 9 m.y. (CRWMS M\&O 1998 [DIRS 105347], Chapter 3, Table 3.1). This eruptive hiatus also marks a distinct shift in the locus of post-caldera basaltic volcanism in the YMR to the southwest (CRWMS M\&O 1998 [DIRS 100129], Figure 3.9-6). The Miocene basalts and post-Miocene basalts are thus, both temporally and spatially distinct. This observation emphasizes the importance of considering the age and location of the post-Miocene basalts (approximately the past 5 m.y. of the volcanic history of the YMR) when calculating the volcanic hazard to the proposed Yucca Mountain repository. The PVHA experts almost exclusively considered the time period of interest to be post- $5 \mathrm{~m}$.y. (with significant weight given to the post- $1 \mathrm{~m} . \mathrm{y}$. period) as the time period of interest in assessing volcanic hazard at Yucca Mountain (CRWMS M\&O 1996 [DIRS 100116], Figure 3-62).

The post-Miocene basalts formed during at least six episodes of volcanism (based on age groupings) that occurred within $50 \mathrm{~km}$ of the proposed Yucca Mountain repository (Figure 6-1). These six episodes, in order of decreasing age, consist of the:

- Basalt of Thirsty Mesa

- Pliocene Crater Flat and Amargosa Valley

- Buckboard Mesa

- Quaternary Crater Flat

- Hidden Cone and Little Black Peak (the Sleeping Butte centers)

- Lathrop Wells.

Three basalt episodes are in, or near the Crater Flat topographic basin within $20 \mathrm{~km}$ of Yucca Mountain. Several aeromagnetic anomalies in the Amargosa Valley have characteristics that indicate buried basaltic volcanic centers (Langenheim et al 1993 [DIRS 148622], p. 1840). One of these anomalies (Anomaly B of Langenheim et al. 1993 [DIRS 148622]) was drilled and basalt cuttings were dated at 3.85 m.y. using the ${ }^{40} \mathrm{Ar}{ }^{39} \mathrm{Ar}$ method (CRWMS M\&O 1998 [DIRS 105347], Chapter 2, Table 2.B). Because of the similarity in age to the $3.75 \mathrm{~m} . \mathrm{y}$. Pliocene 


\subsection{THE PROBABILISTIC VOLCANIC HAZARD ANALYSIS}

In 1995 to 1996, the DOE sponsored the PVHA project to assess the probability of a future volcanic event intersecting the proposed repository at Yucca Mountain. To ensure that a wide range of approaches was considered for the PVHA, the DOE identified 10 experts in the field to participate in the project and evaluate the data. Their evaluations (elicitations) were then combined to produce an integrated assessment of the volcanic hazard that reflects a range of alternative scientific interpretations. This assessment, which focused on the volcanic hazard at the site expressed as the probability of intersection of the proposed repository by a basaltic dike, provided input to an assessment of volcanic risk.

\subsubsection{The Probabilistic Volcanic Hazard Analysis Process}

The major procedural steps in the PVHA were selecting the expert panel members, identifying the technical issues, eliciting the experts' judgments, applying temporal and spatial aspects of probability models, and compiling and presenting the results.

\subsubsection{Selecting the Expert Panel Members}

From more than 70 nominees, 10 individuals were selected to participate in the PVHA project. Efforts were made to balance the panel with respect to technical expertise (geology, geochemistry, and geophysics) and institutional/organizational affiliation. The 10 experts and their affiliations are listed in Table 6-3 (CRWMS M\&O 1996 [DIRS 100116], Table 1-2).

Table 6-3. Probabilistic Volcanic Hazard Analysis Panel Members

\begin{tabular}{|l|c|l|}
\hline \multicolumn{1}{|c|}{ Expert } & Abbreviation & \multicolumn{1}{c|}{ Affiliation } \\
\hline Dr. Richard W. Carlson & RC & Carnegie Institute of Washington \\
\hline Dr. Bruce M. Crowe & BC & Los Alamos National Laboratory \\
\hline Dr. Wendell A. Duffield & WD & United States Geological Survey, Flagstaff \\
\hline Dr. Richard V. Fisher & RF & University of California, Santa Barbara (Emeritus) \\
\hline Dr. William R. Hackett & WH & WRH Associates, Salt Lake City \\
\hline Dr. Mel A. Kuntz & MK & United States Geological Survey, Denver \\
\hline Dr. Alexander R. McBirney & AM & University of Oregon (Emeritus) \\
\hline Dr. Michael F. Sheridan & MS & State University of New York, Buffalo \\
\hline Dr. George A. Thompson & GT & Stanford University \\
\hline Dr. George P. L. Walker & GW & University of Hawaii, Honolulu \\
\hline
\end{tabular}

Source: DTN: MO0002PVHA0082.000 [DIRS 148234].

\subsubsection{Identifying Technical Issues}

The PVHA panel of experts convened between February and December 1995. A technical facilitator/integrator led carefully structured, intensive interactions among the panel members. The experts participated in workshops, field trips, and other interactions that were used to identify sources of agreement and disagreement among them. Each expert played the role of an informed technical evaluator of data, rather than a proponent of a particular interpretation. On 
occasion, however, some experts were asked to present particular interpretations to facilitate discussion and consideration of alternative interpretations. In all the interactions, it was made clear that the purpose of the PVHA was to identify and understand uncertainty, not to eliminate it. It was also emphasized that the purpose was not necessarily to achieve consensus. Instead, disagreement was expected and accepted.

At the core of the PVHA project were four workshops. The primary objective of the workshops was to ensure the experts' understanding of the issues, alternative volcanic hazard models, and the available data on which they would base their technical assessments. The first three workshops focused on the data, volcanic hazard models, and interpretations relevant to the PVHA. The workshops included presentations of data and interpretations by technical specialists from the Los Alamos National Laboratory, the USGS, the University of Nevada, Las Vegas, and the Center for Nuclear Waste Regulatory Analysis, as well as from some PVHA experts. During the fourth workshop, the experts reviewed the preliminary assessments developed by the panel members, after which the individual elicitations were revised, based on feedback received. Two field trips held during the course of the PVHA provided the opportunity for the panel members to observe geologic relationships pertaining to eruptive style, the definition of volcanic events, and the distribution and timing of volcanic activity in the YMR.

\subsubsection{Temporal and Spatial Aspects of Probability Models}

Before the third PVHA workshop, an interactive meeting was held for the benefit of the expert panel in order to focus on the methods available to calculate volcanic hazard. The methods were used to calculate the two main aspects of volcanic hazard probability models: the temporal and spatial aspects.

Temporal models describe the frequency of occurrence of volcanic activity and include homogeneous and non-homogeneous models. Many of the experts used homogeneous Poisson models to define the temporal occurrence of volcanic events, which assumes a uniform rate of volcanism based on the number of volcanic events that occurred during various periods in the past. Non-homogeneous models were used by some experts to consider the possibility that volcanic events are clustered in time or to describe the possible waning or waxing of volcanic activity in the region during the period of time the experts believed was relevant to hazard analysis.

Spatial models describe the spatial distribution (location) of future volcanic activity. The most common PVHA models considered the future occurrence of volcanoes to be homogeneous within particular defined regions or "source zones" (CRWMS M\&O 1996 [DIRS 100116], Figure 3-62). Source zones were defined based on several criteria: the spatial distribution of observed basaltic volcanoes (especially post-5 m.y. volcanoes), structurally-controlled regions, regions defined based on geochemical affinities, tectonic provinces, and other criteria. Non-homogeneous parametric spatial distributions of future volcano occurrences were also modeled (for example, a model was developed showing that the location of future volcanoes will follow a bivariate Gaussian distribution based on the location of volcanoes in Crater Flat). Finally, non-homogeneous, nonparametric spatial density models were used by some experts to assess the spatial distribution of future volcanoes. These models make use of a kernel density 
function and smoothing parameter based on locations of existing centers to obtain the spatial distribution for location of future volcanoes.

\subsubsection{Eliciting the Experts' Judgments}

Formal elicitation followed the third workshop. The process consisted of a two-day individual interview with each expert. To provide consistency, the same interview team was used for all elicitations. Following the elicitation interview, each expert was provided with a written summary of his elicitation, which was prepared by the interview team. The expert reviewed and clarified the summary and had the opportunity to revise any assessments. To promote a full understanding of each individual's judgment, the preliminary assessments made by each member of the expert panel were presented and discussed at the fourth workshop. Following this workshop, each expert had a final opportunity to revise his assessments before the results of the PVHA were finalized (CRWMS M\&O 1996 [DIRS 100116], Appendix E).

\subsubsection{Probabilistic Volcanic Hazard Analysis Results and Uncertainty}

The product of the PVHA was a quantitative assessment of the probability of a volcanic event intersecting the proposed repository and the uncertainty associated with the assessment (CRWMS M\&O 1996 [DIRS 100116], Figure 4-32). Specifically, a probability distribution of the annual frequency of intersection of a basaltic dike with the repository footprint was defined. The contributions to uncertainty from each of the PVHA components are described in Probabilistic Volcanic Hazard Analysis for Yucca Mountain, Nevada (CRWMS M\&O 1996 [DIRS 100116], Section 4.2).

Each of the 10 experts independently arrived at a probability distribution for the annual frequency of intersection of the repository footprint by a dike that typically spanned approximately 2 orders of magnitude (CRWMS M\&O 1996 [DIRS 100116], Figure 4-31). From these individual probability distributions, an aggregate probability distribution for the annual frequency of intersection of the repository footprint by a dike was computed that reflected the uncertainty across the entire expert panel (CRWMS M\&O 1996 [DIRS 100116], Figure 4-32). The individual expert's distributions were combined using equal weights to obtain the aggregate probability distribution. The mean value of the aggregate probability distribution was $1.5 \cdot 10^{-8}$ dike intersections per year, with a 90 percent confidence interval of $5.4 \cdot 10^{-10}$ to $4.9 \cdot 10^{-8}$ (CRWMS M\&O 1996 [DIRS 100116], p. 4-10). Note that these values are updated in this report for the 2003 repository footprint (BSC 2003 [DIRS 162289]) in Section 6.5.3. The composite distribution spanned about three orders of magnitude for intersection frequency. The range in the mean frequencies of intersection for the individual expert's interpretations spanned about one order of magnitude (CRWMS M\&O 1996 [DIRS 100116], Figure 4-32). The variance for frequency of intersection defined by the composite distribution was disaggregated to identify the contributions from each of the sources of uncertainty, including variability between the experts' interpretations (CRWMS M\&O 1996 [DIRS 100116], Figure 4-33). Most of the uncertainty in characterizing the hazard arose from uncertainty in an individual expert's interpretations of the hazard rather than differences in scientific interpretation between the experts (CRWMS M\&O 1996 [DIRS 100116], p. 4-10, Figure 4-33). The probability distribution arrived at by the PVHA accounted for undetected events (buried volcanic events, or intrusive events that never reached the surface). The 
undetected event frequency ranged from 1 to 5 times that of observed events, with most estimates in the range of 1.1 to 1.5 (CRWMS M\&O 1996 [DIRS 100116], Figure 3-62).

The PVHA results indicated that the statistical uncertainty in estimating the event rate was the largest component of intra-expert uncertainty (CRWMS M\&O 1996 [DIRS 100116], Figure 4-33). The next largest uncertainty was uncertainty in the appropriate spatial model. Other important spatial uncertainties included the spatial smoothing distance, Gaussian field parameters, zonation models, and event lengths. The temporal issues of importance included the time period of interest, event counts at a particular center, and the frequency of hidden events (CRWMS M\&O 1996 [DIRS 100116], Figure 4-33).

\subsubsection{Consideration of Alternative Conceptual Models}

The PVHA was in essence an exercise in combining multiple alternative conceptual models into a single distribution that captured the uncertainty in the expert's conceptual models of the physical behavior of volcanism in the YMR. Alternative conceptual models incorporated into the results of the PVHA consisted primarily of alternative temporal and spatial models that describe expected behavior (based on past behavior) of volcanism in the YMR. No single base-case conceptual model is appropriate in the area of volcanism because the underlying physical processes that control the precise timing and location of volcanic events within a particular region remain largely unknown to science.

Although numerous alternative conceptual models were incorporated in the PVHA, several alternative models not considered in the PVHA have emerged since the PVHA was completed in 1996. These models are summarized in Table 6-4 and are discussed in the following section.

Table 6-4. Alternative Conceptual Models Not Considered in the Probabilistic Volcanic Hazard Analysis

\begin{tabular}{|l|l|l|}
\hline \multicolumn{1}{|c|}{ Alternative Models } & \multicolumn{1}{c|}{ Key Conclusions } & \multicolumn{1}{c|}{ Assessment } \\
\hline $\begin{array}{l}\text { Anomalous strain rate in the } \\
\text { YMR (Wernicke et al. 1998 }\end{array}$ & $\begin{array}{l}\text { Anomalously high current strain } \\
\text { rate based on GPS } \\
\text { measurements indicates volcanic } \\
\text { event rate may be } \\
\text { underestimated by factor of 10. }\end{array}$ & $\begin{array}{l}\text { Not considered plausible based on later } \\
\text { measurements from Savage et al. } \\
\text { (1999 [DIRS 118952]) that show low } \\
\text { strain rate as well as questionable } \\
\text { assumptions about links between strain } \\
\text { rate and volcanic event rate. }\end{array}$ \\
\hline $\begin{array}{l}\text { Mantle hotspot beneath the } \\
\text { YMIRS (Smith et al. 2002 } 158735])\end{array}$ & $\begin{array}{l}\text { Anomalously high mantle basalt } \\
\text { source temperatures lead to } \\
\text { underestimation of future } \\
\text { volcanic event rate. }\end{array}$ & $\begin{array}{l}\text { Not considered plausible based on } \\
\text { weight of documented scientific } \\
\text { evidence showing that mantle hotspot is } \\
\text { not present beneath YMR (e.g., Farmer } \\
\text { et al. 1989 [DIRS 105284]. }\end{array}$ \\
\hline $\begin{array}{l}\text { Tectonically weighted } \\
\text { probability models (Connor et } \\
\text { al. 2000 [DIRS 149935], } \\
\text { p. 427) }\end{array}$ & $\begin{array}{l}\text { Weighting of certain tectonic } \\
\text { elements in probability models } \\
\text { lead to probability estimates as } \\
\text { high as 10 }\end{array}$ & $\begin{array}{l}\text { Not considered plausible based on } \\
\text { observation that tectonically weighted } \\
\text { probability models are poor predictors } \\
\text { of location of volcanism in YMR } \\
\text { (Section 6.3.3 of this report). }\end{array}$ \\
\hline
\end{tabular}


Table 6-4. Alternative Conceptual Models Not Considered in the Probabilistic Volcanic Hazard Analysis (Continued)

\begin{tabular}{|l|l|l|}
\hline \multicolumn{1}{|c|}{ Alternative Models } & \multicolumn{1}{c|}{ Key Conclusions } & \multicolumn{1}{c|}{ Assessment } \\
\hline $\begin{array}{l}\text { Significant number of buried or } \\
\text { undetected volcanic centers in } \\
\text { the YMR (Hill and Stamatakos } \\
2002 \text { [DIRS 159500]) }\end{array}$ & $\begin{array}{l}\text { Aeromagnetic anomalies suggest } \\
\text { that significant number of } \\
\text { volcanic events were }\end{array}$ & $\begin{array}{l}\text { Significance of buried volcanoes on } \\
\text { probability estimates cannot be } \\
\text { assessed without further data collection } \\
\text { and update of the PVHA. Sensitivity } \\
\text { underestimating the volcanic } \\
\text { studies documented in Section } 6.5 .4 \text { of } \\
\text { this report are for information purposes } \\
\text { hazard. }\end{array}$ \\
& $\begin{array}{l}\text { only. The results of the 1996 PVHA, as } \\
\text { summarized in Section 7.1 of this } \\
\text { report, are the results that will be used } \\
\text { in TSPA-LA. }\end{array}$ \\
\hline
\end{tabular}

\subsubsection{Significance of Buried Volcanic Centers on Probabilistic Volcanic Hazard Analysis Results}

The uncertainty in the event rate accounted for about 40 percent of the total intra-expert uncertainty (CRWMS M\&O 1996 [DIRS 100116], Figure 4-33). The event rate depends on the number of events estimated for a particular time period and for a particular source zone, and can be expressed as events/year/square kilometer (CRWMS M\&O 1996 [DIRS 100116], p. 3-2; Figure 6-11a of this report). A key parameter for estimating event rates is, therefore, an estimate of the number of volcanic events that have occurred in the YMR, particularly since the Miocene. Since all post-Miocene volcanic centers observable at the surface in the YMR have been identified (Figure 6-1), the only factor that could significantly change PVHA estimates of event counts and the event rate would be evidence of a significant number of previously unidentified buried volcanic centers or intrusions not considered by the PVHA.

Langenheim et al. (1993 [DIRS 148622]) presented data for aeromagnetic anomalies in the Amargosa Valley and interpreted them as shallowly buried basaltic volcanic centers. These data were available to the PVHA experts (CRWMS M\&O 1996 [DIRS 100116], p. B-4), and data and interpretations concerning the Amargosa Valley anomalies were also presented by Langenheim during Workshop 1 of the PVHA project (CRWMS M\&O 1996 [DIRS 100116], p. C-3). In the PVHA, 9 of 10 experts included volcanic events of the Amargosa Valley in their YMR event counts (CRWMS M\&O 1996 [DIRS 100116], Appendix E, pp. RC-8, BC-17, WD-5, WH-7, MK-10, AM-8, MS-8, GT-6, GW-6). The only expert who did not include events of the Amargosa Valley in their YMR event counts considered only the past $2 \mathrm{~m}$.y. to be the relevant time period (CRWMS M\&O 1996 [DIRS 100116], Appendix E, RF-6), thus, excluding the period of time during which the anomalies were probably formed. The most common expert assessment of the number of volcanic events represented by the aeromagnetic anomalies in Amargosa Valley was 5, with slightly less weight assigned to 3, 4, and 6 events (CRWMS M\&O 1996 [DIRS 100116], Figure 3-63). In addition, the PVHA experts assessed a hidden event factor, allowing for additional undetected events not counted in the total YMR event counts that already included the Amargosa Valley event counts (CRWMS M\&O 1996 [DIRS 100116], Figure 3-62, 3-63). These factors typically resulted in an increase of 10 to 50 percent in the rate of volcanic events over that computed from the observed volcanic events. 
New data that could potentially change the assessment of the number of volcanic events by the PVHA experts include an analysis of existing aeromagnetic data for the YMR (Earthfield Technology 1995 [DIRS 147778]) and new ground magnetic surveys of aeromagnetic anomalies (Connor et al. 1997 [DIRS 135969]; Magsino et al. 1998 [DIRS 147781]). A map presented by Earthfield Technology (1995 [DIRS 147778], Appendix II) indicates the presence of as many as 40 to 60 aeromagnetic anomalies within approximately 35 to $40 \mathrm{~km}$ of Yucca Mountain that are interpreted as intrusive bodies; six of these lie within approximately $5 \mathrm{~km}$ of the proposed repository site. The Earthfield Technology (1995 [DIRS 147778]) results were based on the merging of three aeromagnetic data sets: the Timber Mountain, Lathrop Wells, and Yucca Mountain surveys. Subsequent to release of the Earthfield Technology (1995 [DIRS 147778]) report, it was discovered that the report "was flawed by an incomplete and mislocated Timber Mt. Survey" (Feighner and Majer 1996 [DIRS 105078], p. 1). Inspection of the flight survey map in Earthfield Technology (1995 [DIRS 147778], Figure 2) and a corresponding map enclosed in Results of the Analysis of the Timber Mt., Lathrop Wells, and Yucca Mt. Aeromagnetic Data (Feighner and Majer (1996 [DIRS 105078], Appendix I) indicates that the Timber Mountain Survey, which encompasses about 50 percent of the coverage area and the majority of the aeromagnetic anomalies, was mislocated approximately $20 \mathrm{~km}$ to the south-southwest of its correct location. For this reason, further analysis of the anomalies that were presented by Earthfield Technology (1995 [DIRS 147778], Appendix II) and that lie within the Timber Mountain survey is not warranted. The six anomalies located within $5 \mathrm{~km}$ of the proposed repository site (the Yucca Mountain survey) are associated with mapped faults and are probably due to magnetic variation resulting from fault-controlled juxtaposition of rock masses with differing magnetic properties (Feighner and Majer 1996 [DIRS 105078], p. 2; Reamer 1999 [DIRS 119693], p. 32).

The most reliable and detailed data available for magnetic anomalies in the YMR is presented in Connor et al. (1997 [DIRS 135969]) and Magsino et al. (1998 [DIRS 147781]). These data were obtained using ground magnetic surveys of fourteen selected aeromagnetic anomalies located to the north, east, west, and south of the proposed repository site (Magsino et al. 1998 [DIRS 147781], Figure 1-1). Collectively, these surveys represent a comprehensive assessment of aeromagnetic anomalies nearest the proposed repository site and provide confidence that the geologic record of basaltic volcanism near Yucca Mountain is adequately understood. Of the fourteen surveys, seven provide no evidence of buried basalt and three were conducted over areas with known surface exposures of basalt, partly to enhance understanding of the relationship between volcanism and geologic structure (Magsino et al. 1998 [DIRS 147781], Section 4). Four of the 14 surveys provide evidence of buried volcanic centers. Two of these (Anomalies A and $\mathrm{F} / \mathrm{G}$ of the PVHA) were known to the PVHA experts as possible buried basaltic volcanic centers (from the data of Langenheim et al. 1993 [DIRS 148622]; Crowe et al. 1995 [DIRS 100110], Figure 2.5), but the data presented in Connor et al. (1997 [DIRS 135969]) and Magsino et al. (1998 [DIRS 147781]) provide increased detail and confidence of their volcanic origin. Of the two remaining surveys, anomalies in the Steve's Pass area on the southwest margin of Crater Flat are interpreted as buried basalt. Interpretation of a buried, reversely magnetized body of rock southwest of Northern (or Makani) Cone is less certain and may be either a basalt body or Miocene tuff (Magsino et al. 1998 [DIRS 147781], Sections 4.4 and 4.11). Each of the four anomalies representing probable buried volcanic centers occur within volcanic source zones previously specified by the PVHA experts (CRWMS M\&O 1996 [DIRS 100116], 
Appendix E), except for the anomalies in the Steve's Pass area, which lie slightly to the southwest of most experts' volcanic source zones in a direction away from Yucca Mountain.

On the basis of evidence for buried volcanic centers presented in Connor et al. (1997 [DIRS 135969]), Brocoum (1997 [DIRS 147772]) conducted sensitivity analyses to assess the potential impact on the PVHA results of increased event counts in Amargosa Valley and Crater Flat. Considering the experts' method for assessment of event counts, particularly for northeast alignments of vents (as in the case of Amargosa anomaly F/G), the mean value for the number of buried volcanic centers was increased from the original PVHA value of 4.7 events to 6.1 events (Brocoum 1997 [DIRS 147772], Enclosure 1, p. 5). The mean annual frequency of intersection of a dike with the repository footprint was recalculated using the revised event count distributions, resulting in an increase in the mean annual frequency of intersection of 4 percent (Brocoum 1997 [DIRS 147772], Enclosure 1, p. 5). Given the uncertainty factored into the PVHA by assessment of alternative event counts and hidden event factors, small changes in the PVHA event counts have a minor impact on the annual frequency of intersection distribution derived from the PVHA. A later sensitivity analysis presented by Synthesis of Volcanism Studies for the Yucca Mountain Site Characterization Project (CRWMS M\&O 1998 [DIRS 105347], Chapter 6, pp. 6-83 and 6-84) conservatively assumed that all known aeromagnetic anomalies in Crater Flat and the Amargosa Valley were of Quaternary age, instead of Pliocene. Using this assumption, the most likely number of Quaternary volcanic events near Yucca Mountain based on PVHA event counts was increased from 3.8 to 8 events. This increase in the Quaternary event count resulted in a disruption probability of approximately $2.5 \cdot 10^{-8}$ per year (CRWMS M\&O 1998 [DIRS 105347], Chapter 6, p. 6-84), a result not significantly different from the mean PVHA result of $1.5 \cdot 10^{-8}$ per year (CRWMS M\&O 1996 [DIRS 100116], pp. 4-10, 4-14).

The data presented by Connor et al. (1997 [DIRS 135969]) and Magsino et al. (1998 [DIRS 147781]) provide stronger evidence that Anomalies A and F/G (as defined in the PVHA) represent buried volcanic centers, and that at least one anomaly not considered by the PVHA experts represents a probable buried volcanic center. Sensitivity studies (Brocoum 1997 [DIRS 147772]; CRWMS M\&O 1998 [DIRS 105347], Chapter 6) show that the addition of several volcanic events located within already defined volcanic source zones does not significantly impact the results of the PVHA. Significantly, the four anomalies east of Yucca Mountain (Magsino et al. 1998 [DIRS 147781], Figure 1-1) show no evidence of buried volcanic centers and provide confirmatory evidence that the volcanic source zones specified by the experts to the south and west of Yucca Mountain are a valid representation of the spatial distribution of post-Miocene volcanism in the YMR.

In 1999, the USGS conducted a regional aeromagnetic survey for the purpose of assessing potential hydrologic pathways in the Yucca Mountain/Death Valley region (Blakely et al 2000 [DIRS 151881]). Subsequent interpretation of these data indicated that 20 to 24 aeromagnetic anomalies present to the west and south of Yucca Mountain could potentially represent buried basalt (O'Leary et al. 2002 [DIRS 158468]; Hill and Stamatakos 2002 [DIRS 159500]). Section 6.5.4 of this report documents an assessment of how the potential presence of additional buried volcanoes in the YMR could impact the frequency of intersection. 


\subsubsection{Alternative Estimates of the Intersection Probability}

Several alternative estimates of the intersection probability (the annual probability of a volcanic event intersecting the repository footprint) were presented between 1982 and 1998 (Table 6-5). As discussed in the following section (6.3.2), volcanic events in hazard calculations have been represented as both points and lines (Table 6-5). For point events, volcanic source zone areas or the repository area have generally been increased to account for the fact that volcanic events have dimension due to the length of associated dikes. The shorter the event length, the more comparable intersection probability results are for calculations representing volcanic events as points. Intersection probabilities near $10^{-7}$ intersections per year (Ho and Smith 1998 [DIRS 140152], pp. 507 and 508; Reamer 1999, p. 61 [DIRS 119693]) reflect unusually small volcanic source zone areas or unusually long event lengths (Table 6-5).

Most of the published intersection probabilities, including the mean intersection probability estimated in the PVHA, cluster at values slightly greater than $10^{-8}$ per year (Table 6-5), indicating that this probability estimate is robust, given the range of alternative temporal and spatial models, and the different event geometries considered in the probability calculations.

Table 6-5. Published Estimates of the Probability of Intersection of the Proposed Repository at Yucca Mountain by a Volcanic Event

\begin{tabular}{|l|l|l|c|}
\hline \multicolumn{1}{|c|}{ Reference } & \multicolumn{1}{|c|}{$\begin{array}{c}\text { Intersection } \\
\text { Probability (per year) }\end{array}$} & \multicolumn{1}{c|}{ Comment } & $\begin{array}{c}\text { Event } \\
\text { Representation }\end{array}$ \\
\hline $\begin{array}{l}\text { Crowe et al. (1982 [DIRS } \\
\text { 102741]), pp. 184 through 185 }\end{array}$ & $3.3 \cdot 10^{-10}-4.7 \cdot 10^{-8}$ & $\begin{array}{l}\text { Range of alternative probability } \\
\text { calculations. }\end{array}$ & point \\
\hline $\begin{array}{l}\text { Crowe et al. (1993 [DIRS } \\
\text { 100026]), p. 188 }\end{array}$ & $2.6 \cdot 10^{-8}$ & $\begin{array}{l}\text { Median value of probability } \\
\text { distribution. }\end{array}$ & point \\
\hline $\begin{array}{l}\text { Connor and Hill (1995 [DIRS } \\
\text { 102646]), p. 10121 }\end{array}$ & $1-5 \cdot 10^{-8}$ & Range of 3 alternative models. & point \\
\hline $\begin{array}{l}\text { Crowe et al. (1995 [DIRS } \\
\text { 100110]), Table 7.22 }\end{array}$ & $1.8 \cdot 10^{-8}$ & $\begin{array}{l}\text { Median value of 22 alternative } \\
\text { probability models. }\end{array}$ & point \\
\hline $\begin{array}{l}\text { Ho and Smith (1998 [DIRS } \\
\text { 140152]), pp. 507 through 508 }\end{array}$ & $\begin{array}{l}(1) 1.5 \cdot 10^{-8} \\
(2) 1.09 \cdot 10^{-8}, \\
2.83 \cdot 10^{-8}, \\
(3) 3.14 \cdot 10^{-7}\end{array}$ & $\begin{array}{l}\text { 3 alternative models; 3rd } \text { model } \\
\text { assumes a spatial intersection ratio } \\
\text { (using a Bayesian prior) of 8/75 or } \\
\text { 0.11, approximately one order of } \\
\text { magnitude higher than other } \\
\text { published estimates, because } \\
\text { volcanic events are forced to occur } \\
\text { within a small zone enclosing Yucca } \\
\text { Mountain. }\end{array}$ & point \\
\hline $\begin{array}{l}\text { CRWMS M\&O (1998 [DIRS } \\
\text { 105347]), Chapter 6, p. 6-84 }\end{array}$ & $2.5 \cdot 10^{-8}$ & $\begin{array}{l}\text { Sensitivity analysis that } \\
\text { conservatively assumes all } \\
\text { aeromagnetic anomalies in } \\
\text { Amargosa Valley are Quaternary } \\
\text { age. }\end{array}$ & point \\
\hline
\end{tabular}


Table 6-5. Published Estimates of the Probability of Intersection of the Proposed Repository at Yucca Mountain by a Volcanic Event (Continued)

\begin{tabular}{|l|l|l|c|}
\hline \multicolumn{1}{|c|}{ Reference } & \multicolumn{1}{|c|}{$\begin{array}{c}\text { Intersection } \\
\text { Probability (per year) }\end{array}$} & \multicolumn{1}{c|}{$\begin{array}{c}\text { Comment } \\
\text { Comesentation }\end{array}$} \\
\hline $\begin{array}{l}\text { Connor et al. (2000 [DIRS } \\
\text { 149935]), p. 427 }\end{array}$ & $10^{-8}-10^{-7}$ & $\begin{array}{l}\text { Value of } 10^{-7} \text { assumes maximum } \\
\text { event length of } 20 \mathrm{~km} \text {, regional } \\
\text { recurrence rates of } 5 \text { events } / \mathrm{m} . y ., \\
\text { and that crustal density variations } \\
\text { contribute to event location. }\end{array}$ & line \\
\hline
\end{tabular}

\subsubsection{Definitions and Parameters of a Volcanic Event and Implications for Alternative Probability Calculations}

An important issue in the PVHA and in alternative volcanic hazard assessments of the proposed Yucca Mountain repository is the definition of a "volcanic event." The definition of a volcanic event can affect the outcome of probability calculations and must be clearly understood to compare the results of alternative probability calculations meaningfully. The PVHA experts defined a volcanic event to be a spatially and temporally distinct batch of magma ascending from the mantle through the crust as a dike or system of dikes (CRWMS M\&O 1996 [DIRS 100116], Appendix E). The physical manifestations of a volcanic event include the dike or dike system and any surface eruption deposits. For the purposes of probability models discussed in this report (Section 6.5), a volcanic event is defined as a point $(x, y)$ in space representing the expected midpoint of the dike system involved in the magma ascent. The dike system associated with the volcanic event is represented in the probability model by a line element defined in terms of a length, azimuth, and location relative to the point event (Figure 6-8 and Figure 6-10). The term "dike length" used in the PVHA and in this report when discussing volcanic events refers to the total length of the dike system associated with the volcanic event. The phrase "intersection of the repository footprint by a dike" refers to intersection of the emplacement area of the repository by the line element representing the dike system associated with the volcanic event. The possibility that a dike system has width or consists of multiple parallel dikes does not significantly affect the intersection probability and is not part of the calculations in this report. The width of the dikes and the number of parallel dikes does affect the consequences of an intersection and is incorporated into the igneous intrusion scenario presented in Number of Waste Packages Hit by Igneous Intrusion (BSC 2004 [DIRS 170001]). Although the PVHA assumed volcanic events to have both an extrusive and intrusive component (volcano and dike), the output of the PVHA was the annual frequency of intersection of the proposed repository by an intrusive basaltic dike (CRWMS M\&O 1996 [DIRS 100116], Section 4.2, Figure 4-32). The PVHA did not calculate the conditional probability that a dike intersecting the proposed repository would result in an extrusive volcanic eruption through the repository.

Typical dike dimensions assigned by the experts were a dike width of $1 \mathrm{~m}$ and a dike length (the total length of the dike system associated with a volcanic event) of 1 to $5 \mathrm{~km}$ (CRWMS M\&O 1996 [DIRS 100116], Appendix E; Figure 6-2). The most likely values for maximum dike lengths were estimated to be in the range of 17 to $22 \mathrm{~km}$ (CRWMS M\&O 1996 [DIRS 100116], Figure 3-62). The values of maximum dike length represent tails of distributions that have a 
small impact on the probability of dike intersection. The individual PVHA expert dike length distributions can be aggregated to derive a PVHA aggregate dike length distribution. The aggregate dike-length distribution derived from the PVHA has 5th percentile, mean, and 95th percentile values of $0.6,4.0$, and $10.1 \mathrm{~km}$, respectively (Figure 6-2). The most commonly assigned dike orientation centers around $\mathrm{N} 30^{\circ} \mathrm{E}$ (CRWMS M\&O 1996 [DIRS 100116], Figure 3-62).

Prior to the PVHA, most assessments of volcanic hazard to the proposed repository represented volcanic events as points having no physical dimension (CRWMS M\&O 1996 [DIRS 100116], p. 3-16). The physical dimension of events was generally taken into account by appropriately expanding the area of the proposed repository or of volcanic source zones (e.g., Crowe et al. 1995 [DIRS 100110], p. 7-64). The PVHA and probability calculations presented by the NRC since the PVHA have represented volcanic events as having both length and orientation (Reamer 1999 [DIRS 119693]). It is important to compare the different representations of volcanic events in order to compare probability results meaningfully. The PVHA intersection probability represents the probability of a dike intersecting the repository footprint (CRWMS M\&O 1996 [DIRS 100116], Section 3.1.6). The NRC intersection probability represents the intersection of the repository footprint by a vent or vent alignment (Reamer 1999 [DIRS 119693], Sections 4.1.6.3.2 and 4.1.6.3.3, Figures 29 and 30) and assumes that all vents along the alignment are contemporaneous and represent a single volcanic event (e.g., the alignment of Quaternary vents from Makani Cone to Little Cones ([Reamer 1999 [DIRS 119693]]) (see Figure 6-1 in this report). In contrast, the PVHA allowed that an alignment of volcanoes could represent one to several volcanic events that are not necessarily contemporaneous. Conceptually, use of either the PVHA or NRC volcanic event should result in the same intersection probability if the same temporal/spatial models and assumptions are used, as well as the same probability distributions for event length and orientation (Figure 6-3). However, these probabilities represent different physical occurrences and PVHA and NRC model parameters are not equivalent. Since the PVHA intersection probability represents the probability of a dike intersection, the probability of an eruption (conditional on dike intersection) through the proposed repository is equal to, or lower than the intersection probability (Figure 6-3). The NRC intersection probability values are based on the interpretation that every intersection of a vent alignment with the repository footprint results in an eruption through the repository (Reamer 1999 [DIRS 119693], p. 57) and that the probability of intersection by shallow intrusive events that do not erupt is necessarily higher, possibly by a factor of 2-5 (Reamer 1999 [DIRS 119693], p. 60, Figure 5). 

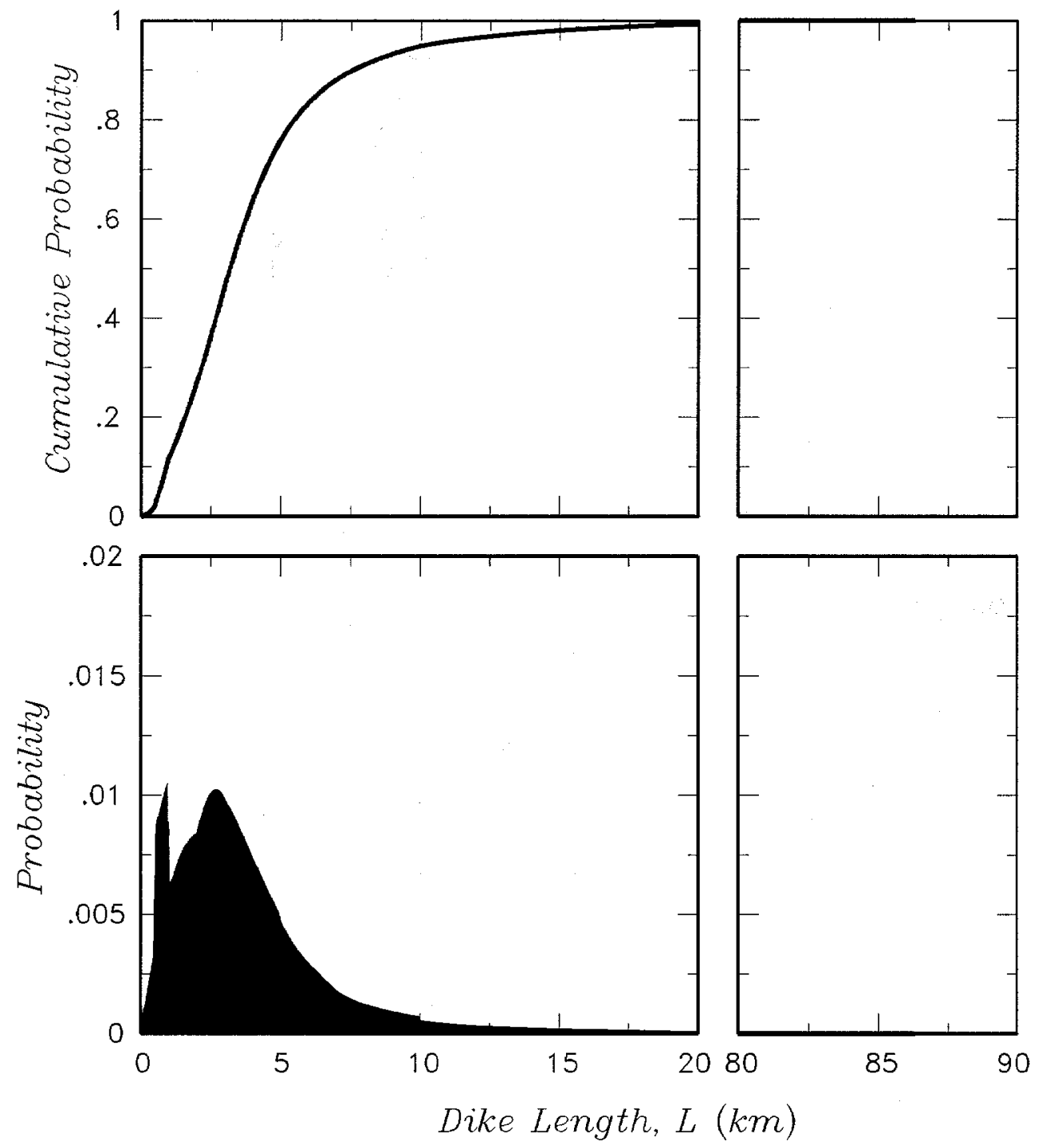

Output DTN: LA0009FP831811.001.

NOTE: The 5th percentile, mean, and 95th percentile values are $0.6,4.0$, and $10.1, \mathrm{~km}$, respectively. The distribution contains a very long upper tail extending to $86 \mathrm{~km}$. The irregular shape of the probability mass function in the lower plot reflects the variation in the distributions defined by the individual experts.

Figure 6-2. Composite Distribution for Dike Length Averaged Across All 10 Probabilistic Volcanic Hazard Analysis Experts 


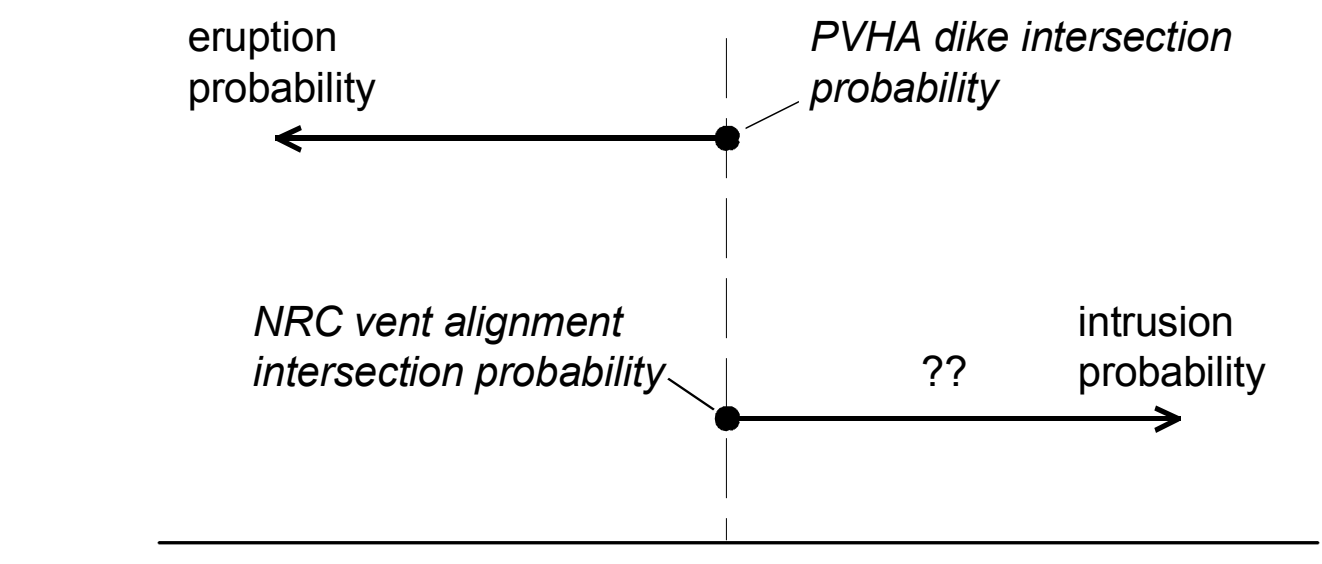

\section{lower probability}

\section{annual probability}

\section{higher probability}

For Information Only.

Source: Reamer 1999 [DIRS 119693]

Figure 6-3. Conceptual Diagram Comparing Event Definitions from the Probabilistic Volcanic Hazard Analysis and Reamer: Implications for Eruption and Intrusion Probabilities Based on Different Event Definitions

The NRC assumes that every vent alignment intersection will result in an eruption through the repository because they conclude that vent spacing along alignments is small compared to the repository footprint (Reamer 1999 [DIRS 119693], Sections 4.1.4.3.3 and 4.1.6.3.2). The technical basis for this conclusion is unclear. In Section 6.5.1.3, a number of alternative approaches for the number and spatial distribution of vents along the dike associated with a volcanic event are formulated based on PVHA expert output and observed vent spacing in the YMR to test for sensitivity of model choice. Using these approaches, the eruption probability is approximately 78 percent of the dike intersection probability because of cases where no vents form within the repository footprint (Table 6-11).

\subsubsection{Intrusive Versus Extrusive Events: Evidence from Analogue Sites}

Another issue requiring discussion is whether dikes or dike systems can reach the near surface without any portion of the system erupting. The NRC (Reamer 1999 [DIRS 119693]) assumption that all vent alignment intersections result in eruption through the proposed repository implies that intrusive events that intersect the proposed repository and do not erupt represent entirely separate temporal events. Using the San Rafael volcanic field as an analogue, the NRC assumes for PA purposes that the probability of separate intrusive events that do not erupt is 2 to 5 times higher than the probability of eruptive events (Reamer 1999 [DIRS 119693], Section 4.1.6.4). Thus, for example, if 5 volcanic events resulting in volcanic eruptions have occurred in the YMR in the past $1 \mathrm{~m} . \mathrm{y}$., the NRC's assumption requires that 10 to 25 additional intrusive events have also occurred, independent in time and location from the events that produced the volcanic eruptions. In the PVHA definition of a volcanic event, intrusive and extrusive events in the YMR are generally considered to be linked on a one-to-one basis-a volcanic event is defined as an extrusive volcano and its associated intrusive dike or dike system. 
Dikes that reach depths of less than 0.5 to $1 \mathrm{~km}$ are thought to erupt at some point along the length of the dike, mainly because of volatile exsolution (CRWMS M\&O 1996 [DIRS 100116], Appendix E, pp. RC-10, BC-6, WH-6, MK-12). The most common multiplier assigned in the PVHA for undetected intrusive events was 1.1 to 1.2 times that of known volcanic events (CRWMS M\&O 1996 [DIRS 100116], Figure 3-62), which is a number lower than the NRC multiplier of 2 to 5 .

An appropriate analogue in the YMR for understanding the relationship between intrusive and extrusive components of a volcanic event is the Paiute Ridge intrusive/extrusive center (Byers and Barnes 1967 [DIRS 101859]) on the northeastern margin of the Nevada Test Site. Paiute Ridge is a small-volume Miocene volcanic center comparable in volume and composition to Quaternary volcanoes near Yucca Mountain (CRWMS M\&O 1998 [DIRS 105347], Chapter 5, p. 5-29). Paleomagnetic, geochronologic, and geochemical data indicate that the entire intrusive/extrusive complex formed during a brief magmatic pulse and, thus, represent a single volcanic event (Ratcliff et al. 1994 [DIRS 106634]; CRWMS M\&O 1998 [DIRS 105347], Chapter 5, p. 5-29). The vents and associated dike system formed within an NNW-trending extensional graben provide excellent exposures of a variety of depths of the system including remnants of surface lava flows, volcanic conduits, and dikes and sills intruded into tuff country rock at depths of up to $300 \mathrm{~m}$ (CRWMS M\&O 1998 [DIRS 105347], Chapter 5, pp. 5-27 through 5-41). There is evidence of shallow structural control of dike emplacement at Paiute Ridge, including dike emplacement along fault planes (Byers and Barnes 1967 [DIRS 101859]; CRWMS M\&O 1998 [DIRS 105347], Chapter 5, pp. 5-27 through 5-28). Dike lengths at Paiute Ridge range from less than 1 to $5 \mathrm{~km}$ (CRWMS M\&O 1998 [DIRS 105347], Chapter 5, p. 5-31), comparable to the range estimated for post-Miocene volcanism near Yucca Mountain (Figure 6-2).

Field observations at Paiute Ridge clearly show that, while some portions of individual dikes stagnated within about $100 \mathrm{~m}$ of the surface without erupting, other portions of the same volcanic event did erupt, as evidenced by associated lava flows and volcanic conduits (Byers and Barnes 1967 [DIRS 101859]; CRWMS M\&O 1998 [DIRS 105347], Chapter 5, pp. 5-29 through 5-33). During the time period considered most significant by the PVHA experts for evaluating volcanic hazard (the past 5 m.y., CRWMS M\&O 1996 [DIRS 100116], Figure 3-62), there is no known episode of dike intrusion to within a few hundred meters of the surface in the YMR that has not been accompanied by an extrusive component. Thus, there is no evidence in the YMR geologic record to suggest that dike intrusions without accompanying eruptions occur 2 to 5 times more frequently than eruptions (Reamer 1999 [DIRS 119693], Figure 5, Sections 4.1.6.3.4 and 4.1.6.4).

The NRC assumption of higher intrusion probabilities in the YMR is based on analogy to the San Rafael volcanic field on the western Colorado Plateau, where an extensive system of shallowly intruded dikes is well exposed (Delaney and Gartner 1997 [DIRS 145370]). Delaney and Gartner (1997 [DIRS 145370], p. 1180) estimate that 174 dikes are represented in the San Rafael dike swarm. Breccias are present along portions of 45 of these dikes, which are interpreted to represent the subsurface beneath eruptive centers (Delaney and Gartner 1997 [DIRS 145370], pp. 1178 and 1191). No attempt is made in Delaney and Gartner (1997 [DIRS 145370]) to estimate the frequency of temporally discrete intrusive versus eruptive events. They suggest only that at least 45 dikes show evidence of eruption along some segment of a dike; other parts 
of the same dike, or other parts of the same dike system; or may have erupted as is observed at Paiute Ridge. Given the Paiute Ridge analogy and the Delaney and Gartner (1997 [DIRS 145370]) interpretation that the San Rafael swarm likely represents the subsurface beneath a large volcanic field active for about a million years (Delaney and Gartner 1997 [DIRS 145370], pp. 1177, 1178, and 1179), it is likely that many individual intrusive/extrusive events are represented at San Rafael, with some portion of a dike system erupting during each event and other portions of the same dike system not erupting. Thus, while the data and discussion presented in Delaney and Gartner (1997 [DIRS 145370]) have been used to argue that intrusive events without an eruptive component occur 2 to 5 times more frequently than intrusive events with an eruptive component, an alternative interpretation is that the intrusion/extrusion ratio is closer to 1 . This alternative interpretation is more consistent with the geologic record of the YMR, as demonstrated at the Paiute Ridge analogue site, and by the conclusions of the PVHA (CRWMS M\&O 1996 [DIRS 100116]).

\subsubsection{Alternative Event Lengths}

The length of dikes or vent alignments (Reamer 1999 [DIRS 119693], Figure 30) can significantly affect intersection probabilities, depending partly on the distance of high-eventfrequency areas from the proposed repository. When volcanic events primarily occur far from the proposed repository, they must have sufficient length to intersect the repository, and longer event lengths will result in higher intersection probabilities. When volcanic events occur more frequently nearer the proposed repository, volcanic events with shorter lengths are able to intersect the repository with higher frequency.

As evaluated by experts in the PVHA, the mean dike length associated with a volcanic event in the YMR is $4 \mathrm{~km}$ and 95 percent of dikes are shorter than $10.1 \mathrm{~km}$ (Figure 6-2). These values are based on observed volcanic features in the YMR. For instance, the maximum vent spacing in the YMR is $5.4 \mathrm{~km}$ between Black and Makani Cones, and volcanic vent alignments lengths are typically in the range of 2 to $5 \mathrm{~km}$ (e.g., Hidden Cone-Little Black Peak, Amargosa Aeromagnetic Anomaly A, Red Cone-Black Cone). The longest proposed vent alignment in the YMR, assuming it represents one volcanic event, is the Quaternary Crater Flat alignment with a length of about $11 \mathrm{~km}$ (Figure 6-1). Observed dikes, such as at Paiute Ridge, range in length from less than 1 to $5 \mathrm{~km}$. Dike and vent alignments of the $3.7 \mathrm{~m}$.y. basalts in southeast Crater Flat (Figure 6-1) are no more than $4 \mathrm{~km}$ in length.

Event lengths used in probability models by researchers from the University of Nevada, Las Vegas (e.g., Smith et al. 1990 [DIRS 101019]) and the NRC (Reamer 1999 [DIRS 119693], Figures 29 and 30) are significantly longer than those assessed by the experts in the PVHA. For example, Smith et al. (1990 [DIRS 101019], p. 81) based the dimensions of "high-risk" volcanic source zones, which were used as a spatial control on event distribution in probability models, on the length of volcanic vent alignments at analogue sites. The analogue site chosen to define the dimensions of the "high-risk" zone is the relatively large-volume Fortification Hill volcanic field near Lake Mead, $200 \mathrm{~km}$ southeast of Yucca Mountain. In terms of volume, Smith et al. (1990 [DIRS 101019], p. 85) acknowledge that this volcanic field is not analogous to Quaternary volcanism near Yucca Mountain. The vent alignment length defined at Fortification Hill is $25 \mathrm{~km}$ (Smith et al. 1990 [DIRS 101019], p. 85). Smith et al. (1990 [DIRS 101019], p. 87) 
consider this length to be an upper bound, and it corresponds to the greater than 99th percentile value of the PVHA event length distribution (Figure 6-2).

Vent alignment lengths are used directly in NRC probability calculations (Reamer 1999 [DIRS 119693], Sections 4.1.6.3.2 and 4.1.6.3.3, Figures 29 and 30) and have a maximum half-length range of 5.2 to $10.2 \mathrm{~km}$, corresponding to a total-length range of 10.4 to $20.4 \mathrm{~km}$. These values are based on the half-length of the Quaternary Crater Flat vent alignment $(5.6 \mathrm{~km}$, the longest half-length observed in the YMR) and the observation that vent alignment half-lengths of $10 \mathrm{~km}$ or more occur in other volcanic fields (Reamer 1999 [DIRS 119693], p. 40). It is notable that approximately 97 percent of the 174 dike lengths measured in the San Rafael volcanic field (discussed above), which the NRC uses as a YMR analog, have total lengths of less than $5 \mathrm{~km}$ (Delaney and Gartner 1997 [DIRS 145370], Figure 4). The median of the length distribution at San Rafael is approximately $1.1 \mathrm{~km}$ and the maximum dike length is 8 to $9 \mathrm{~km}$ (Delaney and Gartner 1997 [DIRS 145370], Figure 4), a distribution not dissimilar to that used in the PVHA (Figure 6-2).

A measure comparable to dike half-length, the distance from the end of the dike nearest the proposed repository to the point of origin of the volcanic event, can be derived from information elicited in the PVHA (Figure 6-4). This distribution has a 5th percentile, mean, and 95th percentile values of $0.2,2$, and $5.6 \mathrm{~km}$, which, given the previous discussions of observed dike lengths, vent spacings, and maximum observed half-length vent alignment of $5.6 \mathrm{~km}$, is in excellent agreement with observed volcanic event features in the YMR. Note that the range of maximum event length values (10 to $20 \mathrm{~km}$ ) used in NRC probability models (Reamer 1999 [DIRS 119693], Figures 29 and 30), are comparable to the maximum dike lengths assessed by the PVHA experts. However, the NRC's use of a uniform distribution for dike half-length results in a much greater weighting in NRC probability models for dike lengths that represent the greater than 95th percentile values assessed by the 10 PVHA experts (Figure 6-2). The NRC intersection probability value of $10^{-7}$ per year, assumed for purposes of NRC PA (Reamer 1999 [DIRS 119693], p. 61), depends on a maximum vent alignment length of $20 \mathrm{~km}$ (Reamer 1999 [DIRS 119693], Figure 30), which is inconsistent with observed vent alignment lengths in the YMR.

\subsubsection{Conceptual Models of Volcanism and Formulation of Probability Models}

In the PVHA and alternative assessments of volcanic hazard to the proposed Yucca Mountain repository, the conceptual model of volcanism-how and where magmas form and what processes control the timing and location of magma ascent through the crust to form volcanoeshas a fundamental impact on how probability models are formulated and on the results of probability models (e.g., Smith et al. 1990 [DIRS 101019]; CRWMS M\&O 1996 [DIRS 100116]; Reamer 1999 [DIRS 119693]).

In general, the PVHA experts viewed the YMR as part of the same extensional tectonic and volcanic regime as the rest of the southern Great Basin portion of the Basin and Range province, but several members of the panel noted the possible additional influence on volcanism of the Walker-Lane structural zone (CRWMS M\&O 1996 [DIRS 100116], Appendix E, e.g., pp. WD-1 and WH-1). The smaller volumes of basalt erupted in the YMR since the Miocene reflects waning of both tectonism and magmatism in this part of the Basin and Range Province 
(CRWMS M\&O 1996 [DIRS 100116], Appendix E, e.g., pp. RC-1, BC-3, WD-2, RF-3, WH-1, MK-1, AM-3).
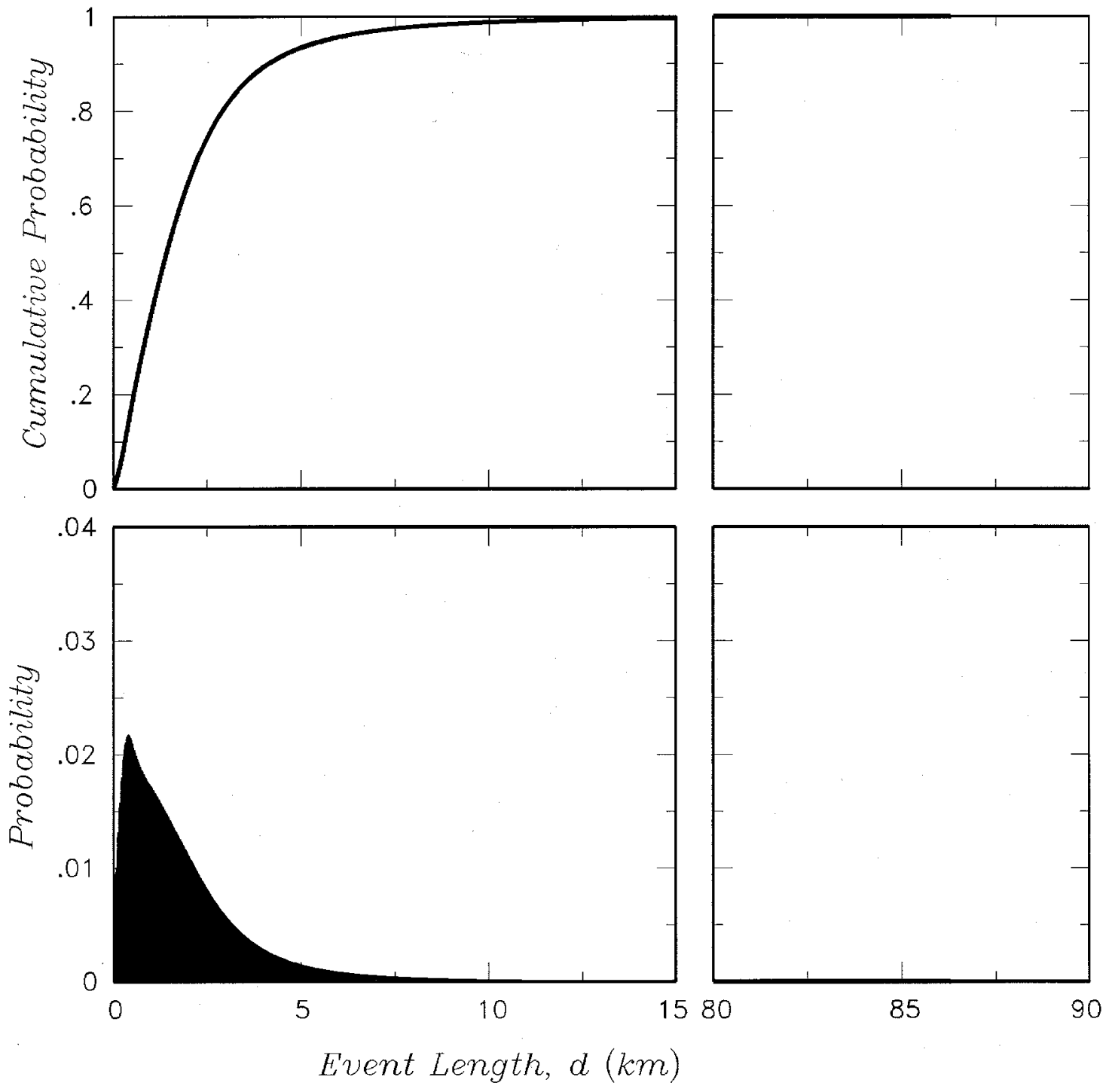

Output DTN: LA0009FP831811.001.

NOTE: This distribution is obtained by convolving the distributions for dike length with those for the location of the point event relative to the dike. The 5th percentile, mean, and 95th percentile values are $0.2,2.0$, and 5.6, $\mathrm{km}$, respectively. The distribution contains a very long upper tail extending to $86 \mathrm{~km}$.

Figure 6-4. Composite Distribution for the Distance from the Point Volcanic Event to the End of the Dike Averaged Across All 10 PVHA Experts

Some PVHA experts distinguished between deep (mantle source) and shallow (upper crustal structure and stress field) processes when considering different scales (regional and local) of spatial control on volcanism (CRWMS M\&O 1996 [DIRS 100116], Appendix E, pp. MK-2 and AM-1). The PVHA experts generally view volcanism in the YMR as a regional-scale phenomenon because of melting processes in the upper lithospheric mantle that produce small 
volumes of alkali basalt, which is a basalt type generated by relatively small percentages of mantle melting compared to other basalt types (CRWMS M\&O 1998 [DIRS 105347], Chapter 4, p. 4-4). The exact mechanism of mantle melting in the YMR is poorly understood, but may be controlled by a complex combination of processes including the effect of residual heat in the lithospheric mantle from previous episodes of volcanism and the presence of a plate subduction system, local variations in volatile (water) content, variations in mantle mineralogy and chemistry, and the effect of regional lithospheric extension (CRWMS M\&O 1996 [DIRS 100116], Appendix E). Researchers who have analyzed magmatic processes in the YMR generally agree that the magnitude of mantle melting has drastically decreased since the middle Miocene and that all melts in the past few million years have been generated within relatively cool (compared to asthenospheric mantle) ancient lithospheric mantle, which is a factor that may contribute to the relatively small and decreasing volume of basaltic melt erupted in the YMR since the Miocene (Farmer et al. 1989 [DIRS 105284]; Yogodzinski and Smith 1995 [DIRS 136262]; CRWMS M\&O 1996 [DIRS 100116], Appendix E; Reamer 1999 [DIRS 119693], pp. 17 and 47).

An alternative to the hypothesis of melting within lithospheric mantle was presented by Smith et al. (2002 [DIRS 158735]), who hypothesized instead, that basaltic melts beneath the YMR are generated within hot, upwelling asthenospheric mantle (mantle "hotspot" model). This model raises the possibility that the recurrence rate of basaltic volcanism near Yucca Mountain (the Crater Flat volcanic field) could increase in the next few thousand years to a level comparable to the more active Lunar Crater volcanic field, $150 \mathrm{~km}$ to the north. This hypothesis is based on a proposed correlation between the timing of volcanic episodes between the Lunar Crater and Crater Flat fields and a proposal that anomalously hot mantle underlies the region beneath both volcanic fields, providing a common mechanism that controls the timing of volcanic activity. If this hypothesis were valid, probability models that estimate the probability of volcanic disruption of the repository might need to be revised to account for the possibility of higher recurrence rates in the future.

The hypothesis that recurrence rates of volcanism could suddenly increase because of anomalously hot mantle beneath the Yucca Mountain area is inconsistent with the following observations:

- The Crater Flat volcanic field is one of the least active volcanic fields in the western United States, while the Lunar Crater field is one of the most active fields within the Basin and Range interior. This fundamental difference in eruptive behavior does not suggest a common physical mechanism that links the two fields. Basaltic volcanic fields are common throughout the western United States, with at least 20 to 30 fields active in the last 5 m.y. Many of these volcanic fields consist of 50 to 100 individual volcanoes, with several of the largest containing more than 300 individual volcanoes. Eruption rates for most fields range from 10 to more than $100 \mathrm{~km} / \mathrm{m}$.y. (Perry and Bowker 1998 [DIRS 159502]). The Lunar Crater field consists of 70 to 100 individual volcanoes, with an eruption rate of approximately $20 \mathrm{~km} / \mathrm{m}$.y. over the past 4 m.y. In contrast, the Crater Flat field consists of about 10 to 15 individual volcanoes with an eruption rate of less than $1 \mathrm{~km}^{3} / \mathrm{m} . \mathrm{y}$. over the past 4 m.y. (Perry and Bowker 1998 [DIRS 159502]). These data indicate a recurrence rate in the Lunar Crater field that is approximately an order of magnitude greater than in the Crater Flat field. If, as proposed, the common 
link between the two fields is anomalously hot mantle, the lower volume, eruption rate, and recurrence rate of the Crater Flat field indicates that the underlying mantle is not as hot or prone to melt as mantle beneath Lunar Crater. The low activity of the Crater Flat field compared to nearly every other volcanic field in the western U.S. indicates that the underlying mantle is not particularly hot. Therefore, there is no evidence to indicate that the recurrence rate of volcanism near Yucca Mountain will ever reach values equivalent to those at Lunar Crater.

- Neodymium isotopic compositions of basalts in the Lunar Crater and Crater Flat volcanic fields are significantly different, indicating fundamentally different mantle sources or fundamental differences in processes that produced the basalts. Smith et al. (2002 [DIRS 158735]) recognized the isotopic differences between the two volcanic fields and speculated that the unusual $\mathrm{Nd}$ isotopic compositions of basalt near Yucca Mountain are due to (1) contamination of asthenospheric melts passing through lithospheric mantle or (2) modification of asthenospheric mantle by fluids or melts derived from subducted crust. Either mechanism would not be expected to affect the basalts near Yucca Mountain selectively, but would instead operate on a much larger scale. For example, because subducted crust existed beneath most of the western United States for tens of millions of years, modifying fluids of melts derived from subducted crust would be expected to modify asthenospheric mantle on a continental scale, not just the small region surrounding Yucca Mountain. Basalts from Lunar Crater have isotopic compositions similar to ocean island basalts, indicating a source in relatively warm and convecting asthenospheric mantle. The unusual $\mathrm{Nd}$ isotopic composition of basalts in the Crater Flat field indicate derivation from a lithospheric mantle source that is old, stable, and cold (nonconvecting) compared to asthenospheric mantle (Perry et al. 1987 [DIRS 162311]; Farmer et al. 1989 [DIRS 105284]; Livaccari and Perry 1993 [DIRS 162310]). Wernicke et al. (1987 [DIRS 107250]), citing tectonic evidence, suggested that the relative lack of volcanism in the YMR until 15 m.y. ago left the lithosphere cold and difficult to extend, compared to more volcanically active and earlier extended regions of the Basin and Range province. The preponderance of evidence indicates that the small volume of basalt and limited volcanic activity near Yucca Mountain reflect an underlying mantle source that is cold and unable to produce significant volcanic activity.

On a more local and shallow crustal scale, most researchers conclude that (1) volcanism is correlated with zones of past or present crustal extension, and (2) once dikes feeding volcanoes enter the shallow upper crust, their location and orientation is influenced by the orientation of the local stress field and the presence of faults that may locally control vent location and alignment. The evidence cited for these two conclusions includes several northeast-oriented vent alignments in the YMR and the association of eruptive centers with known or inferred faults (Smith et al. 1990 [DIRS 101019], p. 83; CRWMS M\&O 1996 [DIRS 100116], Appendix E, p. AM-4; Connor et al. 1997 [DIRS 135969], p. 78; Reamer 1999 [DIRS 119693], Section 4.1.3.3.3; Fridrich et al. 1999 [DIRS 107333], p. 211).

A mechanistic model relating mantle melting and lithospheric extension has recently been proposed for the YMR by Connor et al. (2000 [DIRS 149935]) and additionally, is used as the geologic basis for weighting spatial density models based on crustal density variations across the 
YMR (Reamer 1999 [DIRS 119693], Section 4.1.6.3.3). The conceptual basis of the model is that crustal density variations across the YMR control variations in lithostatic pressure at the base of the crust. These pressure variations in turn control the location of decompression melting within the mantle, which, in turn, controls the location of future igneous activity within the YMR (Connor et al. 2000 [DIRS 149935], pp. 419 through 422).

As formulated, a finite-element model that calculates lateral pressure changes in the YMR based on upper crustal density variations (Connor et al. 2000 [DIRS 149935], p. 420) is a poor predictor of volcano distribution in the YMR. The model predicts that maximum melting (and, hence, more frequent occurrence of volcanism) will occur farthest from the region of high crustal density (Connor et al. 2000 [DIRS 149935], Figure 3). But this model prediction is the opposite of what is observed for the occurrence of post-Miocene volcanism in the YMR because volcanism is concentrated near high-density crust of the Bare Mountain domain, rather than farther to the east (Figure 6-5).

A map of apparent crustal density variation (Connor et al. 2000 [DIRS 149935], Plate 1) shows that low average crustal density extends fairly uniformly for a distance of at least $50 \mathrm{~km}$ east of the Bare Mountain Fault. Within the context of the conceptual model proposed by Connor et al. (2000 [DIRS 149935]) (i.e., crustal density exerts a primary control on location of volcanism), post-Miocene volcanism should occur somewhat randomly across this broad region. Instead, all post-Miocene volcanism near Yucca Mountain is located within 5 to $10 \mathrm{~km}$ of the Bare Mountain fault or near the southern ends of the Windy Wash and Stagecoach Road faults (Fridrich et al. 1999 [DIRS 107333], p. 211), indicating that local zones of extension and upper crustal faulting may exert more direct control on the location of volcanism than the effect of shallow crustal processes on mantle processes (CRWMS M\&O 1996 [DIRS 100116], Appendix E, e.g., pp. AM-5 and MS-2; Fridrich et al. 1999 [DIRS 107333], p. 211; Reamer 1999 [DIRS 119693], Section 4.1.5.3.3). This does not mean that areas of low crustal density and volcanism do not often coincide, but instead means that both are independently influenced or caused by upper crustal faulting and extension.

Connor et al. (2000 [DIRS 149935]) use crustal density as a primary "tectonic" or "geologic" control on volcano distribution (Reamer 1999 [DIRS 119693], Section 4.1.6.3.3), even though volcanoes are not randomly distributed over broad areas of low crustal density as predicted by this model. An alternative method of weighting spatial density models would be to weight by estimated percent of extension within the Crater Flat basin (e.g., Fridrich et al. 1999 [DIRS 107333], Figure 5), thereby tying probability models more directly to a geologic process (faulting and extension) that many researchers agree exerts an important geologic control on volcano location (Smith et al. 1990 [DIRS 101019], p. 83; CRWMS M\&O 1996 [DIRS 100116], Appendix E, pp. AM-5 and MS-2; Connor et al. 1997 [DIRS 135969], p. 78; Reamer 1999 [DIRS 119693], Section 4.1.3.3.3, p. 47). The strong southward and westward increase in extension rate across the Crater Flat basin corresponds well to sites of most recent volcanism in the basin (Fridrich et al. 1999 [DIRS 107333], Figures 1 and 5), as opposed to crustal density variations that are hypothesized to control volcano location, but do not correspond well with volcano location (Reamer 1999 [DIRS 119693], Figure 22). In terms of alternative conceptual models, models based on observable geologic features in the YMR provide a more defensible framework and technical basis for probability calculations than models relying on unobservable 
processes that remain largely speculative (i.e., Reamer 1999 [DIRS 119693], Section 4.1.5.3.2; see also Probability Acceptance Criteria 3, Reamer 1999 [DIRS 119693], p. 24).

In summary, the probability model proposed by Connor et al. (2000 [DIRS 149935]) that relies on spatial density functions weighted by crustal density is not well supported based on observations of volcano distribution within the YMR. Significantly, this probability model is the basis for calculating the highest annual probability value for a volcanic eruption within the proposed repository boundary $\left(9 \times 10^{-8}\right.$ per year, Reamer 1999 [DIRS 119693], Figure 30),

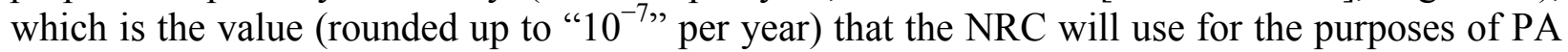
(Reamer 1999 [DIRS 119693], p. 61). It should also be noted that this probability model results in an approximately two-fold increase in the intersection probability compared to unweighted spatial density models (Reamer 1999 [DIRS 119693], Figure 29). As discussed previously in Section 6.3.2.2, the results of this probability model also depend to a large extent on dike lengths that are inconsistent with the geologic record of the YMR.

\subsection{THE CRATER FLAT STRUCTURAL DOMAIN}

Clearly, post-Miocene volcanoes in the YMR are spatially clustered (Crowe et al. 1995 [DIRS 100110], Chapter 3; Connor and Hill 1995 [DIRS 102646], Figure 2). For probability models that incorporate clustering of volcanoes (Connor and Hill 1995 [DIRS 102646]) or specify volcanic source zones based primarily on the location or clustering of volcano centers (CRWMS M\&O 1996 [DIRS 100116]), estimation of the hazard to Yucca Mountain is often dominated by the presence of the Crater Flat cluster. This dominance is due to the relatively high occurrence and Quaternary age of volcanoes in the Crater Flat basin (including Lathrop Wells, which lies within the Crater Flat structural domain and is the youngest volcano in the YMR), and because of the close proximity of Crater Flat volcanoes to Yucca Mountain, compared to other volcanic clusters in the YMR (Figure 6-1).

The Crater Flat structural domain as defined by Fridrich (1999 [DIRS 118942], pp. 170 through 178) is a structural basin or graben. It is bounded on the west by the Bare Mountain fault and on the east by structures buried beneath Jackass Flats (Figure 6-5). It includes the Crater Flat topographic basin on the west and Yucca Mountain near the center of the structural basin (Figure 6-5). Because the proposed Yucca Mountain repository lies within the Crater Flat structural domain, the structural and geophysical features of the domain and the degree to which they influence the location of volcanism within the domain have been key factors in formulating conceptual models of volcanism. Such models are important for assessing hazards to the proposed repository.

The following sections describe the internal structure of the Crater Flat basin, as well as how the PVHA experts and subsequent investigators have interpreted the influence of structural characteristics of the basin to estimate the locations of future volcanic events. Based largely on work published since the PVHA, the evidence that the northeastern and southwestern parts of the basin have different extensional histories that may have influenced the location of basaltic volcanism within the basin is summarized below. 


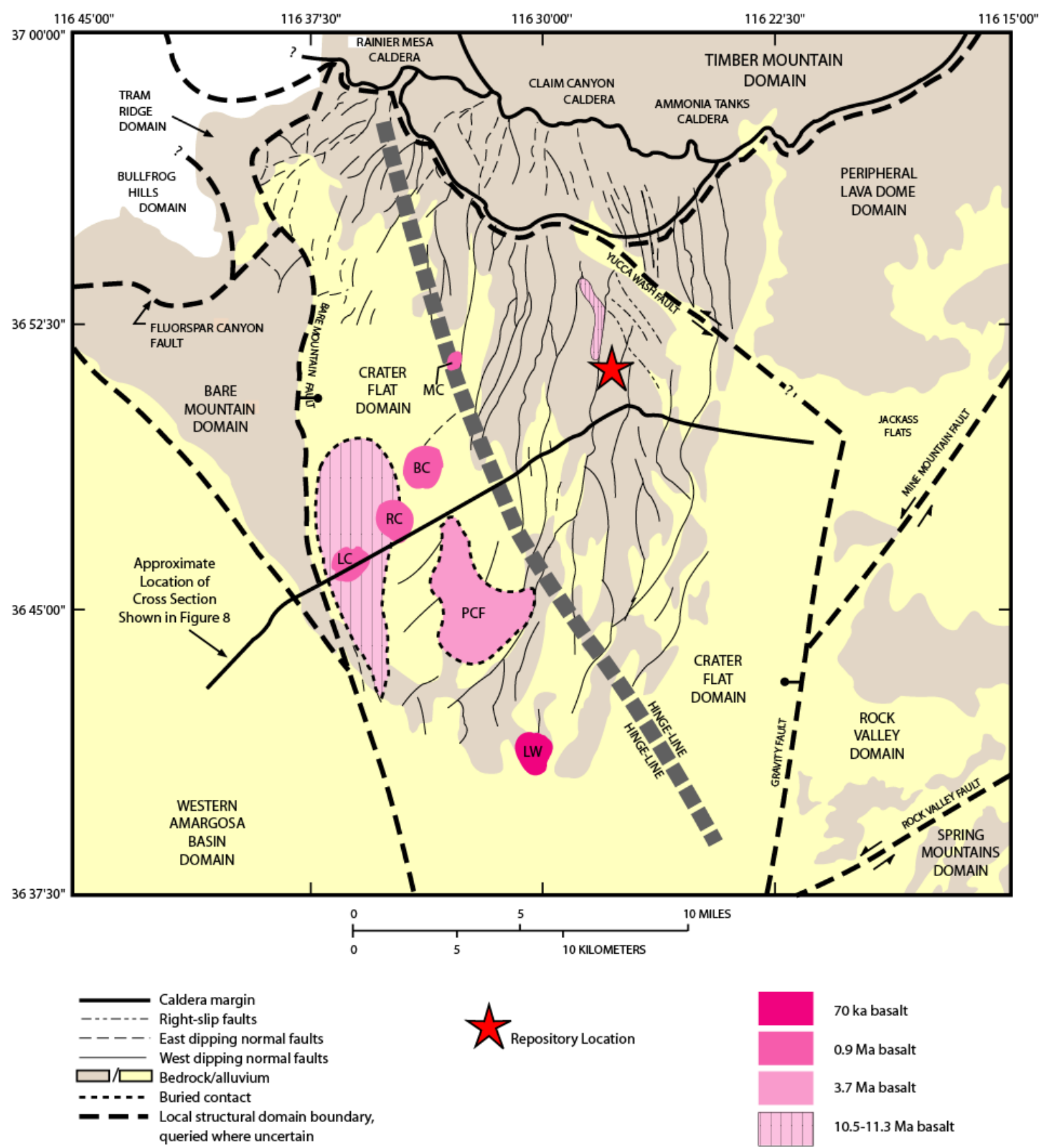

Source: Basalts of different ages are shown in relation to basin structure (modified from Fridrich et al. 1999 [DIRS 118942], Figure 1). The 70-ka age of the Lathrop Wells volcano indicated in the legend was estimated based on preliminary data subsequently published in Heizler et al. (1999) [DIRS 107255], which indicates an age closer to 80 k.y.

NOTE: $\quad \mathrm{PCF}=$ Pliocene Crater Flat; $\mathrm{MC}=$ Makani Cone; $\mathrm{BC}=$ Black Cone; $\mathrm{RC}=$ Red Cone; $\mathrm{LC}=$ Little Cones; $\mathrm{LW}=$ Lathrop Wells; $\mathrm{ka}=$ thousand years ago; $\mathrm{k} \cdot \mathrm{y}=$ thousand years.

Figure 6-5. Local Structural Domains and Domain Boundaries of the Yucca Mountain Region and Internal Structures of the Crater Flat Basin and Selected Parts of Adjacent Domains 


\subsubsection{Internal Structure and Boundaries of the Crater Flat Basin}

The Crater Flat structural domain (also referred to as the Crater Flat basin) comprises the Crater Flat topographic basin (west of Yucca Mountain), Yucca Mountain, and the western part of Jackass Flats. Based on geologic mapping and the interpretation of subsurface structures from geophysical surveys (discussed below), the Crater Flat structural domain appears to comprise a single, westward-sloping, faulted basin (Figure 6-6). The western boundary of the Crater Flat basin coincides with the Bare Mountain fault and the northward extension of the fault into the Tram Ridge and Tate's Wash faults (Fridrich 1999 [DIRS 118942], p. 174). The Bare Mountain fault dips steeply $\left(64^{\circ} \pm 5^{\circ}\right.$ near the southern end) and can be imaged by seismic reflection to depths of at least $3.5 \mathrm{~km}$ and possibly to depths of $6 \mathrm{~km}$ (Brocher et al. 1998 [DIRS 100022], pp. 956 and 966). Logically, this major fault probably extends to the brittle-ductile transition in the middle crust. The northern boundary consists of a gradational termination of intrabasin structure at the perimeter of the Timber Mountain caldera complex (Fridrich 1999 [DIRS 118942], p. 174). As defined by Fridrich (1999 [DIRS 118942], pp. 174 and 176), the northeastern boundary coincides with Yucca Wash, which is an alluvium-filled valley inferred to be underlain by a small northwest-striking right-lateral strike slip fault or zone of faults (Fridrich 999 [DIRS 118942], pp. 174 and 176). The fault is nowhere exposed, but is inferred from the fact that Yucca Wash is a linear valley separating Yucca Mountain from a domain to the northeast in which the 12.7 to $12.8 \mathrm{~m} . \mathrm{y}$. Paintbrush Group and older rocks are more extended than on northern Yucca Mountain (Fridrich 1999 [DIRS 118942], p. 176). Day et al. (1998 [DIRS 100027], p. 11) summarize evidence indicating that a major fault is not present beneath Yucca Wash.

The eastern and southern margins of the domain are not physiographically distinct, but rather merge with adjacent portions of the Basin and Range. The eastern margin of the Crater Flat basin is probably a buried down-to-the-west fault known as the Gravity Fault (Fridrich 999 [DIRS 118942], p. 176, Figure 7). The southern margin is inferred from gravity and magnetic data and from discontinuous outcrops to be a fault structure buried beneath young alluvium. It is typically drawn in a northwestern direction along the Amargosa Valley (Fridrich 1999 [DIRS 118942], p. 176). Fundamental changes in the style, timing, and magnitude of extensional deformation occur across all of the boundaries of the Crater Flat basin.

\subsubsection{Fault Orientations, Dip Directions, and Displacements}

In the center of the Crater Flat basin, a sequence of 12.7 to $12.8 \mathrm{~m}$.y. ash-flow tuffs (primarily the Tiva Canyon and Topopah Spring Tuffs of the Paintbrush Group) crop out. These exposed tuff units comprise Yucca Mountain and adjacent mesas. Much of the information about orientation, offset, and timing of faulting is based on examination of faults that cut through the exposed tuffs. Because both Crater Flat and Jackass Flats are basins that have undergone alluviation in the late Quaternary, much of the structure of these basins is not accessible to direct observation. Information on structures beneath Crater Flat and Jackass Flats is derived mainly from seismic, gravity, and aeromagnetic and ground magnetic data. 


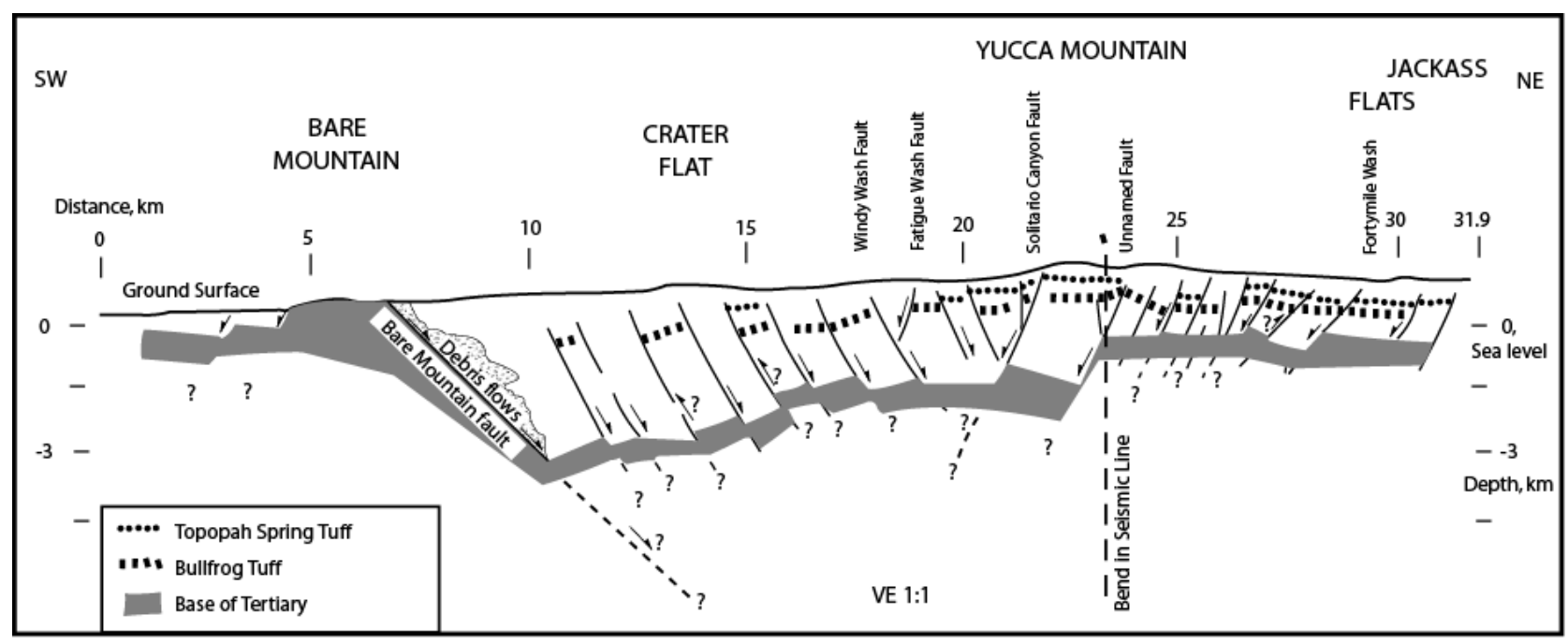

Source: Modified from Brocher et al. 1998 [DIRS 100022].

NOTE: Location of cross section is indicated in Figure 6-5.

Figure 6-6. Schematic Cross Section of the Crater Flat Basin, from Seismic Reflection, Surficial Geology, and Borehole Information

The Crater Flat basin is characterized by an array of closely spaced, small-to-moderate sized extensional faults that generally dip towards the center of the basin (Figure 6-6). Normal faults within the Crater Flat basin strike northerly in the northeastern part of the basin, but change to increasingly northeasterly to the south and west across the basin (Figure 6-5). These orientations can be measured directly where faults are exposed on Yucca Mountain and can be inferred from the strike of aeromagnetic and gravity anomalies buried beneath young basin fill. In general, the fault pattern within Crater Flat basin is roughly radial to the caldera complex to the north and is curved from north to south across the basin. Based on the strike directions of faults within the Crater Flat basin, a northwest-trending "hinge line" can be defined (Fridrich et al. 1999 [DIRS 107333], p. 208) that separates an area of predominantly north-striking faults on the northeast from an area of predominantly northeast-striking faults on the southwest (Figure 6-5). The hinge line also marks the approximate location of (1) the $20^{\circ}$ contour of clockwise rotation of the Tiva Canyon Tuff, (2) a subtle yet abrupt decline in elevation to the southwest, and (3) an increase in Quaternary displacement for faults southwest of the hinge line (Fridrich et al. 1999 [DIRS 107333], p. 208; Stamatakos et al. 1997 [DIRS 138819], p. 327). These observations are consistent with a division of the Crater Flat basin into two parts, separated at the approximate position of the hinge line (Figure 6-5): (1) a northeastern, less extended part, and (2) a southwestern, more extended part (Fridrich et al. 1999 [DIRS 107333], p. 208; Stamatakos et al. 1997 [DIRS 138819], pp. 327 through 328).

Seismic reflection surveys show that the Crater Flat basin is deepest to the west (Brocher et al. 1998 [DIRS 100022], Figure 6; Ferrill et al. 1996 [DIRS 105315], Figure 1b), implying that extension is also greatest to the west. Stratigraphic thickening of Miocene volcanic rocks to the west support this interpretation (Fridrich et al. 1999 [DIRS 107333], 
p. 198). Thus, Crater Flat basin is a single, westward-dipping graben with less fault displacement in the eastern half within which no major faults dominate (Figure 6-6).

Nearly all faults of the Crater Flat basin have at least a small component of oblique offset (Fridrich 1999 [DIRS 118942], p. 177). Stratal tilts increase strongly to the west and south from an area of minimum tilts in the northeastern part of the basin on north Yucca Mountain. Faults in the southern part of the basin have a shallower dip and generally greater hanging wall tilt. In the northeastern part of the basin, cumulative extension is 7 to 15 percent. In contrast, cumulative extension in the southwestern part of the basin is at least 50 to 100 percent. This greater extension results from decreased spacing between the intrabasin faults and to increased average throw of the major faults (Fridrich et al. 1999 [DIRS 107333], pp. 197-198).

\subsubsection{Rotation of Faults}

The curved pattern of faults and the difference in orientation of faults from northeast to southwest, in the Crater Flat basin is attributed to southward increasing clockwise vertical-axis rotation where fault blocks, together with their bounding faults were rotated from their original positions. On the scale of the basin as a whole, the spatial variation of declination (i.e., interpreted as vertical-axis rotation) is very smooth (Rosenbaum et al. 1991 [DIRS 106708], pp. 1976 and 1977; Hudson et al. 1996 [DIRS 106194]; Fridrich et al. 1999 [DIRS 107333], Figure 8). The hinge line that is defined from the strike directions of faults corresponds approximately to the contour of $20^{\circ}$ clockwise rotation of the Tiva Canyon Tuff. In general, more than $20^{\circ}$ of clockwise rotation is present southwest of this line, and less than $20^{\circ}$ of rotation is present northeast of the hinge line. In the northeastern part of the basin, cumulative clockwise rotation is generally less than $5^{\circ}$; in contrast, cumulative rotation in the southwestern part of the basin is greater than $45^{\circ}$ (Fridrich et al. 1999 [DIRS 107333], p. 197). Paleomagnetic data from the Crater Flat basin are interpreted to show that older stratigraphic units are rotated more than younger units and that the major pulse of vertical-axis rotation followed the major episode of extension by about $1 \mathrm{~m}$.y. The major pulse of rotation occurred between 11.6 and $11.45 \mathrm{~m} . \mathrm{y}$. (Hudson et al. 1996 [DIRS 106194]; Fridrich et al. 1999 [DIRS 107333], p. 210). The close association in the areal pattern of vertical-axis rotation with the magnitude of extension in the Crater Flat basin suggests that the rotation and extension are related as a consequence of the fan-like opening of the basin (Fridrich et al. 1999 [DIRS 107333], p. 210).

\subsubsection{Quaternary Slip Rate}

Based on the areal variation in the pattern of late Quaternary extension in the Crater Flat basin, a strong southward increase in deformation rate exists. Slip rates determined on individual faults generally increase to the south (Fridrich et al. 1999 [DIRS 107333], pp. 197 and 208; Fridrich 1999 [DIRS 118942], p. 177). In addition, cumulative late Quaternary (900 to 100 k.y.) extension measured along three profiles yields $0.025,0.1$, and 0.2 percent per m.y. from north to south across the basin (Fridrich et al. 1999 [DIRS 107333], p. 207). Thus, the original fan-like pattern of basin opening established in the Miocene still persists. The continuing pattern of oblique basin opening indicates that vertical-axis rotation must still be occurring at a rate that is significant relative to the rate of extension (Fridrich et al. 1999 [DIRS 107333], pp. 207 and 208). 
Wernicke et al. (1998 [DIRS 103485], p. 2098) presented data from global positioning system surveys that they interpreted as indicating a strain rate near Yucca Mountain three to four times the Basin and Range average. Based on this conclusion, they suggested that the volcanic hazard at Yucca Mountain may have been underestimated by an order of magnitude (Wernicke et al. 1998 [DIRS 103485], p. 2099). A more recent study (Savage et al. 1999 [DIRS 118952]) using data covering a longer time period than Wernicke et al. (1998 [DIRS 103485]) interpreted the data to suggest that within the error of the measurements, the strain rate near Yucca Mountain measured between 1983 to 1998 was not significantly different from zero (Savage et al. 1999 [DIRS 118952], p. 17631).

The suggestion that postulated anomalous strain rates near Yucca Mountain would lead to an order-of-magnitude increase in the volcano recurrence rate is not consistent with the post-Miocene volcanic record of the YMR. The total volume of basalt erupted during the past million years near Yucca Mountain is less than $0.5 \mathrm{~km}^{3}$ and is part of a systematic decline in the volume of basalt erupted over the past 5 m.y. (CRWMS M\&O 1998 [DIRS 105347], Chapter 4, p. 4-12). This million-year record of low-volume volcanism is inconsistent with the hypothesis that approximate 100,000 year time intervals within this period have involved particularly high strain rates that would lead to an order-of-magnitude increase in magmatic activity, as stated by Wernicke et al. (1998 [DIRS 103485], p. 2099). Furthermore, the youngest episode of volcanism near Yucca Mountain occurred as a temporally isolated event approximately 80 k.y. ago at Lathrop Wells, with no volcanism occurring since (CRWMS M\&O 1998 [DIRS 105347], Chapter 2, Sections III and IV). This observation is inconsistent with the Wernicke et al. (1998 [DIRS 103485], p. 2099) hypothesis that Lathrop Wells may represent the onset of a cluster of volcanic events that may continue for several tens of thousands of years. Savage et al. (1998 [DIRS 145359], p. 1007b) calculated that an order-of-magnitude increase in the volcano recurrence rate would result in a 90 percent probability of a new volcano forming between $80 \mathrm{ka}$ and the present. No such event has occurred. Savage et al. (1998 [DIRS 145359], Figure 1) also presented fault displacement data showing that deformation rates in the YMR have decreased since about 60 k.y. ago, suggesting that the region is not currently within a period of anomalous strain rate that would couple to an increased volcano recurrence rate.

\subsubsection{Basin Subsidence and Fault Displacement}

A greater subsidence in the southwestern part of the Crater Flat basin can be inferred from a lower elevation and therefore, a greater sedimentation rate compared to the northeastern part of the basin. A subtle topographic decline (lower on the southwest side) corresponds with the hinge line, defined from the strike directions of faults (discussed above) along most of its length. The lower elevation is a function of greater total amount of extension to the southwest of the hinge line. Most faults that cross the hinge line show a pronounced southward increase in both Quaternary displacement and total bedrock displacement across it (Fridrich et al. 1999 [DIRS 107333], pp. 197 and 208; Fridrich 1999 [DIRS 118942], p. 177), especially near the western margin (Bare Mountain fault) and central part (southern Yucca Mountain) of the basin. Miocene and Pliocene sediments are only slightly offset at the northern end of the Bare Mountain fault, while Holocene sediments are significantly offset near the southern end of the fault (Stamatakos et al. 1997 [DIRS 138819], p. 327). Also, growth of alluvial fans is greater along the southern part of the fault. Differences in fan growth are indicative of increased fault slip in the southwestern part of the basin and are compatible with measured slip rates along the 
Bare Mountain fault from $0.02 \mathrm{~mm} / \mathrm{yr}$ in the north to $0.21 \mathrm{~mm} / \mathrm{yr}$ along the southern part of the fault (Ferrill et al. 1996 [DIRS 105315], p. 562). Along the eastern side of Crater Flat, cumulative offset on the Solitario Canyon fault is approximately $1000 \mathrm{~m}$ greater to the south compared to the north (Stamatakos et al. 1997 [DIRS 138819], p. 327). Greater differential subsidence in the southwestern part of the Crater Flat basin is correlated with a greater thickness of Quaternary alluvium in this part of the basin compared to adjacent parts. For example, lava flows associated with Little Cones are buried beneath approximately $15 \mathrm{~m}$ of alluvium, while the Red and Black Cones of approximately the same age are more completely exposed.

To summarize, a variety of structural data, including fault orientations, direction of dip, total and late Quaternary extension, vertical-axis rotation, and basin subsidence, are interpreted to show that the northeastern part of the Crater Flat basin is significantly different from the southwestern part of the basin. That is, each part of the basin has a distinctive style of deformation; the two regions of the basin can be distinguished from each other across a well-defined though gradational boundary, the hinge line extending obliquely across the Crater Flat basin (Figure 6-5). Thus, the northeastern and southwestern parts of the Crater Flat basin are structurally distinct, with the southwestern part characterized by a history of greater extension.

\subsubsection{Correlation with Volcanism}

The post-Miocene basaltic centers of the Crater Flat basin lie within the southwestern part of the basin (Figure 6-5). This part of the basin is coincident with the zone of greatest transtensional deformation, between the hinge line of the basin and the Bare Mountain fault, suggesting that this extensional zone controlled the ascent of basalt through the upper crust (Fridrich et al. 1999 [DIRS 107333], p. 210). The youngest volcano in the Crater Flat basin, the 80-ka Lathrop Wells volcano, lies between the southern ends of the Windy Wash and Stagecoach Road faults, the most active site of late Quaternary faulting in the Crater Flat basin (Fridrich et al. 1999 [DIRS 107333], p. 211). Thus, there is a close spatial and temporal relationship between sites of extension and volcanism throughout the Crater Flat basin (Fridrich et al. 1999 [DIRS 107333], p. 211). The restriction of three episodes of post-Miocene volcanism to the transtensional zone in the Crater Flat basin suggests that volcanism is less likely to occur at Yucca Mountain, which lies outside of the transtensional zone in an area where no post-Miocene volcanism has occurred (Fridrich et al. 1999 [DIRS 107333], p. 210, Figure 17a). As discussed in the next section, the PVHA experts recognized the close association between volcanism and areas of maximum extension in the YMR (CRWMS M\&O 1996 [DIRS 100116], pp. RC-5, BC-12, AM-5, MS-2, GT-2). Subsequent geologic and geophysical studies provide corroborative evidence that areas of maximum extension in the Crater Flat basin correspond closely to volcanic source zones defined in the PVHA (Stamatakos et al. 1997 [DIRS 138819]; Brocher et al. 1998 [DIRS 100022]; Fridrich et al. 1999 [DIRS 107333]).

\subsubsection{Probabilistic Volcanic Hazard Analysis Volcanic Source Zones: Relationship to Crater Flat Structural Features and the Probability of Dike Intersection}

The correlation between the structurally active part of the Crater Flat basin and sites of volcanism within the basin indicate that Yucca Mountain is near, but not within, a local volcanic zone that may produce small volumes of future volcanism (CRWMS M\&O 1996 [DIRS 100116], Appendix E, expert zone maps). Although local source zones were chosen by 
PVHA experts based largely on the location of past volcanic events, they correspond to the areas of highest cumulative extension and most recent faulting in the Crater Flat basin (Fridrich et al. 1999 [DIRS 107333], Figures 5 and 6), an association recognized by several of the PVHA experts (CRWMS M\&O 1996 [DIRS 100116], pp. RC-5, BC-12, AM-3 through 5, GT-2). In all cases in which local zones were defined, the zones were restricted to the southwestern part of the Crater Flat basin or defined elongated, northwest-trending belts that included the southwestern part and stretched to the Timber Mountain area (Figure 6-7a and Figure 6-7b). All of the local zones excluded the northeastern part of the Crater Flat basin, in which the proposed Yucca Mountain repository is located (Figure 6-7a and Figure 6-7b). Based on structural arguments and the past patterns showing the close association of volcanism and extension, the eastern boundaries of local volcanic source zones defined in the PVHA separate more tectonically active and less tectonically active parts of the Crater Flat basin and may be reasonable predictors of the eastern extent of volcanism expected in the future.

In terms of probability calculations, the volcanic source zones defined in the PVHA represent local regions of higher event frequency (southwestern Crater Flat), while northeastern Crater Flat (which includes Yucca Mountain) falls within a regional background source zone of lower event frequency (Figures 6-7a and 6-7b). According to the intersection probability models used in the PVHA, two mechanisms can generate a disruptive event at Yucca Mountain: either (1) a volcanic event is generated within a local source zone (higher probability event) to the west of Yucca Mountain and has the appropriate location and dike characteristics (length and azimuth) to intersect the proposed repository, or (2) a volcanic event is generated within a regional background zone (lower probability event) and intersects the repository. Because the probability of intersection of a volcanic event with the proposed repository includes components of both mechanisms, the intersection probability estimated for the repository should reflect spatial event frequencies that lie between local source zone values and regional background values. This conclusion is consistent with the results of the PVHA and is appropriate for a site that lies outside of a local volcanic source zone, but near enough to possibly be affected by dikes generated within the source zone.

In summary, many models of the experts related the areas of greatest likelihood for future volcanic activity to the region where previous volcanism has occurred and in which extensional deformation has been, and continues to be greatest, i.e., to the southwestern part of the Crater Flat basin (CRWMS M\&O 1996 [DIRS 100116], pp. RC-5, BC-12, AM-5, MS-2, GT-2, and expert zone maps; Figure 6-7a and Figure 6-7b). Analysis by the NRC also indicates that the highest likelihood of future volcanic activity is in southwestern Crater Flat (Reamer 1999 [DIRS 119693], Sections 4.1.5.4 and 4.1.6.3.3; Figure 6-26). Given that the southern and southwestern part of the Crater Flat basin is the most extended (Ferrill et al. 1996 [DIRS 105315]; Stamatakos et al. 1997 [DIRS 138819]; Fridrich et al. 1999 [DIRS 107333]; Reamer 1999 [DIRS 119693], p. 47) and that the locus of post-Miocene volcanism in the Crater Flat basin lies in the south and southwestern part of the basin (Fridrich et al. 1999 [DIRS 107333]; Reamer 1999 [DIRS 119693], p. 47), volcanic source zones defined in the PVHA and centered in southwestern Crater Flat are consistent with the tectonic history and structural features of the Crater Flat structural domain (Figure 6-7a and Figure 6-7b). 


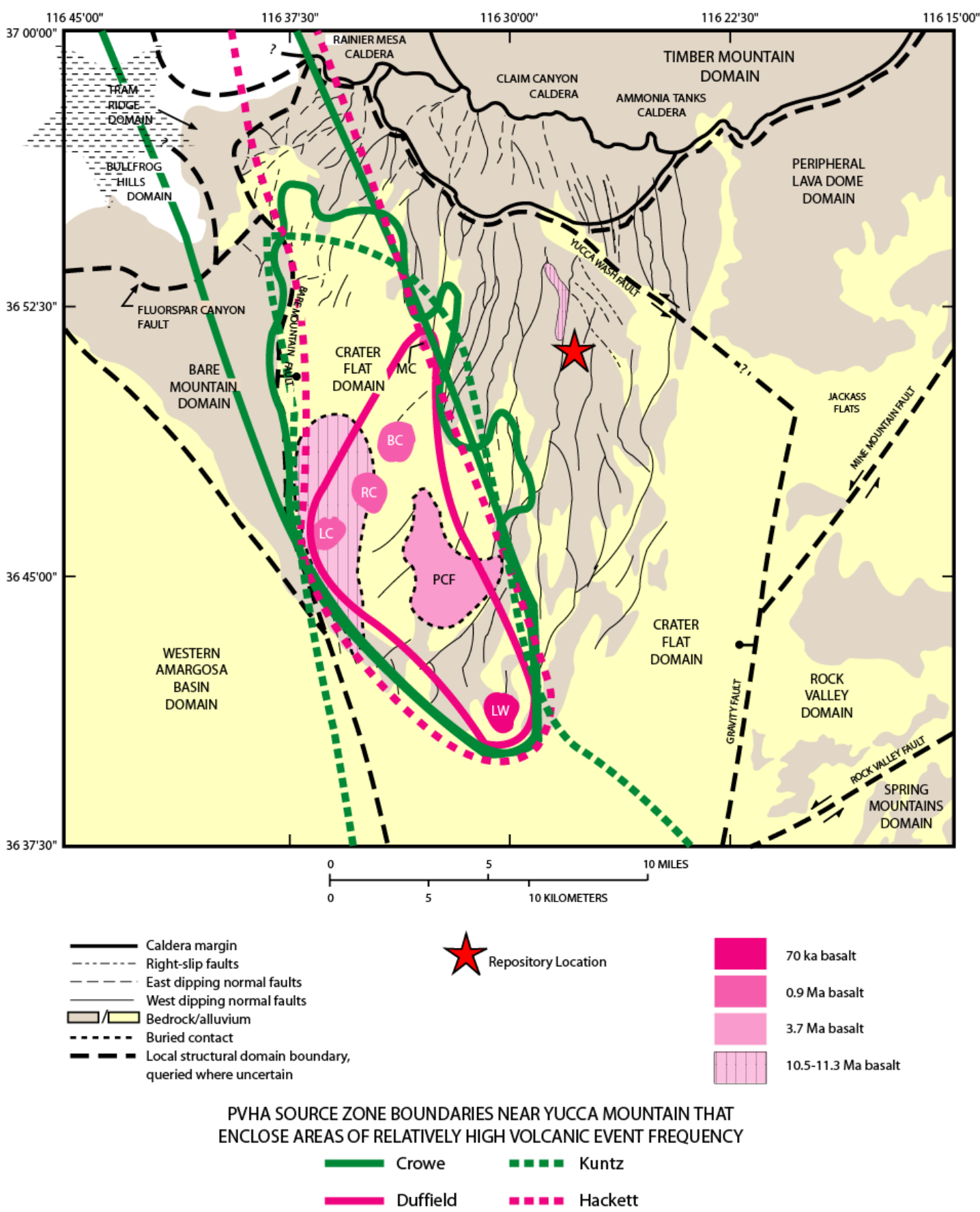

DTN: MO0002PVHA0082.000 [DIRS 148234] (for zone boundaries only).

Source: Superimposed on the Fridrich et al. (1999 [DIRS 107333], Figure 1) map are boundaries of selected volcanic source zones (locally homogeneous spatial and temporal model, CRWMS M\&O 1996

[DIRS 100116] Section 3.13) that were defined by the PVHA experts and that lie within the Crater Flat basin (CRWMS M\&O 1996 [DIRS 100116], Appendix E).

NOTE: $M C=$ Makani Cone; $B C=$ Black Cone; $R C=$ Red Cone; $L C=$ Little Cones; $L W=$ Lathrop Wells.

Figure 6-7a. Local Structural Domains and Domain Boundaries of the Yucca Mountain Region and Internal Structures of the Crater Flat Basin and Selected Parts of Adjacent Domains 


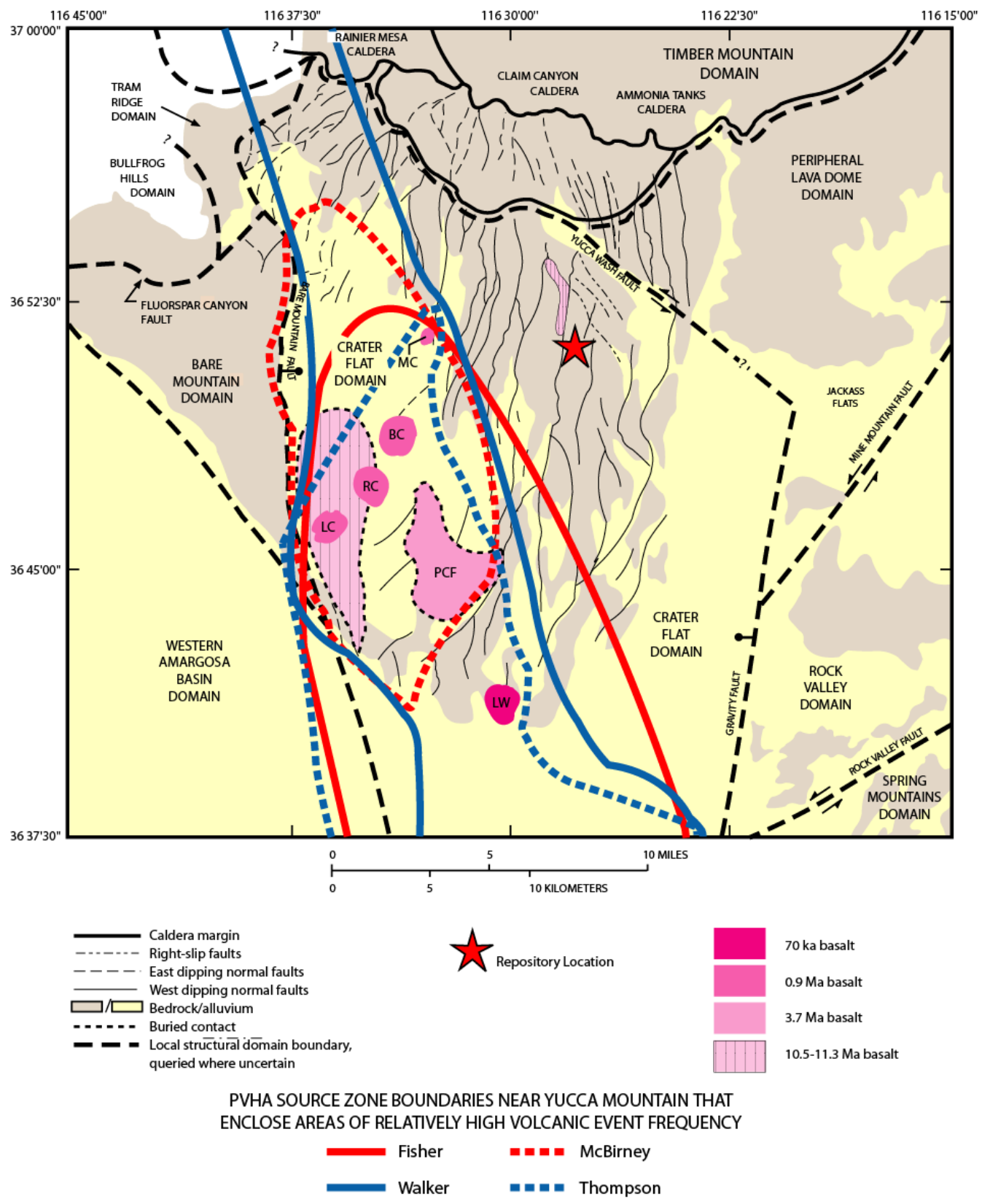

DTN: MO0002PVHA0082.000 [DIRS 148234] (for zone boundaries only).

Source: Superimposed on the Fridrich et al. (1999 [DIRS 107333], Figure 1) map are boundaries of selected volcanic source zones (locally homogeneous spatial and temporal model, CRWMS M\&O 1996

[DIRS 100116], Section 3.13) that were defined by the PVHA experts and that lie within the Crater Flat basin (CRWMS M\&O 1996 [DIRS 100116], Appendix E).

NOTE: $M C=$ Makani Cone; $B C=$ Black Cone; $R C=$ Red Cone; $L C=$ Little Cones; $L W=$ Lathrop Wells.

Figure 6-7b. Local Structural Domains and Domain Boundaries of the Yucca Mountain Region and Internal Structures of the Crater Flat Basin and Selected Parts of Adjacent Domains 


\subsection{PROBABILISTIC VOLCANIC HAZARD ANALYSIS FOR THE REPOSITORY FOOTPRINT}

The PVHA (CRWMS M\&O 1996 [DIRS 100116]) presented a methodology for calculating the frequency of intersection of the proposed repository by a volcanic event. The interpretations of 10 experts were used to compute a distribution for the frequency of intersection and quantify the scientific uncertainty in the PVHA assessment. The configuration of the repository emplacement area (BSC 2003 [DIRS 162289]) has a different outline from that used in the PVHA (CRWMS M\&O 1996 [DIRS 100116]). Consequently, the distribution for frequency of intersection is recalculated in this section of the report, based on the volcanic hazard model developed in the PVHA, but using the 2003 repository footprint (BSC 2003 [DIRS 162289]).

To evaluate the consequences of an intersection, information is needed on the length and orientation of the intersecting dike or dikes and the probability that an eruptive center (the vent above the conduit feeding an erupting volcano) forms within the emplacement area of the repository. Although not computed in the original PVHA study, the length and orientation of intersecting dikes can be obtained as part of the calculation process without any additional assumptions. This section of the report develops these assessments from the PVHA volcanic hazard model. The PVHA experts were not asked to make assessments of the number and location for eruptive centers along the length of the dike system associated with a volcanic event. The PVHA experts did assess the number of volcanic events represented by the observed eruptive centers in the YMR. These assessments, together with the characteristics of Quaternary volcanoes in the YMR and a limited number of assumptions (described in Section 5), are used to derive empirical distributions for the number of eruptive centers per volcanic event. Application of these assessments in the calculation of the number of eruptive centers within the proposed repository requires assessment of the possible correlation between number of eruptive centers and dike length and on the spatial distribution of eruptive centers along the length of the dike. Calculations are performed in this report using a range of possible assessments to incorporate these uncertainties into the analysis.

\subsubsection{Description of the PVHA Volcanic Hazard Model Formulation}

In the context of the PVHA volcanic hazard model, a volcanic event is a spatially and temporally distinct batch of magma ascending from the mantle through the crust as a dike or system of dikes (CRWMS M\&O 1996 [DIRS 100116], Appendix E). The volcanic event is defined as a point in space representing the expected midpoint of the dike system involved in the magma ascent. The dike system associated with the volcanic event is represented in the PVHA probability model by a line element defined in terms of a length, azimuth, and location relative to the point event (Figure 6-8). The term "dike length" used in the PVHA and in this report when discussing volcanic events, refers to the total length of the dike system associated with the volcanic event. The phrase "intersection of the repository footprint by a dike" refers to intersection of the emplacement area of the repository by the line element representing the dike system associated with the volcanic event. The width of the dikes and the number of parallel dikes does affect the consequences of an intersection and is included in Number of Waste Packages Hit by Igneous Intrusion (BSC 2004 [DIRS 170001]). 
This section describes the formulation of the volcanic hazard model developed in the PVHA (CRWMS M\&O 1996 [DIRS 100116], Section 3), its extension to compute the distributions for the length and azimuth of intersecting dikes within the repository footprint, and the number of eruptive centers within this footprint. The mathematical description of the formulation is presented in Appendix A. The calculations were performed utilizing the 2003 repository layout (BSC 2003 [DIRS 162289]) and the repository footprint polygon, which was developed as described in Appendix B.

\subsubsection{Frequency of Intersection of the Repository Footprint by a Dike}

The approach used to compute the frequency of intersection of the proposed repository by a volcanic event is illustrated in Figure 6-8, Figure 6-9, and Figure 6-10. The PVHA experts specified spatial and temporal models that define the frequency of occurrence of volcanic events in the region around Yucca Mountain. A grid is constructed over this region with a spacing of $0.5 \mathrm{~km}$ in the $x$ (east-west) and $y$ (north-south) directions (a 1-km spacing was used in the original PVHA calculation, CRWMS M\&O 1996 [DIRS 100116]). At each location in the grid, $x$ and $y$, the annual frequency of occurrence of volcanic events is computed from the experts' spatial and temporal models. The volcanic events occurring at any point will have an associated dike. The experts defined distributions for the length and orientation of the possible dike or dike system that may be associated with volcanic events. Shown schematically on Figure 6-8 are four possible alternative geometries of the dike system associated with the volcanic event. Of these four, two are at the proper orientation and of sufficient length to intersect the repository footprint. Using the distributions for dike length and orientation, the fraction of all of the possible alternative dike systems associated with volcanic events at any point that intersect the proposed repository is computed. This fraction is defined as the conditional probability of intersection for volcanic events at a point. (The probability is called a conditional probability because it is conditional on the occurrence of a volcanic event.).

Figure 6-9 illustrates how the conditional probability of intersection is computed. The dike system associated with a volcanic event at point $(x, y)$ has a total length $L$. The distance $d$ from the point $(x, y)$ to the end of the dike system in the direction of the repository is important for determining whether or not intersection of the repository footprint occurs. Distance $d$ is some fraction of the total length $L$ depending on how the dike system is oriented with respect to the volcanic event. (How distance $d$ is determined is discussed in the paragraph below.) Given a distance $d$, all dikes with azimuths between $\phi_{1}$ and $\phi_{2}$ will intersect the repository footprint. The probability that the dike will have an azimuth between $\phi_{1}$ and $\phi_{2}$ is determined by the PVHA experts' distributions for dike orientation. The probability that the dike system will have length $d$ is determined by the PVHA experts' distributions for the total length of the dike system $L$ and the location of the dike system with respect to the volcanic event. Combing these two probability distributions produces the conditional probability of intersection for point $(x, y)$. 


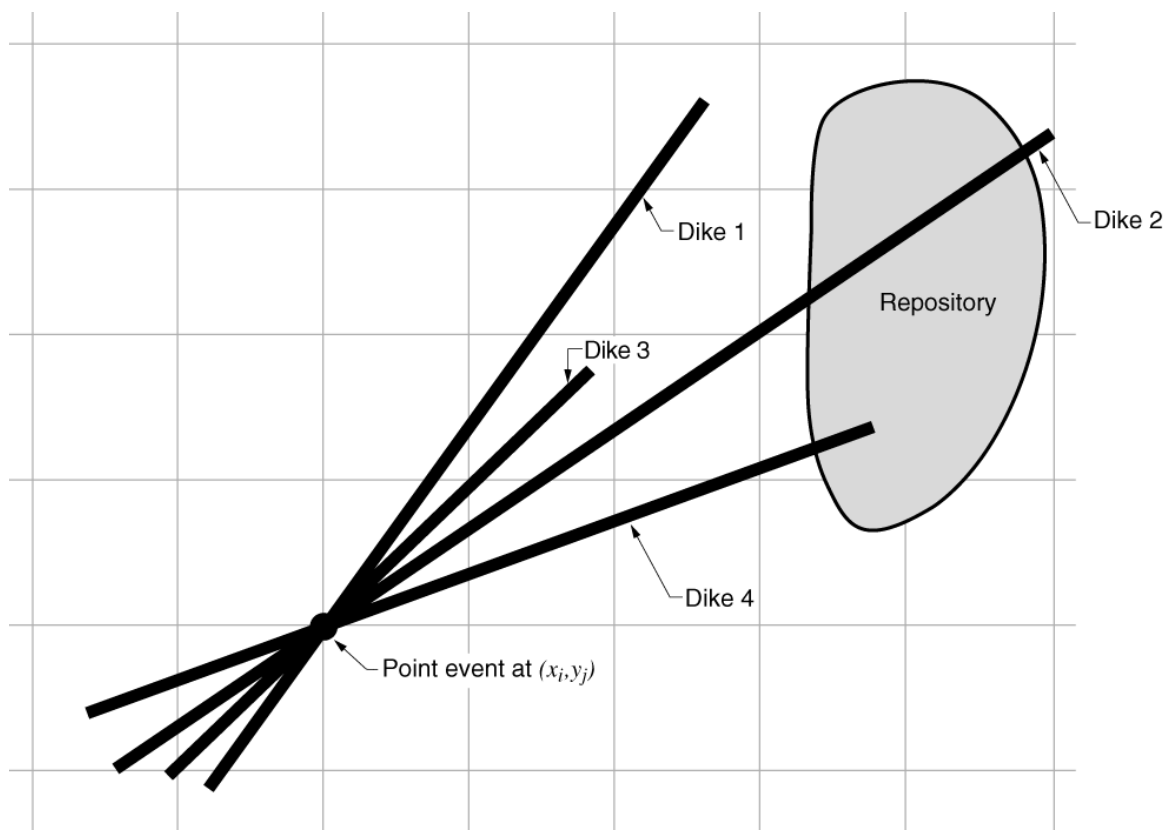

For Information Only

NOTE: Dikes labeled 1 through 4 represent four alternative geometries for the dikes associated with a volcanic event at point $\left(x_{i}, y_{j}\right)$.

Figure 6-8. Schematic Illustrating Procedure for Computing the Frequency of Intersection of the Proposed Repository by a Volcanic Event

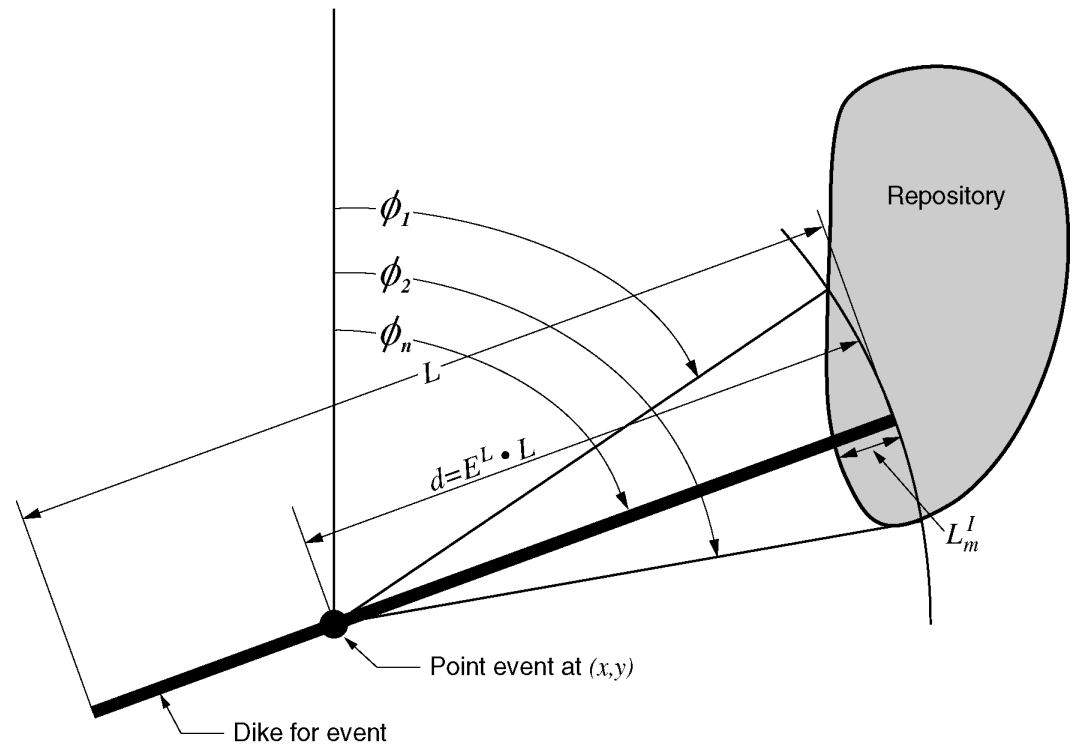

For Information Only

NOTE: $L$ is the length of the dike, $d$ is the distance from the volcanic event at point $(x, y)$ to the end of the dike, $\phi_{1}$ and $\phi_{2}$ are the range in azimuths for which a dike extending a distance $d$ from point $(x, y)$ will intersect the repository, and $L_{m}^{\prime}$ is the length of the intersecting dike within the repository when the dike is at azimuth $\phi_{n}$.

Figure 6-9. Illustration of the Process Used to Compute the Conditional Probability of Intersection of the Proposed Repository by a Volcanic Event 

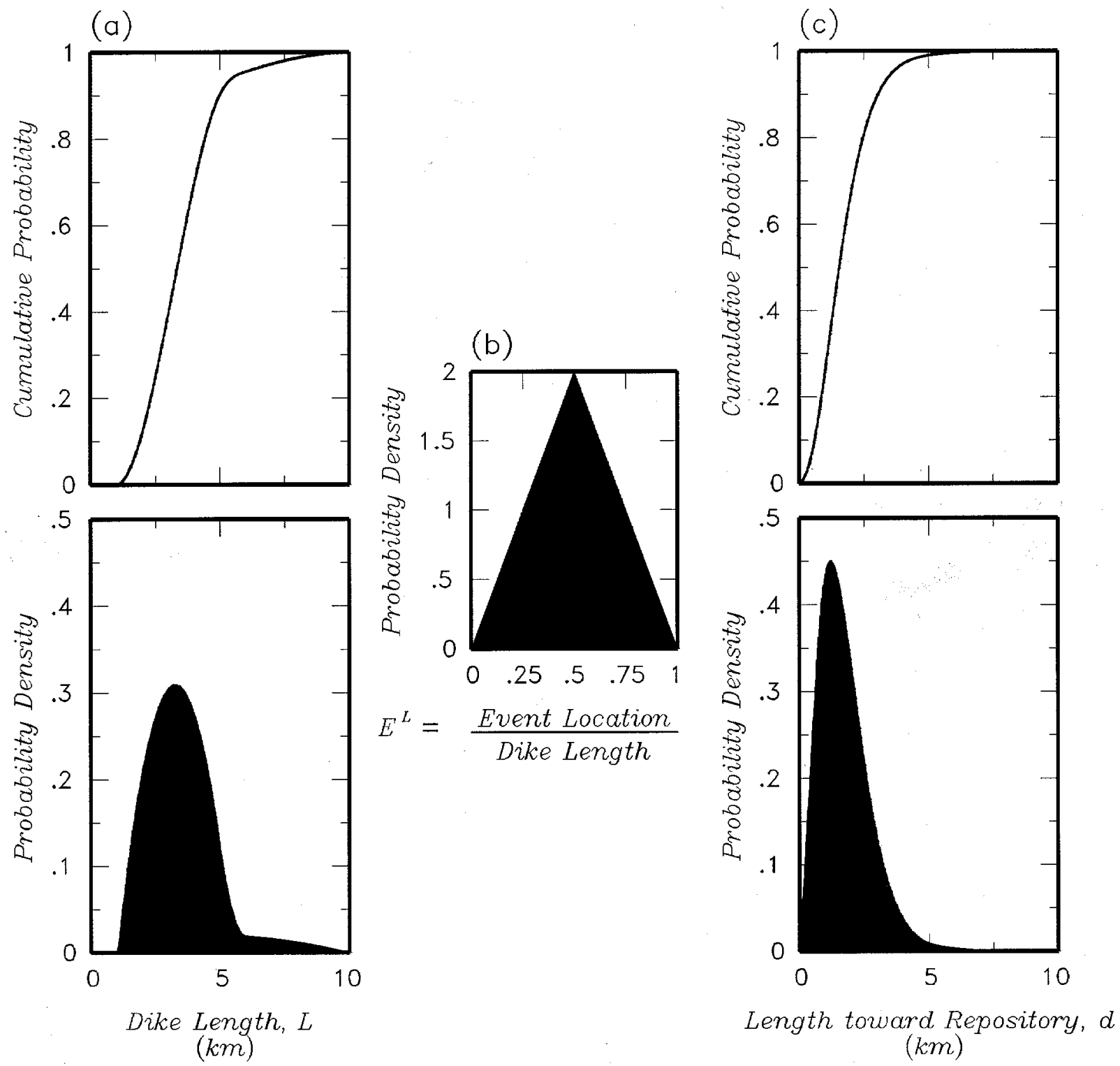

(b)

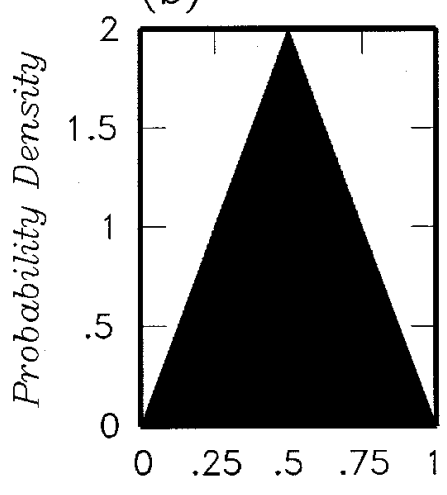

$E^{L}=\frac{\text { Event Location }}{\text { Dike Length }}$

Length toward Repository, d $(\mathrm{km})$

For Information Only

Figure 6-10. Example Distributions for Dike Length, L, (part a); Normalized Location of the Point Volcanic Event Relative to the Total Length of the Dike, EL, (part b); and the Resulting Distribution for Distance from the Point Volcanic Event to the End of the Dike, $d$ (part c) 
Figure 6-10 illustrates how the distribution for distance $d$ is obtained. Part (a) of Figure 6-10 shows an example probability distribution for the total length $L$ of the dike system associated with a volcanic event. Typically, these distributions were defined by the PVHA experts to be skewed with long upper tails. Part (b) shows a distribution for the normalized location of the dike system relative to the point volcanic event, parameter EL. If all dike systems were centered on the volcanic event, then EL would always equal 0.5 and $d$ would always equal L/2. However, the PVHA volcanic hazard model allowed for the possibility that the dike system near the surface was not necessarily centered on the volcanic event and EL was allowed to vary over the range of 0 to 1 . The PVHA experts specified distributions for EL that were symmetric about 0.5 (the expected center of the event relative to the total length of the dike) and typically had higher probability for locations at the midpoint (the dike centered on the event point) than at the ends (the dike extending for its full length in one direction away from the event point). It is because the parameter EL is allowed to vary between 0 and 1, that the point volcanic event is defined as the "expected" center (the mean value of EL is equal to 0.5 in all cases) rather than just the center of the volcanic event. Part (c) shows the resulting probability and cumulative probability distributions for the distance $\mathrm{d}$ from the proposed repository to the end of the dike obtained by convolving the distributions from (a) and (b).

The frequency of intersecting volcanic events occurring at point $(x, y)$ in Figure 6-8 is then obtained by multiplying the frequency of volcanic events occurring at that point by the conditional probability of intersection for that point. The process is repeated for all locations in the grid, producing the frequency of intersection at each point. The sum of these values over all locations in the grid is the annual frequency of intersection of the proposed repository by volcanic events, the computed result of the PVHA volcanic hazard model.

Figure 6-11 shows the components of this calculation. Part (a) shows the spatial distribution of volcanic event frequency. The contour value at any point represents the expected annual frequency of volcanic events per square kilometer. These values represent the weighted average of all of the PVHA experts' alternative spatial and temporal models for the occurrence of volcanic events. Areas with the highest event frequency (contoured intervals from orange to red) outline Crater Flat and a small region around the Lathrop Wells volcano. Areas with the next level of event frequency (yellow contoured areas) extend to the northwest to Sleeping Buttes and to the south into Amargosa Valley. There is also a small yellow area at Buckboard Mesa northeast of the repository location. The areas of higher event frequency represent areas of post-Miocene volcanism in the YMR and areas where future volcanism is considered more likely to occur. Part (b) of Figure 6-11 shows a map of the product of the volcanic event frequency (part a) and the conditional probability of intersection for each point $(x, y)$. It is a map of the spatial distribution of volcanic events that contribute to the mean annual frequency of intersection (the integral of the displayed densities equals the mean annual frequency of intersection). In those areas that are shown in white, the conditional probability of intersection is very low and dike systems for volcanic events that occur in these areas are very unlikely to intersect the repository. The north-northeast - south-southwest elongation of the region shown on Part (b) of Figure 6-11 reflects the highest weighted orientation of dike systems in the PVHA volcanic hazard model. The shape of the yellow region to the southwest of the repository location matches that of the high frequency region for Crater Flat on part (a), with a high intensity point at Lathrop Wells. The Buckboard Mesa region to the northeast of the repository also shows a contribution to the intersection frequency. 
(a)

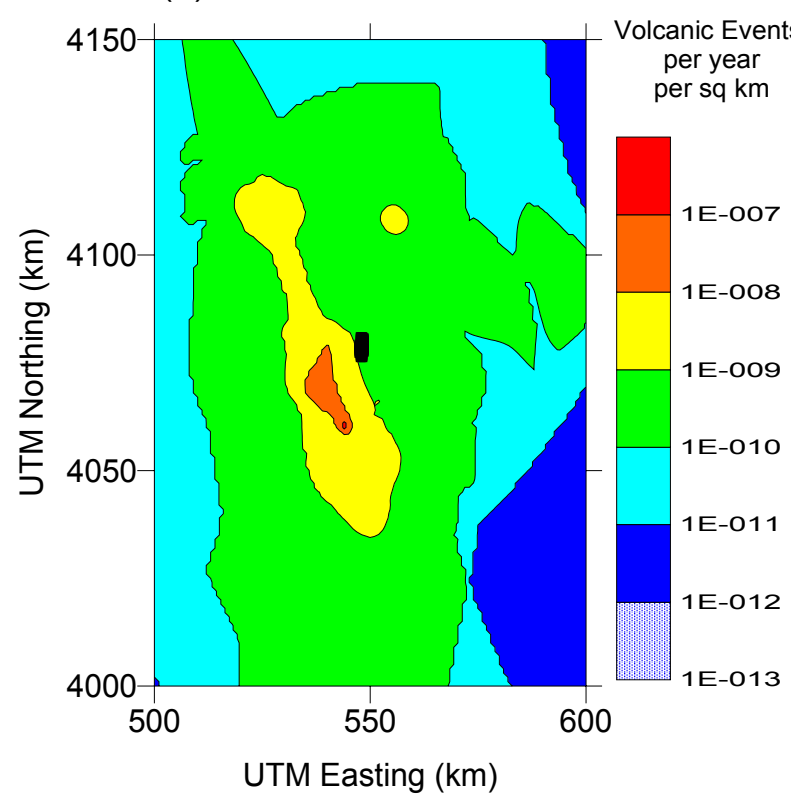

(b)

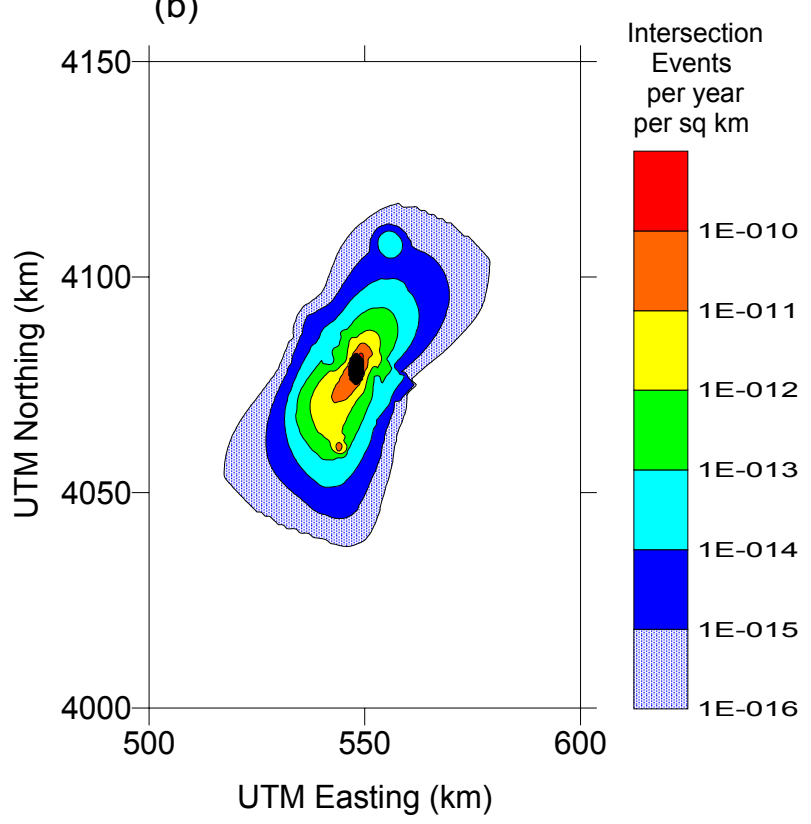

Output DTNs: (a) LA0009FP831811.001; (b) LA0303BY831811.001.

NOTE: The maps represent the mean results averaged over 10 experts and over each expert's logic tree (CRWMS M\&O 1996 [DIRS 100116], Appendix E). The black area in the center of the maps is the location of the proposed repository.

Figure 6-11. Spatial Distribution of Volcanic Hazard Defined by the Probabilistic Volcanic Hazard Analysis Expert Panel: (a) Spatial distribution of Expected Volcanic Event Frequency and (b) Spatial Distribution of Expected Intersection Frequency

In all assessments of the effects of rare phenomena, there is considerable uncertainty in selecting the appropriate models and model parameters arising from limited data and (or) alternative interpretations of the available data. The PVHA experts quantified the uncertainty in the annual frequency of intersection of the proposed repository by developing sets of alternative probability models and model parameters for all aspects of the hazard calculation. These models were organized in the logic tree format shown in Figure 6-12a and Figure 6-12b.

A logic tree consists of a series of nodes or levels representing the sequence of assessments that must be made to perform the analysis. The order of these nodes reflects a progression from general or global assessments of alternative models, to the specific assessment of individual model parameters. In a logic tree, all assessments are made conditional on the path leading to a particular node. As a simple example, the first node of the tree may address assessing the relative credibility of two alternative conceptual models, Model A or Model B. The second level of the tree would then address the assessment of the model parameters. On the Model A branch from the first node, the assessment at the second level node would address only the parameters for Model A under the assumption that Model A applies to the problem. On the Model B branch, the assessment at the second level node would address only the parameters for Model B under the assumption that Model B applies. The logic tree methodology allows for alternative models, hypotheses, and parameter values to be weighted and incorporated into the analysis in a logical and transparent way. Thus, it provides a convenient approach for breaking a large, complex assessment into a sequence of smaller, simpler components that can be more easily addressed. 


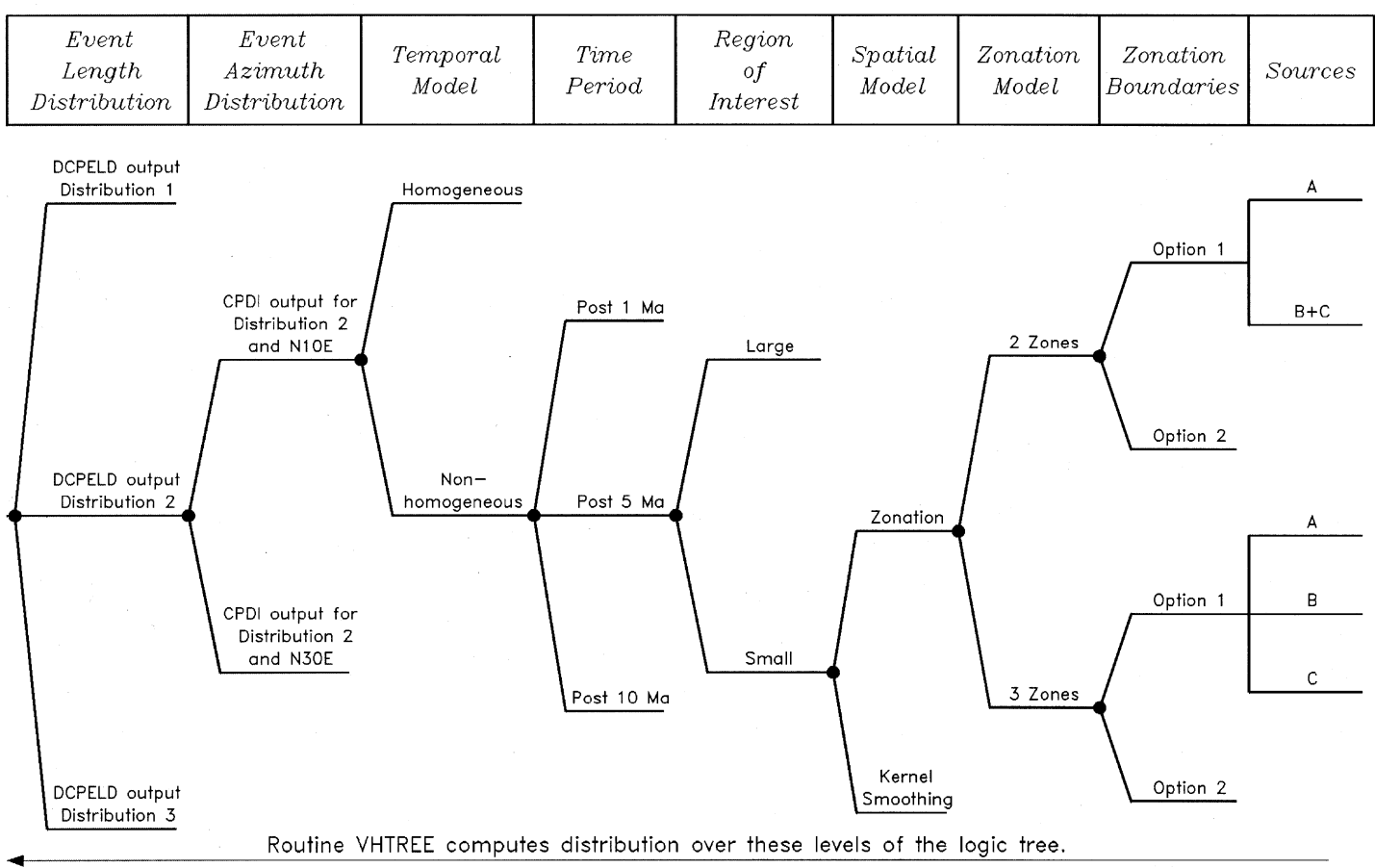

Source: Modified from CRWMS M\&O 1996 [DIRS 100116].

Figure 6-12a. Logic Tree Structure Used to Characterize Uncertainty in Volcanic Hazard

\begin{tabular}{|c|c|c|c|c|c|c|c|c|c|c|c|c|c|c|c|c|}
\hline Source & $\begin{array}{l}\text { Age } \\
\text { Data }\end{array}$ & $\begin{array}{c}\text { Zone } \\
\text { Boundary } \\
\text { Trans. }\end{array}$ & $h$ & $\begin{array}{l}\text { Source } \\
\text { Rate } \\
\text { Basis }\end{array}$ & $\begin{array}{l}\text { Source } \\
\text { Rate } \\
\text { Factor }\end{array}$ & $\begin{array}{c}L W \\
\text { Counts }\end{array}$ & $\begin{array}{l}\text { NWCF } \\
\text { Counts }\end{array}$ & $\begin{array}{c}\text { SECF } \\
\text { Counts }\end{array}$ & $\begin{array}{c}A V \\
\text { Counts }\end{array}$ & $\begin{array}{c}S B \\
\text { Counts }\end{array}$ & $\begin{array}{c}T M \\
\text { Counts }\end{array}$ & $\begin{array}{c}B M \\
\text { Counts }\end{array}$ & $\begin{array}{c}\text { Field } \\
\text { Parameters }\end{array}$ & $\begin{array}{l}\text { Other } \\
\text { Counts }\end{array}$ & $\begin{array}{l}\text { Hidden } \\
\text { Event } \\
\text { Factor }\end{array}$ & Rate \\
\hline
\end{tabular}

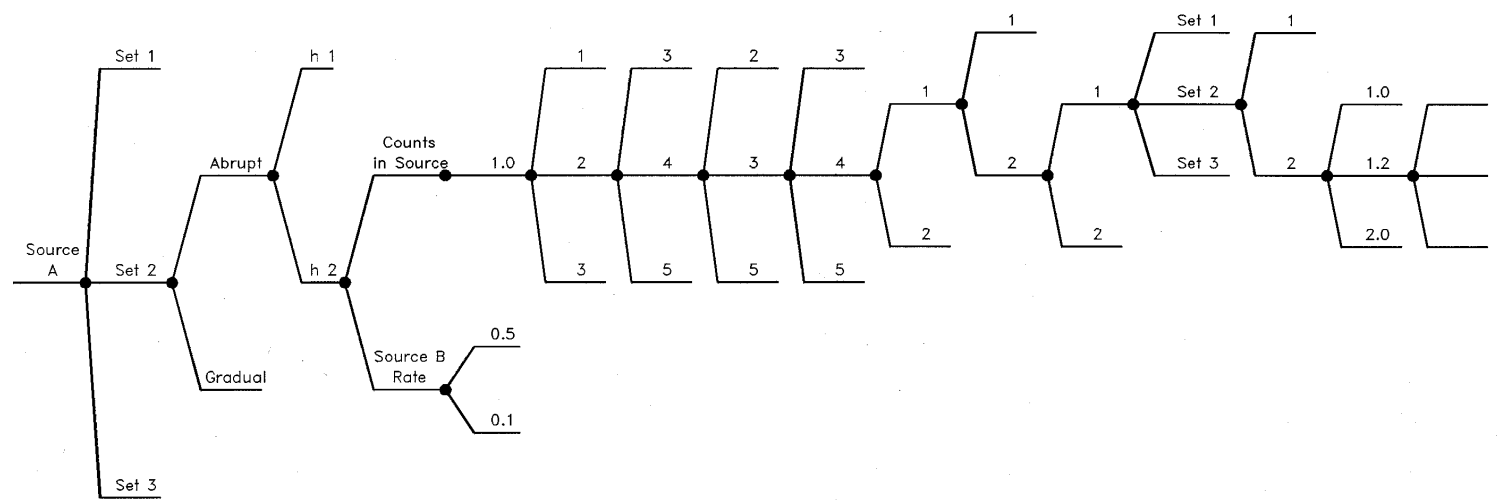

Routine VHTREE computes distribution over

Routines UZVH, UZVPVH, FKVH, FKVPVH, ZBCKVH, PFGVH, and FPFGVH these levels of the logic tree.

Source: Modified from CRWMS M\&O 1996 [DIRS 100116].

NOTE: These sub-trees are attached to the overall logic tree shown on Figure 6-12a.

Figure 6-12b. Logic Tree Structure for Sub-trees Addressing Uncertainty in Volcanic Hazard from Specific Sources 
At each node, a set of branches is used to define discrete alternatives for alternative credible models or parameter values that characterize the uncertainty in the assessment. The alternative branches are defined to be a mutually exclusive and collectively exhaustive set of alternatives. The weights are assigned to each branch to represent the relative likelihood or degree of belief that the branch represents the correct value or state of the input parameter. The weights on the branches at each node are treated as conditional probabilities, with the branch weights summing to unity at each node.

For assessments such as the PVHA, the weights depend strongly upon expert judgment (subjective probabilities) because the available data are too limited to allow for objective statistical analysis and because scientific judgment is needed to weigh alternative scientific interpretations of the available data. The logic tree approach simplifies these subjective assessments because the uncertainty in a single parameter is considered individually and all other parameters leading up to that parameter assessment are assumed to be known with certainty. Thus, the nodes of the logic tree are sequenced to provide for the conditional aspects or dependencies among the parameters and to provide a logical progression of assumptions from the general to the specific in defining the input parameters for an evaluation.

Figure 6-12a and Figure 6-12b show the general logic tree structure used to represent the scientific uncertainties in the PVHA computation. The logic tree is structured to move from the assessment of the general framework on the left (Figure 6-12a) to specific assessments of individual volcanic zones and volcanic centers on the right (Figure 6-12b). The specific definition of volcanic source zone or the estimate of the number of events that may have occurred at a volcanic center are often dependent upon more general assessments of the appropriate time period or region of interest. Thus, the dependent assessments are placed to the right, and the independent assessments are placed to the left.

The first two nodes of the logic tree address specification of alternative distributions for the length and orientation of dikes associated with the events. These parameters are used to compute the conditional probability of intersection. The assessments of these two distributions are placed first in the logic tree because they apply to all events that may occur in the region and are not dependent on the spatial or temporal models used to model volcanic event occurrence.

The remaining levels of the logic tree shown on Figure 6-12a address the alternative spatial and temporal models used to characterize the occurrence of volcanic events in the Yucca Mountain region. These assessments include various time periods representative of the current rate of volcanic events, alternative temporal models, alternative regions over which the hazard is evaluated, and alternative spatial models.

At this point, the logic tree is expanded into sub-trees, one for each of the identified volcanic sources. The vertical bar without a dot denotes additive hazard from multiple sources, (e.g., a local source zone and a background source). To the right of this point of the logic tree each source is considered to be acting independently, and the distribution in the total computed hazard is obtained by convolving the independent distributions obtained for each source. 
The logic tree structure for each volcanic source sub-tree is shown on Figure 6-12b. These logic trees address the parameters for the various spatial and temporal models for the individual volcanic sources and the number of volcanic events that have occurred at each of the major volcanic centers. The final node addresses the statistical uncertainty in estimating the volcanic rate parameter for the given temporal model and data set. This statistical uncertainty includes the uncertainty in the homogenous or non-homogeneous Poisson rates and the uncertainty in the volume predictable rate. Detailed descriptions of the PVHA volcanic hazard model are presented in Probabilistic Volcanic Hazard Analysis for Yucca Mountain, Nevada (CRWMS M\&O 1996 [DIRS 100116], Section 3 and Appendix E).

Each pathway through the composite logic tree (Figure 6-12a and Figure 6-12b) represents a complete interpretation of the volcanic hazard at the site for which a frequency of intersection is computed. Each pathway is associated with a probability equal to the product of the conditional probabilities of all the branches along the way. The result of computing the hazard for all pathways is a discrete distribution for frequency of intersection, representing the uncertainty in the volcanic hazard at a site.

\subsubsection{Conditional Distribution for Length and Azimuth of an Intersecting Dike}

The PVHA analysis did not make any assessment of the consequences of an intersection of the repository footprint by a dike. Consequently, a potential dike that extended all the way through the proposed repository, such as Dike 2 on Figure 6-8, has the same contribution to the frequency of intersection as a shorter dike that only extends part way into the proposed repository, such as Dike 4 on Figure 6-8. However, an assessment of consequences requires information on the length and orientation of the intersecting dikes within the proposed repository. This information is obtained by breaking down (disaggregating) the intersection frequency into relative frequencies for discrete increments of dike intersection length and azimuth.

Referring to Figure 6-9, the pictured dike system has a specific azimuth of $\phi_{n}$. and a length of intersection within the repository footprint of $L_{m}^{I}$. A series of bins with length increments of 50 meters and azimuth increments of $5^{\circ}$ were defined. This discretization is sufficiently fine to provide an accurate picture of the distribution of lengths and azimuths of intersecting dikes. Then, when a volcanic event produces an intersection in the hazard calculation, the resulting length and azimuth within the repository footprint are computed and the event is assigned to the appropriate bin. At the end of the calculation, the value in each bin represents the frequency of intersections that produce the specific values of length and azimuth represented by the bin parameters. The sum of the numbers in all of the length-azimuth bins equals the frequency of intersection. The values in each bin divided by the frequency of intersection provide a conditional distribution for length and azimuth, given an intersection. The only parameters that affect the calculation of the conditional distributions for dike intersection length and azimuth are the dike length, dike location on the volcanic event, and dike azimuth distributions. Thus, this calculation is completely defined by the interpretations developed by the PVHA expert panel (CRWMS M\&O 1996 [DIRS 100116], Appendix E) and requires no additional assumptions. 


\subsubsection{Conditional Distribution for the Number of Eruptive Centers}

This section discusses the formulation for assessing the conditional distribution for the number of eruptive centers within the footprint of the proposed repository. The development is based on the concept that eruptive centers will occur at uncertain locations along the length of the dike system associated with a volcanic event. The length of intersection within the repository footprint, compared to the total length of the dike system, the number of eruptive centers per volcanic event, and the spatial distribution of eruptive centers along the length of the dike system provide the bases for assessing the likelihood that one or more eruptive centers will occur within the repository footprint. The total length of the dike system and the length of intersection within the proposed repository are computed as part of the formulation presented above in Sections 6.5.1.1 and 6.5.1.2, and are completely defined by the PVHA experts' interpretations without any additional assumptions. The number of eruptive centers per volcanic event and the spatial distribution of eruptive centers along the length of a dike were not defined as part of the PVHA expert elicitation. However, with the limited set of assumptions (Section 5), these can be derived from the experts' interpretations. There are alternative ways that these assumptions can be applied. In keeping with the concept of uncertainty characterization employed in the PVHA, these alternatives were used to develop alternative assessments of the conditional distribution for the number of eruptive centers within the repository footprint. These alternative assessments are then combined using relative weights assigned to each to produce a composite assessment.

Number of Eruptive Centers Associated with a Volcanic Event-The assumptions described in Section 5.1 and 5.2 provide the basis for using the mapped volcanoes in the YMR to derive assessments of the number of eruptive centers per volcanic event from the PVHA experts' interpretations. Two alternative approaches are used as described below.

The first approach uses the number of mapped volcanoes to derive empirical distributions for the number of eruptive centers per volcanic event independent of any assessment of the total length of the dike system associated with the volcanic event. In this approach, volcanic events can have from 1 to 5 eruptive centers, the range in number of individual volcanoes associated with a single volcanic event, as defined by the PVHA experts using the YMR data. For example, the observed five volcanoes in Crater Flat are assumed to correspond to five eruptive centers using the assumption described in Section 5.1. These eruptive centers may have been caused by 1 to 5 volcanic events, with each PVHA expert providing a probability distribution for the number of volcanic events. These assessments can be used to produce a distribution for the number of eruptive centers per volcanic event. If the Crater Flat volcanoes were produced by five individual volcanic events, then the data indicate one eruptive center per volcanic event. If, on the other hand, the five volcanoes (and their associated eruptive centers) were created by one volcanic event, then the data indicate five eruptive centers per volcanic event. Using each expert's assessments of volcanic event counts and the number of separate eruptive centers that have occurred in the Quaternary, distributions for the number of separate eruptive centers per volcanic event were developed. These distributions are developed in Appendix $\mathrm{C}$ and shown in Figure 6-13. 


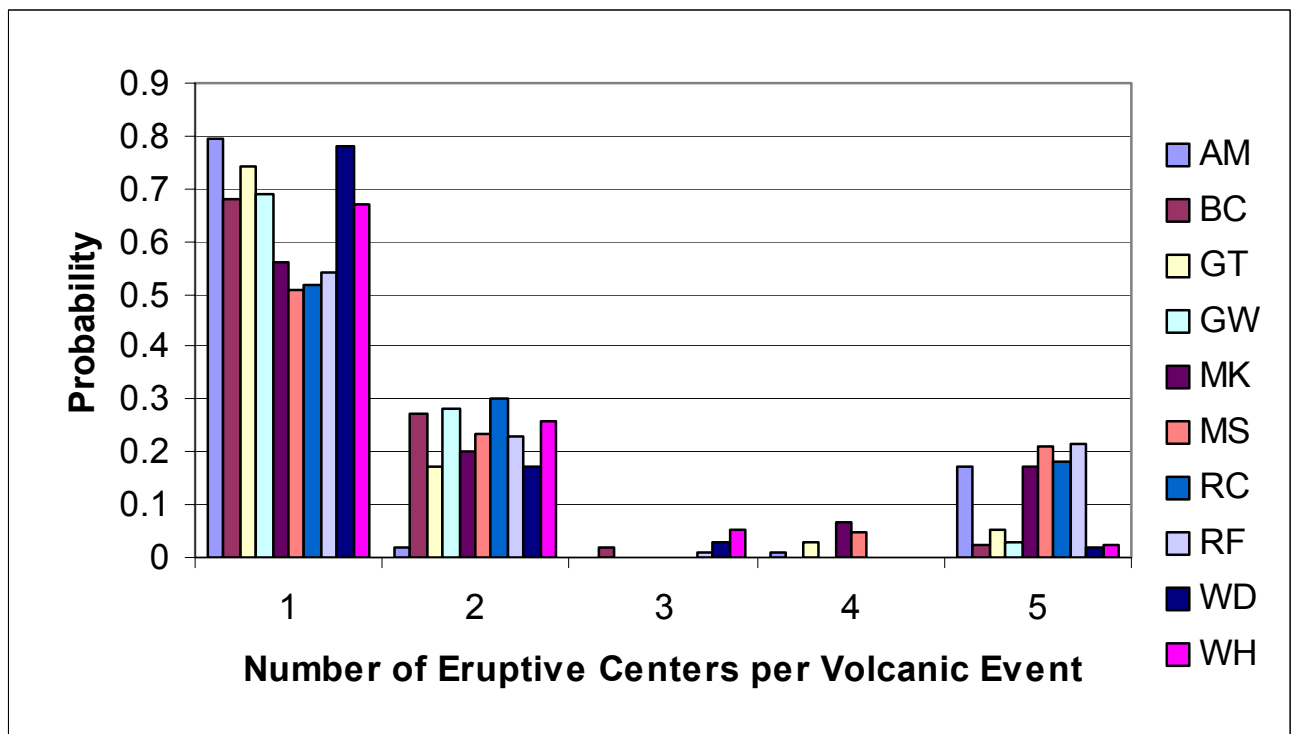

Output DTN: LA0009FP831811.001.

Source: from Appendix C, Figure C-1.

NOTE: The two-letter code refers to the initials of the 10 PVHA experts in Table 6-3.

Figure 6-13. Distributions for Number of Eruptive Centers per Volcanic Event Derived from the Probabilistic Volcanic Hazard Analysis Experts' Interpretations

The distributions shown on Figure 6-13 were developed without explicit consideration of the length of the dike system associated with the volcanic events. The PVHA experts' distributions for dike length were also assessed without consideration of the number of eruptive centers associated with a volcanic event. However, the calculation of the conditional probability of the number of eruptive centers with the repository footprint requires the conditional distribution of the number of eruptive centers given the dike length (Appendix A). The limiting conditions that define the relationship between two variables are complete independence and complete dependence. These two limiting conditions are used to define alternatives for the influence of dike length on the number of eruptive centers on a dike. Complete independence implies that the conditional distribution for number of eruptive centers is equal to the distributions shown on Figure 6-13, regardless of the total length of the dike system. Complete dependence implies that the number of eruptive centers varies directly with dike length (it is considered unrealistic to have a negative correlation). The correlation between dike length and number of eruptive centers per event was set to the maximum value by making the distributions for number of eruptive centers per volcanic event shown on Figure 6-13 rank correlated with the corresponding expert's dike length distribution.

The longest proposed single-event dike represented by the Quaternary volcanoes in the YMR is the 11.2-km spacing between Little Cones SW and Makani Cone in Crater Flat. However, many of the PVHA experts specified distributions for dike length with upper tails that greatly exceed this length. Thus, the distributions shown on Figure 6-13 may not be representative of conditions for very long dikes. To address this issue, an alternative approach for defining the number of eruptive centers was included. In the second approach, the number of eruptive centers 
is defined on the basis of an average density per kilometer of dike length or equivalently, by the average spacing between eruptive centers. For a given dike length, the number of eruptive centers is found by dividing the dike length by the average spacing (rounding to the nearest integer).

The same process used to derive the distribution for number of eruptive centers per volcanic event from the PVHA experts' assessments was used to evaluate the average spacing between eruptive centers. For example, if the five volcanoes in Crater Flat are considered to constitute a single volcanic event, then the 11.2-km distance between Little Cones SE and Makani Cone in Crater Flat divided by 4 (the number of intervals between eruptive centers) gives an average spacing of $2.8 \mathrm{~km}$. An alternative assessment might be that Crater Flat contains two volcanic events. One volcanic event may consist of Makani and Black Cones. These two cones are located $5.4 \mathrm{~km}$ apart. The other volcanic event would then consist of Red Cone and the two Little Cones. The distance between Red Cone and Little Cone SW is $3.2 \mathrm{~km}$, resulting in an average spacing for this volcanic event of $1.6 \mathrm{~km}$. The other Quaternary volcano cluster with multiple cones is Hidden Cone and Little Black Peak near Sleeping Butte, $2.5 \mathrm{~km}$ apart. If these are considered to be the result of a single volcanic event, the average spacing between eruptive centers for this event is $2.5 \mathrm{~km}$. Empirical distributions for the average spacing between eruptive centers in an individual volcanic event were developed as described in Appendix C, by considering all of the alternative volcanic event assessments made by each expert. These distributions are listed in Table 6-6. Note that the minimum value of the average spacing of eruptive centers in the empirical distributions is $0.46 \mathrm{~km}$ (the spacing between Little Cones NE and Little Cones SW). Using this average spacing and the maximum repository dimensions, the maximum possible number of eruptive centers within the repository footprint is 13 . Table 6-7 lists the mean or expected value of the distributions given in Table 6-6 for each of the PVHA experts to provide a basis for comparison.

In this second approach the total number of eruptive centers is directly correlated with the total length of the dike system.

Table 6-6. Empirical Distribution for Average Spacing between Eruptive Centers Calculation Results

\begin{tabular}{|l|l|}
\hline \multicolumn{1}{|c|}{ PVHA Expert } & \multicolumn{1}{|c|}{ Empirical Distribution for Average Spacing between Eruptive Centers (km) } \\
\hline Alex McBirney (AM) & $0.46(0.0272), 2.01(0.0492), 2.45(0.0253), 2.80(0.8859), 2.88(0.0124)$ \\
\hline Bruce Crowe (BC) & $0.46(0.4031), 1.62(0.0489), 2.45(0.1874), 2.80(0.0914), 2.88(0.2203), 5.35(0.0489)$ \\
\hline George Thompson (GT) & $0.46(0.4720), 2.01(0.1279), 2.45(0.1839), 2.80(0.1705), 2.88(0.0457)$ \\
\hline George Walker (GW) & $0.46(0.5916), 2.45(0.1767), 2.80(0.0800), 2.88(0.1517)$ \\
\hline Mel Kuntz (MK) & $0.46(0.0550), 2.01(0.2100), 2.45(0.2950), 2.80(0.4200), 2.88(0.0200)$ \\
\hline Michael Sheridan (MS) & $0.46(0.0388), 2.01(0.1330), 2.45(0.3238), 2.80(0.4656), 2.88(0.0388)$ \\
\hline Richard Carlson (RC) & $0.46(0.1186), 2.45(0.3608), 2.80(0.4020), 2.88(0.1186)$ \\
\hline Richard Fisher (RF) & $0.46(0.0842), 1.62(0.0192), 2.45(0.3383), 2.80(0.5199), 2.88(0.0192), 5.35(0.0192)$ \\
\hline Wendell Duffield (WD) & $0.46(0.6445), 2.45(0.0322), 2.80(0.0833), 2.88(0.1560), 4.09(0.0840)$ \\
\hline William Hackett (WH) & $0.46(0.4078), 2.45(0.1844), 2.80(0.0851), 2.88(0.1844), 4.09(0.1383)$ \\
\hline
\end{tabular}

OUTPUT DTN: LA0009FP831811.004.

Source: from Appendix C, Table C-13 of this document.

NOTE: The values in ( ) are the empirical probability for the preceding value of average spacing. 
Table 6-7. Expected Value for Average Eruptive Center Spacing

\begin{tabular}{|l|c|}
\hline \multicolumn{1}{|c|}{ PVHA Expert } & $\begin{array}{c}\text { Expected Value for Average Spacing } \\
\text { Between Eruptive Centers } \mathbf{( k m )}\end{array}$ \\
\hline Alex McBirney (AM) & 2.7 \\
\hline Bruce Crowe (BC) & 1.9 \\
\hline George Thompson (GT) & 1.5 \\
\hline George Walker (GW) & 1.4 \\
\hline Mel Kuntz (MK) & 2.4 \\
\hline Michael Sheridan (MS) & 2.5 \\
\hline Richard Carlson (RC) & 2.4 \\
\hline Richard Fisher (RF) & 2.5 \\
\hline Wendell Duffield (WD) & 1.4 \\
\hline William Hackett (WH) & 2.0 \\
\hline
\end{tabular}

Output DTN: LA0009FP831811.001.

Source: from Appendix C, Table C-12.

Spatial Distribution of Eruptive Centers Along a Dike System-The assumption described in Section 5.3 provides the basis for specification of the spatial distribution of eruptive centers along the length of the dike system. The minimum information probability distribution for the random location of a point on a line is the uniform distribution between the limits of the line length. The assumption listed in Section 5.3 applies the uniform distribution to eruptive center location. Two alternative applications of the uniform distribution were used to capture the range of possible behaviors when multiple eruptive centers occur along the length of the dike system for a single volcanic event, as illustrated in Figure 6-14.

The first approach specifies the location of each eruptive center independently of the others and is designated the independent, uniformly distributed (IUD) approach. The probability that an individual eruptive center will occur within the repository is equal to the length of intersecting dike within the proposed repository divided by the total length of the dike system. Over many volcanic events, this approach on average will produce eruptive centers spaced out over the total length of the volcanic events. However, for an individual event, a range of behaviors may occur. Part (a) of Figure 6-14 shows 20 simulations using the IUD approach. Some of the simulations produce relatively uniform spaced eruptive centers and some produce highly clustered eruptive centers.

Dense clustering of multiple eruptive centers can be prevented by imposing a minimum spacing between the eruptive centers. Taking this approach to the limit would result in uniform spacing of eruptive centers along the length of the dike. Part (b) of Figure 6-14 shows 20 simulations using an approach in which the length of the dike is divided into equal length segments, one segment for each eruptive center. Applying the assumption described in Section 5.3, each eruptive center is randomly located within its segment following a uniform distribution. This approach, designated the uniformly spaced, randomly distributed (USRD) approach, produces a broader spread between the eruptive centers in each simulation compared with the IUD approach, while still allowing for clustering of two eruptive centers along the length of the dike. Some clustering is expected to occur on occasion, given the close spacing between Little Cones SW and Little Cones NE. The probability that the eruptive center associated with each 
dike-length segment will occur within the repository footprint now becomes the length of that segment within the repository divided by the length of that segment.

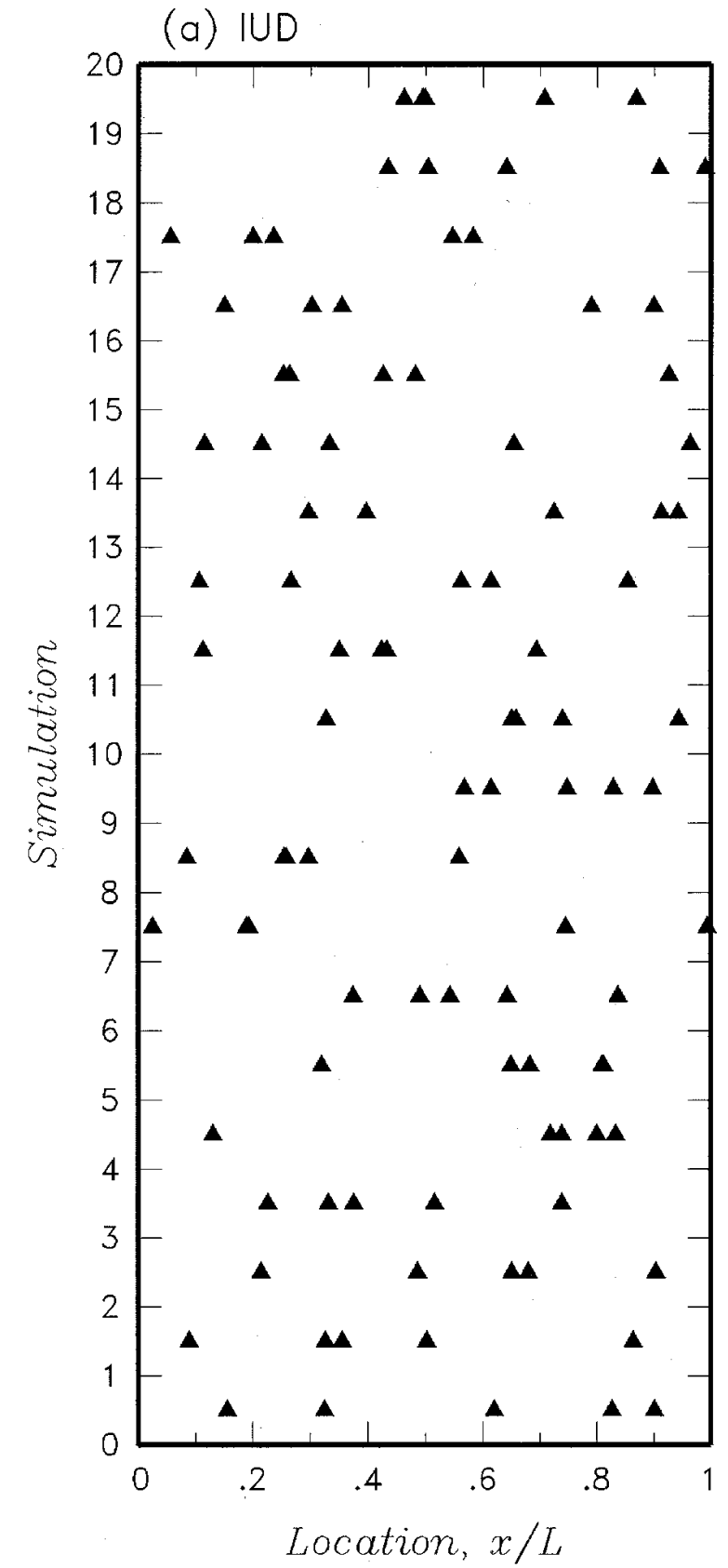

(b) USRD

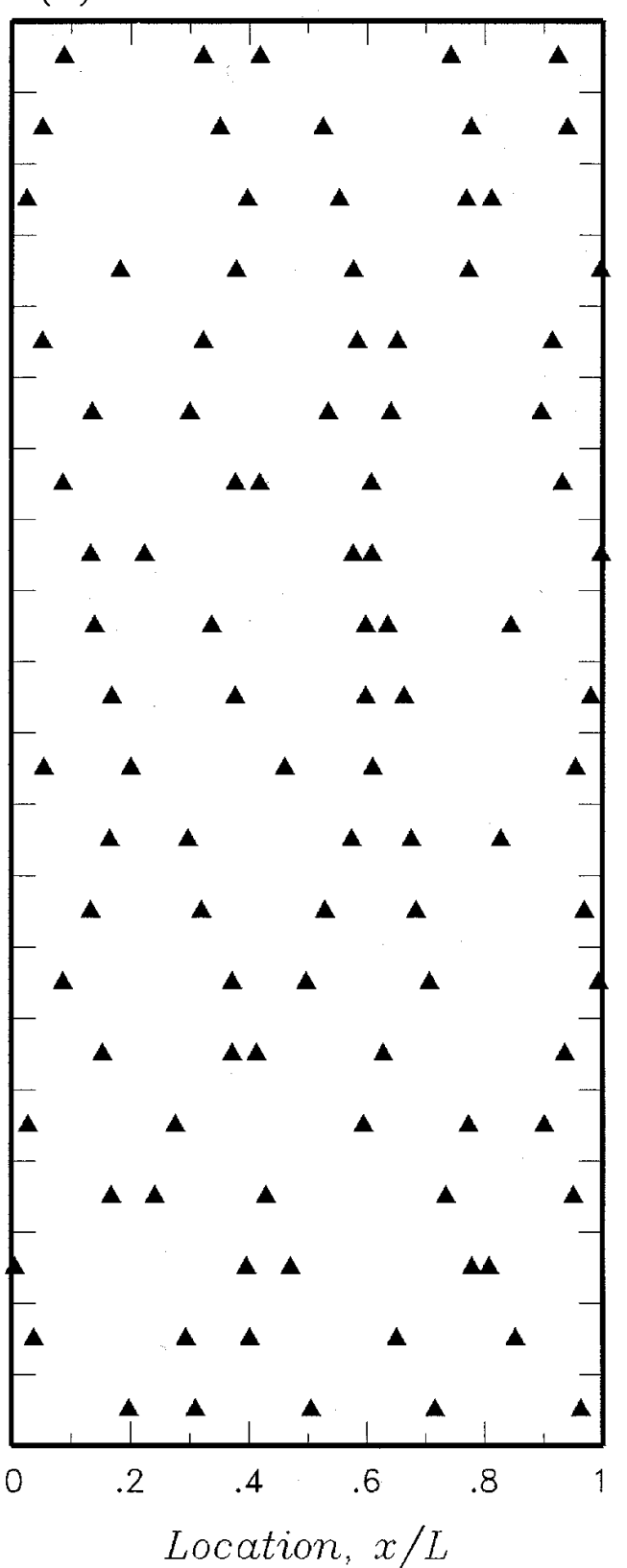

For Information Only

NOTE: Each row of triangles represents a separate simulation of the locations of five eruptive centers along the length of a dike system. The solid triangles show the locations of the individual eruptive centers for each simulation.

Figure 6-14. Example Simulations of the Distribution of Eruptive Centers along the Length of a Dike for: (a) the Independent, Uniformly Distributed (IUD) Spatial Distribution and (b) the Uniformly Spaced, Randomly Distributed (USRD) Spatial Distribution 
Figure 6-15a and Figure 6-15b compare the probabilities of eruptive centers occurring within the repository footprint as a function of dike length using these two approaches for the spatial distribution of eruptive centers. In Figure 6-15a, the length of intersection within the repository is held fixed at $1 \mathrm{~km}$ and the number of eruptive centers associated with the volcanic event is held fixed at 2 . The three plots grouped on the left show the probability of 0,1 , or 2 eruptive centers occurring within the repository footprint as a function of the total length of the dike system, and the single plot on the right shows the probability of at least one eruptive center within the repository. The parameter $r^{E C}$ indicates the number of eruptive centers within the repository. For a total length $L$ of $1 \mathrm{~km}$, the entire dike lies within the repository (the length of intersection is fixed at 1). Therefore, the probability for $r^{E C}=3$ is 1.0 and the probability for $r^{E C}=1$ or $r^{E C}=0$ is zero (no portion of the dike lies outside of the repository). As length $L$ increases while holding the length of intersection fixed at 1, some portion of the dike now lies outside of the repository. For the $I U D$ spatial distribution there is now a finite probability that both eruptive centers will lie outside of the repository $\left(r^{E C}=0\right)$. The probability increases continuously with increasing length $L$. For the USRD spatial distribution, over half of the dike lies within the repository until the total length $L$ reaches $2 \mathrm{~km}$. Thus, the probability for $r^{E C}=0$ remains at zero until $L$ reaches $2 \mathrm{~km}$. At that point, the probability $r^{E C}=1$ becomes 1.0 for the USRD approach because half of the dike, and thus one complete dike segment, lies within the repository. For $L$ greater than 2, the probability $r^{E C}=2$ becomes zero for the USRD approach in this example because it was computed assuming that one end of the dike system was penetrating the repository footprint. If the dike system were straddling the repository, then the probability the $r^{E C}=2$ would be greater than 0 .
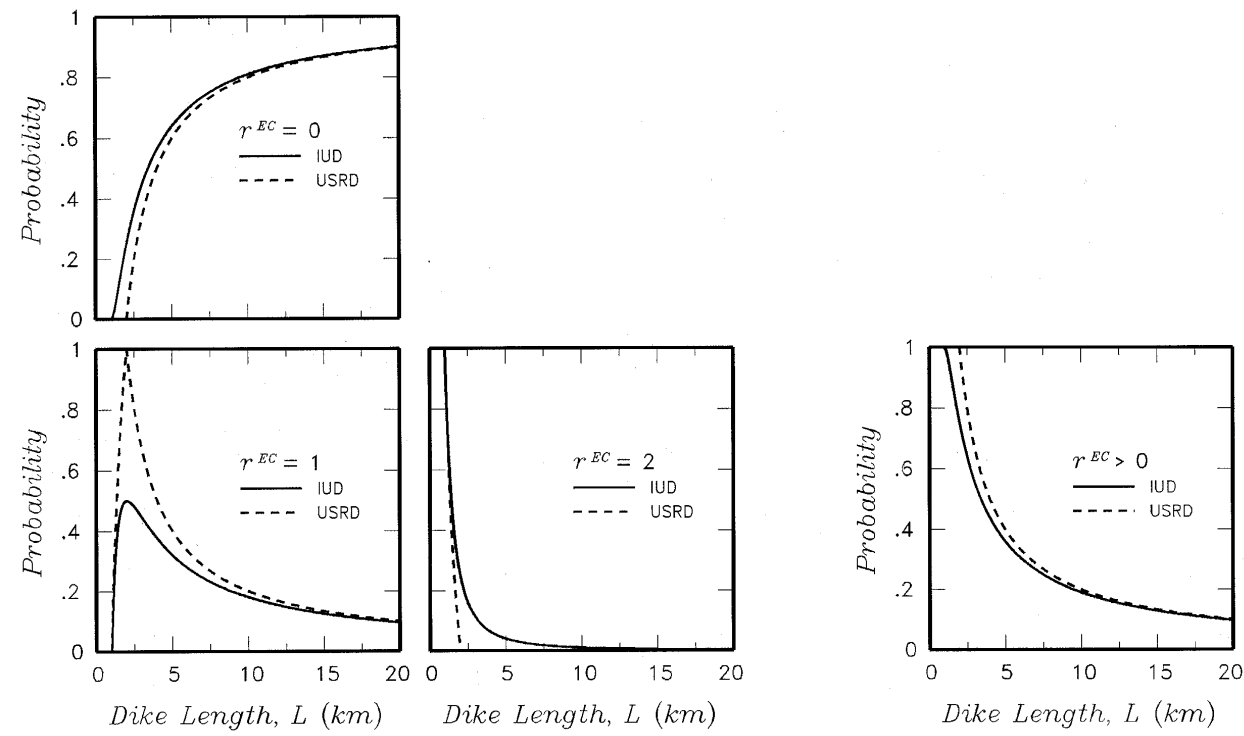

For Information Only

NOTE: Results are shown for the independent, uniformly distributed (IUD) and the uniformly spaced, randomly distributed (USRD) spatial distributions.

Figure 6-15a. Probability for the Number of Eruptive Centers Within the Repository Footprint, $\mathrm{r}^{\mathrm{EC}}$, as a Function of Dike Length, L, for the Length of Intersection Equal to $1 \mathrm{~km}$ and the Number of Eruptive Centers Associated with the Volcanic Event Equal to 2 

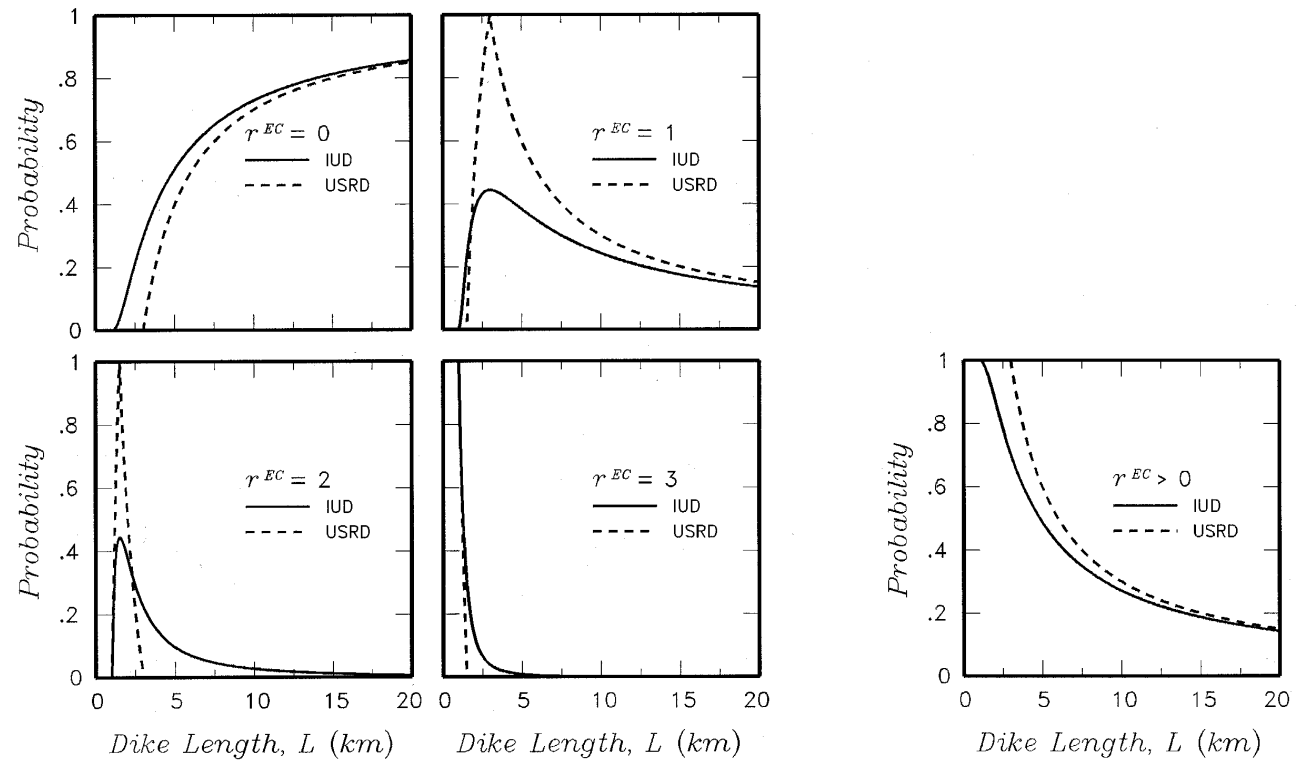

For Information Only

NOTE: Results are shown for the independent, uniformly distributed (IUD) and the uniformly spaced, randomly distributed (USRD) spatial distributions.

Figure 6-15b. Probability for the Number of Eruptive Centers Within the Repository Footprint, $\mathrm{r}^{\mathrm{EC}}$, as a Function of Dike Length, L, for the Length of Intersection Equal to $1 \mathrm{~km}$ and the Number of Eruptive Centers Associated with the Volcanic Event Equal to 3

Figure 6-15b repeats this example calculation with the total number of eruptive centers associated with the volcanic event increased to 3. The behavior is similar to that shown on Figure 6-15a. For all total lengths, the USRD spatial distribution approach produces a higher probability that at least one eruptive center will occur within the repository footprint $\left(r^{E C}\right.$ is greater than 0). Except for short dike lengths, use of the IUD spatial distribution produces a higher probability of multiple eruptive centers within the repository footprint for a fixed length of intersection.

The USRD spatial density approach is also consistent with the concept of determining the number of eruptive centers associated with a volcanic event on the basis of an average spacing between eruptive centers and total dike system length. In this approach the density of eruptive centers is fixed at a specified average spacing and the number of eruptive centers is determined by dividing this average spacing into the total length of the dike system, $L$. The total length of the dike system is divided into segments with lengths equal to the average spacing between eruptive centers. The location of the eruptive center within each segment is then specified by a uniform distribution following the assumption discussed in Section 5.3. This modified form of the USRD spatial distribution is designated the USRD-FD approach for uniformly spaced-randomly distributed with fixed density.

Figure 6-16 shows an example calculation of the probability of one or more eruptive centers occurring within the repository footprint for the USRD-FD approach. The example is the same one as that shown in Figure 6-15a. For short dike lengths, the USRD-FD approach results in a lower probability for one or more centers within the proposed repository than the other two 
approaches. However, as the dike length increases, the USRD-FD approach reaches a nearly constant probability of 0.4 for intersection by one eruptive center ( 0.4 equals the intersection length of $1 \mathrm{~km}$ divided by the fixed average spacing of $2.5 \mathrm{~km}$ ).
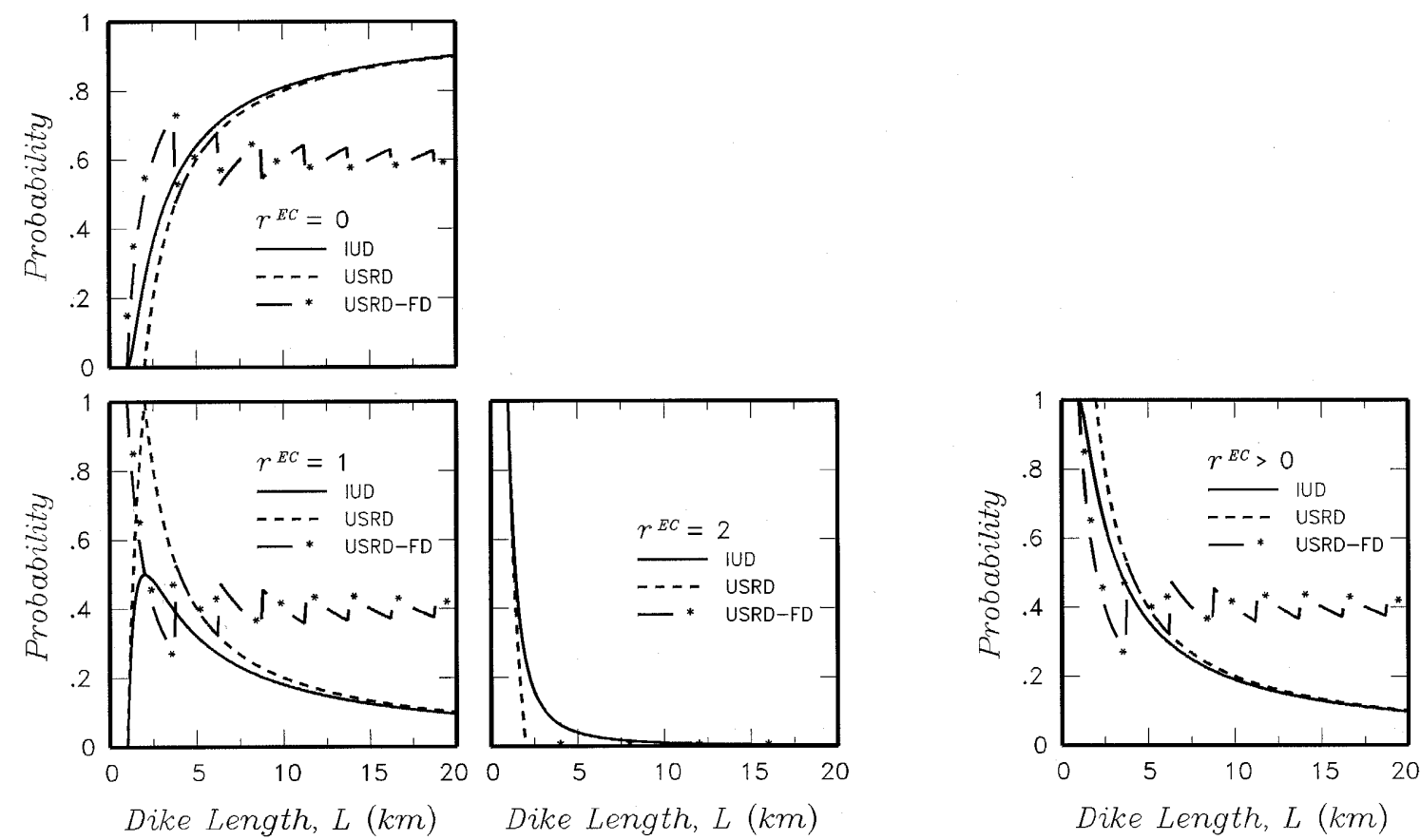

For Information Only

NOTE: Results are shown for the independent, uniformly distributed (IUD), the uniformly spaced, randomly distributed (USRD), and the uniformly spaced, randomly distributed with fixed density (USRD-FD) spatial distributions. Total number of eruptive centers is fixed at 2 for the IUD and USRD approaches and is determined from the total dike length and an average spacing of $2.5 \mathrm{~km}$ for the USRD-FD approach. As in Figure $6-15 a$, the length of intersection is fixed at $1 \mathrm{~km}$.

Figure 6-16. Example Probabilities for the Number of Eruptive Centers within the Repository Footprint, $\mathrm{r}^{\mathrm{EC}}$, Computed with the Total Number of Eruptive Centers Defined by an Average Spacing of $2.5 \mathrm{~km}$ between Eruptive Centers Compared to Probabilities Computed Using a Fixed Total Number of 2 Eruptive Centers

Computation of the Conditional Distribution for the Number of Eruptive Centers-The process for computing the conditional distribution for number of eruptive centers can now be described. Referring back to Figure 6-9, the pictured dike system has a total length $L$ and a length of intersection within the repository of $L_{m}^{I}$. Given the total number of eruptive centers associated with the volcanic event and one of the alternative approaches for the spatial distribution of eruptive centers along the length of the dike system, the probability of $0,1,2$, etc. eruptive centers within the repository is computed. These probabilities are multiplied by the frequency of volcanic events at point $(x, y)$ that produce intersection lengths of $L_{m}^{I}$ for total dike system lengths $L$ defined in Section 6.5.1.2. The process is repeated for the full distribution of possible dike lengths and then over the spatial grid for possible volcanic event locations. The sum of event frequencies that produce $0,1,2$, etc. eruptive centers within the repository footprint is then divided by the total frequency of intersection (Section 6.5.1.1) to produce the conditional distribution for number of eruptive centers within the repository. 
The approaches developed above for specifying the total number of eruptive centers associated with a volcanic event and their spatial distribution along the length of the dike system lead to five alternative assessments for the conditional probability distribution for number of eruptive centers within the repository footprint. The five approaches are summarized below:

1. The independent, uniformly distributed, uncorrelated (IUD-UC) approach. The distribution for the total number of eruptive centers per volcanic event is derived from the PVHA experts' interpretations (Figure 6-13). These distributions are uncorrelated with the distributions for dike length. The location for each eruptive center is defined by a uniform distribution over the total length of the dike, and if multiple eruptive centers occur in a volcanic event, the distributions for their locations are independent.

2. The independent, uniformly distributed, correlated (IUD-C) approach. The distribution for the total number of eruptive centers per volcanic event is derived from the PVHA experts' interpretations (Figure 6-13). These distributions are completely correlated with the distributions for dike length. The location for each eruptive center is defined by a uniform distribution over the total length of the dike and if multiple eruptive centers occur in a volcanic event, the distributions for their locations are independent.

3. The uniformly spaced, randomly distributed, uncorrelated (USRD-UC) approach. The distribution for the total number of eruptive centers per volcanic event is derived from the PVHA experts' interpretations (Figure 6-13). These distributions are uncorrelated with the distributions for dike length. The total length of the dike is divided into equal segments, one for each eruptive center. Within each segment, the location of the eruptive center is defined by a uniform distribution over the length of the segment.

4. The uniformly spaced, randomly distributed, correlated (USRD-C) approach. The distribution for the total number of eruptive centers per volcanic event is derived from the PVHA experts' interpretations (Figure 6-13). These distributions are completely correlated with the distributions for dike length. The total length of the dike is divided into equal segments, one for each eruptive center. Within each segment, the location of the eruptive center is defined by a uniform distribution over the length of the segment.

5. The uniformly spaced, randomly distributed, fixed density (USRD-FD) approach. The total number of eruptive centers per volcanic event is determined by dividing the total length of the dike by an average distance between eruptive centers derived from the PVHA experts' interpretations (Table 6-6). The total length of the dike is divided into equal segments, one for each eruptive center. Within each segment, the location of the eruptive center is defined by a uniform distribution over the length of the segment.

Application of the results of this report in assessing the impact of disruptive events requires a rule for combining the results obtained from these five approaches. In the overall framework of the PVHA, this is accomplished by assigning weights to each model. These weights are derived by separately examining the three issues addressed by the alternative approaches. 
The first issue is the overall approach for evaluating the number of eruptive centers per volcanic event. The two approaches are to define a distribution for the total number based on the observed Quaternary data, or to define the average spacing using the Quaternary data and compute the number for each dike length. These two approaches are considered to be equally credible. They both rely to an equal degree on the observed data and the PVHA experts' interpretations of these data to define the characteristics of volcanic events in the YMR. Thus, the two approaches are given equal weight.

The second issue is the appropriate spatial distribution for eruptive centers along the length of the dike or dike system. Two alternative approaches are used, one in which the location of each eruptive center is independent of the others (IUD), and one in which the eruptive centers are spaced out along the total length of the dike system (USRD). The simulations shown on Figure 6-14 indicate that the IUD spatial model often produces tight clustering of multiple eruptive centers. This is somewhat at odds with the limited observations for eruptive centers in the vicinity of Yucca Mountain. Therefore, the URSD model is strongly preferred over the IUD model by a ratio of $3: 1$, yielding weights of 0.75 for the USRD models and 0.25 for the IUD models. Note that this assessment applies to the cases where the number of eruptive centers is derived from the distributions shown on Figure 6-13. When the number of eruptive centers is derived from an average spacing, only the USRD model is applied because it is consistent with the basis for determining the number of eruptive centers.

The third issue addresses the correlation between the distributions for number of eruptive centers per volcanic event shown on Figure 6-13 and the distributions for the length of the dike associated with a volcanic event developed by the PVHA experts. Two alternatives are used: the two distributions are uncorrelated and the two distributions are fully correlated. It is likely that there is some degree of correlation because longer total dike lengths would provide more opportunity for the formation of vents and presumably result from volcanic events with larger volumes. Thus, the fully correlated model is slightly favored $(0.6)$ to the uncorrelated model (0.4). Again, this assessment applies only to the cases where the number of eruptive centers is derived from the distributions shown in Figure 6-13. Determining the number of eruptive centers for a volcanic event using the average spacing and the total length produces full correlation between length and number of eruptive centers.

Combining these three sets of weights yields the following relative weighting of the five approaches for computing the conditional distribution for number of eruptive centers within the repository footprint:

- The weight for the $I U D-U C$ approach is equal to 0.5 for the approach for number of centers, times 0.25 for the spatial approach, times 0.4 for uncorrelated number of eruptive centers and dike length distributions, yielding a weight of 0.05 .

- The weight for the IUD-C approach is equal to 0.5 for the approach for number of centers, times 0.25 for the spatial approach, times 0.6 for correlated number of eruptive centers and dike length distributions, yielding a weight of 0.075 . 
- The weight for the USRD-UC approach is equal to 0.5 for the approach for number of centers, times 0.75 for the spatial approach, times 0.4 for uncorrelated number of eruptive centers and dike length distributions, yielding a weight of 0.15 .

- The weight for the USRD-C approach is equal to 0.5 for the approach for number of centers, times 0.75 for the spatial approach, times 0.6 for uncorrelated number of eruptive centers and dike length distributions, yielding a weight of 0.225 .

- The weight for the USRD-FD approach is 0.5 for the approach, with only the USRD spatial approach applying because the correlation issue is not pertinent, yielding a weight of 0.5 .

These weights are used to combine the results for the five alternative approaches to number of eruptive centers to produce a composite result of the analyses.

Incorporation of Potential Effect of Repository Openings-The above approaches developed for assessing the spatial distribution of eruptive centers along the length of the dike or dikes associated with a volcanic event assume that the presence of the repository drifts has no impact on the likelihood of an eruptive conduit forming within the repository footprint. There exists some potential that the presence of the repository opening may induce formation of an eruptive center if intersection occurs. Therefore, two approaches are used to address the effect of the repository openings. The first approach considers the repository openings to have no effect and uses the weighted combination of the five approaches described above to develop the conditional distributions for $0,1,2,3$, etc. intersecting eruptive centers. The second approach considers that the repository openings will induce at least one eruptive center. For this approach the distribution for the number of intersecting eruptive centers is derived from the results of the first approach by setting the conditional probability of no intersecting eruptive centers to zero and renormalizing the probabilities for $1,2,3$, etc. intersecting eruptive centers to sum to unity. For example, if the first approach resulted in a conditional distribution for the number of intersecting eruptive centers of $\{0(0.4), 1(0.3), 2(0.2), 3(0.1)\}$, then the second approach would result in the distribution for the number of intersecting eruptive centers of $\{1(0.5), 2(0.333), 3(0.167)\}$. Because there has not been significant study of the issue and the PVHA experts were not elicited on this question, maximum uncertainty weights of 0.5 are applied to these two approaches for assessing the effect of the repository openings. As a result, the composite distribution for the number of eruptive centers intersecting the proposed repository in the above example would be $\{0(0.2), 1(0.4), 2(0.267), 3(0.133)\}$. 


\subsubsection{Description of Probabilistic Volcanic Hazard Calculation}

This section briefly describes the implementation of the formulation presented in Section 6.5.1. A complete description is presented in Appendix A.

\subsubsection{Computation of Frequency of Intersection of the Repository Footprint by a Dike}

The computational scheme used in Probabilistic Volcanic Hazard Analysis for Yucca Mountain, Nevada (CRWMS M\&O 1996 [DIRS 100116]) and repeated in this report consists of the steps shown on Figure 3-1. These steps are performed for each of the volcanic hazard models developed by the 10 PVHA experts.

Step 1: Discrete cumulative distributions for dike length are developed from the experts' assessments using software routines FITCD V1.0 (LANL 2000 [DIRS 148532]) or SFCD V1.0 (LANL 2000 [DIRS 148533]) (e.g., part (a) of Figure 6-10). These distributions are then convolved with the expert's event location on the dike distribution (e.g., part (b) of Figure 6-10) to produce distributions for volcanic event length (e.g., part (c) of Figure 6-10) using software routine DCPELD V1.0 (LANL 2000 [DIRS 148534]). This step develops the distribution for parameter $d$ shown on Figure 6-9.

Step 2: The conditional probability of intersection is computed for each set of parameters defined by a unique event length distribution from Step 1 and a unique dike azimuth distribution using software routine CPDI V1.0 (LANL 2000 [DIRS 148535]). The output from individual runs of software routine CPDI is stored for use in the next step of the calculation.

Step 3: The rate of intersection is computed for individual volcanic hazard source models using software routines specific to the type of source:

- Software routines UZVH V1.0 (LANL 2000 [DIRS 148536]) and UZVPVH V1.0 (LANL 2000 [DIRS 148537]) for source zones

- Software routines FKVH V1.0 (LANL 2000 [DIRS 148567]), FKVPVH V1.0 (LANL 2000 [DIRS 148538]), and ZBCKVH V1.0 (LANL 2000 [DIRS 148539]) for kernel density sources

- Software routines PFGVH V1.0 (LANL 2000 [DIRS 148542]) and FPFGVH V1.0 (LANL 2000 [DIRS 148543]) for 2-D Gaussian field sources.

The characterization of individual volcanic sources is defined by the alterative parameters indicated on the right hazard side of the volcanic source logic tree shown on Figure 6-12b. These parameters depend upon the alternative source definitions, temporal models, and time periods of interest. The software routines used to compute the hazard from an individual source contain a set of 12 nested DO loops to enumerate all of the alternative parameter sets (see Figure 6-12b). Given a set of parameters, the frequency of volcanic events is computed for a specific source using the formulation appropriate for the source type. This frequency is multiplied by the conditional probability of intersection, from the output of routine CPDI V1.0 and summed over all points within the source to obtain the frequency of intersection from volcanic events associated with the source. The software routines store the mean frequency of 
intersection and the distribution in the frequency of intersection in output files for use in the final step of the computation. Separate output files are created for all of the alternative sets of source model parameters and for the alternative parameters that describe the associated dikes.

Step 4: The results from Step 3 are combined over the distributions for both the source model parameters and the associated dikes (see Figure 6-12a and Figure 6-12b) to compute the full distribution for frequency of intersection specified by an individual PVHA expert's interpretations. The results for each expert are then combined with equal weights to obtain the composite distribution. These calculations are performed using software routine VHTREE V1.0 (LANL 2000 [DIRS 148544]). Complete enumeration of all of the alternative parameter sets is achieved by a series of nested DO loops. The mean value and various percentiles of the distribution for frequency of intersection of the repository footprint by a dike are computed from the discrete distribution for frequency of intersection defined by the alternative end branches of the volcanic hazard model logic trees.

The 2003 repository footprint used for the calculations in this report is shown on Figure 6-17a (BSC (2003 [DIRS 162289]), but this footprint has been superseded by a more recent design (BSC 2004 [DIRS 164519]). The calculations performed in the PVHA (CRWMS M\&O 1996 [DIRS 100116]) used the repository footprint shown in Figure 6-17b. The 2003 repository design (BSC 2003 [DIRS 162289]) calls for a longer and narrower emplacement area compared to the design used at the time of the PVHA (Figure 6-17b). Appendix B presents the coordinates of the drifts in the 2003 repository footprint and their transformation to UTM kilometers. The repository footprint polygon used for calculations in this report uses values obtained from Repository Design, Repository/PA IED Subsurface Facilities (BSC 2003 [DIRS 162289]) and modified to provide a clearance of approximately $55 \mathrm{~m}$ around the drift coordinates (see Figure 6-17a) to account for the effect of the size of eruptive centers in the calculations (see Appendix B). The final footprint polygon used for calculation information is contained in output DTN: LA0303BH831811.001. 


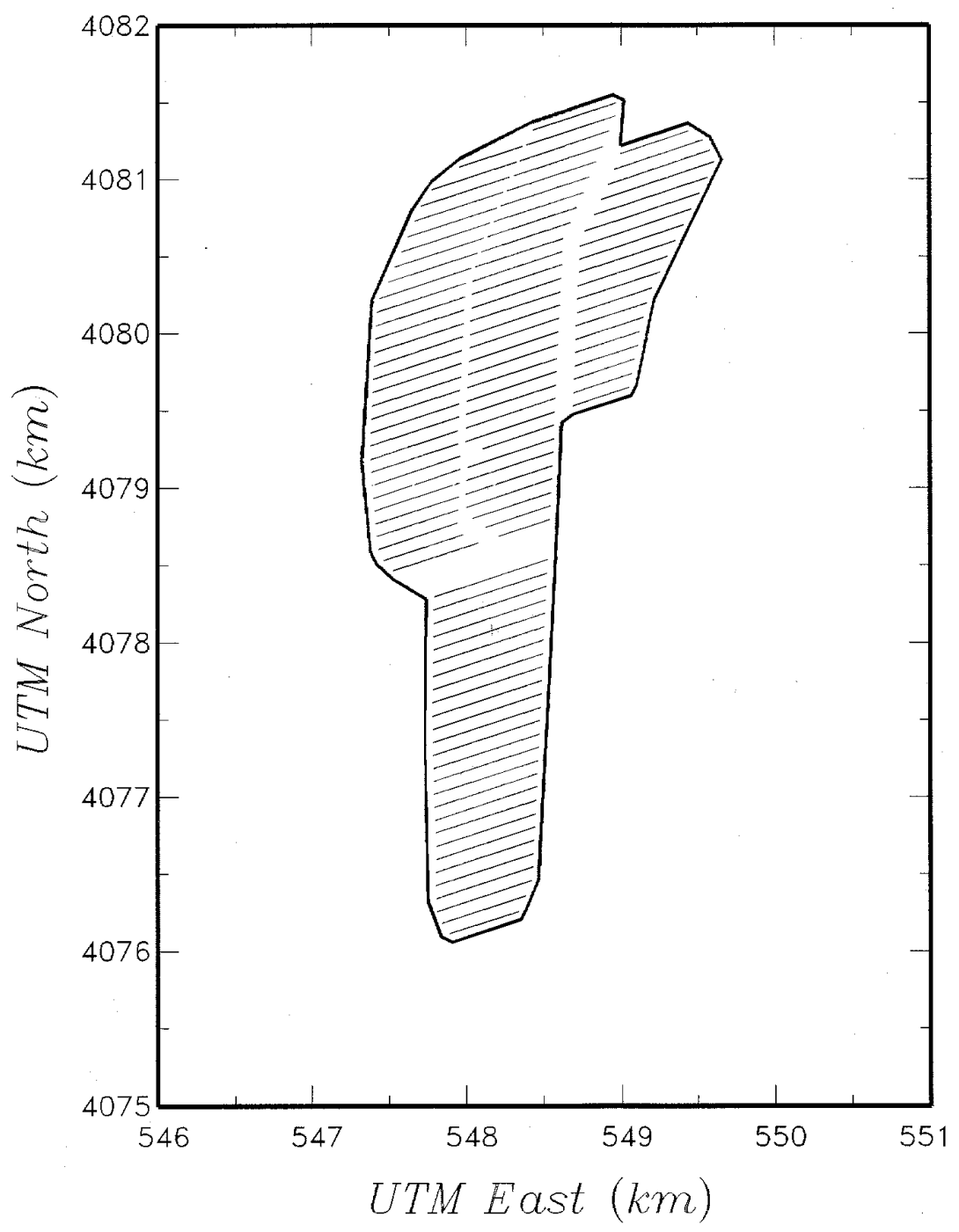

Output DTN: LA0303BY831811.001.

Figure 6-17a. Repository Emplacement Drifts and Footprint Polygon Encompassing the Emplacement Panels

The most recent proposed repository design differs from the design used for the calculations in this report by having one less emplacement drift at the north end of panel 3 (BSC 2004 [DIRS 164519]). This decreases the north-south extent of the footprint by approximately $100 \mathrm{~m}$ but has a negligible impact on the current calculations. For comparison, the difference in north-south dimension between the repository footprint used for the current calculation (BSC 2003 [DIRS 162289]) and the footprint used in the PVHA is approximately $1500 \mathrm{~m}$ (Figure 16b). This difference resulted in a difference in the calculated mean of the frequency of intersection of about $13 \%$. Based on this comparison, the difference in the mean frequency of intersection caused by the small change in the most recent proposed repository design (BSC 2004 [DIRS 164519] is expected to be less than 1\%, which is negligible given the overall range of uncertainty in the results. 


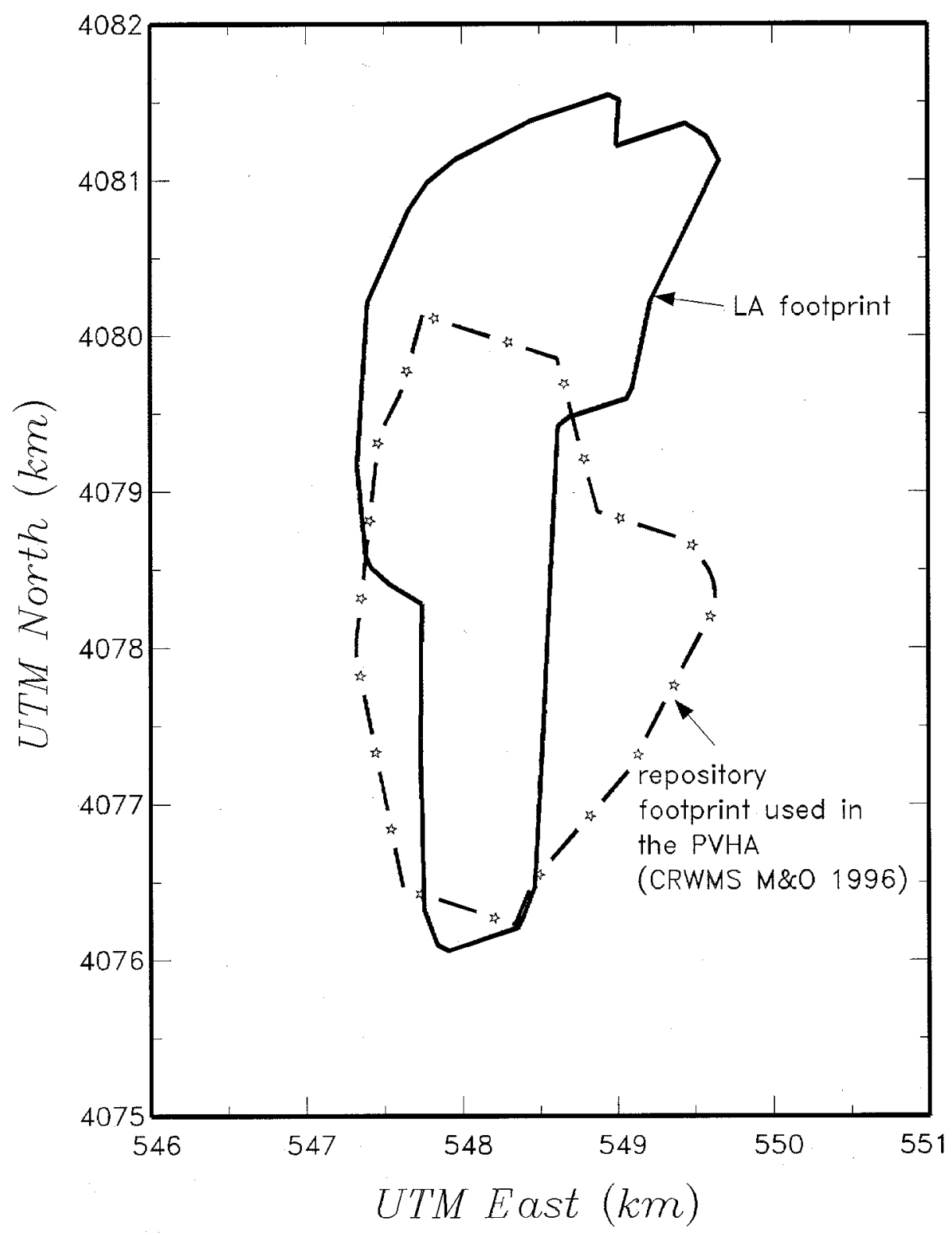

Output DTN: LA0303BY831811.001.

NOTE: PVHA reference in figure is CRWMS M\&O (1996 [DIRS 100116]).

Figure 6-17b. Location of 2003 Repository Footprint (BSC 2003 [DIRS 162289]) Compared to Repository Footprint Used in the Probabilistic Volcanic Hazard Analysis

\subsubsection{Computation of Distributions for Length, Azimuth, and Number of Eruptive Centers}

The computations performed in Probabilistic Volcanic Hazard Analysis for Yucca Mountain, Nevada (CRWMS M\&O 1996 [DIRS 100116]) were made for all possible sets of parameters (full enumeration of the logic tree branches) defined by the volcanic hazard characterization of each of the PVHA experts (CRWMS M\&O 1996 [DIRS 100116], Appendix E). However, the 
objective of this analysis is a disaggregation of the intersection frequency into intersection frequencies with specific values of intersecting dike length, dike azimuth, and number of eruptive centers. Repeating the calculation including this disaggregation would require exhaustive computation and storage of the spatial disaggregation of the hazard for all possible parameter sets. Therefore, a simulation approach was used to develop random sample parameter sets from the PVHA experts' logic trees and to speed up the computation process. As discussed subsequently in the results (Section 6.5.3), the mean and distribution for the frequency of intersection of the repository footprint by a dike computed by full enumeration and by simulation for each PVHA expert's interpretation and for the composite result generally agree within a few percent. The approach used to obtain the spatial disaggregation of the frequency of intersection consists of the following steps (see Figure 3-2).

Step 1: The conditional probability of intersection was taken directly from the computation for the frequency of intersection discussed above. The files containing the conditional probability of intersection for each set of parameters were created using routine CPDI V1.0 (LANL 2000 [DIRS 148535]) and using inputs processed through routines FITCD V1.0 (LANL 2000 [DIRS 148532]), SFCD V1.0 (LANL 2000 [DIRS 148533]), and DCPELD V1.0 (LANL 2000 [DIRS 148534]). This process is a repeat of steps 1 and 2 discussed in Section 6.5.2.1.

Step 2: The second step in the calculation involved computation of the spatial disaggregation of frequency of intersection hazard for the individual sources specified by the alternative source parameter sets and for the alternative dike parameters. For the reasons discussed at the beginning of this section, simulation is used to select random samples of the parameter subset, which is used to compute the frequency of intersection for an individual source type. The approach used to generate these parameter subsets is Latin hypercube sampling (McKay et al. 1979 [DIRS 127905], pp. 243-245). The software routines used to compute the frequency of intersection replace the 12 nested DO loops with simulation of 50 parameter sets using Latin hypercube sampling from the 12 independent and discrete parameter distributions representing the right hand side of the individual source logic tree shown on Figure 6-12b. The product of the Latin hypercube sampling is 50 equally likely outcomes from each expert's model for an individual volcanic source.

The simulation software routines are designated UZVHLH V1.0 (LANL 2000 [DIRS 148545), UZVPVHLH V1.0 (LANL 2000 [DIRS 148547]), FKVHLH V1.0 (LANL 2000 [DIRS 148546]), FKVPVHLH V1.0 (LANL 2000 [DIRS 148551]), ZBCKVHLH V1.0 (LANL 2000 [DIRS 148550]), PFGVHLH V1.0 (LANL 2000 [DIRS 148552]), and FPFGVHLH V1.0 (LANL 2000 [DIRS 148553]). They use the same input files used to compute the frequency of intersection by full enumeration (Step 3 in Section 6.5.2.1).

Step 3: The third step in the calculation is computation of the distribution for the spatial disaggregation of the hazard for each PVHA expert's interpretation. The full enumeration of the possible parameter sets is again replaced by simulation of 50 equally likely parameter sets using Latin hypercube sampling. The software routine VHTIELHS V1.0 (LANL 2000 [DIRS 148554]) is used to perform this calculation for the volcanic hazard model developed by each of the PVHA experts. The result of this calculation is the frequency of intersection at each point in the $0.5 \mathrm{~km} \times 0.5 \mathrm{~km}$ grid covering the Yucca Mountain region. Part (b) of Figure 6-11 shows a map of this result, averaged over all 10 of the PVHA experts' models. 
Step 4: The composite distribution for the frequency of intersection of the repository footprint by a dike is now represented by the 2,500 $\times 10$ simulation results for the 10 PVHA experts. Each expert's distribution was assigned equal weight in the PVHA aggregation process. Thus, the composite 25,000 simulations of annual frequency of intersection are all equally likely. The 25,000 simulations of annual frequency of intersection are ranked and the simulations that produce various percentiles of the distribution are identified (e.g., the 95th percentile is the simulation with rank $0.95 \times 25,000=23,750)$. Simulation results that are close to each percentile (within a rank of \pm 250 ) and that are from different experts are also identified to capture the range of expert interpretations. These simulations are identified using software routine CFRAC V1.0 (LANL 2000 [DIRS 148560]).

Step 5: Steps 1 through 4 provide the values of disaggregated frequency of intersection and the expected value for the spatial disaggregation of the frequency of the intersection for each of the possible dike geometry distributions (the first two levels of the logic tree shown on Figure 6-12a). The final step is the discretization of the conditional probability of intersection into increments of intersection length, intersection azimuth, and number of eruptive centers within the repository footprint for each volcanic event location. Software routine DILECDLH V1.0 (BSC 2000 [DIRS 168221]) is used to discretize the conditional probability of intersection into the designated bins for length and azimuth within the proposed repository. The inputs to program DILECDLH are: (1) the spatial disaggregation of the frequency of intersection; (2) the dike length and volcanic event location distributions for the corresponding parameter set; (3) a joint distribution for dike length and the number of eruptive centers on a dike, which is computed using software routines FITIDSR V1.0 (LANL 2000 [DIRS 148557], SFIDSR V1.0 (LANL 2000 [DIRS 148571]), and DLECD V1.0 (LANL 2000 [DIRS 148558]); and (4) the spatial distribution of eruptive centers along the dike.

As discussed in Section 6.5.1.3, five alternative approaches are used to compute the number and spatial distributions of eruptive centers along the length of the dike system associated with a volcanic event. All five of these approaches are used to obtain conditional distributions for the number of eruptive centers within the repository footprint given an intersection by a volcanic event. A weighted average of the results of these five approaches is computed using the weights developed in Section 6.5.1.3. As a final step, the potential effect of the repository opening is incorporated as described at the end of Section 6.5.1.3.

The calculations performed in Step 5 are carried out at three levels of the distribution for frequency of intersection: the mean frequency of intersection, the 5th percentile frequency of intersection, and the 95th percentile frequency of intersection. The resulting conditional distributions for intersection length, intersection azimuth, and number of eruptive centers with the repository footprint do not represent the mean, 5th percentile, and 95th percentile values of these distributions. Instead, they represent the distribution of length, azimuth, and number of eruptive centers conditional on the frequency of intersection equaling the mean, 5th percentile and 95 th percentile value. 


\subsubsection{Results}

\subsubsection{Frequency of Dike Intersection of the Repository Footprint}

Table 6-8 lists the mean annual frequency of intersection of the repository footprint and percentiles of the distribution for the frequency of intersection computed by full enumeration and by simulation with Latin hypercube sampling for the repository footprint. The results are listed for each expert, indicated by the expert's initials from Table 6-3, and for the composite distribution over all 10 experts, with equal weight assigned to the individual expert assessments. The results computed by full enumeration of the experts' logic trees are indicated by the suffix-FEn in the column headings (e.g., AM-FEn) and the results computed by simulation are indicated by the suffix-Sim in the column headings (e.g., AM-Sim). The percent difference in the frequency of intersection is also listed in the tables. The differences between the frequencies of intersection computed by full enumeration and by simulation are generally small, ranging from -25.7 percent to +20.5 percent, indicating that simulation with Latin hypercube sampling reliably represents the full distribution for frequency of intersection.

Table 6-8. Frequency of Intersection for the Repository Footprint

\begin{tabular}{|c|c|c|c|c|c|c|c|c|c|}
\hline & $A M^{1}-F E n^{2}$ & AM-Sim ${ }^{2}$ & $\begin{array}{c}\% \\
\text { Difference }^{3}\end{array}$ & BC-FEn & BC-Sim & $\begin{array}{c}\% \\
\text { Difference }\end{array}$ & GT-FEn & GT-Sim & $\begin{array}{c}\% \\
\text { Difference }\end{array}$ \\
\hline Mean & $0.696 \mathrm{E}-08$ & 0.698E-08 & 0.2 & $0.136 \mathrm{E}-07$ & $0.135 \mathrm{E}-07$ & -0.3 & $0.379 \mathrm{E}-07$ & $0.374 \mathrm{E}-07$ & 1.3 \\
\hline 0.05 & $0.199 \mathrm{E}-08$ & $0.212 \mathrm{E}-08$ & 6.3 & $0.118 \mathrm{E}-08$ & $0.118 \mathrm{E}-08$ & -4.9 & $0.123 \mathrm{E}-07$ & $0.117 \mathrm{E}-07$ & -4.8 \\
\hline 0.1 & $0.245 \mathrm{E}-08$ & $0.253 E-08$ & 3.0 & $0.195 \mathrm{E}-08$ & $0.179 \mathrm{E}-08$ & -8.5 & $0.148 \mathrm{E}-07$ & $0.149 \mathrm{E}-07$ & 0.7 \\
\hline 0.15 & $0.282 \mathrm{E}-08$ & $0.303 \mathrm{E}-08$ & 7.5 & $0.251 \mathrm{E}-08$ & $0.238 \mathrm{E}-08$ & -5.1 & $0.174 \mathrm{E}-07$ & $0.172 \mathrm{E}-07$ & -0.9 \\
\hline 0.2 & $0.316 \mathrm{E}-08$ & $0.318 \mathrm{E}-08$ & 0.4 & $0.295 \mathrm{E}-08$ & $0.278 \mathrm{E}-08$ & -5.8 & $0.204 \mathrm{E}-07$ & $0.192 \mathrm{E}-07$ & -5.8 \\
\hline 0.3 & $0.363 \mathrm{E}-08$ & $0.364 \mathrm{E}-08$ & 0.2 & $0.398 \mathrm{E}-08$ & $0.389 \mathrm{E}-08$ & -2.3 & $0.229 \mathrm{E}-07$ & $0.226 \mathrm{E}-07$ & -1.2 \\
\hline 0.4 & $0.407 \mathrm{E}-08$ & $0.402 \mathrm{E}-08$ & -1.3 & $0.550 \mathrm{E}-08$ & $0.542 \mathrm{E}-08$ & -1.4 & $0.263 \mathrm{E}-07$ & $0.265 \mathrm{E}-07$ & 0.6 \\
\hline 0.5 & $0.457 \mathrm{E}-08$ & $0.467 \mathrm{E}-08$ & 2.1 & $0.832 \mathrm{E}-08$ & $0.819 \mathrm{E}-08$ & -1.5 & $0.316 \mathrm{E}-07$ & $0.322 \mathrm{E}-07$ & 1.8 \\
\hline 0.6 & $0.549 \mathrm{E}-08$ & $0.529 \mathrm{E}-08$ & -3.7 & $0.132 \mathrm{E}-07$ & $0.136 \mathrm{E}-07$ & 3.5 & $0.372 \mathrm{E}-07$ & $0.387 \mathrm{E}-07$ & 4.3 \\
\hline 0.7 & $0.676 \mathrm{E}-08$ & $0.646 \mathrm{E}-08$ & -4.4 & $0.178 \mathrm{E}-07$ & $0.176 \mathrm{E}-07$ & -1.2 & $0.447 \mathrm{E}-07$ & $0.436 \mathrm{E}-07$ & -2.3 \\
\hline 0.8 & $0.851 \mathrm{E}-08$ & $0.827 \mathrm{E}-08$ & -2.8 & $0.240 \mathrm{E}-07$ & $0.240 \mathrm{E}-07$ & -0.2 & $0.525 \mathrm{E}-07$ & $0.501 \mathrm{E}-07$ & -4.6 \\
\hline 0.85 & $0.102 \mathrm{E}-07$ & $0.111 \mathrm{E}-07$ & 8.6 & $0.263 \mathrm{E}-07$ & $0.265 \mathrm{E}-07$ & 0.6 & $0.617 \mathrm{E}-07$ & $0.575 \mathrm{E}-07$ & -6.7 \\
\hline 0.9 & $0.141 \mathrm{E}-07$ & $0.138 \mathrm{E}-07$ & -2.7 & $0.309 \mathrm{E}-07$ & $0.307 \mathrm{E}-07$ & -0.8 & $0.676 \mathrm{E}-07$ & $0.656 \mathrm{E}-07$ & -3.0 \\
\hline 0.95 & $0.209 E-07$ & $0.214 \mathrm{E}-07$ & 2.4 & $0.417 \mathrm{E}-07$ & $0.402 \mathrm{E}-07$ & -3.6 & $0.776 \mathrm{E}-07$ & $0.756 \mathrm{E}-07$ & -2.6 \\
\hline
\end{tabular}


Table 6-8. Frequency of Intersection for the Repository Footprint (Continued)

\begin{tabular}{|c|c|c|c|c|c|c|c|c|c|c|}
\hline & GW-FEn & GW-Sim & $\begin{array}{c}\% \\
\text { Difference }\end{array}$ & MK-FEn & MK-Sim & $\begin{array}{c}\% \\
\text { Difference }\end{array}$ & MS-FEn & \multicolumn{2}{|c|}{ MS-Sim } & $\begin{array}{c}\% \\
\text { Difference }\end{array}$ \\
\hline Mean & $0.675 \mathrm{E}-08$ & 0.695E-08 & 3.1 & $0.123 \mathrm{E}-07$ & $0.120 \mathrm{E}-07$ & -2.0 & $0.190 \mathrm{E}-07$ & \multicolumn{2}{|c|}{$0.186 \mathrm{E}-07$} & -1.7 \\
\hline 0.05 & $0.126 \mathrm{E}-08$ & $0.121 \mathrm{E}-08$ & -3.9 & $0.437 \mathrm{E}-09$ & 0.468E-09 & 7.3 & $0.324 \mathrm{E}-08$ & \multicolumn{2}{|c|}{$0.341 \mathrm{E}-08$} & 5.3 \\
\hline 0.1 & $0.174 \mathrm{E}-08$ & $0.180 \mathrm{E}-08$ & 3.6 & $0.912 \mathrm{E}-09$ & $0.103 E-08$ & 13.4 & $0.468 \mathrm{E}-08$ & \multicolumn{2}{|c|}{$0.436 \mathrm{E}-08$} & -6.8 \\
\hline 0.15 & $0.219 \mathrm{E}-08$ & $0.216 \mathrm{E}-08$ & -1.5 & $0.174 \mathrm{E}-08$ & $0.186 \mathrm{E}-08$ & 7.0 & $0.589 \mathrm{E}-08$ & \multicolumn{2}{|c|}{$0.539 \mathrm{E}-08$} & -8.4 \\
\hline 0.2 & $0.257 \mathrm{E}-08$ & $0.233 E-08$ & -9.2 & $0.251 \mathrm{E}-08$ & $0.247 \mathrm{E}-08$ & -1.8 & $0.708 \mathrm{E}-08$ & \multicolumn{2}{|c|}{$0.629 \mathrm{E}-08$} & -11.2 \\
\hline 0.3 & $0.331 \mathrm{E}-08$ & $0.312 \mathrm{E}-08$ & -5.7 & $0.398 \mathrm{E}-08$ & $0.390 \mathrm{E}-08$ & -2.1 & $0.977 \mathrm{E}-08$ & \multicolumn{2}{|c|}{$0.841 \mathrm{E}-08$} & -13.9 \\
\hline 0.4 & $0.407 \mathrm{E}-08$ & $0.401 \mathrm{E}-08$ & -1.6 & $0.603 \mathrm{E}-08$ & $0.576 \mathrm{E}-08$ & -4.4 & $0.126 \mathrm{E}-07$ & \multicolumn{2}{|c|}{$0.110 \mathrm{E}-07$} & -12.4 \\
\hline 0.5 & $0.501 \mathrm{E}-08$ & $0.493 E-08$ & -1.7 & $0.813 \mathrm{E}-08$ & $0.791 \mathrm{E}-08$ & -2.7 & $0.155 \mathrm{E}-07$ & \multicolumn{2}{|c|}{$0.148 \mathrm{E}-07$} & -4.3 \\
\hline 0.6 & $0.631 \mathrm{E}-08$ & $0.587 \mathrm{E}-08$ & -7.0 & $0.107 \mathrm{E}-07$ & $0.106 \mathrm{E}-07$ & -0.9 & $0.195 \mathrm{E}-07$ & \multicolumn{2}{|c|}{$0.188 \mathrm{E}-07$} & -3.4 \\
\hline 0.7 & $0.794 \mathrm{E}-08$ & $0.791 \mathrm{E}-08$ & -0.4 & $0.141 \mathrm{E}-07$ & $0.139 \mathrm{E}-07$ & -1.7 & $0.234 \mathrm{E}-07$ & \multicolumn{2}{|c|}{$0.238 \mathrm{E}-07$} & 1.4 \\
\hline 0.8 & $0.102 \mathrm{E}-07$ & $0.104 \mathrm{E}-07$ & 1.4 & $0.186 \mathrm{E}-07$ & $0.186 \mathrm{E}-07$ & 0.0 & $0.282 \mathrm{E}-07$ & \multicolumn{2}{|c|}{$0.286 \mathrm{E}-07$} & 1.6 \\
\hline 0.85 & $0.120 \mathrm{E}-07$ & $0.123 E-07$ & 2.2 & $0.219 \mathrm{E}-07$ & $0.216 \mathrm{E}-07$ & -1.3 & $0.316 \mathrm{E}-07$ & $0.318 \mathrm{E}-\mathrm{C}$ & & 0.7 \\
\hline 0.9 & $0.138 \mathrm{E}-07$ & $0.139 \mathrm{E}-07$ & 0.4 & $0.275 \mathrm{E}-07$ & $0.265 \mathrm{E}-07$ & -3.7 & $0.363 \mathrm{E}-07$ & $0.366 \mathrm{E}-\mathrm{C}$ & & 0.8 \\
\hline 0.95 & $0.174 \mathrm{E}-07$ & $0.155 \mathrm{E}-07$ & -10.6 & $0.363 \mathrm{E}-07$ & $0.357 \mathrm{E}-07$ & -1.7 & $0.447 \mathrm{E}-07$ & $0.443 \mathrm{E}-\mathrm{C}$ & & -0.8 \\
\hline & RC-FEn & RC-Sim & $\begin{array}{c}\% \\
\text { Difference } \\
\end{array}$ & RF-FEn & RF-Sim & $\begin{array}{c}\% \\
\text { Difference } \\
\end{array}$ & WD-FEn & WD-Si & & \begin{tabular}{|c|}
$\%$ \\
Difference \\
\end{tabular} \\
\hline Mean & $0.157 \mathrm{E}-07$ & $0.151 \mathrm{E}-07$ & -3.7 & $0.199 \mathrm{E}-07$ & $0.197 \mathrm{E}-07$ & -0.8 & $0.166 \mathrm{E}-08$ & $0.200 \mathrm{E}-\mathrm{C}$ & & 20.5 \\
\hline 0.05 & $0.123 E-08$ & $0.130 \mathrm{E}-08$ & 5.8 & $0.437 \mathrm{E}-08$ & $0.437 \mathrm{E}-08$ & 0.1 & $0.138 \mathrm{E}-09$ & $0.134 \mathrm{E}-\mathrm{C}$ & & -3.0 \\
\hline 0.1 & $0.191 \mathrm{E}-08$ & $0.177 \mathrm{E}-08$ & -7.3 & $0.617 \mathrm{E}-08$ & $0.573 \mathrm{E}-08$ & -7.0 & $0.204 \mathrm{E}-09$ & $0.205 E-$ & & 0.3 \\
\hline 0.15 & $0.251 \mathrm{E}-08$ & $0.237 \mathrm{E}-08$ & -5.8 & $0.759 \mathrm{E}-08$ & $0.687 \mathrm{E}-08$ & -9.5 & $0.257 \mathrm{E}-09$ & $0.256 \mathrm{E}-\mathrm{C}$ & & -0.4 \\
\hline 0.2 & $0.339 \mathrm{E}-08$ & $0.310 \mathrm{E}-08$ & -8.4 & $0.891 \mathrm{E}-08$ & $0.816 \mathrm{E}-08$ & -8.4 & 0.339E-09 & $0.352 \mathrm{E}-\mathrm{C}$ & & 3.9 \\
\hline 0.3 & $0.468 \mathrm{E}-08$ & $0.439 \mathrm{E}-08$ & -6.1 & $0.112 \mathrm{E}-07$ & $0.111 \mathrm{E}-07$ & -1.2 & $0.537 \mathrm{E}-09$ & $0.539 \mathrm{E}$ & & 0.3 \\
\hline 0.4 & $0.741 \mathrm{E}-08$ & $0.736 \mathrm{E}-08$ & -0.7 & $0.138 \mathrm{E}-07$ & $0.141 \mathrm{E}-07$ & 2.5 & $0.100 \mathrm{E}-08$ & $0.743 \mathrm{E}$ & & -25.7 \\
\hline 0.5 & $0.977 \mathrm{E}-08$ & $0.992 \mathrm{E}-08$ & 1.5 & $0.170 \mathrm{E}-07$ & $0.173 \mathrm{E}-07$ & 1.8 & $0.123 \mathrm{E}-08$ & $0.124 \mathrm{E}$ & & 0.7 \\
\hline 0.6 & $0.129 \mathrm{E}-07$ & $0.130 \mathrm{E}-07$ & 0.5 & $0.200 \mathrm{E}-07$ & 0.196E-07 & -1.8 & $0.123 \mathrm{E}-08$ & $0.124 \mathrm{E}$ & & 0.8 \\
\hline 0.7 & $0.174 \mathrm{E}-07$ & $0.176 \mathrm{E}-07$ & 1.2 & $0.234 \mathrm{E}-07$ & $0.234 \mathrm{E}-07$ & -0.3 & $0.151 \mathrm{E}-08$ & $0.153 \mathrm{E}$ & & 0.9 \\
\hline 0.8 & $0.229 \mathrm{E}-07$ & $0.230 \mathrm{E}-07$ & 0.4 & $0.282 \mathrm{E}-07$ & $0.283 \mathrm{E}-07$ & 0.3 & $0.263 \mathrm{E}-08$ & $0.229 \mathrm{E}$ & & -12.9 \\
\hline 0.85 & $0.309 \mathrm{E}-07$ & $0.303 \mathrm{E}-07$ & -2.0 & $0.316 \mathrm{E}-07$ & $0.321 \mathrm{E}-07$ & 1.5 & $0.295 \mathrm{E}-08$ & $0.293 \mathrm{E}$ & & -0.7 \\
\hline 0.9 & $0.372 \mathrm{E}-07$ & $0.348 \mathrm{E}-07$ & -6.4 & $0.363 \mathrm{E}-07$ & $0.379 \mathrm{E}-07$ & 4.4 & $0.380 \mathrm{E}-08$ & $0.382 \mathrm{E}$ & & 0.4 \\
\hline 0.95 & $0.525 \mathrm{E}-07$ & $0.437 \mathrm{E}-07$ & -16.7 & $0.457 \mathrm{E}-07$ & $0.444 \mathrm{E}-07$ & -2.8 & $0.457 \mathrm{E}-08$ & $0.535 \mathrm{E}$ & & 16.9 \\
\hline & & H-FEn & WH-Sim & $\%$ Diff & ference & Composite ${ }^{4}$ Fen & n Composi & $i e^{4}$ Sim & & Difference \\
\hline Mean & & $353 \mathrm{E}-07$ & $0.357 \mathrm{E}-07$ & & 0.9 & $0.169 \mathrm{E}-07$ & 0.168 & $\mathrm{E}-07$ & & -0.6 \\
\hline 0.05 & & $692 \mathrm{E}-08$ & $0.702 \mathrm{E}-08$ & & 1.5 & 0.741E-09 & 0.743 & E-09 & & 0.2 \\
\hline 0.1 & & $371 \mathrm{E}-08$ & $0.874 \mathrm{E}-08$ & & 0.4 & $0.148 \mathrm{E}-08$ & 0.149 & E-08 & & 0.4 \\
\hline 0.15 & & 102E-07 & $0.102 \mathrm{E}-07$ & & 0.1 & $0.229 \mathrm{E}-08$ & 0.227 & E-08 & & -1.1 \\
\hline 0.2 & & $120 \mathrm{E}-07$ & $0.120 \mathrm{E}-07$ & & 0.5 & $0.302 \mathrm{E}-08$ & 0.296 & E-08 & & -2.0 \\
\hline 0.3 & & 170E-07 & $0.164 \mathrm{E}-07$ & & 3.5 & $0.457 \mathrm{E}-08$ & 0.449 & E-08 & & -1.8 \\
\hline 0.4 & & 234E-07 & $0.233 \mathrm{E}-07$ & & 0.6 & $0.692 \mathrm{E}-08$ & 0.673 & $\mathrm{E}-08$ & & -2.7 \\
\hline
\end{tabular}


Table 6-8. Frequency of Intersection for the Repository Footprint (Continued)

\begin{tabular}{|c|c|c|c|c|c|c|}
\hline \hline & WH-FEn & WH-Sim & \% Difference & Composite $^{4}$ Fen & Composite $^{4}$ Sim & \% Difference \\
\hline 0.5 & $0.295 \mathrm{E}-07$ & $0.299 \mathrm{E}-07$ & 1.3 & $0.100 \mathrm{E}-07$ & $0.992 \mathrm{E}-08$ & -0.8 \\
\hline 0.6 & $0.355 \mathrm{E}-07$ & $0.363 \mathrm{E}-07$ & 2.2 & $0.145 \mathrm{E}-07$ & $0.142 \mathrm{E}-07$ & -1.9 \\
\hline 0.7 & $0.437 \mathrm{E}-07$ & $0.440 \mathrm{E}-07$ & 0.8 & $0.204 \mathrm{E}-07$ & $0.203 \mathrm{E}-07$ & -0.8 \\
\hline 0.8 & $0.537 \mathrm{E}-07$ & $0.542 \mathrm{E}-07$ & 0.9 & $0.269 \mathrm{E}-07$ & $0.276 \mathrm{E}-07$ & 2.6 \\
\hline 0.85 & $0.603 \mathrm{E}-07$ & $0.607 \mathrm{E}-07$ & 0.8 & $0.331 \mathrm{E}-07$ & $0.330 \mathrm{E}-07$ & -0.5 \\
\hline 0.9 & $0.692 \mathrm{E}-07$ & $0.696 \mathrm{E}-07$ & 0.5 & $0.407 \mathrm{E}-07$ & $0.410 \mathrm{E}-07$ & 0.7 \\
\hline 0.95 & $0.871 \mathrm{E}-07$ & $0.891 \mathrm{E}-07$ & 2.3 & $0.550 \mathrm{E}-07$ & $0.533 \mathrm{E}-07$ & -3.0 \\
\hline
\end{tabular}

Output DTN: LA0303BY831811.001.

${ }^{1} \mathrm{AM}=$ Alex McBirney, $\mathrm{BC}=$ Bruce Crowe, $\mathrm{GT}=$ George Thompson, $\mathrm{GW}=$ George Walker, MK = Mel Kuntz, MS =

Michael Sheridan, RC = Richard Carlson, RF = Richard Fisher, $W D=$ Wendell Duffield, $W H=$ William Hackett.

${ }^{2} \mathrm{FEn}=$ results from full enumeration, $\mathrm{Sim}=$ results from simulations with Latin hypercube sampling.

${ }^{3}$ The percent difference is computed as (Sim - FEn)/FEn. It represents the percent difference between the frequency of intersection computed by full enumeration and by simulation.

${ }^{4}$ The composite distributions are computed giving equal weight to the individual expert's distributions.

The computed distribution for the annual frequency of intersection of the repository footprint by a dike is shown in Figure 6-18. Part (a) of Figure 6-18 shows the computed distributions for the frequency of intersection aggregated over all of the 10 PVHA experts' interpretations, together with the median and mean values obtained for each expert's interpretation. Part (b) of Figure 6-18 compares the 5th to 95th percentile range for frequency of intersection obtained for each expert's interpretation with that for the aggregate distributions.

The computed mean annual frequency of intersection of the repository footprint by a dike is 1.7 $\times 10^{-8}$ for the 2003 repository footprint (BSC 2003 [DIRS 162289]) as compared to $1.5 \times 10^{-8}$ obtained in the PVHA (CRWMS M\&O 1996 [DIRS 100116], p. 4-10). The computed 5th and 95th percentiles of the uncertainty distribution for frequency of intersection are $7.4 \times 10^{-10}$ and $5.5 \times 10^{-8}$, respectively, as compared to $5.4 \times 10^{-10}$ and $4.9 \times 10^{-8}$ obtained in the PVHA (CRWMS M\&O 1996 [DIRS 100116], p. 4-10).

The composite uncertainty distributions for frequency of intersection that are the output of these calculations are located in the output file PVHA-4P.DST in Output DTN: LA0302BY831811.001 The file consists of a title record, a record giving the number of points in the composite distribution, and $n$ records containing the $n$ discrete values of frequency of intersection, the associated probability mass, and the cumulative probability, which together define the cumulative probability density function (CDF). 

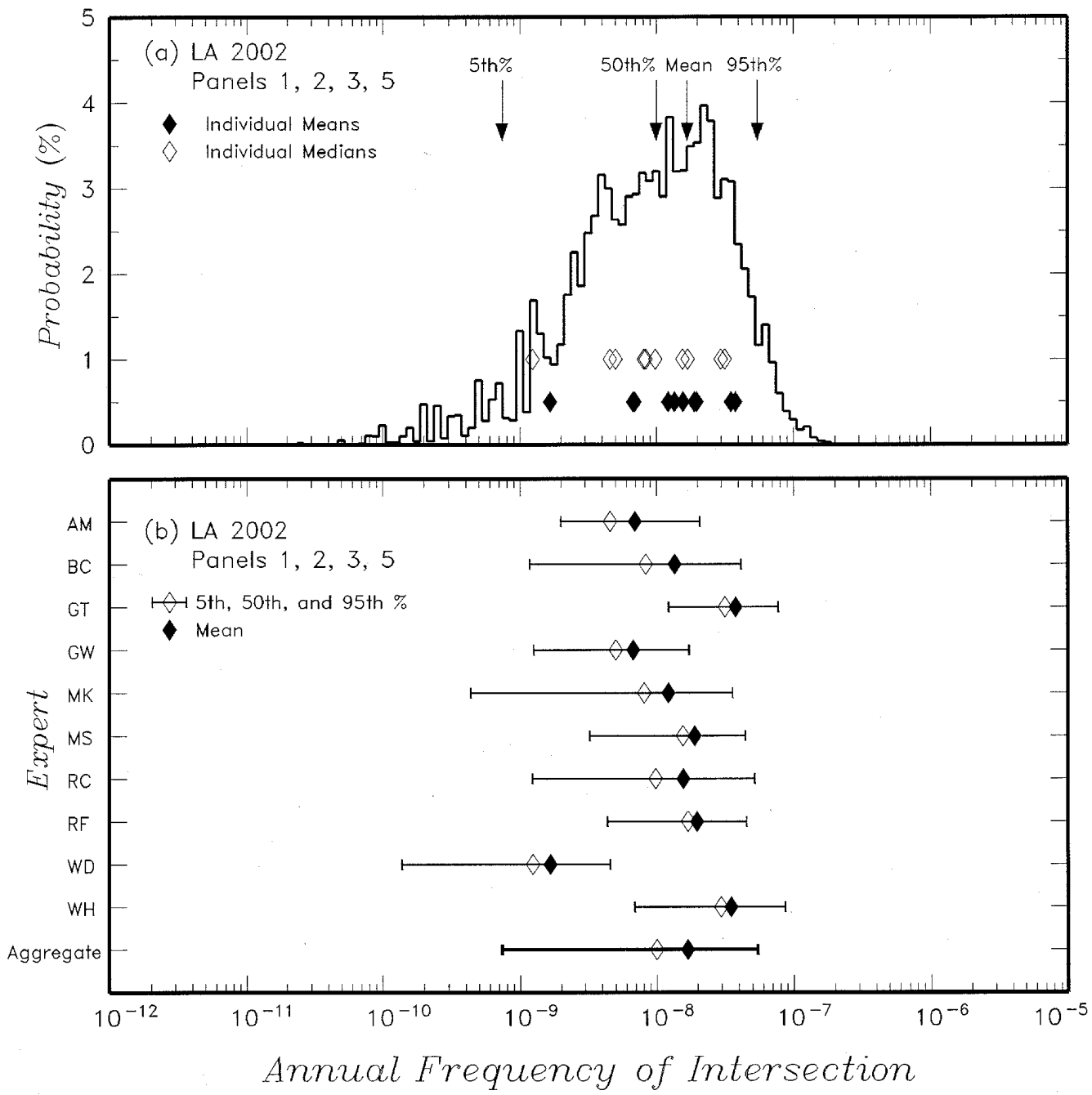

Output DTN: LA0303BY831811.001.

NOTE: (a) Aggregate distribution and median and means for individual PVHA expert interpretations. (b) Range for 5th to 95th percentiles for results from individual PVHA expert interpretations compared to range for aggregate distribution. Two-letter code indicates initials of experts from Table 6-3.

Figure 6-18. Annual Frequency of Intersecting the Repository Footprint

\subsubsection{Conditional Distributions for Intersection Length, Azimuth, and Number of Eruptive Centers within the Repository Footprint}

The Latin hypercube sampling process described in Section 6.5.2.2 was used to compute joint distributions for length and azimuth of dike intersection at the mean, 5th, and 95th percentile frequencies of intersection. At each of these frequencies of intersection, distributions for the number of eruptive centers within the repository footprint were developed, conditional on the length and azimuth within the repository of the intersecting dike system. The joint distributions are listed in three output files (Output DTN: LA0303BY831811.001): file CCSM-LA.CMP provides the joint distribution for length and azimuth of dike intersection and conditional distributions for the number of eruptive centers corresponding to the mean frequency of 
intersection; file CC05-LA.CMP provides the joint distribution for length and azimuth of dike intersection and conditional distributions for the number of eruptive centers corresponding to the $5^{\text {th }}$ percentile frequency of intersection; and file CC95-LA.CMP provides the joint distribution for length and azimuth of dike intersection and conditional distributions for the number of eruptive centers corresponding to the $95^{\text {th }}$ percentile frequency of exceedance. Each file consists of a title record, a record giving the number of points in the joint distribution for dike intersection length and azimuth, and $n$ records containing the $n$ pairs of intersection length $\left(L_{m}^{I}\right)$ and azimuth $\left(\phi_{n}\right)$ and the joint probability of an intersection having that length and azimuth within the proposed repository. Also listed for each $L_{m}^{I}$ and $\phi_{n}$ pair, is the composite conditional distribution for the number of eruptive centers within the proposed repository given the pair $L_{m}^{I}$ and $\phi_{n}$.

Figure 6-19, Figure 6-20, and Figure 6-21 show the marginal distributions for intersection length, intersection azimuth, and number of eruptive centers for the repository footprint, respectively, computed from the joint distributions described above (a marginal distribution represents the variation in a single parameter averaged over the variations in the other parameters). These results are also summarized in Table 6-9, Table 6-10, and Table 6-11. The marginal distributions are computed from the joint distributions using software routine MARGIN V1.1 (BSC 2000 [DIRS 168223]) (Figure 3-2). The results indicate the degree to which the distributions for length and azimuth of intersecting dikes and the number of eruptive centers vary with frequency of intersection. For example, results listed in Table 6-9 indicate that similar marginal distributions for dike intersection length are obtained at the 5th, mean, and 95th frequencies of intersection. The marginal distributions for intersection azimuth obtained at the 5 th, mean, and 95th frequencies of intersection (Table 6-10) are also similar.

Figure 6-21 shows the marginal distributions for the number of eruptive centers within the repository footprint obtained using the five alternative approaches for the number and spatial distribution of eruptive centers along the length of the dike system. The IUD-UC approach produces the lowest probability of one or more eruptive centers within the proposed repository, approximately 0.4 , and the USRD-FD approach produces the highest probability, approximately 0.6. The values plotted in Figure 6-21 are those computed using the five alternative approaches for evaluating the number and spatial distribution of eruptive centers under the assumption that the presence of the proposed repository opening has no effect on the location of eruptive centers. These distributions are listed in the second through sixth columns of Table 6-11 under the overall subheading of "Random Location" for the formulation of eruptive center spatial distribution. The seventh column of Table 6-11 shows the marginal distribution for the weighted average results of the five approaches, using the weights described at the end of Section 6.5.1.3 and indicated in the column headings. The eighth column of Table 6-11 shows the marginal distribution for number of eruptive centers within the repository footprint under the assumption that the presence of the repository openings results in at least one eruptive center within the repository footprint, given an intersection. The last column of Table 6-11 lists the final composite marginal distribution, which represents an equally weighted average of the random location assumption and the renormalized random distributions with $\mathrm{P}\left(r^{E C}=0\right)=0$ (eighth column). Similar marginal distributions for the number of eruptive centers are obtained at the 5 th, mean, and 95th frequencies of intersection. 

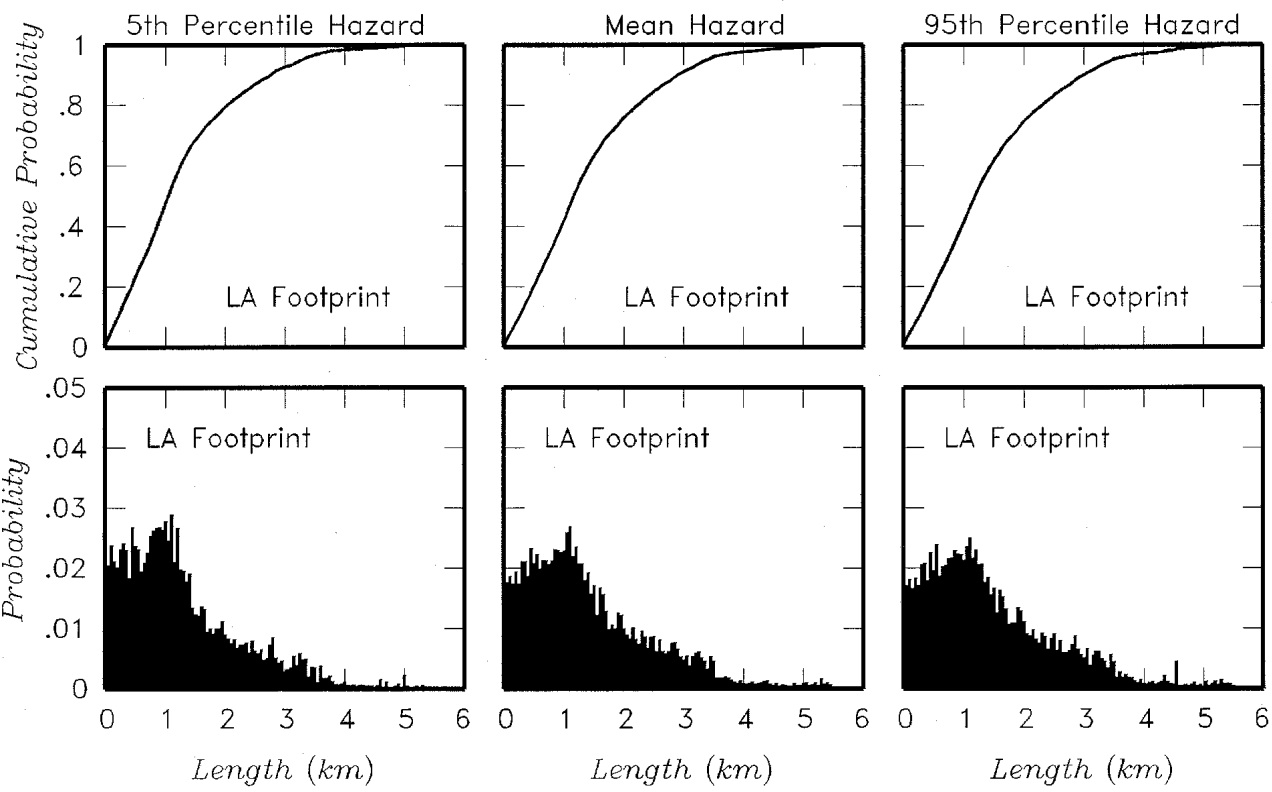

Output DTN: LA0303BY831811.001.

NOTE: These distributions are conditional on the occurrence of an intersection. The distributions are developed for the specified value of the frequency of intersection.

Figure 6-19. Marginal Distributions for Dike Intersection Length, $L^{\prime}$, for the 5th Percentile, Mean, and 95th Percentile Frequency of Intersection
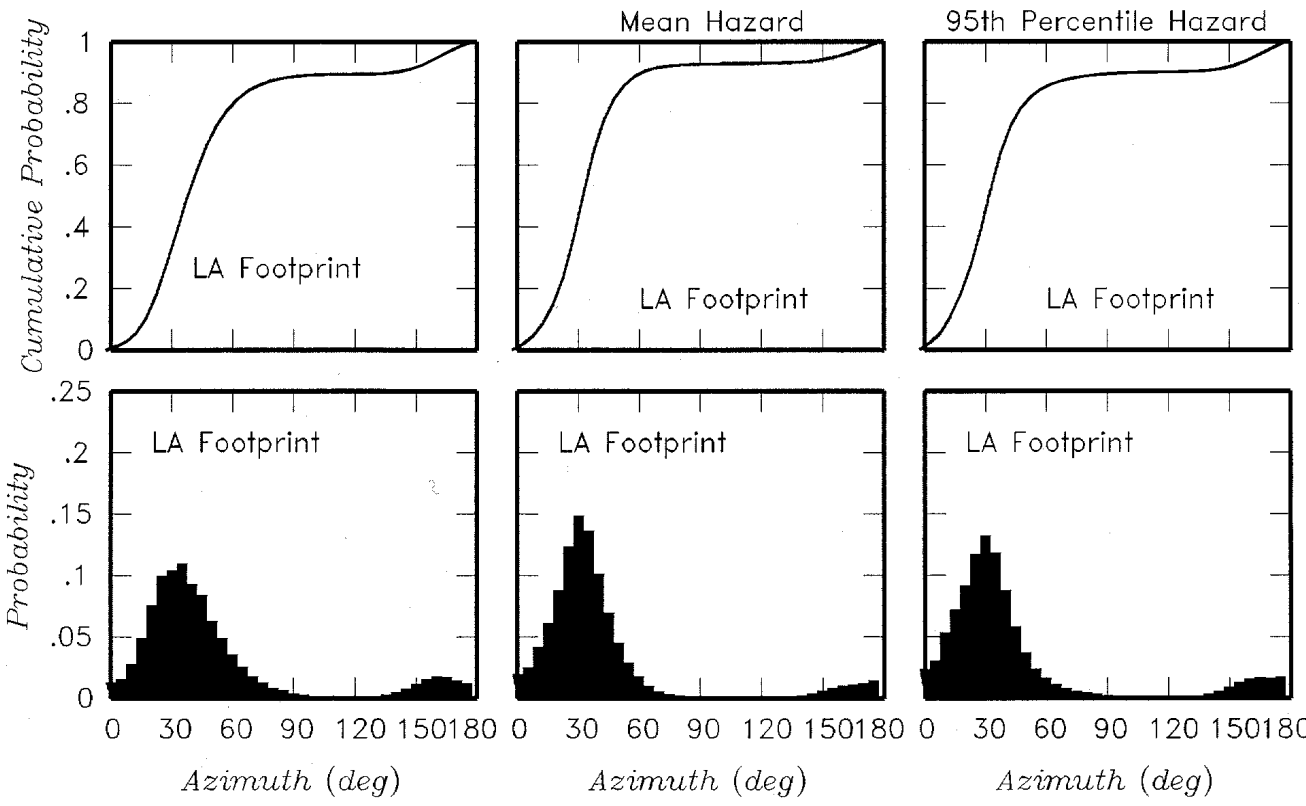

Azimuth (deg)

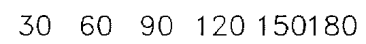

Azimuth (deg)

Output DTN: LA0303BY831811.001.

NOTE: These distributions are conditional on the occurrence on an intersection. The distributions are developed for the specified value of the frequency of intersection.

Figure 6-20. Marginal Distributions for Dike Intersection Azimuth, $\phi$, for the 5th Percentile, Mean, and 95th Percentile Frequency of Intersection for the Repository Footprint 
5th Percentile Hazard

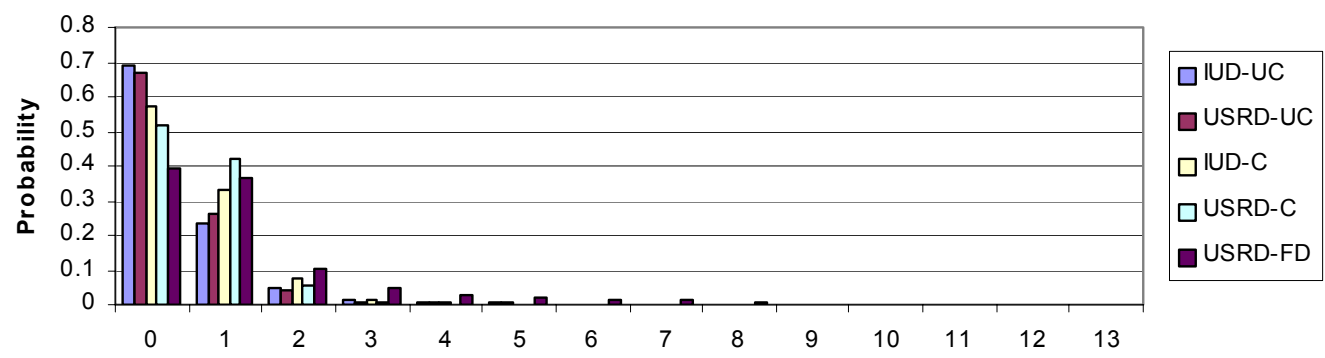

Num ber of Eruptive Centers within Repository Footprint

Mean Hazard
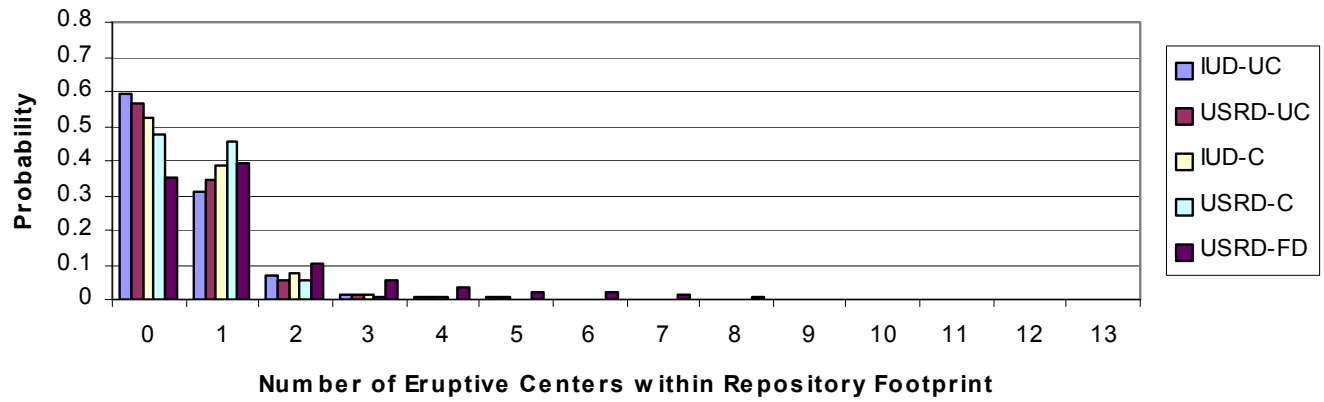

Num ber of Eruptive Centers within Repository Footprint

95th Percentile Hazard

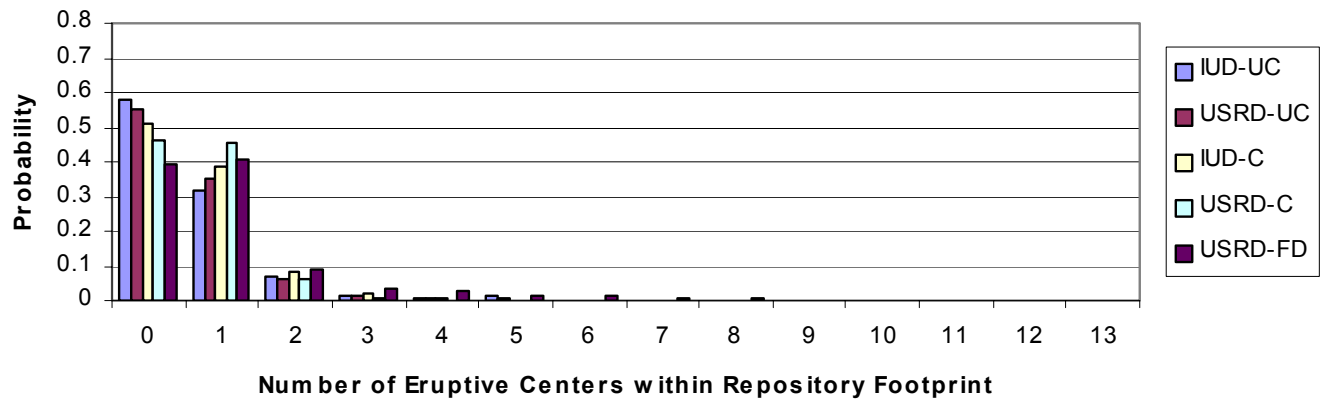

Output DTN: LA0303BY831811.001.

NOTE: IUD = independent; uniformly distributed; USRD = uniformly spaced; randomly distributed;

$\mathrm{UC}=$ uncorrelated length and number of eruptive centers per volcanic event distributions; $\mathrm{C}=$ correlated length and number of eruptive centers per volcanic event distributions; FD = fixed density for number of eruptive centers per volcanic event. These distributions are conditional on the occurrence on an intersection. The distributions are developed for the specified value of the frequency of intersection.

Figure 6-21. Marginal Distributions for the Number of Eruptive Centers within the Repository Footprint, $r^{E C}$, for the 5th Percentile, Mean, and 95th Percentile Frequency of Intersection 
Table 6-9. Marginal Distributions for Dike Intersection Length for the 5th Percentile, Mean, and 95th Percentile Frequency of Intersection of the Repository Footprint

\begin{tabular}{|c|c|c|c|}
\hline \multirow[b]{2}{*}{$\begin{array}{l}\text { Dike Intersection } \\
\text { Length (km) }\end{array}$} & \multicolumn{3}{|c|}{ Probability Mass } \\
\hline & $\begin{array}{c}\text { 5th Percentile Frequency } \\
\text { of Intersection }\end{array}$ & $\begin{array}{l}\text { Mean Frequency } \\
\text { of Intersection }\end{array}$ & $\begin{array}{c}\text { 95th Percentile } \\
\text { Frequency of Intersection }\end{array}$ \\
\hline $0.0-0.255$ & 0.1288 & 0.1088 & 0.1051 \\
\hline$>0.255-0.505$ & 0.1159 & 0.1048 & 0.1012 \\
\hline$>0.505-0.755$ & 0.1114 & 0.1054 & 0.1047 \\
\hline$>0.755-1.005$ & 0.1336 & 0.1128 & 0.1105 \\
\hline$>1.005-1.255$ & 0.1208 & 0.1189 & 0.1137 \\
\hline$>1.255-1.505$ & 0.0821 & 0.0909 & 0.0888 \\
\hline$>1.505-1.755$ & 0.0583 & 0.0674 & 0.0679 \\
\hline$>1.755-2.005$ & 0.0492 & 0.0553 & 0.0591 \\
\hline$>2.005-2.255$ & 0.0382 & 0.0430 & 0.0433 \\
\hline$>2.255-2.505$ & 0.0353 & 0.0421 & 0.0417 \\
\hline$>2.505-2.755$ & 0.0296 & 0.0323 & 0.0324 \\
\hline$>2.755-3.005$ & 0.0255 & 0.0318 & 0.0334 \\
\hline$>3.005-3.255$ & 0.0219 & 0.0263 & 0.0285 \\
\hline$>3.255-3.505$ & 0.0190 & 0.0226 & 0.0230 \\
\hline$>3.505-3.755$ & 0.0104 & 0.0089 & 0.0106 \\
\hline$>3.755-4.005$ & 0.0044 & 0.0055 & 0.0065 \\
\hline$>4.005-4.255$ & 0.0028 & 0.0043 & 0.0046 \\
\hline$>4.255-4.505$ & 0.0025 & 0.0050 & 0.0062 \\
\hline$>4.505-4.755$ & 0.0036 & 0.0028 & 0.0066 \\
\hline$>4.755-5.005$ & 0.0039 & 0.0033 & 0.0031 \\
\hline$>5.005-5.255$ & 0.0016 & 0.0036 & 0.0044 \\
\hline$>5.255-5.505$ & 0.0013 & 0.0042 & 0.0043 \\
\hline$>5.505-5.755$ & 0.0001 & 0.0003 & 0.0003 \\
\hline
\end{tabular}

Output DTN: LA0307BY831811.001. 
Table 6-10. Marginal Distribution for Intersecting Dike Azimuth for the 5th Percentile, Mean, and 95th Percentile Frequency of Intersection of the Repository Footprint

\begin{tabular}{|c|c|c|c|}
\hline \multirow[b]{2}{*}{$\begin{array}{c}\text { Intersecting Dike } \\
\text { Azimuth }\left({ }^{\circ}\right)\end{array}$} & \multicolumn{3}{|c|}{ Probability Mass } \\
\hline & $\begin{array}{l}\text { 5th percentile } \\
\text { Frequency of } \\
\text { Intersection }\end{array}$ & $\begin{array}{l}\text { Mean Frequency of } \\
\text { Intersection }\end{array}$ & $\begin{array}{c}\text { 95th percentile } \\
\text { Frequency of } \\
\text { Intersection }\end{array}$ \\
\hline$>-2.5-12.5$ & 0.0560 & 0.0861 & 0.1072 \\
\hline$>12.5-22.5$ & 0.1240 & 0.1485 & 0.1636 \\
\hline$>22.5-32.5$ & 0.2030 & 0.2717 & 0.2491 \\
\hline$>32.5-42.5$ & 0.2015 & 0.2372 & 0.2060 \\
\hline$>42.5-52.5$ & 0.1463 & 0.1146 & 0.0955 \\
\hline$>52.5-62.5$ & 0.0841 & 0.0464 & 0.0402 \\
\hline$>62.5-72.5$ & 0.0431 & 0.0157 & 0.0188 \\
\hline$>72.5-82.5$ & 0.0209 & 0.0053 & 0.0099 \\
\hline$>82.5-92.5$ & 0.0102 & 0.0023 & 0.0055 \\
\hline$>92.5-102.5$ & 0.0043 & 0.0011 & 0.0031 \\
\hline$>102.5-112.5$ & 0.0013 & 0.0005 & 0.0017 \\
\hline$>112.5-122.5$ & 0.0005 & 0.0004 & 0.0009 \\
\hline$>122.5-132.5$ & 0.0019 & 0.0011 & 0.0015 \\
\hline$>132.5-142.5$ & 0.0072 & 0.0037 & 0.0049 \\
\hline$>142.5-152.5$ & 0.0193 & 0.0100 & 0.0145 \\
\hline$>152.5-162.5$ & 0.0327 & 0.0182 & 0.0280 \\
\hline$>162.5-172.5$ & 0.0316 & 0.0230 & 0.0325 \\
\hline$>172.5-177.5$ & 0.0121 & 0.0142 & 0.0170 \\
\hline
\end{tabular}

Output DTN: LA0307BY831811.001. 
Table 6-11. Marginal Distribution for Number of Eruptive Centers within the Proposed Repository for the 5th Percentile, Mean, and 95th Percentile Frequency of Intersection of the Repository Footprint

\begin{tabular}{|c|c|c|c|c|c|c|c|c|}
\hline \multirow[b]{3}{*}{$\begin{array}{c}\text { Number of } \\
\text { Eruptive } \\
\text { Centers in } \\
\text { Proposed } \\
\text { Repository } \\
r^{E C} \\
\end{array}$} & \multicolumn{7}{|c|}{ Formulation for Eruptive Center Spatial Distribution } & \multirow[b]{3}{*}{$\begin{array}{c}\text { Final } \\
\text { Composite } \\
\text { Marginal } \\
\text { Probability }\end{array}$} \\
\hline & \multicolumn{6}{|c|}{$\begin{array}{c}\text { Random Location } \\
\text { (weight } 0.5 \text { ) }\end{array}$} & \multirow{2}{*}{\begin{tabular}{|c|}
$\begin{array}{c}\text { Repository } \\
\text { Induces } \\
\text { Eruptive } \\
\text { Center } \\
\text { (weight } 0.5)\end{array}$ \\
\\
Renormalized \\
such that \\
$\mathrm{P}\left(r^{E C}=0\right)=0$
\end{tabular}} & \\
\hline & \begin{tabular}{|} 
Independent, \\
Uniformly \\
Distributed, \\
Uncorrelated, \\
(weight 0.05)
\end{tabular} & \begin{tabular}{|} 
Uniformly \\
Spaced, \\
Randomly \\
Distributed, \\
Uncorrelated, \\
(weight 0.15 )
\end{tabular} & \begin{tabular}{|c} 
Independent, \\
Uniformly \\
Distributed, \\
Correlated, \\
(weight \\
$\mathbf{0 . 0 7 5 )}$
\end{tabular} & \begin{tabular}{|c} 
Uniformly \\
Spaced, \\
Randomly \\
Distributed, \\
Correlated, \\
(weight \\
0.225 ) \\
\end{tabular} & $\begin{array}{c}\text { Uniformly } \\
\text { Spaced, } \\
\text { Randomly } \\
\text { Distributed, } \\
\text { Fixed Density, } \\
\text { (weight 0.5) }\end{array}$ & $\begin{array}{l}\text { Weighted } \\
\text { Average } \\
\text { For } \\
\text { Random } \\
\text { Location } \\
\end{array}$ & & \\
\hline \multicolumn{9}{|c|}{ Conditional Distributions for 5th Percentile Frequency of Intersection } \\
\hline 0 & 0.693 & 0.672 & 0.571 & 0.516 & 0.391 & 0.490 & 0 & 0.245 \\
\hline 1 & 0.232 & 0.264 & 0.328 & 0.419 & 0.369 & 0.355 & 0.738 & 0.546 \\
\hline 2 & 0.0489 & 0.0414 & 0.0775 & 0.0537 & 0.102 & 0.0775 & 0.140 & 0.109 \\
\hline 3 & 0.0108 & 0.0098 & 0.0171 & 0.0088 & 0.0495 & 0.0300 & 0.0539 & 0.0419 \\
\hline 4 & 0.00688 & 0.00566 & 0.00520 & 0.00159 & 0.0301 & 0.0170 & 0.0273 & 0.0222 \\
\hline 5 & 0.00903 & 0.00728 & 0.00105 & 0.00015 & 0.0186 & 0.0109 & 0.0157 & 0.0133 \\
\hline 6 & 0 & 0 & 0 & 0 & 0.0151 & 0.00755 & 0.00985 & 0.00870 \\
\hline 7 & 0 & 0 & 0 & 0 & 0.0120 & 0.00598 & 0.00762 & 0.00680 \\
\hline 8 & 0 & 0 & 0 & 0 & 0.00677 & 0.00339 & 0.00423 & 0.00381 \\
\hline 9 & 0 & 0 & 0 & 0 & 0.00227 & 0.00114 & 0.00134 & 0.00124 \\
\hline 10 & 0 & 0 & 0 & 0 & 0.00269 & 0.00135 & 0.00166 & 0.00151 \\
\hline 11 & 0 & 0 & 0 & 0 & 0.00078 & 0.00039 & 0.00044 & 0.00041 \\
\hline 12 & 0 & 0 & 0 & 0 & 0.00033 & 0.00016 & 0.00018 & 0.00017 \\
\hline 13 & 0 & 0 & 0 & 0 & 0.00005 & 0.00002 & 0.00003 & 0.00002 \\
\hline \multicolumn{9}{|c|}{ Conditional Distributions for Mean Frequency of Intersection } \\
\hline 0 & 0.590 & 0.568 & 0.521 & 0.477 & 0.348 & 0.435 & 0 & 0.218 \\
\hline 1 & 0.312 & 0.347 & 0.383 & 0.454 & 0.390 & 0.394 & 0.740 & 0.567 \\
\hline 2 & 0.0661 & 0.0576 & 0.0756 & 0.0585 & 0.104 & 0.0829 & 0.134 & 0.108 \\
\hline 3 & 0.0140 & 0.0129 & 0.0148 & 0.0085 & 0.0540 & 0.0327 & 0.0533 & 0.0430 \\
\hline 4 & 0.00746 & 0.00616 & 0.00477 & 0.00137 & 0.0349 & 0.0194 & 0.0282 & 0.0238 \\
\hline 5 & 0.0103 & 0.00833 & 0.00097 & 0.00012 & 0.0240 & 0.0139 & 0.0187 & 0.0163 \\
\hline 6 & 0 & 0 & 0 & 0 & 0.0181 & 0.00903 & 0.0111 & 0.0101 \\
\hline 7 & 0 & 0 & 0 & 0 & 0.01271 & 0.00636 & 0.00763 & 0.00699 \\
\hline 8 & 0 & 0 & 0 & 0 & 0.00617 & 0.00308 & 0.00362 & 0.00335 \\
\hline 9 & 0 & 0 & 0 & 0 & 0.00269 & 0.00135 & 0.00154 & 0.00144 \\
\hline 10 & 0 & 0 & 0 & 0 & 0.00171 & 0.00086 & 0.00098 & 0.00092 \\
\hline 11 & 0 & 0 & 0 & 0 & 0.00149 & 0.00075 & 0.00086 & 0.00080 \\
\hline 12 & 0 & 0 & 0 & 0 & 0.00084 & 0.00042 & 0.00049 & 0.00045 \\
\hline 13 & 0 & 0 & 0 & 0 & 0.00010 & 0.00005 & 0.00006 & 0.00005 \\
\hline
\end{tabular}


Table 6-11. Marginal Distribution for Number of Eruptive Centers within the Proposed Repository for the 5th Percentile, Mean, and 95th Percentile Frequency of Intersection of the Repository Footprint (Continued)

\begin{tabular}{|c|c|c|c|c|c|c|c|c|}
\hline \multirow[b]{3}{*}{$\begin{array}{c}\text { Number of } \\
\text { Eruptive } \\
\text { Centers in } \\
\text { Proposed } \\
\text { Repository } \\
r^{E C} \\
\end{array}$} & \multicolumn{7}{|c|}{ Formulation for Eruptive Center Spatial Distribution } & \multirow[b]{3}{*}{$\begin{array}{c}\text { Final } \\
\text { Composite } \\
\text { Marginal } \\
\text { Probability }\end{array}$} \\
\hline & \multicolumn{6}{|c|}{$\begin{array}{l}\text { Random Location } \\
\text { (weight } 0.5 \text { ) }\end{array}$} & \multirow{2}{*}{\begin{tabular}{|c|}
$\begin{array}{c}\text { Repository } \\
\text { Induces } \\
\text { Eruptive } \\
\text { Center } \\
\text { (weight } 0.5)\end{array}$ \\
\\
Renormalized \\
such that \\
$\mathrm{P}\left(r^{E C}=0\right)=0$ \\
\end{tabular}} & \\
\hline & \begin{tabular}{|c|} 
\\
Independent, \\
Uniformly \\
Distributed, \\
Uncorrelated, \\
(weight 0.05) \\
\end{tabular} & \begin{tabular}{|} 
Uniformly \\
Spaced, \\
Randomly \\
Distributed, \\
Uncorrelated, \\
(weight 0.15)
\end{tabular} & \begin{tabular}{|} 
Independent, \\
Uniformly \\
Distributed, \\
Correlated, \\
(weight \\
0.075 ) \\
\end{tabular} & \begin{tabular}{|c|} 
Uniformly \\
Spaced, \\
Randomly \\
Distributed, \\
Correlated, \\
(weight \\
0.225 ) \\
\end{tabular} & $\begin{array}{c}\text { Uniformly } \\
\text { Spaced, } \\
\text { Randomly } \\
\text { Distributed, } \\
\text { Fixed Density, } \\
\text { (weight 0.5) } \\
\end{array}$ & $\begin{array}{l}\text { Weighted } \\
\text { Average } \\
\text { For } \\
\text { Random } \\
\text { Location } \\
\end{array}$ & & \\
\hline \multicolumn{9}{|c|}{ Conditional Distributions for 95th Percentile Frequency of Intersection } \\
\hline 0 & 0.576 & 0.551 & 0.511 & 0.464 & 0.393 & 0.451 & 0 & 0.225 \\
\hline 1 & 0.316 & 0.355 & 0.385 & 0.459 & 0.410 & 0.406 & 0.789 & 0.597 \\
\hline 2 & 0.0699 & 0.0628 & 0.0795 & 0.0648 & 0.087 & 0.0768 & 0.118 & 0.0972 \\
\hline 3 & 0.0169 & 0.0155 & 0.0177 & 0.0102 & 0.0362 & 0.0249 & 0.0393 & 0.0321 \\
\hline 4 & 0.00948 & 0.00765 & 0.00591 & 0.00188 & 0.0242 & 0.0146 & 0.0209 & 0.0177 \\
\hline 5 & 0.0114 & 0.00893 & 0.00126 & 0.00017 & 0.0167 & 0.0104 & 0.0142 & 0.0123 \\
\hline 6 & 0 & 0 & 0 & 0 & 0.0126 & 0.00629 & 0.00764 & 0.00696 \\
\hline 7 & 0 & 0 & 0 & 0 & 0.00940 & 0.00470 & 0.00558 & 0.00514 \\
\hline 8 & 0 & 0 & 0 & 0 & 0.00469 & 0.00234 & 0.00271 & 0.00253 \\
\hline 9 & 0 & 0 & 0 & 0 & 0.00225 & 0.00113 & 0.00126 & 0.00119 \\
\hline 10 & 0 & 0 & 0 & 0 & 0.00173 & 0.00086 & 0.00098 & 0.00092 \\
\hline 11 & 0 & 0 & 0 & 0 & 0.00145 & 0.00073 & 0.00082 & 0.00077 \\
\hline 12 & 0 & 0 & 0 & 0 & 0.00079 & 0.00040 & 0.00045 & 0.00042 \\
\hline 13 & 0 & 0 & 0 & 0 & 0.00007 & 0.00003 & 0.00004 & 0.00004 \\
\hline
\end{tabular}

Output DTN: LA0307BY831811.001.

NOTE: Results presented in this table were rounded to at most three significant digits after calculation.

The results summarized in Table 6-9, Table 6-10, and Table 6-11 indicate that the conditional distributions for intersecting dike length, intersecting dike azimuth, and number of eruptive centers within the repository footprint are not sensitive to the underlying frequency of intersection, as there is little variation between the results obtained at the 5th, mean, and 95th frequencies of intersection. Therefore, the results obtained for the mean frequency of intersection can be used to assess the consequences of intrusive and extrusive distribution for all frequencies of intersection.

\subsubsection{Sensitivity Studies}

Sensitivity studies are documented in this section to assess (1) the impact of new aeromagnetic data (Blakely et al. 2000 [DIRS 151881]; O'Leary et al. 2002 [DIRS 158468]; Hill and Stamatakos 2002 [DIRS 159500]) on the frequency of intersection of the repository footprint, and (2) the impact of alternative conceptual models (i.e., the potential for buried volcanic events undetectable by previous geophysical surveys) on the frequency of intersection. These sensitivity studies test whether additional buried basalts suggested by new aeromagnetic data or 
postulated in alternative conceptual models could lead to significant changes in the results of the 1996 PVHA (CRWMS M\&O 1996 [DIRS 100116]). "Significant" is defined in Brocoum (1997 [DIRS 147772]) as a change in the mean of the probability distribution by half an order of magnitude or more. Compared to the mean annual frequency of intersection of $1.5 \times 10^{-8}$ determined in the 1996 PVHA, significant changes would correspond to mean annual frequencies of greater than approximately $5 \times 10^{-8}$ or less than approximately $5 \times 10^{-9}$.

The results of these sensitivity studies are considered non-Q because the input data (O'Leary et al. 2002 [DIRS 158468]; Hill and Stamatakos 2002 [DIRS 159500]) were not obtained using Yucca Mountain Project quality procedures and additional postulated buried volcanic events used for the sensitivity studies are strictly hypothetical with no basis in existing data. The results are for information only and are not to be used for purposes of assessing repository performance.

\subsubsection{Impact of 1999 Aeromagnetic Data on Frequency of Intersection}

Anomalies observed in aeromagnetic and ground magnetic data gathered by the USGS and the Center for Nuclear Waste Regulatory Analysis, respectively, since completion of the PVHA suggest the possibility that a number of basaltic volcanic centers are buried beneath alluvium in Crater Flat and the northern Amargosa Valley (Blakely et al. 2000 [DIRS 151881]; O'Leary et al. 2002 [DIRS 158468]; Hill and Stamatakos 2002 [DIRS 159500]). Interpretation of these data indicates that 20 to 24 magnetic anomalies occur within Crater Flat and the northern Amargosa Valley that could represent buried basaltic volcanoes (O'Leary et al. 2002 [DIRS 158468]; Hill and Stamatakos 2002 [DIRS 159500]). Of these anomalies, 8 were known at the time of the PVHA from previous surveys and were considered as possible volcanic events as part of the PVHA (Figure 6-22).

This section summarizes the methodology and results of an evaluation carried out as part of this report to determine the effect of the possible presence of buried volcanic centers on the results of the PVHA. The results of the evaluation are considered non-Q because the input data (O'Leary et al. 2002 [DIRS 158468]; Hill and Stamatakos 2002 [DIRS 159500]) were not obtained using Yucca Mountain Project quality procedures. The results are for information only and are not to be used for purposes of assessing repository performance.

Evaluation of the effect on the probability estimate from potential buried volcanic centers requires an estimate of the age of possible buried centers and an assessment of the likelihood that anomalies or groups of anomalies represent buried basaltic volcanic centers.

The probable age range of potential buried volcanic centers was estimated by using a range of calculated sedimentation rates in Crater Flat and the Amargosa Valley, and the modeled depth of anomalies from O'Leary et al. 2002 [DIRS 158468]. For two cases, the basalt in Crater Flat encountered in drill hole $\mathrm{VH}-2$ and the basalt of Anomaly B, sedimentation rates were calculated by dividing the known depth (from drilling) of the buried basalt by the measured age of the basalt. These calculations give sedimentation rates of 0.03 and $0.04 \mathrm{~mm} / \mathrm{yr}$, respectively. A third case, Little Cones, has buried flows that have been characterized by ground magnetic surveys (Stamatakos et al. 1997 [DIRS 138819]). Using a modeled depth to the top of the flows of $15 \mathrm{~m}$, a flow thickness of $10 \mathrm{~m}$, and an age of 0.77-0.98 m.y. (Stamatakos et al. 1997 [DIRS 138819], p. 328), the calculated sedimentation rate is $0.025-0.32 \mathrm{~mm} / \mathrm{yr}$. 


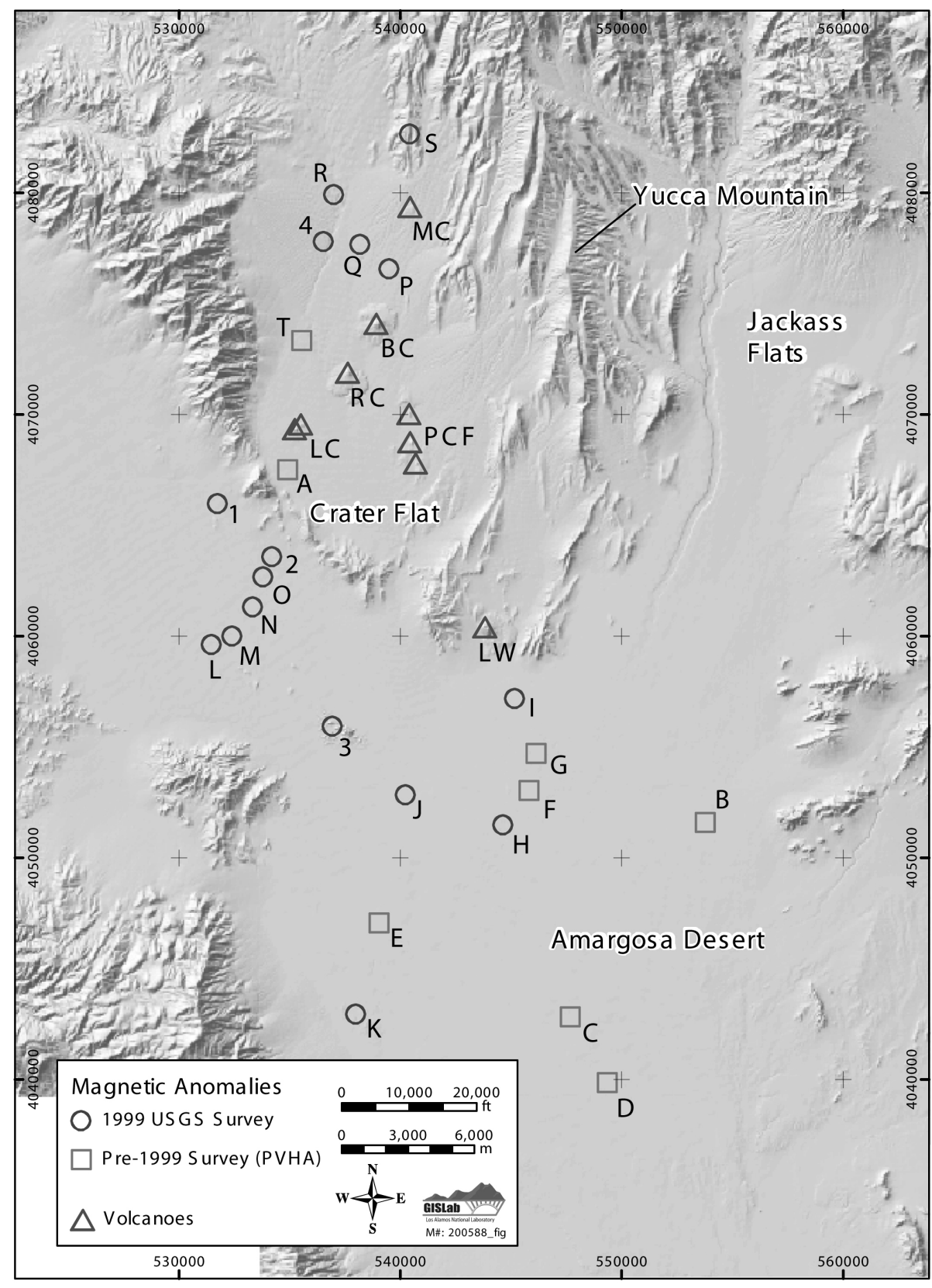

Source: Magnetic Anomaly designations are from Hill and Stamatakos 2002. [DIRS 159500]; (Coordinates from Hill and Stamatakos 2002 [DIRS 159500]).

NOTE: $\quad \mathrm{MC}=$ Makani Cone; $\mathrm{BC}=$ Black Cone; $\mathrm{RC}=$ Red Cone; $\mathrm{LC}=$ Little Cones; $\mathrm{LW}=$ Lathrop Wells. $\mathrm{PCF}=$ Pliocene Crater Flat.

Figure 6-22. Locations of Potential Buried Basalt Inferred from Aeromagnetic Data 
Using the range of calculated sedimentation rates discussed above and the modeled burial depth of anomalies (O'Leary et al. 2002 [DIRS 158468]), minimum and maximum ages were estimated for individual anomalies. Maximum ages for anomalies range from 2.5 to $8.3 \mathrm{~m} . \mathrm{y}$. and minimum ages range from 1.25 to 6.25 m.y. The exception to this age range is Anomaly T, which was estimated to be approximately $11 \mathrm{~m}$.y. in age. Consideration of magnetic polarity data adds another age constraint and a "most likely" age was chosen for each anomaly within the age range estimated for that anomaly. This approach leads to most likely ages for the anomalies that range from 2.6 to 6.3 m.y. All age ranges represent minimum ages (and, thus, are conservative for the purposes of volcanic hazard analysis) because they do not account for the thickness of the basalt bodies in calculating the depth of sediments deposited after basalt was emplaced.

The PVHA experts made evaluations of the likelihood that the magnetic anomalies identified at that time represented buried volcanic centers. An individual expert's confidence that an anomaly represented buried basalt generally depended on the expert's interpretation of the shape, magnetic signature, and geologic setting of the anomaly (CRWMS M\&O 1996 [DIRS 100116]). O'Leary et al. (2002 [DIRS 158468]) and Hill and Stamatakos (2002 [DIRS 159500]) used similar criteria to rank their confidence that the 20 to 24 anomalies identified in their reports represent buried basalt using a scale of 1 to 4 (O'Leary et al. 2002 [DIRS 158468]) and high, medium, and low (Hill and Stamatakos 2002 [DIRS 159500]). Qualitatively, the rankings used in these two reports lead to similar conclusions regarding scientific confidence that particular anomalies represent buried basalt. The number of magnetic anomalies identified in these reports that may represent buried basalt depends upon the resolution of the aeromagnetic data. Hill and Stamatokos (2002 [DIRS 159500]) suggest that basaltic features with areas smaller than $1 \mathrm{~km}^{2}$ are generally undetectable using the data presented in O’Leary et al. (2002 [DIRS 158468]).

The potential impact of the aeromagnetic and ground magnetic data on the probability of igneous disruption of the proposed repository was assessed by developing distributions for the number of volcanic events represented by the anomalies, assigning these events to the volcanic sources defined by the experts in the 1996 PVHA, and calculating the annual frequency of intersection of the repository footprint. The distributions for the number of volcanic events were developed using the tendency of each expert to group, or not group, aligned anomalies into single or multiple volcanic events. Two cases were developed. In the 1996 PVHA, the experts did not consider all of the anomalies identified at that time to be buried volcanic centers. Instead, to varying degrees, they factored the likelihood that the anomalies represented buried volcanic centers into their assessments of the number of volcanic events that have occurred. Case 1 for this study was developed to be consistent with this approach. The distributions for the number of volcanic events represented by the magnetic anomalies for Case 1 were developed by the authors of this scientific analysis report using the qualitative likelihood that the anomalies represent buried volcanic centers discussed in the previous paragraph, and using each expert's tendency for including anomalies with various levels of confidence into those experts' distributions for volcanic events. In Case 2, all anomalies were assumed to be buried volcanic centers, and the distributions for the number of volcanic events were developed by the authors of this report based only on each expert's tendency for grouping aligned volcanic centers into events.

The PVHA experts considered the time period of interest for computing the rate of volcanic events in the YMR to range from the past $1 \mathrm{~m} . \mathrm{y}$. to the past $10 \mathrm{~m} . \mathrm{y}$., with the most likely time 
period to be the past 4.5 to $5 \mathrm{~m} . \mathrm{y}$. With the exception of Anomaly T, the age estimates for the anomalies generally fall within the past $6 \mathrm{~m}$.y. For purposes of these sensitivity analyses, it was assumed that the ages of 22 anomalies (A, B, C, D, E, F, G, H, I, J, K, L, M, N, O, P, Q, R, 1, 2, 3 , and 4) fall within the past 4.5- to 5-m.y. time period. The age of Anomaly T was assumed to fall within the past 9 to $10 \mathrm{~m} . \mathrm{y}$. time period. Two of the PVHA experts considered a time period of the past $2 \mathrm{~m} . \mathrm{y}$. The range in age estimates for Anomalies O, 1, and 2 overlaps the 2 m.y. time period and, for these sensitivity analyses, these anomalies were given a 50 percent probability of being less than 2 m.y. in age.

Table 6-12 lists the results of the sensitivity analyses in terms of the mean number of volcanic events occurring within the time period used by the experts to define the rate of volcanic events. For those experts who considered a $5 \mathrm{~m} . \mathrm{y}$. time period, the sensitivity analyses indicate an approximate 50 percent increase in the mean number of events for Case 1 (which incorporates the likelihood that the anomalies represent buried volcanic centers) and an approximate 100 percent increase in the mean number of events for Case 2 (which assumes that all of the anomalies represent buried volcanic centers).

Table 6-12. Comparison of Mean Number of Volcanic Events for 1996 Probabilistic Volcanic Hazard Analysis Assessment with Sensitivity Analysis Values

\begin{tabular}{|c|c|c|c|c|c|c|}
\hline \multirow[b]{3}{*}{ Expert } & \multicolumn{6}{|c|}{ Time Period } \\
\hline & \multicolumn{3}{|c|}{ Quaternary } & \multicolumn{3}{|c|}{ Plio-Quaternary } \\
\hline & 1996 & Case $1^{b}$ & Case $2^{b}$ & 1996 & Case $1^{b}$ & Case $2^{b}$ \\
\hline AM & - & - & - & 14.5 & 21.8 & 27.2 \\
\hline $\mathrm{BC}$ & - & - & - & 16.7 & 24.0 & 29.7 \\
\hline GT & - & - & - & 14.5 & 22.3 & 29.0 \\
\hline GW & - & - & - & 14.8 & 22.8 & 30.6 \\
\hline MK & 4.1 & 4.6 & 5.6 & 11.1 & 17.9 & 25.6 \\
\hline MS & - & - & - & 14.4 & 24.5 & 25.6 \\
\hline $\mathrm{RC}$ & - & - & - & 12.0 & 18.5 & 24.4 \\
\hline RF & 4.4 & 5.1 & 5.9 & - & - & - \\
\hline WD & 6.6 & 6.6 & 6.6 & - & - & - \\
\hline $\mathrm{WH}$ & - & - & - & 15.7 & 18.4 & 30.4 \\
\hline Average & 5.0 & 5.4 & 6.0 & 14.2 & 21.3 & 27.8 \\
\hline
\end{tabular}

Source: Ziegler (2002 [DIRS 171274]).

a $\mathrm{AM}=$ Alexander McBirney; $\mathrm{BC}=$ Bruce Crowe; $\mathrm{GT}=$ George Thompson; $\mathrm{GW}=$ George Walker; MK = Mel Kuntz; MS = Michael Sheridan; RC = Richard Carlson; RF = Richard Fisher; WD = Wendell Duffield; $\mathrm{WH}=$ William Hackett.

${ }^{b}$ Case 1 and Case 2 were developed by the authors of this report based on the 1996 PVHA experts' preferences for grouping aligned volcanic centers into volcanic events.

For the two experts who considered a 2 m.y. time period, the sensitivity analyses result in increases of 10 and 20 percent for Case 1 and Case 2, respectively. Duffield considered only a $1 \mathrm{~m} . \mathrm{y}$. time period but assigned low probabilities that some of the anomalies are less than $1 \mathrm{~m} . \mathrm{y}$. in age (CRWMS M\&O 1996 [DIRS 100116]). Applying this assessment to the larger population of anomalies results in less than a 1 percent increase in the mean number of volcanic events.

For each expert in this sensitivity study, the distributions for the number of volcanic events developed were assigned to the appropriate volcanic sources defined by the PVHA experts. In general, the magnetic anomalies lie within or slightly to the west of the experts' Crater Flat and 
Amargosa Valley sources. Therefore, for these sensitivity analyses, the volcanic events represented by the magnetic anomalies were assigned to the experts' Crater Flat and Amargosa Valley sources (i.e., source zones, Gaussian fields, kernel density functions) rather than to larger background source zones.

Figure 6-23 and Figure 6-24 show the results of the sensitivity analyses in terms of the computed distributions for the frequency of intersection of the repository footprint by a basaltic dike. The footprint used for these analyses is the 70,000- metric tons of uranium (MTU) no-backfill repository layout (primary-plus-contingency blocks) used in REV 01 (BSC 2003 [DIRS 163769]) of this report. Use of this footprint results in approximately 6 percent lower frequencies of intersections than if the 2003 repository footprint (BSC 2003 [DIRS 162289]) had been used to assess the impact (based on comparison of the mean annual frequency of intersection from the two footprints). The results are summarized in Table 6-13. The volcanic event count distributions developed for sensitivity Case 1 result in a 22 percent increase in the mean annual frequency of intersection and those for sensitivity Case 2 result in a 40 percent increase. The increase in the frequency of intersection is less than the increase in the mean number of volcanic events because the additional events are located in the more active volcanic sources to the west of the site. As indicated in Figure 6-11, a significant portion of the volcanic hazard results from the occurrence of volcanic events near or to the northeast of the proposed repository, areas in which the estimated rate of volcanic events is not greatly affected by inclusion of the additional magnetic anomalies in the volcanic event count distributions.

\subsubsection{Impact of Potential Undetected Volcanic Events on Frequency of Intersection}

In addition to potential buried volcanoes identified in the 1999 USGS aeromagnetic survey, the possibility exists that additional undetected buried volcanoes may also exist in the YMR. This is of particular concern in areas immediately to the east and west of the repository (Jackass Flats and Crater Flat, respectively; Figure 6-22). These areas have a complex magnetic background signal due to underlying faulted-Miocene-tuff bedrock, making it more difficult to identify possible buried volcanoes using existing data (Hill and Stamatakos [DIRS 159500], p. 2-22). The presence of undetected volcanoes, depending on their age and location, could impact estimates of the frequency of intersection of the repository footprint estimated in the 1996 PVHA.

To evaluate the effect of potential undetected buried volcanic events on the estimate of the annual frequency of intersection of the repository footprint, an additional number of volcanic events beyond the maximum number suggested by existing data (O'Leary et al. 2002 [DIRS 158468]; Hill and Stamatakos 2002 [DIRS 159500]) are postulated in this report to be buried in the alluvial-filled basins east and west of Yucca Mountain. The results of this sensitivity study are considered non-Q because the input data (O'Leary et al. 2002 [DIRS 158468]; Hill and Stamatakos 2002 [DIRS 159500]) were not obtained using Yucca Mountain Project quality procedures and the additional postulated buried volcanic events used for the sensitivity study are strictly hypothetical with no basis in existing data. The results are for information only and are not to be used for purposes of assessing repository performance. 

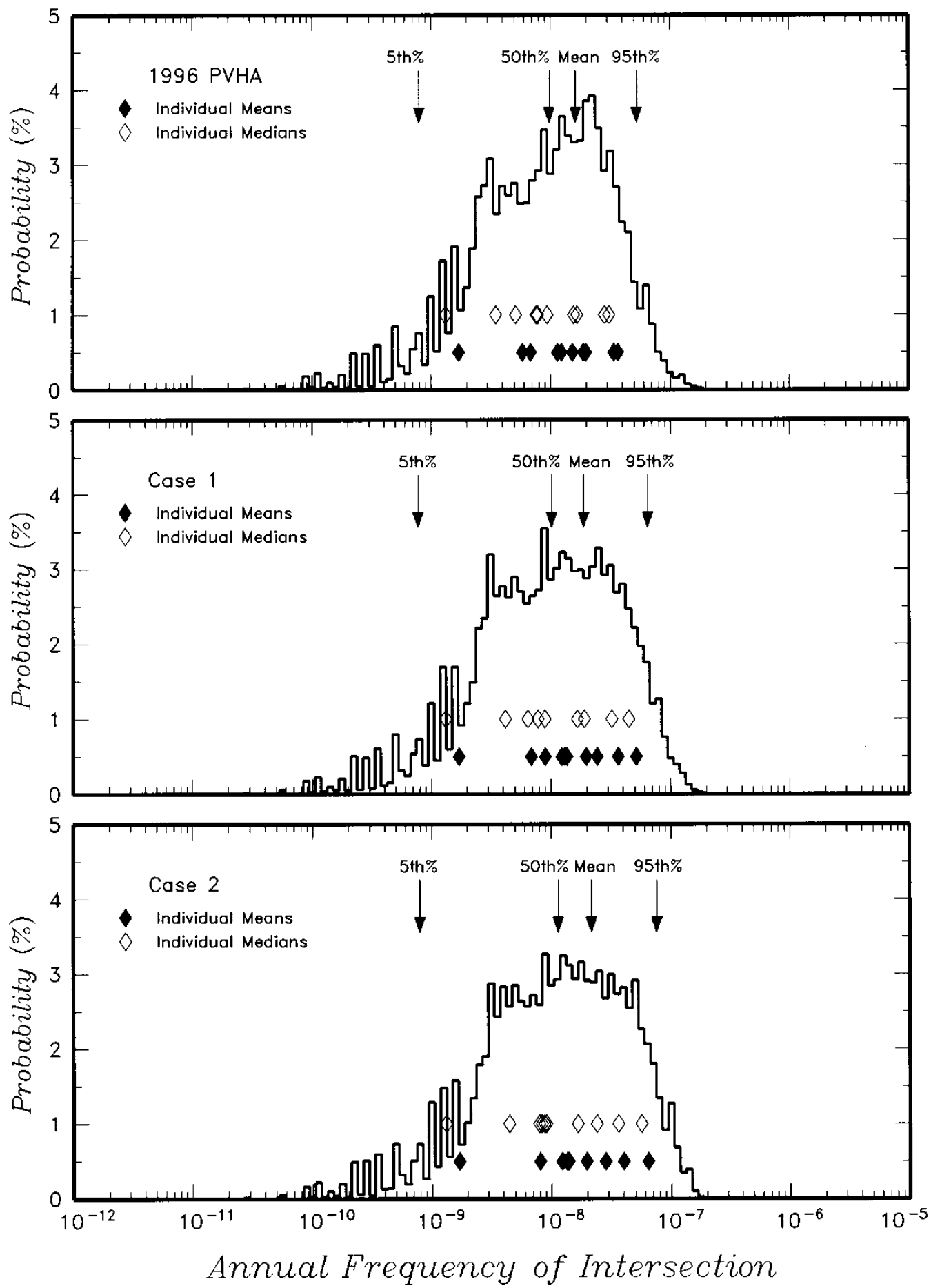

Source: Ziegler (2002 [DIRS 171274]).

NOTE: Results labeled 1996 use the PVHA volcanic event counts; results labeled Case 1 and Case 2 use the volcanic event counts developed in this sensitivity analysis.

Figure 6-23. Composite Annual Frequency of Intersection of the Repository Footprint for Sensitivity Cases for the Primary-plus-Contingency Block Case of the 70,000 Metric Tons of Uranium No-Backfill Layout 


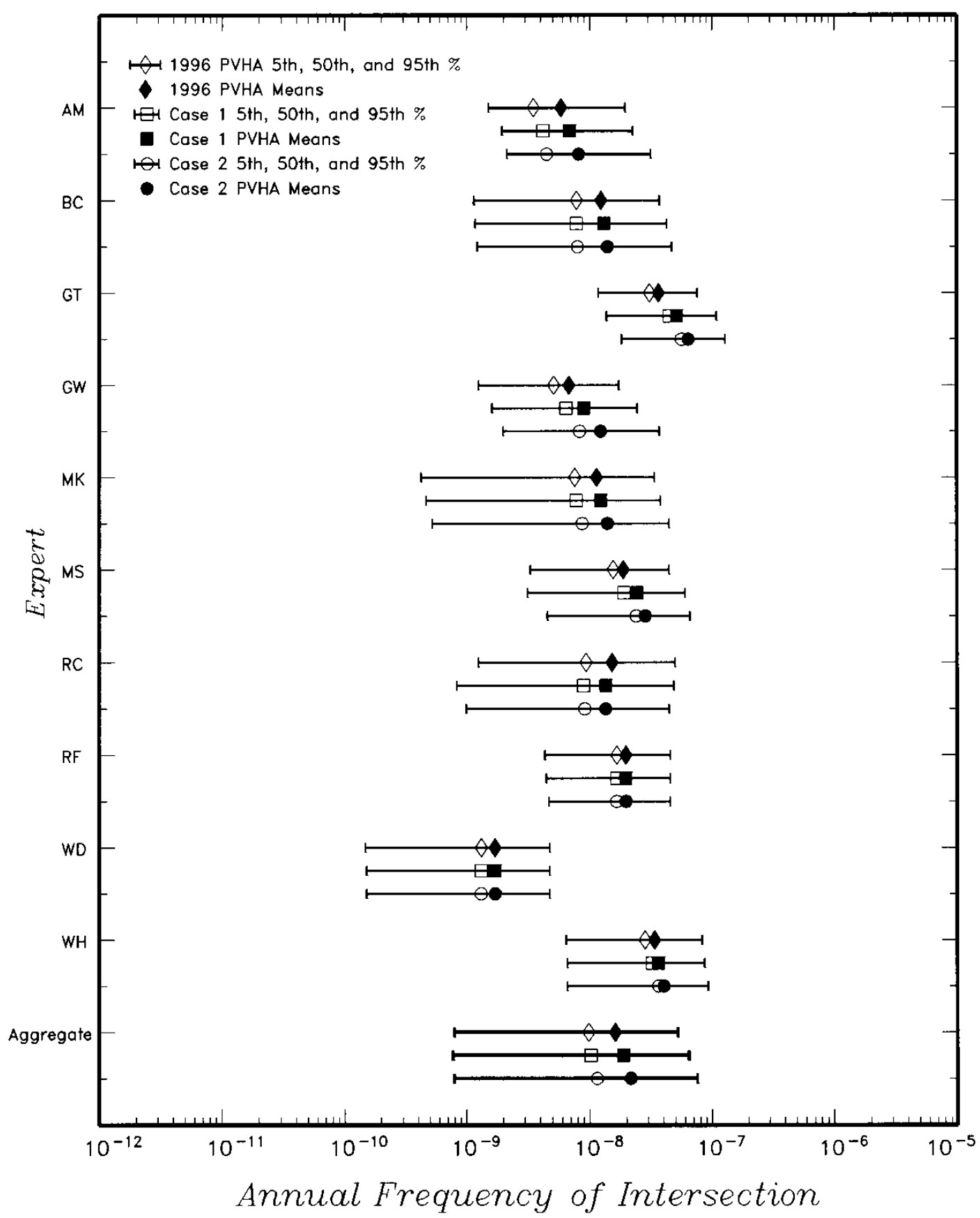

Source: Ziegler (2002 [DIRS 171274]).

NOTE: Results labeled 1996 use the PVHA volcanic event counts; results labeled Case 1 and Case 2 use the volcanic event counts developed for the sensitivity cases.

Figure 6-24. Individual Expert Results for Annual Frequency of Intersection of the Repository Footprint for Sensitivity Cases for the Primary-plus-Contingency Block Case of the 70,000 Metric Tons of Uranium No-Backfill Layout 
Table 6-13. Summary of Computed Frequency of Intersection for 70,000-Metric Tons of Uranium No-Backfill Repository Layout (primary + contingency blocks) from Sensitivity Cases

\begin{tabular}{|l|c|c|c|c|}
\hline \multirow{2}{*}{ Input Parameters } & \multicolumn{4}{|c|}{ Annual Frequency of Intersection } \\
\cline { 2 - 5 } 1996 PVHA & 5th percentile & 50th percentile & Mean & 95th percentile \\
\hline Sensitivity Case 1 & $7.9 \mathrm{E}-10$ & $9.8 \mathrm{E}-09$ & $1.6 \mathrm{E}-08$ & $5.2 \mathrm{E}-08$ \\
\hline Sensitivity Case 2 & $7.8 \mathrm{E}-10$ & $1.0 \mathrm{E}-08$ & $1.9 \mathrm{E}-08$ & $6.5 \mathrm{E}-08$ \\
\hline
\end{tabular}

Source: Ziegler (2002 [DIRS 171274]).

\subsection{Scenario Development}

To evaluate the impact of potential undetected buried volcanic events on the frequency of intersection of the repository footprint, a basis was derived for postulating the number and location of undetected volcanic events.

The basis for the number of potential undetected volcanic events was determined using the following steps:

1. An area of approximately $130 \mathrm{~km}^{2}$ was defined in the northern Amargosa Desert that encompasses twelve magnetic anomalies (1, 2, 3, F, G, H, I, J, L, M, N, O). Assuming that buried volcanic centers cause magnetic anomalies, that all anomalies are due to volcanic centers, and that the maximum density of magnetic anomalies is readily discernable by visual inspection, this area can be used to define a reasonable maximum buried volcanic center density in the Yucca Mountain region (Figure 6-25).

2. It is assumed that all buried volcanic centers, and therefore potential undetected volcanic events, are between approximately 2 and $5 \mathrm{~m} . \mathrm{y}$. old (Pliocene age). Two million years is assumed to be the minimum time necessary to completely bury a volcanic center.

3. Based on groupings of anomalies with medium to high confidence of representing buried basalt (Hill and Stamatakos 2002 [DIRS 159500], Table 1) and the tendency for experts to group aligned volcanic centers into volcanic events, the twelve anomalies were interpreted by the authors of this report as likely to represent six volcanic events $(1,[\mathrm{~L}+\mathrm{M}+\mathrm{N}+\mathrm{O}+2$ (=2 events) $], 3, \mathrm{I},[\mathrm{F}+\mathrm{G}+\mathrm{H}])$. Anomaly $\mathrm{J}$ was not considered in the event count because it has a low confidence of representing buried basalt (Hill and Stamatakos 2002 [DIRS 159500], Table 1). These six volcanic events occur within an area of approximately $130 \mathrm{~km}^{2}$, resulting in an event density of 0.046 events $/ \mathrm{km}^{2}$.

4. Assuming the event density derived in Step 3 represents a reasonable maximum event density for Pliocene volcanic events in Crater Flat and Jackass Flats, the event density was applied to the approximate areas of Crater Flat $\left(200 \mathrm{~km}^{2}\right)$ and western Jackass Flats $\left(185 \mathrm{~km}^{2}\right)$ to derive an expected maximum number of Pliocene volcanic events in each area. This approach resulted in a maximum of nine expected Pliocene volcanic events in both Crater Flat and Jackass Flats (numbers are rounded to whole numbers). 
5. Assuming four known Pliocene volcanic events in Crater Flat and zero known Pliocene volcanic events in Jackass Flats, five additional volcanic events are required in Crater Flat and nine additional volcanic events are required in Jackass Flats. The four known Pliocene volcanic events in Crater Flat include two events at the surface in southeastern Crater Flat (CRWMS M\&O 1996 [DIRS 100116]) and two magnetic anomalies (A and Q) with medium to high confidence of representing buried basalt (Hill and Stamatakos 2002 [DIRS 159500], Table 1).

Locations of each event were assumed to be random within the areas defined for event locations in Crater Flat and western Jackass Flats (Figure 6-25).

\subsection{Impact of Scenario on Frequency of Intersection}

The impact of the scenario defined in Section 6.5.4.2.1 on the annual frequency of intersection was assessed by comparing the results of the following two cases:

Case 1: Best estimate input parameters were developed from the PVHA defined inputs (CRWMS M\&O 1996 [DIRS 100116]) and the results of the 1999 USGS aeromagnetic survey discussed in Section 6.5.4.1. The selected time period of interest was the past 5 m.y. The volcanic event counts were set to 1 for Lathrop Wells, 2 for Sleeping Buttes, 3 for Northwest Crater Flat (combined Little Cones, combined Red and Black Cones, and Makani Cone), 1 for Buckboard Mesa, 2 for Southeast Crater Flat, 1 for Thirsty Mesa, and 12 buried events (A, B, C, D, E, combined F-G-H, I, combined L-M-N-O, Q, 1, 2, and 3). The average hidden-event factor distribution was set to $\{1.0(0.18), 1.15(0.47), 1.5(0.17), 2,(0.13), 4(0.05)\}$. The event length distribution was taken to be the composite distribution shown in Figure 6-4. The average dike orientation distribution was set at 90 percent of the events oriented $\mathrm{N} 27^{\circ} \mathrm{E}$ (standard deviation 15 degrees) and 10 percent of the events oriented $\mathrm{N} 19^{\circ} \mathrm{W}$ (standard deviation 12 degrees).

Case 2: An additional five buried events in Crater Flat and nine buried events in Jackass Flat were added to Case 1. These additional events were placed at random (uniform likelihood of location) within the areas shown on Figure 6-25. Ten simulations of event locations were generated, which are shown in Figure 6-26. The additional events were also assumed to have occurred within the past 5 m.y.

The scenario calculations were performed using two spatial models defined in the PVHA (CRWMS M\&O 1996 [DIRS 100116]): the parametric field shape model (2-D Gaussian) and the kernel density model. Only these two models were used because the postulated additional hidden-event locations could be directly incorporated within their framework without additional assumptions.

Gaussian kernels were used in the kernel density spatial model with the distribution for the smoothing parameter $h$ set to $\{3.6 \mathrm{~km}(0.333), 6.2 \mathrm{~km}(0.245), 8.9 \mathrm{~km}(0.311)$, and $12 \mathrm{~km}$ $(0.111)\}$. 


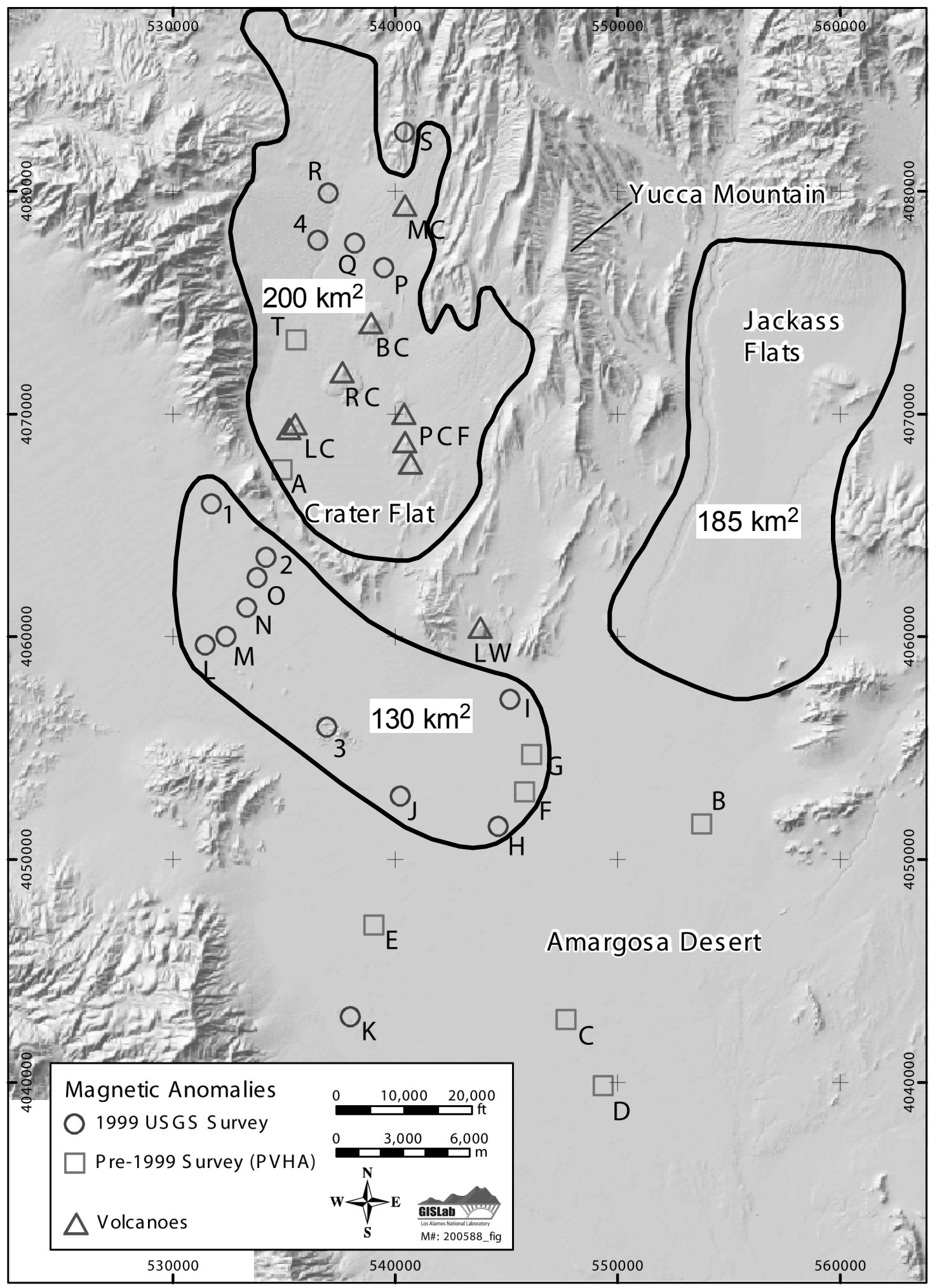

Source: Perry et al. (2003 [DIRS 171285], pp. 25-27, 29-31).

Figure 6-25. Areas Used to Define the Hidden-Events Scenario 


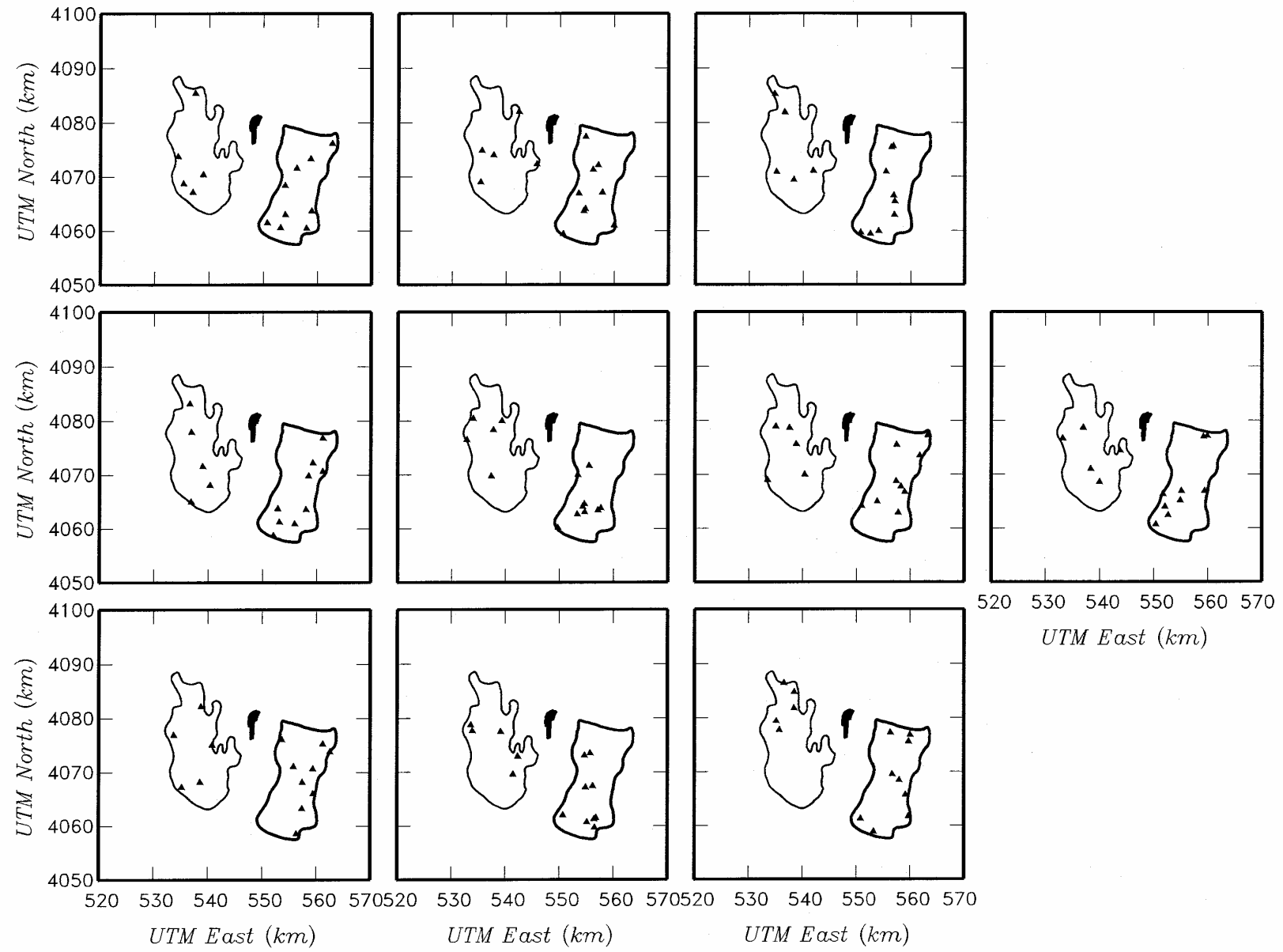

Source: Perry et al. (2003 [DIRS 171285], pp. 25-27, 29-31).

NOTE: The location of simulated events is shown by solid triangles. The location of the proposed repository is shown by the filled polygon.

Figure 6-26. Simulated Hidden-Event Locations in Crater Flat and Jackass Flats Used in Scenario Calculation

Figure 6-27 shows example results for the 2-D Gaussian parametric field shape model (events at Sleeping Butte, Thirsty Mesa, and Buckboard Mesa were considered to be separate fields consistent with PVHA interpretations and were not included in fitting the field shape to the event locations). Including the additional events in Jackass Flat broadens the fitted volcanic field shape and places the field center between the two concentrations of events. An alternative model not included in this analysis would be to assume that the events in Jackass Flat represent a separate field from those in Crater Flat. This alternative model would result in a smaller increase in the volcanic event density in the immediate vicinity of the proposed repository location. 
Case 1

Case 2

\section{Events/ yr/ sq km}
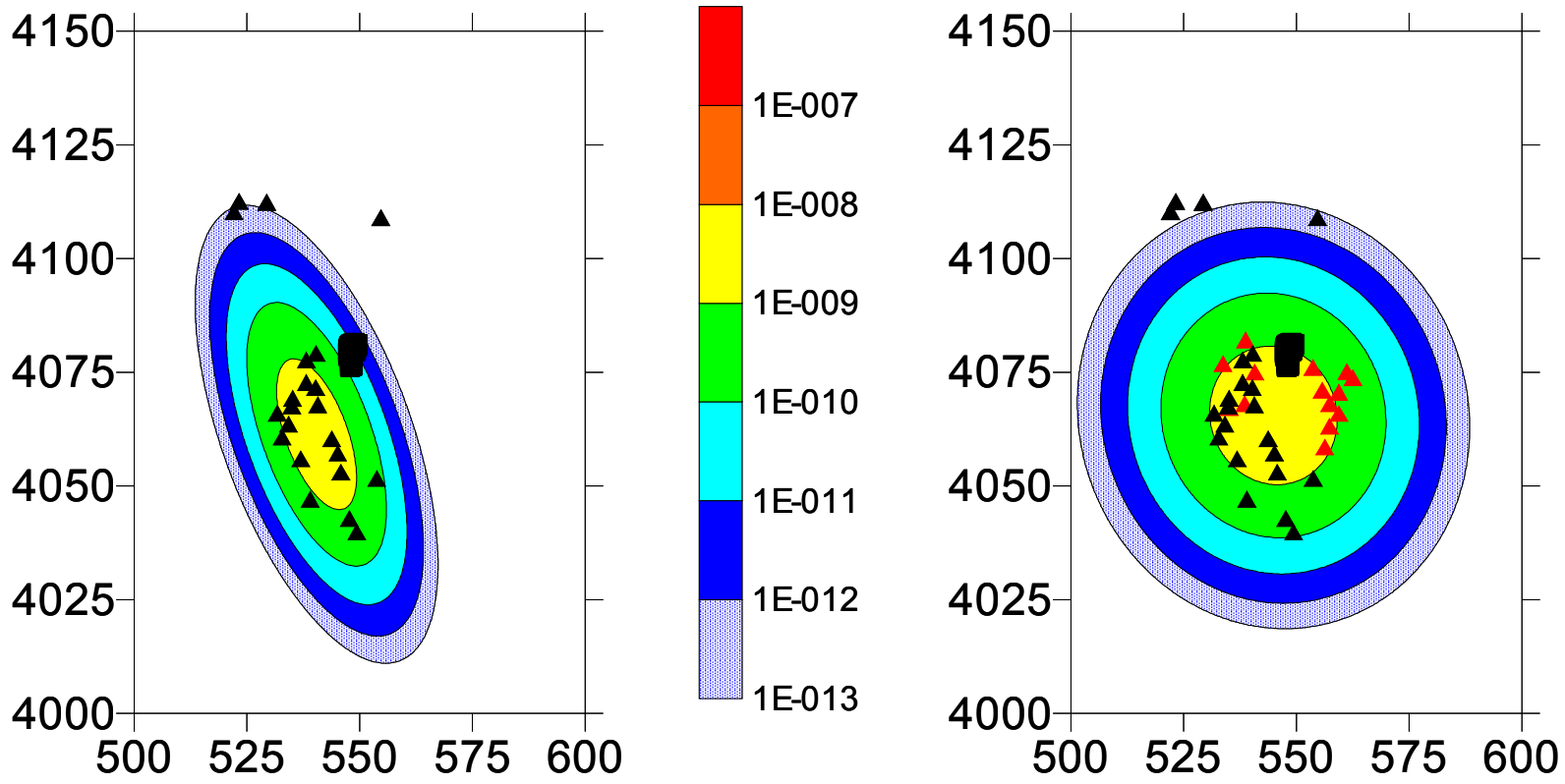

For Information Only

NOTE: The location of simulated events is shown by solid triangles: black for Case- 1 events, red for additional Case-2 events. The location of the proposed repository is shown by the filled polygon. Events at Sleeping Butte, Thirsty Mesa, and Buckboard Mesa were not included in the field.

Figure 6-27. Example of Effect of Hidden-Event Scenario on the Spatial Density of Volcanic Events Computed Using the 2-D Gaussian Parametric Field Shape Model

Figure 6-28 shows example results for the kernel density spatial model. For small values of $h$, the additional events produce a second concentration east of Yucca Mountain. For large values of $h$, the two concentrations merge, producing a spatial density pattern similar to that generated by the parametric field shape model (Figure 6-27).

Table 6-14 summarizes the results of the hidden-events scenario calculations. The inclusion of additional events in Crater Flat and Jackass Flat produce an increase in the annual frequency of intersection by a factor of 3 to 13, depending upon the spatial model. This increase is primarily a result of the effect of events in Jackass Flat on the spatial density of volcanic events (Figure 6-27 and Figure 6-28). Note that the additional hidden events represent an increase of a factor of 1.6 in the total number of events. 
Case 1
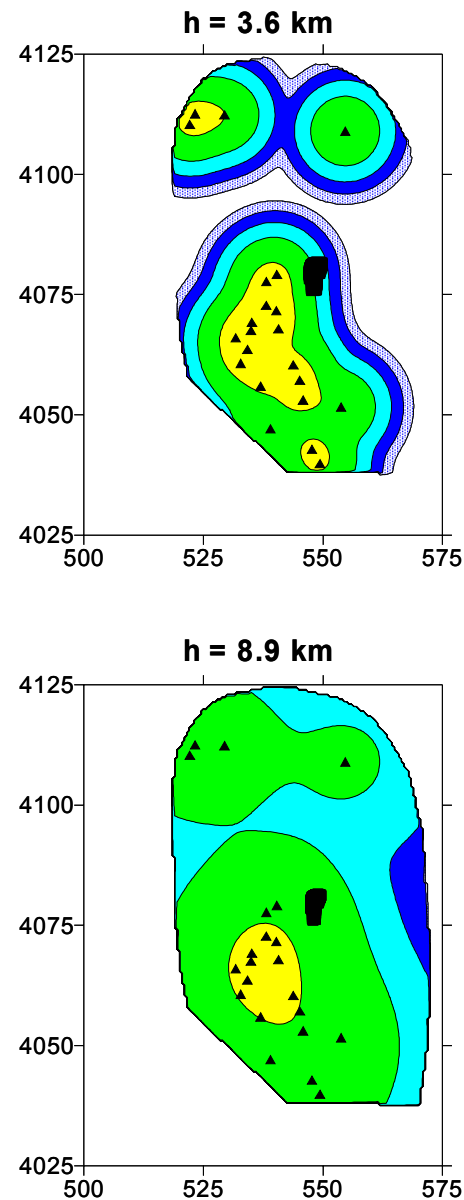

Case 2

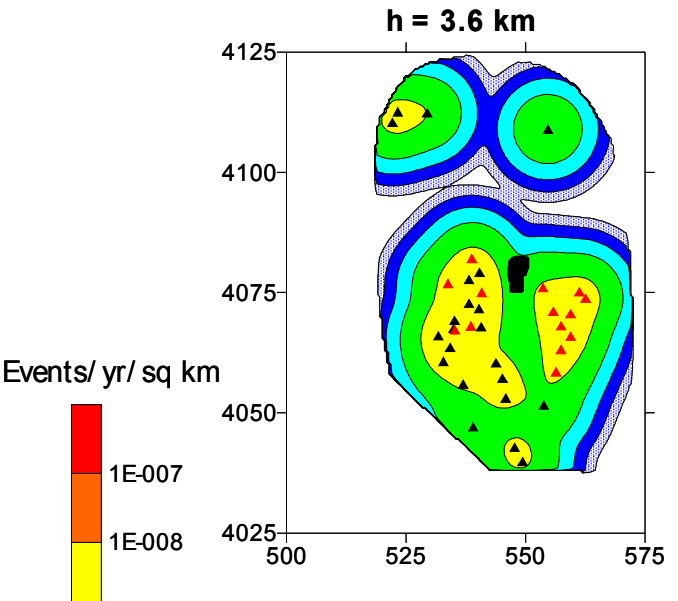

1E-009
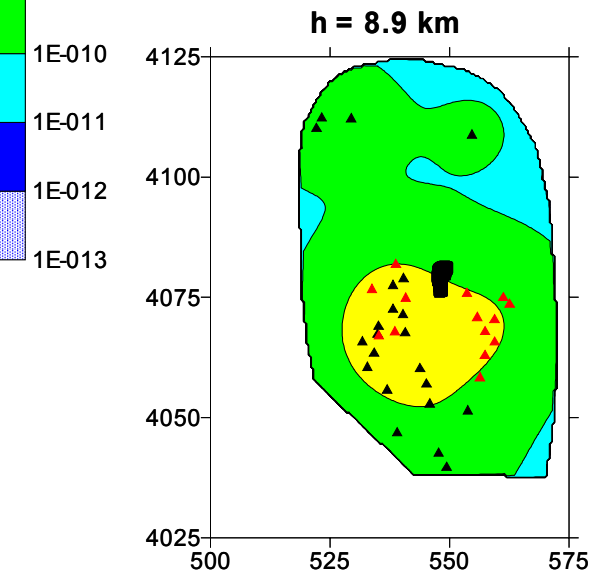

For Information Only

NOTE: The location of simulated events is shown by solid triangles: black for Case-1 events, red for additional Case- 2 events. The location of the proposed repository is shown by the filled polygon.

Figure 6-28. Example of Effect of Hidden-Event Scenario on the Spatial Density of Volcanic Events Computed Using the Kernel Density Spatial Model

Table 6-14. Summary of Computed Frequency of Intersection for 70,000 Metric Tons of Uranium NoBackfill Repository Layout (primary + contingency blocks) from Hidden-Events Scenario Cases

\begin{tabular}{|l|c|c|}
\hline \multirow{2}{*}{\multicolumn{1}{|c|}{ Spatial Model }} & \multicolumn{2}{c|}{ Annual Frequency of Intersection } \\
\cline { 2 - 3 } & Case 1 & Case 2 \\
\hline Parametric Field Shape & $0.7 \times 10^{-8}$ & $9.7 \times 10^{-8}$ \\
\hline Kernel Density & $2.2 \times 10^{-8}$ & $6.3 \times 10^{-8}$ \\
\hline Equally Weighted Average & $1.5 \times 10^{-8}$ & $8.0 \times 10^{-8}$ \\
\hline
\end{tabular}

Source: Perry et al. (2003 [DIRS 171285], pp. 25-27, 29-31). 


\section{INTENTIONALLY LEFT BLANK}




\section{CONCLUSIONS OF SCIENTIFIC ANALYSIS}

\subsection{SUMMARY}

The result of the PVHA (CRWMS M\&O 1996 [DIRS 100116]), the annual frequency of intersection of the proposed repository by a volcanic event (dike), has been recalculated using PVHA outputs to account for the 2003 repository footprint (the outline of the waste emplacement area) and extended to include the probability of an eruption within the repository footprint, conditional on a dike intersection (Table 7-1). The change in the annual frequency of intersection due to differences between the 2003 repository footprint and the repository footprint used at the time of PVHA is small $\left(1.7 \times 10^{-8}\right.$ per year versus $1.5 \times 10^{-8}$ per year), constituting an increase in the annual probability of intersection of approximately 13 percent. A conceptual framework for the probability calculations, based on PVHA outputs and subsequent studies, accounts for deep (mantle) and shallow (structural control) processes that influence volcanic event distribution and recurrence rate in the YMR. The framework presented here emphasizes the close correlation between the distribution of volcanic events and areas of crustal extension and faulting in the YMR, and within this context, the appropriateness of volcanic source zone boundaries defined in the PVHA. The framework also emphasizes the appropriate selection of parameter distributions that affect probability models and provides support for comparison of alternative scenarios and parameter selection within the framework of the volcanic history of the YMR. Alternative models presented by Connor et al. (2000 [DIRS 149935]) that result in higher eruption probabilities $\left(10^{-7}\right.$ versus $1.7 \times 10^{-8}$ per year) than those presented here, are found to employ input parameters that either represent extreme values (e.g., event length) or assume a specific geologic control (i.e., crustal density) on spatial distribution while not considering more defensible and observable controls (i.e., crustal extension and structure). Spatial density models weighted by crustal density result in higher event frequencies at the proposed repository site, while the same models weighted by an alternative geologic control, such as cumulative crustal extension across the Crater Flat structural domain would likely lead to decreased event frequencies at the site. Connor et al. (2000 [DIRS 149935]) state that the highest value $\left(10^{-7} \mathrm{per}\right.$ year) in their range of calculated probability values $\left(10^{-8}\right.$ to $10^{-7}$ per year) cannot be considered more or less likely than any other value they have calculated using alternative probability models. The analysis in this report suggests that the choice of input parameters used by Connor et al. (2000 [DIRS 149935]), compared to those used in the PVHA, logically places their highest probability value at the extreme upper tail of a probability distribution.

The annual frequency of intersection of the repository footprint by a dike or dike system associated with a volcanic event and the annual frequency of a volcanic event producing one or more eruptive centers within the proposed repository have been recalculated based on the 2003 repository footprint (BSC 2003 [DIRS 162289]). These results are summarized in Table 7-1. The annual frequency of disruption of the repository by one or more eruptive centers is obtained by multiplying the frequency of intersection from Figure 6-18, by the conditional probability of the occurrence of at least one eruptive center ( 1 minus the conditional probability of 0 centers) from the right-hand column of Table 6-11. The reported probability values represent the annual frequencies of intrusive and extrusive disruption of the repository waste emplacement footprint by a volcanic event, which may consist of multiple parallel dikes (see definition of volcanic event at the beginning of Section 6.5). Users of the results of this scientific analysis must 
consider the distribution for the number of parallel dikes associated with a volcanic event in assessing the consequences of igneous intrusion.

Conditional distributions for the length and azimuth of the intersecting dike and the number of eruptive centers occurring within the repository footprint are developed for the three values of frequency of intersection in Table 7-1. These distributions are very similar for the three levels of frequency of intersection. Because of this similarity, it is appropriate to use the conditional distributions obtained for the mean frequency of intersection to perform consequence analyses and as input to TSPA.

The inputs to this scientific analysis report are the results of an expert elicitation conducted in a manner consistent with the guidance in the Branch Technical Position on Expert Elicitation (Kotra et al. 1996 [DIRS 100909]). The PVHA experts explicitly quantified the uncertainties in their interpretations, and these uncertainties are represented in the outputs of this report in the form of probability distributions. Thus, it is concluded that the results of this report form an appropriate basis for the evaluation of the consequences of volcanic hazards in the YMR. Yucca Mountain Review Plan, Final Report (NRC 2003 [DIRS 163274]) acceptance criteria have been met as described in Appendix D of this report.

Table 7-1. Summary Frequencies of Disruptive Volcanic Events for the License Application Footprint

\begin{tabular}{|c|c|c|}
\hline $\begin{array}{c}\text { Annual Frequency of Intersection } \\
\text { of Proposed Repository by a } \\
\text { Volcanic Event }\end{array}$ & $\begin{array}{c}\text { Composite Conditional } \\
\text { Probability of at Least One } \\
\text { Eruptive Center }\end{array}$ & $\begin{array}{c}\text { Annual Frequency of Occurrence } \\
\text { of One or More Eruptive Centers } \\
\text { within Proposed Repository }\end{array}$ \\
\hline $7.4 \times 10^{-10}(5$ th percentile) & 0.75 & $5.6 \times 10^{-10}$ \\
\hline $1.7 \times 10^{-8}$ (mean) & 0.78 & $1.3 \times 10^{-8}$ \\
\hline $5.5 \times 10^{-8}$ (95th percentile) & 0.77 & $4.3 \times 10^{-8}$ \\
\hline
\end{tabular}

Output DTN: LA0307BY831811.001.

NOTE: Results presented in this table were rounded to two significant digits after calculation.

\subsection{OUTPUT DATA}

The outputs of this scientific analysis report based on the 2003 repository footprint (BSC 2003 [DIRS 162289]) are described in detail in Section 6.5.3. They are summarized as the following:

1. A discrete probability distribution for the annual frequency of intersection of the repository emplacement area footprint by a dike or dike system. This distribution is given in output file PVHA-4PA.DST (Output DTN: LA0307BY831811.001). The file contains three columns of data. The first column contains discrete values for the annual frequency of intersection. The second column contains the probability mass associated with each frequency of intersection. The third column contains the cumulative probability that the frequency of intersection is equal to, or lower than the corresponding value in the first column. This data file was modified from file PVHA-4P.DST (Output DTN: LA0302BY831811.001) to conform to the requirements of input distributions to TSPA. 
2. A discrete probability distribution for the annual frequency of disruption of the repository emplacement area footprint by one or more eruptive centers. This distribution is obtained by multiplying the first column of output file PVHA-4PA.DST (Output DTN: LA0307BY831811.001) by 0.782 , the conditional probability of disruption by at least one eruptive center, given intersection of the repository. As discussed in Sections 6.5.3.2 and 7.1, it is considered appropriate to use the conditional probability obtained for the mean frequency of intersection to define the full distribution for frequency of extrusive disruption.

3. Conditional joint probability distributions for length and azimuth of an intersecting dike and number of eruptive centers within the repository footprint, output files CCSM-LA.CMP, CC05-LA.CMP, and CC95-LA.CMP (Output DTN: LA0302BY831811.001). As discussed in Sections 6.5.3.2 and 7.1, it is considered appropriate to use the distributions obtained for the mean frequency of intersection (output file CCSM-LA.CMP) to evaluate consequences at all frequencies of intersection.

In addition, there are a number of other data sets associated with this analysis report. Output DTN: LA303BY831811.001 contains the repository footprint polygon developed in Appendix B and data used to generate figures and tables in Section 6 of this report. Output DTN: LA307BY831811.001 contains additional data used to generate figures and tables in Section 6 and 7. Output DTN: LA0009FP831811.001 contains the data files for PVHA 1996 volcanic hazard model and data used to generate some figures in Section 6 and Appendix C. Output DTN: LA0009FP831811.004 contains additional data from Appendix C. See Section 6.1.3 for a fuller description.

\subsection{UNCERTAINTIES}

The data and parameter inputs to the PVHA, as well as their uncertainty, were defined as part of the expert elicitation process. All of the uncertainties defined by the elicitation process were fully propagated through the probability models and are reflected in the final probability distribution. Selection of particular parameter values, ranges, and bounding assumptions for conceptual models were arrived at through the process of expert elicitation. The contributions to uncertainty from each of the PVHA components are described in Probabilistic Volcanic Hazard Analysis for Yucca Mountain, Nevada (CRWMS M\&O 1996 [DIRS 100116], Section 4.2) and Section 6.3.1.5 of this scientific analysis report. 


\section{INTENTIONALLY LEFT BLANK}




\section{INPUTS AND REFERENCES}

\subsection{DOCUMENTS CITED}

Altman, W.D.; Donnelly, J.P.; and Kennedy, J.E. 1988. Peer Review for High-

Level Nuclear Waste Repositories: Generic Technical Position. NUREG-1297.

Washington, D.C.: U.S. Nuclear Regulatory Commission. TIC: 200651.

Altman, W.D.; Donnelly, J.P.; and Kennedy, J.E. 1988. Qualification of Existing

103750

Data for High-Level Nuclear Waste Repositories: Generic Technical Position.

NUREG-1298. Washington, D.C.: U.S. Nuclear Regulatory Commission.

TIC: 200652.

Blakely, R.J.; Langenheim, V.E.; Ponce, D.A.; and Dixon, G.L. 2000.

151881

Aeromagnetic Survey of the Amargosa Desert, Nevada and California: A Tool for

Understanding Near-Surface Geology and Hydrology. Open-File Report 00-188.

[Denver, Colorado]: U.S. Geological Survey. TIC: 248767.

Brocher, T.M.; Hunter, W.C.; and Langenheim, V.E. 1998. "Implications of

100022

Seismic Reflection and Potential Field Geophysical Data on the Structural

Framework of the Yucca Mountain-Crater Flat Region, Nevada." Geological

Society of America Bulletin, 110, (8), 947-971. Boulder, Colorado: Geological

Society of America. TIC: 238643.

Brocoum, S.J. 1997. "Evaluation of Data Provided at U.S. Department of Energy

147772

(DOE) and U.S. Nuclear Regulatory Commission (NRC) Igneous Activity

Technical Exchange, February 25-26, 1997.” Letter from S.J. Brocoum

(DOE/YMSCO) to J.T. Greeves (NRC), June 4, 1997, with enclosure.

ACC: MOL.19970722.0276; MOL.19970722.0277.

BSC (Bechtel SAIC Company) 2003. Characterize Framework for Igneous

163769

Activity at Yucca Mountain, Nevada. ANL-MGR-GS-000001 REV 01. Las Vegas,

Nevada: Bechtel SAIC Company. ACC: DOC.20040106.0003.

BSC 2003. Repository Design, Repository/PA IED Subsurface Facilities.

162289

800-IED-EBS0-00401-000-00C. Las Vegas, Nevada: Bechtel SAIC Company.

ACC: ENG.20030303.0002.

BSC 2004. Atmospheric Dispersal and Deposition of Tephra from a Potential

170026

Volcanic Eruption at Yucca Mountain, Nevada. MDL-MGR-GS-000002, Rev. 01.

Las Vegas, Nevada: Bechtel SAIC Company.

BSC 2004. Characterize Eruptive Processes at Yucca Mountain, Nevada.

169980

ANL-MGR-GS-000002, Rev. 02. Las Vegas, Nevada: Bechtel SAIC Company.

BSC 2004. D\&E / PA/C IED Subsurface Facilities. 800-IED-WIS0-00101-000-

00A. Las Vegas, Nevada: Bechtel SAIC Company. ACC: ENG.20040309.0026.

164519 
BSC 2004. Dike/Drift Interactions. MDL-MGR-GS-000005, Rev. 01. Las Vegas, 170028 Nevada: Bechtel SAIC Company.

BSC 2004. Features, Events, and Processes: Disruptive Events. ANL-WIS-MD- 170017 000005, Rev. 02. Las Vegas, Nevada: Bechtel SAIC Company.

BSC 2004. Igneous Intrusion Impacts on Waste Packages and Waste Forms.

MDL-EBS-GS-000002 REV 01. Las Vegas, Nevada: Bechtel SAIC Company.

ACC: DOC.20040421.0002.

BSC 2004. Number of Waste Packages Hit by Igneous Intrusion. ANL-MGR-GS-

170001 000003, Rev. 01. Las Vegas, Nevada: Bechtel SAIC Company.

BSC 2004. Q-List. 000-30R-MGR0-00500-000-000 REV 00. Las Vegas, Nevada: 168361 Bechtel SAIC Company. ACC: ENG.20040721.0007.

BSC 2004. Technical Work Plan for Igneous Activity Assessment for Disruptive Events. TWP-WIS-MD-000007 REV 06. Las Vegas, Nevada: Bechtel SAIC Company. ACC: DOC.20040820.0001.

BSC 2004. Total System Performance Assessment (TSPA) Model/Analysis for the License Application. MDL-WIS-PA-000004, Rev. 00. Las Vegas, Nevada: Bechtel SAIC Company.

Byers, F.M., Jr. and Barnes, H. 1967. Geologic Map of the Paiute Ridge Quadrangle, Nye and Lincoln Counties, Nevada. Map GQ-577.

Washington, D.C.: U.S. Geological Survey. ACC: HQS.19880517.1104.

Canori, G.F. and Leitner, M.M. 2003. Project Requirements Document. 166275 TER-MGR-MD-000001 REV 02. Las Vegas, Nevada: Bechtel SAIC Company. ACC: DOC.20031222.0006.

Connor, C.B. and Hill, B.E. 1995. "Three Nonhomogeneous Poisson Models for 102646 the Probability of Basaltic Volcanism: Application to the Yucca Mountain Region, Nevada." Journal of Geophysical Research, 100, (B6), 10,107-10,125. Washington, D.C.: American Geophysical Union. TIC: 237682.

Connor, C.B.; Stamatakos, J.; Ferrill, D.; Hill, B.E.; Magsino, S.B.L.; La Femina, P.; and Martin, R.H. 1996. "Integrating Structural Models into Probabilistic Volcanic Hazard Analyses: An Example from Yucca Mountain, NV.” Abstracts with Programs - Geological Society of America, 28, (7), A-192. Boulder, Colorado: Geological Society of America. TIC: 247409. 
Connor, C.B.; Stamatakos, J.A.; Ferrill, D.A.; Hill, B.E.; Ofoegbu, G.I.; Conway, 149935 F.M.; Sagar, B.; and Trapp, J. 2000. "Geologic Factors Controlling Patterns of Small-Volume Basaltic Volcanism: Application to a Volcanic Hazards Assessment at Yucca Mountain, Nevada." Journal of Geophysical Research, 105, (B1), 417-432. Washington, D.C.: American Geophysical Union. TIC: 247906.

Crowe, B.; Perry, F.; Geissman, J.; McFadden, L.; Wells, S.; Murrell, M.; Poths, J.; 100110 Valentine, G.A.; Bowker, L.; and Finnegan, K. 1995. Status of Volcanism Studies for the Yucca Mountain Site Characterization Project. LA-12908-MS.

Los Alamos, New Mexico: Los Alamos National Laboratory.

ACC: HQO.19951115.0017.

Crowe, B.M. and Perry, F.V. 1990. "Volcanic Probability Calculations for the 100973

Yucca Mountain Site: Estimation of Volcanic Rates." Proceedings of the Topical Meeting on Nuclear Waste Isolation in the Unsaturated Zone, FOCUS '89, September 17-21, 1989, Las Vegas, Nevada. Pages 326-334. La Grange Park, Illinois: American Nuclear Society. TIC: 212738.

Crowe, B.M.; Johnson, M.E.; and Beckman, R.J. 1982. "Calculation of the 102741

Probability of Volcanic Disruption of a High-Level Radioactive Waste Repository Within Southern Nevada, USA." Radioactive Waste Management and the Nuclear Fuel Cycle, 3, (2), 167-190. New York, New York: Harwood Academic Publishers. TIC: 222179.

Crowe, B.M.; Perry, F.V.; Valentine, G.A.; Wallmann, P.C.; and Kossik, R. 1993. 100026 "Simulation Modeling of the Probability of Magmatic Disruption of the Potential Yucca Mountain Site." Proceedings of the Topical Meeting on Site Characterization and Model Validation, FOCUS '93, September 26-29, 1993, Las Vegas, Nevada. Pages 182-191. La Grange Park, Illinois: American Nuclear Society. TIC: 102245.

CRWMS M\&O 1996. Probabilistic Volcanic Hazard Analysis for Yucca Mountain, Nevada. BA0000000-01717-2200-00082 REV 0. Las Vegas, Nevada: CRWMS M\&O. ACC: MOL.19971201.0221.

CRWMS M\&O 1998. “Geochemistry." Book 3 - Section 6 of Yucca Mountain Site Description. B00000000-01717-5700-00019 REV 00. Las Vegas, Nevada: CRWMS M\&O. ACC: MOL.19980729.0052.

CRWMS M\&O 1998. Synthesis of Volcanism Studies for the Yucca Mountain Site Characterization Project. Deliverable 3781MR1. Las Vegas, Nevada: CRWMS M\&O. ACC: MOL.19990511.0400.

Day, W.C.; Dickerson, R.P.; Potter, C.J.; Sweetkind, D.S.; San Juan, C.A.; Drake, 100027 R.M., II; and Fridrich, C.J. 1998. Bedrock Geologic Map of the Yucca Mountain Area, Nye County, Nevada. Geologic Investigations Series I-2627. Denver, Colorado: U.S. Geological Survey. ACC: MOL.19981014.0301. 
Delaney, P.T. and Gartner, A.E. 1997. "Physical Processes of Shallow Mafic Dike 145370 Emplacement Near the San Rafael Swell, Utah." Geological Society of America Bulletin, 109, (9), 1177-1192. Boulder, Colorado: Geological Society of America. TIC: 247421.

Detournay, E.; Mastin, L.G.; Pearson, J.R.A.; Rubin, A.M.; and Spera, F.J. 2003. 169660 Final Report of the Igneous Consequences Peer Review Panel, with Appendices.

Las Vegas, Nevada: Bechtel SAIC Company. ACC: MOL.20031014.0097; MOL.20030730.0163.

DOE (U.S. Department of Energy) 1998. Total System Performance Assessment. 100550 Volume 3 of Viability Assessment of a Repository at Yucca Mountain. DOE/RW-0508. Washington, D.C.: U.S. Department of Energy, Office of Civilian Radioactive Waste Management. ACC: MOL.19981007.0030.

Earthfield Technology 1995. Summary Report Magnetic and Gravity Study of the Yucca Mountain Area, Nevada. Houston, Texas: Earthfield Technology. ACC: MOL.20000228.0374.

Farmer, G.L.; Perry, F.V.; Semken, S.; Crowe, B.; Curtis, D.; and DePaolo, D.J. 1989. "Isotopic Evidence on the Structure and Origin of Subcontinental Lithospheric Mantle in Southern Nevada." Journal of Geophysical Research, 94, (B6), 7885-7898. Washington, D.C.: American Geophysical Union.

TIC: 201800.

Feighner, M.A. and Majer, E.L. 1996. Results of the Analysis of the Timber Mt., Lathrop Wells, and Yucca Mt. Aeromagnetic Data. Milestone SPT23KM4. Berkeley, California: Lawrence Berkeley National Laboratory. ACC: MOL.19971204.0767.

Ferrill, D.A.; Stamatakos, J.A.; Jones, S.M.; Rahe, B.; McKague, H.L.; Martin, 105315 R.H.; and Morris, A.P. 1996. "Quaternary Slip History of the Bare Mountain Fault (Nevada) from the Morphology and Distribution of Alluvial Fan Deposits." Geology, 24, (6), 559-562. Boulder, Colorado: Geological Society of America. TIC: 234557.

Fridrich, C.J. 1999. "Tectonic Evolution of the Crater Flat Basin, Yucca Mountain 118942 Region, Nevada." Chapter 7 of Cenozoic Basins of the Death Valley Region. Wright, L.A. and Troxel, B.W., eds. Special Paper 333. Boulder, Colorado: Geological Society of America. TIC: 248054.

Fridrich, C.J.; Whitney, J.W.; Hudson, M.R.; and Crowe, B.M. 1999. "Space-Time Patterns of Late Cenozoic Extension, Vertical Axis Rotation, and Volcanism in the Crater Flat Basin, Southwest Nevada." Chapter 8 of Cenozoic Basins of the Death Valley Region. Wright, L.A. and Troxel, B.W., eds. Special Paper 333. Boulder, Colorado: Geological Society of America. TIC: 248054. 
Heizler, M.T.; Perry, F.V.; Crowe, B.M.; Peters, L.; and Appelt, R. 1999. "The

107255 Age of Lathrop Wells Volcanic Center: $\mathrm{An}{ }^{40} \mathrm{Ar} /{ }^{39} \mathrm{Ar}$ Dating Investigation." Journal of Geophysical Research, 104, (B1), 767-804. Washington, D.C.: American Geophysical Union. TIC: 243399.

Hill, B.E. and Stamatakos, J.A. 2002. Evaluation Of Geophysical Information 159500 Used to Detect and Characterize Buried Volcanic Features in the Yucca Mountain Region. San Antonio, Texas: Center for Nuclear Waste Regulatory Analyses. TIC: 252846.

Ho, C-H. and Smith, E.I. 1998. "A Spatial-Temporal/3-D Model for Volcanic 140152 Hazard Assessment: Application to the Yucca Mountain Region, Nevada." Mathematical Geology, 30, (5), 497-510. New York, New York: Plenum Publishing Corporation. TIC: 245110.

Hudson, M.R.; Minor, S.A.; and Fridrich, C.J. 1996. "The Distribution, Timing, and Character of Steep-Axis Rotations in a Broad Zone of Dextral Shear in Southwestern Nevada." Abstracts with Programs - Geological Society of America, 28, (7), A-451. Boulder, Colorado: Geological Society of America. TIC: 234723.

Kotra, J.P.; Lee, M.P.; Eisenberg, N.A.; and DeWispelare, A.R. 1996. Branch 100909 Technical Position on the Use of Expert Elicitation in the High-Level Radioactive Waste Program. NUREG-1563. Washington, D.C.: U.S. Nuclear Regulatory Commission. TIC: 226832.

Langenheim, V.E.; Kirchoff-Stein, K.S.; and Oliver, H.W. 1993. "Geophysical 148622 Investigations of Buried Volcanic Centers Near Yucca Mountain, Southwest Nevada." High Level Radioactive Waste Management, Proceedings of the Fourth Annual International Conference, Las Vegas, Nevada, April 26-30, 1993. 2, 18401846. La Grange Park, Illinois: American Nuclear Society. TIC: 208542.

Livaccari, R.F. and Perry, F.V. 1993. "Isotopic Evidence for Preservation of 162310 Cordilleran Lithospheric Mantle During the Sevier-Laramide Orogeny, Western United States." Geology, 21, (8), 719-722. Boulder, Colorado: Geological Society of America. TIC: 239258.

Magsino, S.L.; Connor, C.B.; Hill, B.E.; Stamatakos, J.A.; La Femina, P.C.; Sims, 147781 D.A.; and Martin, R.H. 1998. CNWRA Ground Magnetic Surveys in the Yucca Mountain Region, Nevada (1996-1997). CNWRA 98-001. San Antonio, Texas: Center for Nuclear Waste Regulatory Analyses. TIC: 247807.

McKay, M.D.; Beckman, R.J.; and Conover, W.J. 1979. "A Comparison of Three Methods for Selecting Values of Input Variables in the Analysis of Output from a Computer Code." Technometrics, 21, (2), 239-245. Alexandria, Virginia: American Statistical Association. TIC: 221741. 
NRC (U.S. Nuclear Regulatory Commission) 2003. Yucca Mountain Review Plan, 163274 Final Report. NUREG-1804, Rev. 2. Washington, D.C.: U.S. Nuclear Regulatory Commission, Office of Nuclear Material Safety and Safeguards. TIC: 254568.

O’Leary, D.W.; Mankinen, E.A.; Blakely, R.J.; Langenheim, V.E.; and Ponce, D.A. 158468 2002. Aeromagnetic Expression of Buried Basaltic Volcanoes Near Yucca Mountain, Nevada. Open-File Report 02-020. Denver, Colorado: U.S. Geological Survey. ACC: MOL.20020627.0225.

Perry, F. 2004. Characterize Igneous Framework and Probability. Scientific 171285 Notebook SN-LANL-SCI-298-V1. Pages 1-37 ACC: MOL.20040407.0028.

Perry, F.V. and Bowker, L.M. 1998. "Petrologic and Geochemical Constraints on 159502 Basaltic Volcanism in the Great Basin." Chapter 4 of Volcanism Studies: Final Report for the Yucca Mountain Project. Perry, F.V.; Crowe, B.M.; Valentine, G.A.; and Bowker, L.M.; eds. LA-13478. Los Alamos, New Mexico: Los Alamos National Laboratory. TIC: 247225.

Perry, F.V. and Crowe, B.M. 1992. "Geochemical Evidence for Waning Magmatism and Polycyclic Volcanism at Crater Flat, Nevada." High Level Radioactive Waste Management, Proceedings of the Third International Conference, Las Vegas, Nevada, April 12-16, 1992. 2, 2356-2365. La Grange Park, Illinois: American Nuclear Society. TIC: 204231.

Perry, F.V.; Baldridge, W.S.; and DePaolo, D.J. 1987. "Role of Asthenosphere and 162311 Lithosphere in the Genesis of Late Cenozoic Basaltic Rocks from the Rio Grande Rift and Adjacent Regions of the Southwestern United States." Journal of Geophysical Research, 92, (B9), 9193-9213. [Washington, D.C.]: American Geophysical Union. TIC: 225114.

Perry, F.V.; Crowe, B.M.; Valentine, G.A.; and Bowker, L.M., eds. 1998. Volcanism Studies: Final Report for the Yucca Mountain Project. LA-13478. Los Alamos, New Mexico: Los Alamos National Laboratory. TIC: 247225.

Ratcliff, C.D.; Geissman, J.W.; Perry, F.V.; Crowe, B.M.; and Zeitler, P.K. 1994. 106634 "Paleomagnetic Record of a Geomagnetic Field Reversal from Late Miocene Mafic Intrusions, Southern Nevada." Science, 266, 412-416. Washington, D.C.: American Association for the Advancement of Science. TIC: 234818.

Reamer, C.W. 1999. "Issue Resolution Status Report (Key Technical Issue: Igneous Activity, Revision 2)." Letter from C.W. Reamer (NRC) to Dr. S. Brocoum (DOE/YMSCO), July 16, 1999, with enclosure.

ACC: MOL.19990810.0639. 
Rosenbaum, J.G.; Hudson, M.R.; and Scott, R.B. 1991. "Paleomagnetic

106708

Constraints on the Geometry and Timing of Deformation at Yucca Mountain, Nevada.” Journal of Geophysical Research, 96, (B2), 1963-1979.

Washington, D.C.: American Geophysical Union. TIC: 225126.

Savage, J.C.; Connor, C.B.; Stamatakos, J.A.; Ferrill, D.A.; Hill, B.E.; Davis, J.L.;

Wernicke, B.P.; and Bennett, R.A. 1998. "Detecting Strain in the Yucca Mountain Area, Nevada." Science, 282, ([5391]), 1007b. Washington, D.C.: American Association for the Advancement of Science. TIC: 243445.

Savage, J.C.; Svarc, J.L.; and Prescott, W.H. 1999. "Strain Accumulation at Yucca Mountain, Nevada, 1983-1998." Journal of Geophysical Research, 104, (B8), 17627-17631. Washington, D.C.: American Geophysical Union. TIC: 245645.

Sawyer, D.A.; Fleck, R.J.; Lanphere, M.A.; Warren, R.G.; Broxton, D.E.; and Hudson, M.R. 1994. "Episodic Caldera Volcanism in the Miocene Southwestern Nevada Volcanic Field: Revised Stratigraphic Framework, ${ }^{40} \mathrm{Ar} /{ }^{39} \mathrm{Ar}$ Geochronology, and Implications for Magmatism and Extension." Geological Society of America Bulletin, 106, (10), 1304-1318. Boulder, Colorado: Geological Society of America. TIC: 222523.

Smith, E.I.; Feuerbach, D.L.; Naumann, T.R.; and Faulds, J.E. 1990. "The Area of 101019 Most Recent Volcanism Near Yucca Mountain, Nevada: Implications for Volcanic Risk Assessment." High Level Radioactive Waste Management, Proceedings of the International Topical Meeting, Las Vegas, Nevada, April 8-12, 1990. 1, 81-90.

La Grange Park, Illinois: American Nuclear Society. TIC: 202058.

Smith, E.I.; Keenan, D.L.; and Plank, T. 2002. "Episodic Volcanism and Hot 158735 Mantle: Implications for Volcanic Hazard Studies at the Proposed Nuclear Waste Repository at Yucca Mountain, Nevada." GSA Today, 12, (4), 4-10. Boulder, Colorado: Geological Society of America. TIC: 253146.

Stamatakos, J.A.; Connor, C.B.; and Martin, R.H. 1997. "Quaternary Basin Evolution and Basaltic Volcanism of Crater Flat, Nevada, from Detailed Ground Magnetic Surveys of the Little Cones." Journal of Geology, 105, 319-330. Chicago, Illinois: University of Chicago. TIC: 245108.

Wernicke, B.; Davis, J.L.; Bennett, R.A.; Elosegui, P.; Abolins, M.J.; Brady, R.J.; House, M.A.; Niemi, N.A.; and Snow, J.K. 1998. "Anomalous Strain Accumulation in the Yucca Mountain Area, Nevada." Science, 279, 2096-2100. New York, New York: American Association for the Advancement of Science. TIC: 235956. 
Wernicke, B.P.; Christiansen, R.L.; England, P.C.; and Sonder, L.J. 1987.

107250

"Tectonomagmatic Evolution of Cenozoic Extension in the North American Cordillera." Continental Extensional Tectonics. Coward, M.P.; Dewey, J.F.; and Hancock, P.L., eds. Special Publication No. 28. Pages 203-221. [Oxford, England:

Geological Society]. TIC: 225180.

Yogodzinski, G.M. and Smith, E.I. 1995. "Isotopic Domains and the Area of 136262 Interest for Volcanic Hazard Assessment in the Yucca Mountain Area."

Transactions of the American Geophysical Union, 76, (46), F669. Washington, D.C.: American Geophysical Union. TIC: 237939.

Ziegler, J.D. 2002. “Transmittal of Report Addressing Key Technical Issue (KTI) Agreement Item Igneous Activity (IA) 1.02." Letter from J.D. Ziegler (DOE/YMSCO) to J.R. Schlueter (NRC), September 26, 2002, 0926024421, OL\&RC: TCG-1820, with enclosure. ACC: MOL.20021104.0351.

\subsection{CODES, STANDARDS, REGULATIONS, AND PROCEDURES}

10 CFR 63. Energy: Disposal of High-Level Radioactive Wastes in a Geologic Repository at Yucca Mountain, Nevada. Readily available.

156605

AP-2.22Q, Rev. 1 ICN 1. Classification Analyses and Maintenance of the Q-List

AP-SIII.9Q, 1 ICN 7. Scientific Analysis

AP-SV.1Q, Rev. 1 ICN 1. Control of the Electronic Management of Information

\subsection{QUALIFIED SOFTWARE}

LANL (Los Alamos National Laboratory) 2000. Software Routine: CFRAC.FOR 148560 V1.0. V1.0. 10254-1.0-00.

LANL 2000. Software Routine: FITFIELD.FOR V1.0. V1.0. 10263-1.0-00.

LANL 2000. Software Routine: FIT2CNTR.FOR V1.0. V1.0. 10261-1.0-00.

LANL 2000. Software Routine: UZVPVHLH.FOR V1.0. V1.0. 10280-1.0-00.

148547

LANL 2000. Software Routine: ZBCKVHLH.FOR V1.0. V1.0. 10284-1.0-00.

148550

LANL 2000. Software Routine: FKVPVHLH.FOR V1.0. V1.0. 10268-1.0-00.

148551

LANL 2000. Software Routine: PFGVHLH.FOR V1.0. V1.0. 10274-1.0-00.

148552

LANL 2000. Software Routine: FPFGVHLH.FOR V1.0. V1.0. 10270-1.0-00.

148553

LANL 2000. Software Routine: VHTIELHS.FOR V1.0. V1.0. 10281-1.0-00.

148554 
LANL 2000. Software Routine: FITIDSR.FOR V1.0. V1.0. 10264-1.0-00. 148557

LANL 2000. Software Routine: COMBDELD.FOR V1.0. V1.0. 10288-1.0-00. 148617

LANL 2000. Software Routine: FITCD.FOR V1.0. V1.0. 10262-1.0-00. 148532

LANL 2000. Software Routine: SFCD.FOR V1.0. V1.0. 10275-1.0-00. 148533

LANL 2000. Software Routine: DCPELD.FOR V1.0. V1.0. 10258-1.0-00. 148534

LANL 2000. Software Routine: CPDI.FOR V1.0. V1.0. 10257-1.0-00. 148535

LANL 2000. Software Routine: UZVH.FOR V1.0. V1.0. 10277-1.0-00. 148536

LANL 2000. Software Routine: UZVPVH.FOR V1.0. V1.0. 10279-1.0-00. 148537

LANL 2000. Software Routine: FKVPVH.FOR V1.0. V1.0. 10267-1.0-00. 148538

LANL 2000. Software Routine: ZBCKVH.FOR V1.0. V1.0. 10283-1.0-00. 148539

LANL 2000. Software Routine: PFGVH.FOR V1.0. V1.0. 10273-1.0-00. 148542

LANL 2000. Software Routine: FPFGVH.FOR V1.0. V1.0. 10269-1.0-00. 148543

LANL 2000. Software Routine: VHTREE.FOR V1.0. V1.0. 10282-1.0-00. 148544

LANL 2000. Software Routine: UZVHLH.FOR V1.0. V1.0. 10278-1.0-00. 148545

LANL 2000. Software Routine: FKVHLH.FOR V1.0. V1.0. 10266-1.0-00. 148546

LANL 2000. Software Routine: DLECD.FOR V1.0. V1.0. 10260-1.0-00. 148558

LANL 2000. Software Routine: FKVH.FOR V1.0. V1.0. 10265-1.0-00. 148567

LANL 2000. Software Routine: SFIDSR.FOR V1.0. V1.0. 10276-1.0-00. 148571

BSC 2000. Software Routine: COMBSF. V 1.1. PC, Windows 95. 10255-1.1-00. 168218

BSC 2000. Software Routine: COMBSM. V 1.1. PC, Windows 95. 10256-1.1-00. 168220

BSC 2000. Software Routine: DILECDLH. V 1.1. PC, Windows 95. 10259-1.1-00.

BSC 2000. Software Routine: MARGIN. V 1.1. PC, Windows 95. 10271-1.1-00. 168223 
BSC 2000. Software Routine: NECPDS. V 1.1. PC, Windows 95. 10272-1.1-00. 168238

Dynamic Graphics 2000. Software Code: EARTHVISION. V5.1. SGI/IRIX 6.5. 167994 10174-5.1-00.

\subsection{INPUT DATA AND OTHER REFERENCED DTNS}

LA0004FP831811.002. Volume of Volcanic Centers in the Yucca Mountain

Region. Submittal date: 04/14/2000.

LA0305DK831811.002. Locations and Thicknesses of Tephra (Ashfall) from

164026

Lathrop Wells Cone, Nevada. Submittal date: 05/09/2003.

LA0407DK831811.001. Physical Parameters of Basaltic Magma and Eruption

170768

Phenomena. Submittal date: 07/15/2004.

LAFP831811AQ97.001. Chemical and Geochronology Data for the Revision and

Final Publication of the Volcanism Synthesis Report. Submittal date: 08/29/1997.

MO0002PVHA0082.000. Probabilistic Volcanic Hazard Analysis for Yucca Mountain, Nevada. Submittal date: 02/17/2000.

MO0003YMP98126.001. Quaternary and Pliocene Basalt. Submittal date:

149605

03/02/2000.

MO0407SEPFEPLA.000. LA FEP List. Submittal date: 07/20/2004.

170760

\subsection{OUTPUT DATA}

LA0009FP831811.001. Compilation and Summaries of Data Supporting Computation of Volcanic Event Intersection Frequencies. Submittal date: 09/01/2000.

LA0009FP831811.004. Data Summaries Supporting Computation of Volcanic Event Intersection Frequencies for the 70,000 MTU Repository Layout. Submittal date: $09 / 14 / 2000$.

LA0302BY831811.001. Characterize Igneous Framework and Probability. Submittal date: 02/05/2003.

LA0303BY831811.001. Characterize Igneous Framework Figures and Tables. Submittal date: 04/07/2003.

LA0307BY831811.001. Characterize Igneous Framework Additional Output. Submittal date: 07/29/03. 
APPENDIX A

DESCRIPTION OF MATHEMATICAL FORMULATION AND IMPLEMENTATION OF PROBABILISTIC VOLCANIC HAZARD ANALYSIS 
Section A1 of this Appendix describes the mathematical formulation used to compute the conditional distributions for the length and azimuth of intersecting dikes and the conditional distribution for the number of eruptive centers within the repository footprint. Section 2 of this Appendix describes the implementation of that formulation.

\section{A1 MATHEMATICAL FORMULATION}

The mathematical formulation used to compute the frequency of intersection of the repository footprint by a volcanic event is described in detail in the PVHA report (CRWMS M\&O 1996 [DIRS 100116], Section 3). The focus of this section is to describe the extension of that mathematical formulation to the computation of the conditional distributions for length and azimuth of intersecting dikes and the conditional distributions for number of eruptive centers within the repository footprint.

\section{A1.1 Frequency of Intersection of the Repository Footprint by a Dike}

This section restates the PVHA formulation (CRWMS M\&O 1996 [DIRS 100116], Section 3) to introduce terms and notation.

The PVHA study provided a distribution for the annual frequency of intersection of the proposed repository, $v^{I}(t)$, computed using the relationship (CRWMS M\&O 1996 [DIRS 100116], p. 3-2):

$$
v^{I}(t)=\iint_{R} \lambda(x, y, t) \cdot P^{I}(\mid x, y) \mathrm{d} x \mathrm{~d} y
$$

where $\lambda(x, y, t)$ is the rate density of volcanic events at location $(x, y)$ for the current time $t ; P^{I}(\mid x, y)$ is the conditional probability that a dike associated with the volcanic event at point $(x, y)$ intersects the proposed repository boundary; and $R$ is the region surrounding the proposed repository. Note that the notation for intersection has been changed from a subscript $I$ in Probabilistic Volcanic Hazard Analysis for Yucca Mountain, Nevada (CRWMS M\&O 1996 [DIRS 100116]) to a superscript $I$ in this report for clarity.

The actual calculation was performed on a $0.5-\mathrm{km} \times 0.5-\mathrm{km}$ grid spacing using the numerical summation:

$$
v^{I}(t)=\sum_{i} \sum_{j} \lambda\left(x_{i}, y_{j}, t\right) \cdot P^{I}\left(x_{i}, y_{j}\right) \Delta x \Delta y
$$

The PVHA experts quantified the uncertainty in $v^{I}(t)$ by developing a set of alternative probability models and model parameters for all aspects of the hazard calculation. These models were organized in the logic tree format shown in Figure 6-12a and Figure 6-12b.

The end branches of these logic trees define a discrete joint distribution for the parameters, $\Theta$, required to perform the calculation. Thus, Equation A-2 becomes:

$$
v^{I}\left(t \mid \theta_{S}\right)=\sum_{i} \sum_{j} \lambda\left(x_{i}, y_{j}, t \mid \theta_{S}\right) \cdot P^{I}\left(x_{i}, y_{j}, \theta_{S}\right) \Delta x \Delta y
$$


where $\theta_{S}$ is the parameter set associated with an individual end branch of one expert's logic tree. The probability that $v^{I}\left(t \mid \theta_{S}\right)$ is the correct frequency of intersection, given the expert's characterization of the uncertainty in the process, is given by the probability that the parameter set $\Theta$ takes on the specific values defined by $\theta_{S}, P\left(\Theta=\theta_{S}\right)$. This discrete probability is obtained by multiplying all of the conditional probabilities at each node along the path through the logic tree that leads to $\theta_{S}$. The mean or expected frequency of intersection is given by:

$$
\mathrm{E}\left[v^{I}(t)\right]=\sum_{s} v^{I}\left(t \mid \theta_{S}\right) \cdot P\left(\Theta=\theta_{S}\right)
$$

and the percentiles of the distribution for $v^{I}(t)$ are obtained by ordering the values of $v^{I}\left(t \mid \theta_{S}\right)$ and then summing the probabilities $P\left(\Theta=\theta_{S}\right)$ until the desired percentiles are reached.

The models used to obtain $\lambda\left(x, y, t \mid \theta_{S}\right)$ are described in Section 3 of the PVHA report (CRWMS M\&O 1996 [DIRS 100116]). They are not described here because they do not impact the development of the conditional distributions for length and azimuth of intersecting dikes and the number of eruptive centers within the repository.

\section{A1.2 Conditional Distribution for Length and Azimuth of an Intersecting Dike}

The above formulation for the PVHA hazard computation gives the overall frequency of intersection, $v^{I}(t)$. However, to compute the consequences of an intersection, one needs to know the distribution for length and orientation of the intersecting dikes. This distribution is developed by breaking down (disaggregating) the total frequency, $v^{I}\left(t \mid \theta_{S}\right)$, into frequencies for specific values of intersecting dike length, $L_{m}^{I}$, and dike azimuth, $\phi_{n}$. The process involves computing the spatial disaggregation of the frequency of intersection into the contributions from each location $\left(x_{i}, y_{j}\right)$ in the spatial grid around the proposed repository, $v_{x_{i,} y_{j}}^{I}\left(t \mid \theta_{S}\right)$ (see Figure 6-8). At each point $\left(x_{i}, y_{j}\right)$, the conditional probability of intersection is the probability that dikes or dike systems of all lengths and azimuths will intersect the proposed repository. The conditional probability of intersection can be divided into probabilities for intersection from dikes with specific lengths and azimuths (see Figure 6-9). As a result, the frequency of intersection from volcanic events at point $\left(x_{i}, y_{j}\right)$ is divided into the frequency of intersection from volcanic events at point $\left(x_{i}, y_{j}\right)$ that produce specific values of length, $L_{m}^{I}$, and azimuth, $\phi_{n}$, within the repository footprint, $v_{x_{i}, y_{j}}^{I}\left(t, L_{m}^{I}, \phi_{n} \mid \theta_{S}\right)$. Summing these frequencies over all locations gives the frequency of intersection with a specific value of length and azimuth from all volcanic events, $v^{I}\left(t, L_{m}^{I}, \phi_{n} \mid \theta_{S}\right)$. Dividing this frequency by the total frequency of intersection, $v^{I}\left(t \mid \theta_{S}\right)$, gives the conditional probability that an intersecting dike will produce a specific value of length and azimuth within the proposed repository.

The conditional probability of intersection, $P^{I}\left(\mid x, y, \theta_{S}\right)$, in Equation A-3 is computed using the relationship (CRWMS M\&O 1996 [DIRS 100116], p. 3-17):

$$
P^{I}\left(x_{i}, y_{j}, \theta_{S}\right)=\int_{0}^{L_{\max } \mid \theta_{S}} f\left(d \mid \theta_{S}\right) \cdot\left[\int_{\phi_{1} \mid x, y, d}^{\phi_{2} \mid x, y, d} f\left(\phi \mid \theta_{S}\right) d \phi\right] \mathrm{d} d
$$


where:

$f\left(d \mid \theta_{S}\right)$ is the probability that a dike associated with a volcanic event at $(x, y)$ will extend a distance $d$ toward the proposed repository

$L_{\max }$ is the maximum length of a dike

$f\left(\phi \mid \theta_{S}\right)$ is the density function for dike azimuth

$\phi_{1} \mid x, y, d$ and $\phi_{2} \mid x, y, d$ define the range of azimuths over which a dike extending $d$ from a volcanic event at $(x, y)$ will intersect the footprint of the proposed repository.

These parameters are illustrated on Figure 6-9. The integration over dike length in Equation A-5 is also computed by summation.

The density function $f\left(d \mid \theta_{S}\right)$ is computed by convolving the distribution for the total length of the dike, $f\left(L \mid \theta_{S}\right)$, with a distribution for the normalized location of the dike relative to the volcanic event, $f\left(E^{L} \mid \theta_{S}\right)$. Figure 6-10 illustrates the process using example distributions defined by one of the PVHA expert panel members. Part (a) of Figure 6-10 shows the probability distribution for the total length of the dike associated with a volcanic event, $f\left(L \mid \theta_{S}\right)$. Typically, these distributions were defined by the PVHA experts to be skewed with long upper tails. Part (b) shows a distribution for the normalized location of the point event (point $(x, y)$ ) relative to the total length of the dike, $f\left(E^{L} \mid \theta_{S}\right)$. These distributions were defined as symmetric distributions over the range of 0 to 1 , typically with higher probability for locations at the midpoint (the dike centered on point $(x, y)$ ) than at the ends (the dike extending for its full length in one direction away from point $(x, y)$ ). Part (c) shows the resulting probability and cumulative probability distributions for distance from the proposed repository to the end of the dike $\left(d=E^{L} \times L\right)$ obtained by convolving the distributions from (a) and (b). Using these definitions, the summation form of Equation A-5 becomes:

$$
P^{I}\left(x_{i}, y_{j}, \theta_{S}\right)=\sum_{L_{p}=0}^{L_{p}=L_{\max } \mid \theta_{S}} P\left(L_{p} \mid \theta_{S}\right) \sum_{E_{o}^{L}=0}^{E_{o}^{L}=1} P\left(E_{o}^{L} \mid \theta_{S}\right) \sum_{\phi_{n}=\phi_{1} \mid x, y, E_{o}^{L} \times L_{p}}^{\phi_{n}=\phi_{2} \mid x, y, E_{o}^{L} \times L_{p}} P\left(\phi_{n} \mid \theta_{S}\right)
$$

where:

$P\left(L_{p} \mid \theta_{S}\right)$ is a discrete probability mass function for dike length

$P\left(E_{o}^{L} \mid \theta_{S}\right)$ is a discrete probability mass function for the relative location of the dike on the volcanic event

$P\left(\phi_{n} \mid \theta_{S}\right)$ is a discrete probability mass function for dike azimuth

$\phi_{1} \mid x, y, E_{o}^{L} \times L_{p}$ and $\phi_{2} \mid x, y, E_{o}^{L} \times L_{p}$ again define the range of azimuths over which a dike extending $d=E_{o}^{L} \times L_{p}$ from a volcanic event at $(x, y)$ will intersect the repository footprint. 
The three probability mass functions are obtained by discretizing the continuous probability density functions developed for $L, E^{L}$, and $\phi$ by the PVHA experts.

As the summation in Equation A-6 is performed, it can be disaggregated into bins defined by azimuth increments, $\phi_{n}$, and intersection length increments, $L_{m}^{I}$, where $L^{I}$ is the length of penetration of a dike into the proposed repository (see Figure 6-9). As a result, Equation A-6 can be rewritten as:

$$
P^{I}\left(x_{i}, y_{j}, \theta_{S}\right)=\sum_{m} \sum_{n} P^{I}\left(L_{m}^{I}, \phi_{n} \mid x_{i}, y_{j}, \theta_{S}\right)
$$

The quantity $P^{I}\left(L_{m}^{I}, \phi_{n} \mid x_{i}, y_{j}, \theta_{S}\right)$ is the probability that a dike associated with a volcanic event at location $\left(x_{i}, y_{j}\right)$ will intersect the proposed repository with length $L_{m}^{I}$ and azimuth $\phi_{n}$, and is given by:

$$
P^{I}\left(L_{m}^{I}, \phi_{n} \mid x_{i}, y_{j}, \theta_{S}\right)=\sum_{L_{p}=0}^{L_{p}=L_{\max } \mid \theta_{S}} P\left(L_{p} \mid \theta_{S}\right) \sum_{E_{o}^{L}=0}^{E_{o}^{L}=1} P\left(E_{o}^{L} \mid \theta_{S}\right) \cdot \delta\left(L^{I}=L_{m}^{I}\right) \cdot P\left(\phi_{n} \mid \theta_{S}\right)
$$

where $\delta\left(L^{I}=L_{m}^{I}\right)=1$ for those combinations of $L_{p}, E_{o}^{L}$, and $\phi_{n}$ that result in $L^{I}=L_{m}^{I}$ for a volcanic event at $(x, y)$, and $\delta\left(L^{I}=L_{m}^{I}\right)=0$ otherwise.

Multiplying Equation A-8 by the frequency of volcanic events at $\left(x_{i}, y_{j}\right)$ and summing over all locations yields the frequency of occurrence for intersections of the proposed repository of length $L_{m}^{I}$ and azimuth $\phi_{n}$ :

$$
v^{I}\left(t, L_{m}^{I}, \phi_{n} \mid \theta_{S}\right)=\sum_{i} \sum_{j} \lambda\left(x_{i}, y_{j}, t \mid \theta_{S}\right) \cdot P^{I}\left(L_{m}^{I}, \phi_{n} \mid x_{i}, y_{j}, \theta_{S}\right)
$$

Because the summation of $v^{I}\left(t, L_{m}^{I}, \phi_{n} \mid \theta_{S}\right)$ over the $m \times n L^{I}$ and $\phi$ intervals equals $v^{I}\left(t \mid \theta_{S}\right)$ $\left[v^{I}\left(t \mid \theta_{S}\right)=\sum_{m} \sum_{n} v^{I}\left(t, L_{m}^{I}, \phi_{n} \mid \theta_{S}\right)\right]$, the ratio $v^{I}\left(t, L_{m}^{I}, \phi_{n} \mid \theta_{S}\right) / v^{I}\left(t \mid \theta_{S}\right)$ defines the relative frequency of intersection events with length $L_{m}^{I}$ and azimuth $\phi_{n}$.

Equation A-9 can be recast into the form:

$$
\begin{gathered}
v^{I}\left(t, L_{m}^{I}, \phi_{n} \mid \theta_{S}\right)=\sum_{i} \sum_{j}\left[\lambda\left(x_{i}, y_{j}, t \mid \theta_{S}\right) \cdot P^{I}\left(\mid x_{i}, y_{j}, \theta_{S}\right)\right] \cdot\left[\frac{P^{I}\left(L_{m}^{I}, \phi_{n} \mid x_{i}, y_{j}, \theta_{S}\right)}{P^{I}\left(\mid x_{i}, y_{j}, \theta_{S}\right)}\right] \\
\text { or, if we define: } v_{x_{i}, y_{j}}^{I}\left(t \mid \theta_{S}\right)=\lambda\left(x_{i}, y_{j}, t \mid \theta_{S}\right) \cdot P^{I}\left(\mid x_{i}, y_{j}, \theta_{S}\right) \\
v^{I}\left(t, L_{m}^{I}, \phi_{n} \mid \theta_{S}\right)=\sum_{i} \sum_{j}\left[v_{x_{i}, y_{j}}^{I}\left(t \mid \theta_{S}\right)\right] \cdot\left[\frac{P^{I}\left(L_{m}^{I}, \phi_{n} \mid x_{i}, y_{j}, \theta_{S}\right)}{P^{I}\left(\mid x_{i}, y_{j}, \theta_{S}\right)}\right]
\end{gathered}
$$


The first term in brackets defines the contribution to the frequency of intersection from volcanic events occurring at point $(x, y), v_{x_{i}, y_{j}}^{I}\left(t \mid \theta_{S}\right)$. The second term in brackets defines the joint distribution for intersection length and azimuth from volcanic events at point $(x, y)$ conditional on intersection occurring.

The only parameters of $\theta_{S}$ that affect the second term are the specification of the dike length, dike location on the volcanic event, and dike azimuth distributions. The PVHA experts specified these distributions to be independent of the distributions that characterized the spatial density and frequency of volcanic events (Figure 6-12a). Thus $\Theta$ can be broken into two independent sets: $\Theta^{D}$ and $\Theta^{E}$. Parameters $\Theta^{D}$ are those that define the distributions for total length, location relative to the point volcanic event, and azimuth of the dike associated with the volcanic event (the parameters used in the computation of the conditional probability $P^{I}(\mid x, y)$ ). These parameters are defined by the first two levels of the logic tree shown on Figure 6-12a. Parameters $\Theta^{E}$ are those that define the distribution for volcanic event frequency, $\lambda(x, y, t)$. These parameters are defined by all of the remaining levels of the logic trees shown on Figure 6-12a and Figure 6-12b. Therefore, the expected or mean value of $v^{I}\left(t, L_{m}^{I}, \phi_{n} \mid \theta_{S}\right)$ (Equation A-4) can be written as:

$$
\begin{gathered}
\mathrm{E}\left[v^{I}\left(t, L_{m}^{I}, \phi_{n} \mid \Theta\right)\right]=\sum_{\Theta^{D}} P\left(\Theta^{D}=\theta_{S_{D}}^{D}\right)\left\{\sum_{i} \sum_{j}\left[\frac{P^{I}\left(L_{m}^{I}, \phi_{n} \mid x_{i}, y_{j}, \theta_{S_{D}}^{D}\right)}{P^{I}\left(\mid x_{i}, y_{j}, \theta_{S_{D}}^{D}\right)}\right]^{\times}\right. \\
\left.\sum_{\Theta^{E}} P\left(\Theta^{E}=\theta_{S_{E}}^{E}\right) \cdot \lambda\left(x_{i}, y_{j}, t \mid \theta_{S_{E}}^{E}\right) \times P^{I}\left(L_{m}^{I}, \phi_{n} \mid x_{i}, y_{j}, \theta_{S_{D}}^{D}\right)\right\} \\
\mathrm{E}\left[v^{I}\left(t, L_{m}^{I}, \phi_{n} \mid \Theta\right)\right]=\sum_{\Theta^{D}} P\left(\Theta^{D}=\theta_{S_{D}}^{D}\right)\left\{\sum_{i} \sum_{j}\left[\frac{\left.P^{I}\left(L_{m}^{I}, \phi_{n} \mid x_{i}, y_{j}, \theta_{S_{D}}^{D}\right)\right]}{P^{I}\left(x_{i}, y_{j}, \theta_{S_{D}}^{D}\right)}\right] \mathrm{E}\left[v_{x_{i}, y_{j}}^{I}\left(t \mid \theta_{S_{D}}^{D}\right)\right]\right\}
\end{gathered}
$$

where $\mathrm{E}\left[v_{x_{i}, y_{j}}^{I}\left(t \mid \theta_{S_{D}}^{D}\right)\right]$ is the expected value of $v_{x_{i}, y_{j}}^{I}(t)$ conditional on the set of dike parameters $\theta_{S_{D}}^{D}$. The form of Equation A-11 greatly improves the efficiency of the calculation because the terms involving the conditional probability of intersection need to be computed only once for each dike parameter set, $\theta_{S_{D}}^{D}$, rather than for every combination of the parameters $\theta_{S_{E}}^{E}$ that define the distribution for volcanic event frequency.

\section{A1.3 Conditional Distribution for the Number of Eruptive Centers}

This section develops the mathematical formulation for assessing the conditional distribution for the number of eruptive centers within the footprint of the proposed repository. The development is based on the concept that eruptive centers will occur at uncertain locations along the length of the dike associated with a volcanic event. The length of intersection within the repository 
footprint compared to the total length of the dike, the number of eruptive centers per volcanic event, and the spatial distribution of eruptive centers along the length of the dike provide the bases for assessing the likelihood that one or more eruptive centers will occur within the repository footprint. The total length of the dike and the length of intersection within the proposed repository are computed as part of the formulation presented in Section A1.2 of this appendix and are completely defined by the PVHA experts' interpretations. The number of eruptive centers per volcanic event and the spatial distribution of eruptive centers along the length of a dike were not defined as part of the PVHA expert elicitation. However, with the limited set of assumptions (Section 5), the number of eruptive centers and their spatial distribution were derived from the experts' interpretations. Section 6.5.1.3 describes the alternative ways that these assumptions were applied.

Using the approaches for the spatial distribution of eruptive centers described in Section 6.5.1.3, the formulation from Section A1.2 is expanded to define the distribution for the number of eruptive centers that occur within the proposed repository. In the previous section, the contributions to the frequency of intersection from each location $(x, y)$ in the spatial grid around the proposed repository, $v_{x_{i}, y_{j}}^{I}\left(t \mid \theta_{S}\right)$, were divided into probabilities for intersection with specific lengths and azimuths, $v_{x_{i}, y_{j}}^{I}\left(t, L_{m}^{I}, \phi_{n} \mid \theta_{S}\right)$. This calculation involved looping over the possible dike lengths and azimuths. During this calculation, the models for number and spatial distribution of eruptive centers above can be used to compute the number of volcanic events that produce 0,1 , 2,3 , etc. eruptive centers in the proposed repository. As a result, $v_{x_{i}, y_{j}}^{I}\left(t, L_{m}^{I}, \phi_{n} \mid \theta_{S}\right)$ is divided into the frequency of intersection from volcanic events at point $(x, y)$ that produce specific numbers of eruptive centers, $r^{E C}$, within the proposed repository, $v_{x_{i}, y_{j}}^{I}\left(t, L_{m}^{I}, \phi_{n},\left.r^{E C}\right|_{\theta_{S}}\right)$. Summing these values over all locations $(x, y)$ gives the frequency of intersection with a specific number of eruptive centers in the proposed repository, $v^{I}\left(t, L_{m}^{I}, \phi_{n}, r^{E C} \mid \theta_{S}\right)$. Dividing this frequency by the total frequency of intersection, $v^{I}\left(t \mid \theta_{S}\right)$, gives the conditional probability that an intersecting event will produce a specific number of eruptive centers in the proposed repository.

The disaggregation of $v_{x_{i}, y_{j}}^{I}\left(t, L_{m}^{I}, \phi_{n} \mid \theta_{S}\right)$ into $v_{x_{i}, y_{j}}^{I}\left(t, L_{m}^{I}, \phi_{n}, r^{E C} \mid \theta_{S}\right)$ for $r^{E C}=0,1,2, \ldots$ eruptive centers is accomplished by computing the conditional distribution for $r^{E C}$, given the total length of the dike, $L$, the length of intersection within the repository footprint, $L^{I}$, the number of eruptive centers associated with the volcanic event, $n^{E C}$, and the spatial distribution for the location of eruptive centers. Note that the assumption listed in Section 5.2 results in $n^{E C} \geq 1$.

Two alternative approaches were used to define the spatial distribution of eruptive centers along the length of the dike system associated with a volcanic event.

The first approach, the IUD approach, specifies the location of each eruptive center independently of the others using a uniform distribution over the length of the dike system. The second approach, the USRD approach, divides the length of the dike into equal length segments, one segment for each eruptive center. Each eruptive center is randomly located within its segment following a uniform distribution. 


\section{Independent, Uniformly Distributed (IUD) Spatial Distribution}

In this approach, the location of each eruptive center is uniformly distributed along the total length of the dike and the location of each eruptive center is independent of all of the others. Thus, the occurrence of each eruptive center within the footprint of the proposed repository is an independent Bernoulli trial with probability of success, $p$, equal to the length of intersecting dike within the proposed repository, $L^{I}$, divided by the total length of the dike, $L$. Under these conditions, the conditional probability distribution for the number of eruptive centers within the repository footprint, $r^{E C}$, given $n^{E C}$ eruptive centers associated with the volcanic event, is given by the binomial distribution:

$$
P_{I U D}\left(r^{E C} \mid n^{E C}, L, L^{I}\right)=\left(\begin{array}{l}
n^{E C} \\
r^{E C}
\end{array}\right)\left(\frac{L^{I}}{L}\right)^{r^{E C}}\left(1-\frac{L^{I}}{L}\right)^{n^{E C}-r^{E C}}
$$

where $\left(\begin{array}{c}n^{E C} \\ r^{E C}\end{array}\right)$ is the binomial coefficient and the subscript $I U D$ refers to independent, uniformly distributed eruptive centers.

\section{Uniformly Spaced, Randomly Distributed (USRD) Spatial Distribution}

The alternative approach for the spatial distribution of eruptive centers is that they are spaced more or less equidistant along the length of the dike. If $n^{E C}$ eruptive centers are generated along the length of the dike, then each eruptive center is located within a segment of length $L^{s}=L / n^{E C}$. If the location of the eruptive center within each segment is defined by a uniform distribution, the probability that an eruptive center associated with segment $q$ will occur within the repository footprint is equal to the length of segment $q$ within the boundary of the proposed repository, $L_{q}^{s I}$, divided by the total length of the segment, $L_{q}^{s}$. There can be at most two segments of a dike that have partial penetration of the repository footprint in one volcanic event (there may be more segments that lie entirely within the repository footprint). If only the $q^{\text {th }}$ segment penetrates into the repository footprint, then the probabilities for zero or one eruptive center within the proposed repository are given by:

$$
\begin{gathered}
P_{U S R D}\left(r^{E C}=0 \mid n^{E C}, L, L^{I}\right)=1-\frac{L_{q}^{s I}}{L_{q}^{s}} \\
P_{U S R D}\left(r^{E C}=1 \mid n^{E C}, L, L^{I}\right)=\frac{L_{q}^{S I}}{L_{q}^{s}}
\end{gathered}
$$


If the $q^{\text {th }}$ and $(q+1)^{\text {th }}$ segments penetrate into the repository footprint, then the probabilities for zero, one, or two eruptive centers within the proposed repository are given by:

$$
\begin{gathered}
P_{U S R D}\left(r^{E C}=0 \mid n^{E C}, L, L^{I}\right)=\left(1-\frac{L_{q}^{s I}}{L_{q}^{s}}\right)\left(1-\frac{L_{q+1}^{s I}}{L_{q+1}^{s}}\right) \\
P_{U S R D}\left(r^{E C}=1 \mid n^{E C}, L, L^{I}\right)=\left(\frac{L_{q}^{s I}}{L_{q}^{s}}\right)\left(1-\frac{L_{q+1}^{s I}}{L_{q+1}^{s}}\right)+\left(1-\frac{L_{q}^{s I}}{L_{q}^{s}}\right)\left(\frac{L_{q+1}^{s I}}{L_{q+1}^{s}}\right) \\
P_{U S R D}\left(r^{E C}=2 \mid n^{E C}, L, L^{I}\right)=\left(\frac{L_{q}^{s I}}{L_{q}^{s}}\right)\left(\frac{L_{q+1}^{s I}}{L_{q+1}^{s}}\right)
\end{gathered}
$$

If one or more segments lie entirely within the repository footprint, then the probability of an eruptive center occurring within the proposed repository is unity for these segments. In such a case, the value of $r^{E C}$ in Equations A-13 and A-14 is increased by the number of wholly contained segments. For example, if one segment lies completely within the proposed repository and one spans the boundary of the proposed repository, then Equation A-13 becomes:

$$
\begin{gathered}
P_{U S R D}\left(r^{E C}=0 \mid n^{E C}, L, L^{I}\right)=0 \\
P_{U S R D}\left(r^{E C}=1 \mid n^{E C}, L, L^{I}\right)=1-\frac{L_{q}^{s I}}{L_{q}^{s}} \\
P_{U S R D}\left(r^{E C}=2 \mid n^{E C}, L, L^{I}\right)=\frac{L_{q}^{s I}}{L_{q}^{s}}
\end{gathered}
$$

\section{Conditional Distribution}

In evaluating the consequences of an intersection of the repository footprint by the dike system associated with a volcanic event, it is more informative to define $P\left(r^{E C}\right)$ conditional on the length of intersection, $L_{m}^{I}$. Equation A-8 defines the joint probability of intersection length and azimuth for a volcanic event at point $\left(x_{i}, y_{j}\right), P^{I}\left(L_{m}^{I}, \phi_{n} \mid x_{i}, y_{j}, \theta_{S_{D}}^{D}\right)$. As indicated in developing Equation A-11, the only parameters that affect the calculation of the conditional probability of intersection are $\theta_{S_{D}}^{D}$. Thus $P^{I}\left(L_{m}^{I}, \phi_{n} \mid x_{i}, y_{j}, \theta_{S}\right)$ in Equation A-8 can be rewritten as $P^{I}\left(L_{m}^{I}, \phi_{n} \mid x_{i}, y_{j}, \theta_{S_{D}}^{D}\right)$. In addition, the probability for the number of eruptive centers within the proposed repository, Equations A-12, A-13, and A-14, is dependent on the number of eruptive centers per volcanic event, $n^{E C}$. Appendix $\mathrm{C}$ develops distributions for $n^{E C}, P\left(n^{E C}=\eta \mid L_{p}, \theta_{S_{D}}^{D}\right)$, which may be conditional on the total length of the dike, $L_{p}$. 
The parameter set $\theta_{S_{D}}^{D}$ is expanded to include any alternatives for assessing $P\left(n^{E C}=\eta\right)$. Using these definitions, the joint probability of $r^{E C}$ eruptive centers in the proposed repository for a volcanic event at $(x, y)$ producing a length of intersection of $L_{m}^{I}$ at an azimuth of $\phi_{n}$ is given by:

$$
\begin{aligned}
P^{I}\left(L_{m}^{I}, \phi_{n}, r^{E C} \mid x_{i}, y_{j}, \theta_{S_{D}}^{D}\right)= & \sum_{L_{p}=0}^{L_{p}=L_{\max } \mid \theta_{S_{D}}^{D}} P\left(L_{p} \mid \theta_{S_{D}}^{D}\right) \sum_{E_{o}^{L}=0}^{E_{o}^{L}=1} P\left(E_{o}^{L} \mid \theta_{S_{D}}^{D}\right) \cdot \delta\left(L^{I}=L_{m}^{I}\right) \cdot P\left(\phi_{n} \mid \theta_{S_{D}}^{D}\right) \times \\
& \sum_{\eta=1}^{\eta=n_{\text {max }}^{E C}} P\left(n^{E C}=\eta \mid L_{p}, \theta_{S_{D}}^{D}\right) P\left(r^{E C} \mid L_{p}, L_{m}^{I}, n^{E C}=\eta\right)
\end{aligned}
$$

with $P\left(r^{E C} \mid L_{p}, L_{m}^{I}, n^{E C}=\eta\right)$ given by either Equation A-12 or Equations A-13 and A-14.

Multiplying Equation A-16 by $\lambda\left(x_{i}, y_{j}, t \mid \theta_{S_{D}}^{D}\right)$, the frequency of volcanic events at $\left(x_{i}, y_{j}\right)$, and summing over all locations yields the frequency of occurrence for intersections of the proposed repository of length $L_{m}^{I}$ and azimuth $\phi_{n}$ with $r^{E C}$ eruptive centers within the repository:

$$
v^{I}\left(t, L_{m}^{I}, \phi_{n}, r^{E C} \mid \theta_{S}\right)=\sum_{i} \sum_{j} \lambda\left(x_{i}, y_{j}, t \mid \theta_{S_{E}}^{E}\right) \cdot P^{I}\left(L_{m}^{I}, \phi_{n}, r^{E C} \mid x_{i}, y_{j}, \theta_{S_{D}}^{D}\right)
$$

Because the summation of $v^{I}\left(t, L_{m}^{I}, \phi_{n}, r^{E C} \mid \theta_{S}\right)$ over $r^{E C}=0$ to $r^{E C}=n_{\max }^{E C}$ equals $v\left(t, L_{m}^{I}, \phi_{n} \mid \theta_{S}\right)$, the ratio $v^{I}\left(t, L_{m}^{I}, \phi_{n}, r^{E C} \mid \theta_{S}\right) / v^{I}\left(t, L_{m}^{I}, \phi_{n} \mid \theta_{S}\right)$ defines the relative frequency of intersection events with length $L_{m}^{I}$ and azimuth $\phi_{n}$. that produce $r^{E C}$ eruptive centers within the proposed repository.

In the same manner that Equation A-9 was recast as Equation A-10, Equation A-17 can be recast into the form:

$$
v^{I}\left(t, L_{m}^{I}, \phi_{n}, r^{E C} \mid \theta_{S}\right)=\sum_{i} \sum_{j} v_{x_{i}, y_{j}}^{I}\left(t \mid \theta_{S_{E}}^{E}, \theta_{S_{D}}^{D}\right) \cdot\left\lfloor\frac{P^{I}\left(L_{m}^{I}, \phi_{n}, r^{E C} \mid x_{i}, y_{j}, \theta_{S_{D}}^{D}\right)}{P^{I}\left(\mid x_{i}, y_{j}, \theta_{S_{D}}^{D}\right)}\right\rfloor
$$

where the substitution $v_{x_{i}, y_{j}}^{I}\left(t \mid \theta_{S_{E}}^{E}, \theta_{S_{D}}^{D}\right)=\lambda\left(x_{i}, y_{j}, t \mid \theta_{S_{E}}^{E}\right) \cdot P^{I}\left(\mid x_{i}, y_{j}, \theta_{S_{D}}^{D}\right)$ has been made. Equation A-18 may be adapted in a manner similar to Equation A-11 to improve the efficiency of the computation of the expected value of $v^{I}\left(t, L_{m}^{I}, \phi_{n}, r^{E C} \mid \theta_{S}\right)$, producing:

$$
\begin{array}{rl}
\mathrm{E}\left[v^{I}\left(t, L_{m}^{I}, \phi_{n}, r^{E C} \mid \Theta\right)\right]=\sum_{\Theta^{D}} & P\left(\Theta^{D}=\theta_{S_{D}}^{D}\right) . \\
& \left\{\sum_{i} \sum_{j}\left[\frac{P^{I}\left(L_{m}^{I}, \phi_{n}, r^{E C} \mid x_{i}, y_{j}, \theta_{S_{D}}^{D}\right)}{P^{I}\left(x_{i}, y_{j}, \theta_{S_{D}}^{D}\right)}\right] \mathrm{E}\left[v_{x_{i}, y_{j}}^{I}\left(t \mid \theta_{S_{D}}^{D}\right)\right]\right\}
\end{array}
$$




\section{A2 IMPLEMENTATION OF MATHEMATICAL FORMULATION}

This section describes the implementation of the formulation presented in Section A1 of this appendix. Equations A-3 and A-5 provide the relationships used to compute the frequency of intersection, $V(t)$. Equations A-10, A-11, A-18, and A-19 provide the relationships used to compute the frequency of intersecting volcanic events that produce an intersection length of $L_{m}^{I}$, at an azimuth of $\phi_{n}$, with $r^{E C}$ eruptive centers occurring within the repository footprint.

\section{A2.1 Frequency of Intersection of the Repository Footprint by a Dike}

The computational scheme used in Probabilistic Volcanic Hazard Analysis for Yucca Mountain, Nevada (CRWMS M\&O 1996 [DIRS 100116]) and repeated in this report consists of the steps shown on Figure 3-1 (repeated for each expert's interpretation).

Step 1: Discrete cumulative distributions for dike length are developed from the experts' assessments using software routines FITCD V1.0 (LANL 2000 [DIRS 148532]) or SFCD V1.0 (LANL 2000 [DIRS 148533]) (e.g., part (a) of Figure 6-10). These distributions are then convolved with the event location of the dike on the volcanic event (e.g., part (b) of Figure 6-10) to produce distributions for volcanic event length (e.g., part (c) of Figure 6-10) using software routine DCPELD V1.0 (LANL 2000 [DIRS 148534]).

Step 2: The conditional probability of intersection, $P^{I}\left(x_{i}, y_{j}, \theta_{S_{D}}^{D}\right)$, is computed for each set of parameters $\theta_{S_{D}}^{D}$ (defined by a unique event length distribution from Step 1 and a unique azimuth distribution) using software routine CPDI V1.0 (LANL 2000 [DIRS 148535]).

Step 3: The rate of intersection, $v^{I}(t)$, is computed using software routines specific to the type of source (software routines UZVH V1.0 (LANL 2000 [DIRS 148536]) and UZVPVH V1.0 (LANL 2000 [DIRS 148537]) for source zones; routines FKVH V1.0 (LANL 2000 [DIRS 148567]), FKVPVH V1.0 (LANL 2000 [DIRS 148538]), and ZBCKVH V1.0 (LANL 2000 [DIRS 148539]) for kernel density sources; and routines PFGVH V1.0 (LANL 2000 [DIRS 148542]) and FPFGVH V1.0 (LANL 2000 [DIRS 148543]) for 2-D Gaussian field sources). The characterization of individual volcanic sources is defined by a 12-parameter subset of $\theta_{S_{E}}^{E}$. The distribution for these parameters depends upon the alternative source definitions, temporal models, and time periods of interest. To denote this breakdown of $\theta_{S_{E}}^{E}$, the parameter set $\theta_{S_{A S M}}^{E}$ represents the alternative source models (including temporal models) and parameter set $\theta_{S_{I S P}}^{E} \mid \theta_{S_{A S M}^{E}}^{E}$ represents the individual source parameters, which are conditional on the chosen source and temporal models $\theta_{S_{A S M}}^{E}$. The software routines used to compute the hazard from an individual source contain a set of 12 nested DO loops to enumerate all of the alternative versions of $\theta_{S_{I S P}}^{E} \mid \theta_{S_{A S M}^{E}}^{E}$ (see Figure 6-12b). Given a set of parameters, the frequency of volcanic events, $\lambda_{\alpha}\left(x_{i}, y_{j}, t \mid \theta_{S_{I S P}}^{E}\right)$, is computed for a specific source, $\alpha$, using the formulation appropriate for the source type. This frequency is multiplied by the conditional probability of intersection, $P^{I}\left(x_{i}, y_{j}, \theta_{S_{D}}^{D}\right)$, from the output of routine CPDI V1.0 and summed over all points within the source to obtain the frequency of intersection from volcanic events associated with source $\alpha$. 
The software routines store the mean frequency of intersection and the distribution in the frequency of intersection (computed over the distributions for $\theta_{S_{I S P}}^{E} \mid \theta_{S_{A S M}}^{E}$ in output files for use in the final step of the computations). Separate output files are created for all of the alternative sets of source model parameters, $\theta_{S_{A S M}^{E}}^{E}$, and for the alternative parameters that describe the associated dikes, $\theta_{S_{D}}^{D}$.

Step 4: The results from Step 3 are combined over the distributions for $\theta_{S_{A S M}}^{E}$ and $\theta_{S_{D}}^{D}$ (see Figure 6-12a and Figure 6-12b) to compute the full distribution for frequency of intersection specified by an individual PVHA expert's interpretations. The results for each expert are then combined to obtain the composite distribution. These calculations are performed using software routine VHTREE V1.0 (LANL 2000 [DIRS 148544]). Complete enumeration of all of the alternative parameter sets $\theta_{S_{A S M}}^{E}$ is again achieved by a series of nested DO loops. The mean value and various percentiles of the distribution for frequency of intersection of the repository footprint by a dike were computed from the discrete distribution for $\nu\left(t \mid \theta_{S_{D}}^{D}, \theta_{S_{E}}^{E}\right)$ as described above in Section A1.1. These computations are then combined using equal weights to produce a composite distribution for frequency of intersection.

\section{A2.2 Distributions for Length, Azimuth, and Number of Eruptive Centers}

The computations performed in Probabilistic Volcanic Hazard Analysis for Yucca Mountain, Nevada (CRWMS M\&O 1996 [DIRS 100116]) were made for all possible sets of $\theta_{S_{D}}^{D}$ and $\theta_{S_{E}}^{E}$ defined by the volcanic hazard characterization of each of the PVHA experts (full enumeration of the logic tree branches (CRWMS M\&O 1996 [DIRS 100116], Appendix E)). However, the objective of this analysis is a disaggregation of the intersection frequency, $v^{I}\left(t \mid \theta_{S_{D}}^{D}, \theta_{S_{E}}^{E}\right)$, into intersection frequencies with specific values of $L_{m}^{I}, \phi_{n}$, and $r^{E C}$. Repeating the calculation for the spatial disaggregation would require exhaustive computation and storage of the spatial disaggregation of the hazard, $v_{x_{i}, y_{j}}^{I}\left(t \mid \theta_{S_{E}}^{E}, \theta_{S_{D}}^{D}\right)$, for all possible parameter sets $\theta_{S_{E}}^{E}$. Therefore, a simulation approach was used to develop random sample parameter sets $\theta_{S_{E}}^{E}$ from the PVHA experts' logic trees to speed up the computation process. The approach used to obtain the spatial disaggregation of the frequency of intersection consists of the following steps (see Figure 3-2).

Step 1: The conditional probability of intersection, $P^{I}\left(x_{i}, y_{j}, \theta_{S_{D}}^{D}\right)$, was taken directly from the computation for the frequency of intersection discussed above. The files containing $P^{I}\left(x_{i}, y_{j}, \theta_{S_{D}}^{D}\right)$ for each set of parameters $\theta_{S_{D}}^{D}$ were created using routine CPDI V1.0 (LANL 2000 [DIRS 148535]) using inputs processed through routines FITCD V1.0 (LANL 2000 [DIRS 148532]), SFCD V1.0 (LANL 2000 [DIRS 148533]), and DCPELD V1.0 (LANL 2000 [DIRS 148534]).

Step 2: The second step in the calculation involved computation of the spatial disaggregation of frequency of intersection hazard for the individual sources specified by the alternative source parameter sets $\theta_{S_{A S M}^{E}}^{E}$ and for the alternative dike parameters $\theta_{S_{D}}^{D}$. For the reasons discussed above, simulation is used to select random samples of the parameter subset $\theta_{S_{I S P}}^{E} \mid \theta_{S_{A S M}}^{E}$ used to 
compute the frequency of intersection for an individual source type. The approach used to generate these parameter subsets is Latin hypercube sampling (McKay et al. 1979 [DIRS 127905], pp. 243-245). The software routines used to compute the frequency of intersection replace the 12 nested DO loops with simulation of 50 parameter sets, $\theta_{\text {sim }_{I S P}}^{E} \mid \theta_{S_{A S M}}^{E}, \operatorname{sim}_{I S P}=1$ to 50 , using Latin hypercube sampling from the 12 independent, discrete parameter distributions that define $\Theta_{I S P}^{E} \mid \theta_{S_{A S M}}^{E}$. Once a parameter subset is defined, the spatial distribution of $\lambda(x, y, t)$ for source $\alpha$ is computed using the same algorithms employed for the PVHA calculation (CRWMS M\&O 1996 [DIRS 100116]). The disaggregated frequency of intersection, $v_{\alpha, x_{i}, y_{j}}^{I}\left(t \mid \theta_{\text {sim }_{I S P}}^{E}, \theta_{S_{A S M}}^{E}, \theta_{S_{D}}^{D}\right)$, from each simulation for each source $\alpha$ is output to a file along with the mean frequency of intersection for the source. Each simulated parameter set $\theta_{s_{i m} I_{S P}}^{E} \mid \theta_{S_{A S M}^{E}}^{E}$ is an equally likely realization of the possible parameter sets from the joint distribution for $\Theta_{I S P}^{E} \mid \theta_{S_{A S M}}^{E}$. Therefore, the mean frequency of intersection for source $\alpha$, given source model parameter set $\theta_{S_{A S M}^{E}}^{E}$ and dike parameters $\theta_{S_{D}}^{D}, \mathrm{E}\left[v_{\alpha}^{I}\left(t \mid \theta_{S_{A S M}}^{E}, \theta_{S_{D}}^{D}\right)\right]$, and its spatial disaggregation $\mathrm{E}\left[v_{\alpha, x_{i}, y_{j}}^{I}\left(t \mid \theta_{S_{A S M}}^{E}, \theta_{S_{D}}^{D}\right)\right]$, may be estimated by the average of the results from the 50 simulations.

$$
\begin{aligned}
& \mathrm{E}\left[v_{\alpha}^{I}\left(t \mid \theta_{S_{A S M}^{E}}^{E}, \theta_{S_{D}}^{D}\right)\right] \frac{1}{50} \sum_{\operatorname{sim}_{I S P}=1}^{s i m_{S S}=50} v_{\alpha}^{I}\left(t \mid \theta_{\text {sim }_{I S P}}^{E}, \theta_{S_{-A S M}}^{E}, \theta_{S_{D}}^{D}\right) \\
& \text { and } \\
& \mathrm{E}\left[v_{\alpha, x_{i}, y_{j}}^{I}\left(t \mid \theta_{S_{A S M}}^{E}, \theta_{S_{D}}^{D}\right)\right] \frac{1}{50} \sum_{s i m_{I S P}=1}^{s i m_{S P}=50} v_{\alpha, x_{i}, y_{j}}^{I}\left(t \mid \theta_{s i m_{S P}}^{E}, \theta_{S_{-A S M}}^{E}, \theta_{S_{D}}^{D}\right)
\end{aligned}
$$

The simulation software routines are designated UZVHLH V1.0 (LANL 2000 [DIRS 148545), UZVPVHLH V1.0 (LANL 2000 [DIRS 148547]), FKVHLH V1.0 (LANL 2000 [DIRS 148546]), FKVPVHLH V1.0 (LANL 2000 [DIRS 148551]), ZBCKVHLH V1.0 (LANL 2000 [DIRS 148550]), PFGVHLH V1.0 (LANL 2000 [DIRS 148552]), and FPFGVHLH V1.0 (LANL 2000 [DIRS 148553]). They use the same input files used to compute the frequency of intersection by full enumeration.

Step 3: The third step in the calculation is computation of the distribution for the spatial disaggregation of the hazard for each the PVHA expert's interpretation. The full enumeration of the possible parameter sets $\theta_{S_{D}}^{D}$ and $\theta_{S_{A S M}}^{E}$ is again replaced by simulation of 50 equally likely parameter sets. The software routine VHTIELHS V1.0 (LANL 2000 [DIRS 148554]) is used to perform the following operations for the interpretation developed by each of the PVHA experts.

Step 3a. First, all of the possible sets $\theta_{S_{D}}^{D}, \theta_{S_{A S M}}^{E}$ in the joint distribution for $\Theta^{D}$ and $\Theta_{A S M}^{E}$ are enumerated. The joint probability of each set is computed from the PVHA expert's logic tree. 
Step 3b. The mean frequency of intersection for each set of $\theta_{S_{D}}^{D}, \theta_{S_{A S M}}^{E}$ and its spatial disaggregation are estimated from the sum of all the individual source results from Step 2, for those sources present in the parameter set $\theta_{S_{A S W}^{E}}^{E}$,

$$
\begin{gathered}
\mathrm{E}\left[v^{I}\left(t \mid \theta_{S_{A S M}}^{E}, \theta_{S_{D}}^{D}\right)\right] \sum_{\alpha \mid \theta_{S, S M}^{E}} \mathrm{E}\left[v_{\alpha}^{I}\left(t \mid \theta_{S_{A S M}}^{E}, \theta_{S_{D}}^{D}\right)\right] \\
\text { and } \\
\mathrm{E}\left[v_{x_{i}, y_{j}}^{I}\left(t \mid \theta_{S_{A S M}}^{E}, \theta_{S_{D}}^{D}\right)\right] \sum_{\alpha \mid \theta_{S_{S S M}}^{E} \mathrm{E}\left[v_{\alpha, x_{i}, y_{j}}^{I}\left(t \mid \theta_{S_{A S M}}^{E}, \theta_{S_{D}}^{D}\right)\right]}
\end{gathered}
$$

Step 3c. The sets of $\theta_{S_{D}}^{D}, \theta_{S_{A S M}}^{E}$ are then ranked in terms of increasing mean frequency of intersection, $\mathrm{E}\left[v^{I}\left(t \mid \theta_{S_{A S M}}^{E}, \theta_{S_{D}}^{D}\right)\right]$, defining a distribution for $\mathrm{E}\left[v^{I}\left(t \mid \theta_{S_{A S M}}^{E}, \theta_{S_{D}}^{D}\right)\right]$.

Step 3d. Then, 50 parameter sets, $\theta_{\operatorname{sim}_{D}}^{D}, \theta_{\operatorname{sim}_{A S \mathrm{H}}}^{E}$, are selected using Latin hypercube sampling from the distribution for $\mathrm{E}\left[v^{I}\left(t \mid \theta_{S_{A S M}}^{E}, \theta_{S_{D}}^{D}\right)\right]$. For each of these sets, the frequency of intersection and its spatial disaggregation are computed for the 50 simulations of parameters $\theta_{\text {sim }_{I S P}}^{E} \mid\left(\theta_{S_{A S M}}^{E}=\theta_{\text {sim }_{A S M}}^{E}\right)$ by:

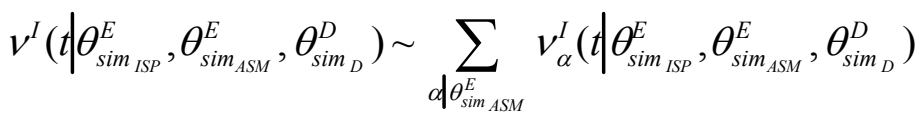

$$
\begin{aligned}
& \text { and } \\
& v_{x_{i}, y_{j}}^{I}\left(t \mid \theta_{\operatorname{sim}_{I S P}}^{E}, \theta_{\operatorname{sim}_{A S M}}^{E}, \theta_{\operatorname{sim}_{D}}^{D}\right) \sim \sum_{\alpha \mid \theta_{\sin _{A S M}}^{E}} v_{\alpha, x_{i}, y_{j}}^{I}\left(t \mid \theta_{\operatorname{sim}_{I S P}}^{E}, \theta_{\operatorname{sim}_{A S M}}^{E}, \theta_{\operatorname{sim}_{D}}^{D}\right)
\end{aligned}
$$

In Equation A-22, $\quad v_{\alpha}^{I}\left(t \mid \theta_{\text {sim }_{S P}}^{E}, \theta_{\text {sim }_{A S}}^{E}, \theta_{\text {sim }_{D}}^{D}\right), \quad$ and its spatial disaggregation, $v_{\alpha, x_{i}, y_{j}}^{I}\left(t \mid \theta_{\text {sim }_{S S P}}^{E}, \theta_{\text {sim }_{A S M}}^{E}, \theta_{\text {sim }_{D}}^{D}\right)$, are the values for source $\alpha$ for the simulated parameter set $\theta_{\text {sim }_{I S P}}^{E} \mid \theta_{S_{A S M}}^{E}, \theta_{S_{D}}^{D}$ from (2) with $\theta_{S_{A S M}^{E}}^{E}, \theta_{S_{D}}^{D}=\theta_{\text {sim }_{A S M}}^{E}, \theta_{\text {sim }_{D}}^{D}$, the source model and dike parameter set selected in one simulation. The result is 2,500 equally likely values for frequency of intersection. The resulting values of the spatial disaggregation of the frequency of intersection, $v_{x_{i}, y_{j}}^{I}\left(t \mid \theta_{\text {sim }_{\text {ISP }}}^{E}, \theta_{\text {sim }_{\text {ASM }}}^{E}, \theta_{\text {sim }_{D}}^{D}\right)$, are written to separate files for each of the 2,500 simulated parameter sets. 
Step 3e. Finally, the expected value for the spatial disaggregation of the frequency of intersection for each of the possible dike parameter sets is estimated from the average of all of the results from Step 3d for which $\theta_{\text {sim }_{D}}^{D}=\theta_{S_{D}}^{D}$.

$$
\mathrm{E}\left[v_{x_{i}, y_{j}}^{I}\left(t \mid \theta_{S_{D}}^{D}\right)\right] \sim \frac{\sum_{\operatorname{sim}_{I S P, A S P, D}=1}^{\operatorname{sim}_{I S P, A S P D}=2500} v_{x_{i}, y_{j}}^{I}\left(t \mid \theta_{\operatorname{sim}_{I S P}}^{E}, \theta_{\operatorname{sim}_{A S M}}^{E}, \theta_{\text {sim }_{D}}^{D}\right) \cdot \delta\left(\theta_{\operatorname{sim}_{D}}^{D}=\theta_{S_{D}}^{D}\right)}{\sum_{\operatorname{sim}_{I S P, A S P, D}=1}^{\operatorname{sim}_{I S P, A S P, D}=2500} \delta\left(\theta_{\text {sim }}^{D}=\theta_{S_{D}}^{D}\right)}
$$

where $\delta\left(\theta_{\operatorname{sim}_{D}}^{D}=\theta_{S_{D}}^{D}\right)=1$ for those simulations where $\theta_{\operatorname{sim}_{D}}^{D}=\theta_{S_{D}}^{D}$, and zero otherwise. Note that $\frac{1}{2,500} \sum_{\operatorname{sim}_{I S P, A S P, D}=1}^{\operatorname{sim}_{I S P, A S P, D}=2500} \delta\left(\theta_{\text {sim }}^{D}=\theta_{S_{D}}^{D}\right) \sim P\left(\Theta^{D}=\theta_{S_{D}}^{D}\right)$.

Figure 6-11, part (b), shows a map of $\mathrm{E}\left[v_{x_{i}, y_{j}}^{I}\left(t \mid \theta_{S_{D}}^{D}\right)\right]$ averaged across all 10 experts. This figure indicates the locations of volcanic events that contribute to the frequency of intersection. Also shown on Figure 6-11, part (a), is a map of the expected frequency of volcanic events, $\mathrm{E}\left[\lambda\left(x_{i}, y_{j}, t \mid \theta_{S_{D}}^{D}\right)\right]$, averaged across all experts. This map was obtained by repeating the calculation for part (b) with the conditional probability of intersection, $P^{I}\left(x_{i}, y_{j}, \theta_{S_{D}}^{D}\right)$, set to 1 at every point $(x, y)$.

Step 4: The composite distribution for the frequency of intersection of the repository footprint by a dike is now represented by the $2,500 \times 10$ simulation results for the 10 PVHA experts. Each expert's distribution was assigned equal weight in the PVHA aggregation process. Thus, the composite 25,000 simulations of $v^{I}(t)$ are all equally likely. The 25,000 simulations of $v^{I}(t)$ are ranked and the simulations that produce various percentile of the distribution for $v^{I}(t)$ are identified (e.g., the 95th percentile is the simulation with rank $0.95 \times 25,000=23,750$ ). Simulation results that are close to each percentile (within a rank of \pm 250 ) and that are for different experts are also identified to capture the range of expert interpretations. These simulations are identified using software routine CFRAC V1.0 (LANL 2000 [DIRS 148560]).

Step 5: Steps 1 through 4 provide the values of $v_{x_{i}, y_{j}}^{I}\left(t \mid \theta_{\operatorname{sim}_{I S P}}^{E}, \theta_{\operatorname{sim}_{A S M}}^{E}, \theta_{\operatorname{sim}_{D}}^{D}\right)$ and $\mathrm{E}\left[v_{x_{i}, y_{j}}^{I}\left(t \mid \theta_{S_{D}}^{D}\right)\right]$ needed for Equations A-10, A-11, A-18, and A-19. What remains is the calculation of $P^{I}\left(L_{m}^{I}, \phi_{n} \mid x_{i}, y_{j}, \theta_{S_{D}}^{D}\right)$ and $P^{I}\left(L_{m}^{I}, \phi_{n}, r^{E C} \mid x_{i}, y_{j}, \theta_{S_{D}}^{D}\right)$, the discretization of the conditional probability of intersection into increments of intersection length, intersection azimuth, and number of eruptive centers within the repository footprint for each volcanic event location $(x, y)$. Software routine DILECDLH V1.0 (BSC 2000 [DIRS 168221]) is used to discretize the conditional probability of intersection, $P^{I}\left(x_{i}, y_{j}, \theta_{S_{D}}^{D}\right)$, into the designated bins for length and azimuth within the proposed repository. The inputs to program DILECDLH are:

- The spatial disaggregation of the frequency of intersection (either the mean result conditional on $\theta_{S_{D}}^{D}$ for one expert from Step 3 or for one of the hazard simulations representative of the $95^{\text {th }}$ percentile of the composite distribution from Step 4) 
- The dike length and volcanic event location distributions for the corresponding parameter set $\theta_{S_{D}}^{D}$

- A joint distribution for dike length and the number of eruptive centers on a dike, $P\left(n^{E C}=\eta \mid L_{p}, \theta_{S_{D}}^{D}\right)$ (computed using software routines FITIDSR V1.0 (LANL 2000 [DIRS 148557], SFIDSR V1.0 (LANL 2000 [DIRS 148571]), and DLECD V1.0 (LANL 2000 [DIRS 148558])

- The spatial distribution of eruptive centers along the dike.

With the exception of the assessments for the number and spatial distribution of eruptive centers, all of the probability distributions required to perform this calculation are defined in Probabilistic Volcanic Hazard Analysis for Yucca Mountain, Nevada (CRWMS M\&O 1996 [DIRS 100116]).

Two alternative approaches are developed for the spatial distribution of eruptive centers in Section 6.5.1.3 and A1.3. In the first approach (designated IUD) the location of each eruptive center is specified by an independent, uniform distribution over the total length of the dike, $L_{p}$. In the second approach (designated USRD) the eruptive centers are spaced out over the full length of the dike with the location each of the $n^{E C}$ eruptive centers uniformly distributed in a segment of length $L_{p} / n^{E C}$. Calculations of $P^{I}\left(L_{m}^{I}, \phi_{n},\left.r^{E C}\right|_{x_{i}}, y_{j}, \theta_{S_{D}}^{D}\right)$ are performed for both approaches. Distributions for the number of eruptive centers on a dike, $P\left(n^{E C}=\eta \mid L_{p}, \theta_{S_{D}}^{D}\right)$, are developed below from the PVHA experts' assessments of the number of eruptive centers associated with a volcanic event.

The distributions for $P\left(n^{E C}=\eta \mid L_{p}, \theta_{S_{D}}^{D}\right)$ derived in Appendix C for total number of eruptive centers associated with a volcanic event (Figure 6-13) are marginal distributions in the sense that they are independent of assessments of dike length and are averaged over an expert's interpretations, $\Theta^{E}$. The calculations need to use the conditional distribution of number of eruptive centers given dike length. The limiting conditions that define the relationship between two variable parameters are complete independence and complete dependence. These two limiting conditions are used to define the influence of dike length on $P\left(n^{E C}=\eta \mid L_{p}, \theta_{S_{D}}^{D}\right)$. Complete independence implies that the conditional distribution for number of eruptive centers is equal to the marginal distribution, and $P\left(n^{E C}=\eta \mid L_{p}, \theta_{S_{D}}^{D}\right)=P\left(n^{E C}=\eta \mid \Theta^{E}\right)$ is used in Equation 16. The resulting discretizations of the frequency of intersection are designated: $v_{I U D-U C}^{I}\left(t, L_{m}^{I}, \phi_{n}, r^{E C} \mid \theta_{S}\right)$ for independent, uniformly distributed spatial locations with the number of eruptive centers uncorrelated with dike length; and $v_{U S R D-U C}^{I}\left(t, L_{m}^{I}, \phi_{n}, r^{E C} \mid \theta_{S}\right)$ for uniformly spaced, randomly distributed spatial locations with the number of eruptive centers uncorrelated with dike length.

Complete dependence implies that the number of eruptive centers varies directly with dike length (it is considered unrealistic to have a negative correlation). The correlation between dike length and number of eruptive centers per event was set to the maximum value by making the marginal 
distributions for dike length and number of eruptive centers per volcanic event rank correlated. This correlation is achieved by specifying a one-to-one correspondence of the marginal CDFs for the two parameters. The resulting discretizations of the frequency of intersect are designated: $v_{I U D-C}^{I}\left(t, L_{m}^{I}, \phi_{n}, r^{E C} \mid \theta_{S}\right)$ for independent, uniformly distributed spatial locations and the number of eruptive centers correlated with dike length; and $v_{U S R D-C}^{I}\left(t, L_{m}^{I}, \phi_{n}, r^{E C} \mid \theta_{S}\right)$ for uniformly spaced, randomly distributed spatial locations and the number of eruptive centers correlated with dike length. These two approaches span the range of correlation considered reasonable (zero to maximum).

The alternative approach for specifying the total number of eruptive centers associated with a volcanic event is to define a distribution for the average spacing between volcanic events and use this distribution, together with the total dike length, to obtain the total number of eruptive centers. Consistent with the number of eruptive centers being defined by an average spacing between eruptive centers, the USRD method is used to defining the spatial distribution for location of eruptive centers along the length of the dike system.

The computation procedure used in software routine DILECDLH V1.1 is as follows:

Step 5a. An input file is created that contains the probability distributions for the length of the dike, $L$, and number of eruptive centers per volcanic event, $n^{E C}$. The probability distribution for $L$ is discretized into the probability mass for $L_{p}$ in $0.05-\mathrm{km}$ increments using module FITIDSR V1.0 (LANL 2000 [DIRS 148557]) or SFIDSR V1.0 (LANL 2000 [DIRS 148571]). The marginal distribution for $n^{E C}$ is listed at the top of the file and the rank correlated value for $n^{E C}$ is listed for each value of $L$ by determining the value in the marginal distribution for $n^{E C}$ that has the same cumulative probability as $L_{p}$ in the marginal distribution for $L$.

Step 5b. For each of the dike parameter sets, $\theta_{S_{D}}^{D}$, the spatial disaggregation of the hazard computed in Steps 3 and 4 is then input into the program. At each location $(x, y)$ that contributes to the frequency of intersection $\left\{v_{x_{i}, y_{j}}^{I}\left(t \mid \theta_{\operatorname{sim}_{I S P}}^{E}, \theta_{\text {sim }_{S S \mathrm{~S}},}^{E}, \theta_{\text {sim }_{D}}^{D}\right)\right.$ or $\mathrm{E}\left[v_{x_{i}, y_{j}}^{I}\left(t \mid \theta_{S_{D}}^{D}\right)-0\right\}$, the direction toward the proposed repository is sampled over $5^{\circ}$ increments in azimuth, with the probability distribution for $P^{I}\left(\phi_{n} \mid \theta_{S_{D}}^{D}\right)$ obtained by computing the probability mass in the interval $\phi_{n}-2.5^{\circ} \leq \phi$ $\leq \phi_{n}-2.5^{\circ}$. At each azimuth, $\phi_{n}, 100$ simulations of $L_{s i m}$ and $E_{s i m}^{L}$ are created by Latin hypercube sampling from the distributions defined for each. For those combinations of $L_{p}$ and $E_{o}^{L}$ at azimuth $\phi_{n}$ that result in intersections with the repository footprint, $L^{I}$ is computed. The probability $P^{I}\left(L_{m}^{I}, \phi_{n} \mid x_{i}, y_{j}, \theta_{S_{D}}^{D}\right)$ defined in Equation A-8 is now approximated by the expression:

$$
P^{I}\left(L_{m}^{I}, \phi_{n} \mid x_{i}, y_{j}, \theta_{S}\right) \sim \frac{1}{100} \delta\left(L^{I}=L_{m}^{I}\right) \cdot P\left(\phi_{n} \mid \theta_{S}\right)
$$


and the probability $P^{I}\left(r^{E C}, L_{m}^{I}, \phi_{n} \mid x_{i}, y_{j}, \theta_{S_{D}}^{D}\right)$ in Equation A-16 is approximated by

$$
\begin{aligned}
P^{I}\left(r^{E C}, L_{m}^{I}, \phi_{n} \mid x_{i}, y_{j}, \theta_{S_{D}}^{D}\right) \sim & \frac{1}{100} \sum_{\substack{s i m=1 \\
\eta=n_{\max }^{E C}}}^{s i m=100} \delta\left(L^{I}=L_{m}^{I}\right) \cdot P\left(\phi_{n} \mid \theta_{S_{D}}^{D}\right) \times \\
& \sum_{\eta=1}^{E C} P\left(n^{E C}=\eta L_{s i m}, \theta_{S_{D}}^{D}\right) P\left(r^{E C} \mid L_{s i m}, L_{m}^{I}, n^{E C}=\eta\right)
\end{aligned}
$$

where $\delta\left(L^{I}=L_{m}^{I}\right)=1$ for those simulation values of $L_{s i m}$ and $E_{\text {sim }}^{L}$ at azimuth $\phi_{n}$ that result in $L^{I}=L_{m}^{I}$ for a volcanic event at $(x, y)$, and $\delta\left(L^{I}=L_{m}^{I}\right)=0$ otherwise. An increment of $0.05 \mathrm{~km}$ is chosen for the intersection length bin size. This length bin size, together with the azimuth bin size of $5^{\circ}$, are sufficient to define clearly the variability in the length and azimuth of intersecting dikes. (The computation of the frequency of intersection is independent of these bin sizes.) Equation A-25 is used five times for the five alternative approaches for $P\left(n^{E C}=\eta \mid L_{s i m}, \theta_{S_{D}}^{D}\right)$ and $P\left(\left.r^{E C}\right|_{\text {sim }}, L_{m}^{I}, n^{E C}=\eta\right)$ described in Section 6.5.1.3.

Step 5c. The results of Step 5b are then used in Equations A-11 and A-19 to estimate the expected frequencies of intersection $\mathrm{E}\left[v^{I}\left(t, L_{m}^{I}, \phi_{n} \mid \Theta\right)\right]$ and $\mathrm{E}\left[v^{I}\left(t, L_{m}^{I}, \phi_{n}, r^{E C} \mid \Theta\right)\right]$, respectively for each of the PVHA expert's interpretations. The definition for $P\left(\Theta^{D}=\theta_{S_{D}}^{D}\right)$ used in Equation A-23 is used in this calculation. The results for each expert are then averaged to obtain an estimate of the composite expected frequencies over all experts using the expressions:

$$
\begin{gathered}
\mathrm{E}\left[v^{I}\left(t, L_{m}^{I}, \phi_{n}\right)\right] \sim \frac{1}{10} \sum_{\text {expert } 1}^{\text {expert } 10} \mathrm{E}\left[v^{I}\left(t, L_{m}^{I}, \phi_{n} \mid \Theta\right)\right] \\
\text { and } \\
\mathrm{E}\left[v^{I}\left(t, L_{m}^{I}, \phi_{n}, r^{E C}\right)\right] \sim \frac{1}{10} \sum_{\text {expert } 1}^{\text {expert } 10} \mathrm{E}\left[v^{I}\left(t, L_{m}^{I}, \phi_{n}, r^{E C} \mid \Theta\right)\right]
\end{gathered}
$$

This calculation is performed using software routine COMBSM (BSC 2000 [DIRS 168220]). The resulting partial frequencies of intersection are then normalized to produce conditional distributions. At each value of $L_{m}^{I}$ and $\phi_{n}$, the computed vales of $\mathrm{E}\left[v^{I}\left(t, L_{m}^{I}, \phi_{n}, r^{E C}\right)\right]$ are divided by $\mathrm{E}\left[v^{I}\left(t, L_{m}^{I}, \phi_{n}\right)\right]$ to produce a distribution for $r^{E C}$ conditional on $L_{m}^{I}$ and $\phi_{n}$. The values of $\mathrm{E}\left[v^{I}\left(t, L_{m}^{I}, \phi_{n}\right)\right]$ are, in turn, divided by $\mathrm{E}\left[v^{I}(t)\right]$ to produce a joint distribution for $L_{m}^{I}$ and $\phi_{n}$ conditional on the mean frequency of intersection. Because Latin hypercube sampling was used instead of full enumeration in Step 2 at a few of the points $(x, y)$ that contribute to the frequency of intersection computed in Step 3, the 100 simulated values of $L_{\text {sim }}$ and $E_{\text {sim }}^{L}$ do not produce any intersections. These intersections occur at locations where only the longest possible dikes combined with values of $E^{L}$ very near 1.0 result in intersections of the repository footprint. As a result, the sum of $\mathrm{E}\left[v^{I}\left(t, L_{m}^{I}, \phi_{n} \Theta \Theta\right)\right]$ over $L_{m}^{I}$ and $\phi_{n}$ for each expert typically equaled about 
97 percent to 99 percent of $\mathrm{E}\left[v^{I}(t \mid \Theta)\right]$. Because the purpose of Step 5 is to obtain a conditional distribution, the computed values of $\mathrm{E}\left[v^{I}\left(t, L_{m}^{I}, \phi_{n} \mid \Theta\right)\right]$ for each expert were normalized in software routine COMBSM V1.0 to sum to the value of $\mathrm{E}\left[v^{I}(t \Theta)\right]$ computed in Step 3 (The true value of $\mathrm{E}\left[v^{I}(t \Theta)\right]$ was computed by full enumeration of the individual expert interpretations.)

Step 5d. Step 4 identified those simulation results that represented the 5th and 95th percentiles of the composite distribution for frequency of intersection. For these parameter sets, designated $\theta^{0.05}$ and $\theta^{0.95}$, the results of Step $5 \mathrm{~b}$ are used in Equations A-10 and A-18 to compute the values of $v^{I}\left(t, L_{m}^{I}, \phi_{n} \mid \theta^{0.05}\right)$ and $v^{I}\left(t, L_{m}^{I}, \phi_{n}, r^{E C} \mid \theta^{0.05}\right)$, respectively, for the 5th percentile hazard and $v^{I}\left(t, L_{m}^{I}, \phi_{n} \mid \theta^{0.95}\right)$ and $v^{I}\left(t, L_{m}^{I}, \phi_{n}, r^{E C} \mid \theta^{0.95}\right)$, respectively, for the 95 th percentile hazard. The results of the individual simulations are averaged using software routine COMBSF (BSC 2000 [DIRS 168218]) to produce the final values of $v^{I}\left(t, L_{m}^{I}, \phi_{n} \mid \theta^{0.05}\right), v^{I}\left(t, L_{m}^{I}, \phi_{n}, r^{E C} \mid \theta^{0.05}\right)$, $v^{I}\left(t, L_{m}^{I}, \phi_{n} \mid \theta^{0.95}\right)$ and $v^{I}\left(t, L_{m}^{I}, \phi_{n}, r^{E C} \mid \theta^{0.95}\right)$. Routine COMBSF performs this calculation, including the normalization so that the sum of $v^{I}\left(t, L_{m}^{I}, \phi_{n} \mid \theta^{0 . x x}\right)$ over $L_{m}^{I}$ and $\phi_{n}$ equals $v^{I}\left(t \mid \theta^{0 . x x}\right)$ obtained in Step 4. The resulting disaggregated frequencies of intersection are then normalized to produce conditional distributions. At each value of $L_{m}^{I}$ and $\phi_{n}$, the computed values of $v^{I}\left(t, L_{m}^{I}, \phi_{n}, r^{E C} \mid \theta^{0.05}\right)$ are divided by $v^{I}\left(t, L_{m}^{I}, \phi_{n} \mid \theta^{0.05}\right)$ and the values of $v^{I}\left(t, L_{m}^{I}, \phi_{n}, r^{E C} \mid \theta^{0.95}\right)$ are divided by $v^{I}\left(t, L_{m}^{I}, \phi_{n} \mid \theta^{0.95}\right)$ to produce a distribution for $r^{E C}$ conditional on $L_{m}^{I}$ and $\phi_{n}$. The values of $v^{I}\left(t, L_{m}^{I}, \phi_{n} \mid \theta^{0.05}\right)$ are, in turn, divided by $v^{I}\left(t \mid \theta^{0.05}\right)$ and the values $v^{I}\left(t, L_{m}^{I}, \phi_{n} \mid \theta^{0.95}\right)$ are divided by $v^{I}\left(t \mid \theta^{0.95}\right)$ to produce joint distributions for $L^{I}{ }_{m}$ and $\phi_{n}$ conditional on the 5 th and 95th percentile values for the frequency of intersection. 


\section{APPENDIX B}

\section{DEVELOPMENT OF FOOTPRINT POLYGON}

FOR THE PROPOSED REPOSITORY 
The coordinates of the emplacement drifts for the 2003 repository design were obtained from the Repository Design, Repository/PA IED Subsurface Facilities (BSC 2003 [DIRS 162289]). These coordinates are given in terms of the Nevada State Plane Coordinate System, Central Zone. The coordinate system used in the PVHA hazard assessment is UTM. The Nevada State Plane coordinates for the emplacement drifts were transformed to UTM (Zone 11) using the coordinate conversion utility in EarthVision 5.1 (Dynamics Graphics 2000 [DIRS 167994]). The transformed coordinates are listed in Table B-1. Subsequent to REV 01 of this report, the emplacement area of the repository has been modified slightly (BSC 2004 [DIRS 164519]). As discussed in Section 6.5.2, this slight decrease in the size of the emplacement area is expected to have a negligible effect on the calculated frequency of intersection.

The calculations performed in this scientific analysis use input data from files that contain the vertices of a polygon for the repository footprint. For the purpose of this analysis, the repository footprint is defined as the outline of the waste emplacement area. A polygon was constructed to encompass the emplacement drifts in panels $1,2,3$, and 5 of the repository design. A buffer zone was added around the emplacement area defined by the drift coordinates in Table B-1 to account for the effect of eruptive conduit size on the calculation of the frequency of dike intersection and the distribution for number of eruptive centers within the repository footprint. The width of the buffer zone $(55 \mathrm{~m})$ was defined in REV 01 of this report (BSC 2003 [DIRS 163769]) as the sum of the mean diameter for eruptive conduits $(52.2 \mathrm{~m})$ and the drift half-width of $2.75 \mathrm{~m}$. The resulting polygon vertices were placed in input file LA2002.FP used in the calculations presented in this report. The footprint polygon file is shown in Figures 6-17a and 6-17b, Section 6.5 .

The Characterize Eruptive Processes at Yucca Mountain, Nevada, report (BSC 2004 [DIRS 169980]) has redefined the distribution for eruptive conduit diameter to be triangular with a mode at $50 \mathrm{~m}$ and a maximum at $150 \mathrm{~m}$. The mean of this distribution is approximately $67 \mathrm{~m}$. If the repository footprint polygon were to be adjusted to account for a $15 \mathrm{~m}$ difference in the width of the buffer zone, the difference in the total length of the footprint polygon would be approximately 0.5 percent and the difference in the area of the repository footprint would be 3 percent. The change in area and length from the 1996 PVHA footprint to the repository footprint represent increases of 12 percent and 41 percent, respectively. These changes produced only a 13 percent increase in the mean frequency of intersection. Thus, increasing the width of the buffer zone by $15 \mathrm{~m}$ is expected to have a very small effect on the computed frequency of intersection and a recalculation is not warranted at this time. It should be noted that the buffer zone width does accommodate the mode of the conduit diameter distribution. Also, the increase in size is partially offset by the modification to the repository design discussed at the beginning of this appendix. 
Table B-1. Repository Drift Coordinates for 2003 Repository Design

\begin{tabular}{|c|c|c|c|c|c|}
\hline \multirow[b]{2}{*}{ Panel } & \multirow[b]{2}{*}{ Drift } & \multicolumn{2}{|c|}{ East Side } & \multicolumn{2}{|c|}{ West Side } \\
\hline & & $\begin{array}{c}\text { UTM } \\
\text { Easting } \\
(\mathrm{km})\end{array}$ & $\begin{array}{c}\text { UTM } \\
\text { Northing } \\
\text { (km) }\end{array}$ & $\begin{array}{c}\text { UTM } \\
\text { Easting } \\
(\mathbf{k m})\end{array}$ & $\begin{array}{c}\text { UTM } \\
\text { Northing } \\
(\mathbf{k m})\end{array}$ \\
\hline 2 & 1 & 548.966 & 4081.495 & 548.434 & 4081.320 \\
\hline 2 & 2 & 548.962 & 4081.408 & 548.392 & 4081.221 \\
\hline 3 & 2 & 548.364 & 4081.212 & 547.959 & 4081.079 \\
\hline 2 & 3 & 548.921 & 4081.310 & 548.351 & 4081.122 \\
\hline 3 & 3 & 548.323 & 4081.113 & 547.782 & 4080.935 \\
\hline 2 & 4 & 548.879 & 4081.211 & 548.309 & 4081.023 \\
\hline 3 & 4 & 548.281 & 4081.014 & 547.711 & 4080.827 \\
\hline 2 & 1 & 549.441 & 4081.310 & 548.997 & 4081.164 \\
\hline 2 & 5 & 548.837 & 4081.112 & 548.267 & 4080.925 \\
\hline 3 & 5 & 548.239 & 4080.915 & 547.669 & 4080.728 \\
\hline 3 & 6 & 547.627 & 4080.629 & 548.198 & 4080.816 \\
\hline 2 & 6 & 548.226 & 4080.826 & 548.796 & 4081.013 \\
\hline 2 & 2 & 548.956 & 4081.065 & 549.532 & 4081.255 \\
\hline 2 & 3 & 549.582 & 4081.186 & 548.914 & 4080.966 \\
\hline 2 & 7 & 548.754 & 4080.913 & 548.184 & 4080.726 \\
\hline 3 & 7 & 548.156 & 4080.717 & 547.586 & 4080.529 \\
\hline 3 & 8 & 547.544 & 4080.431 & 548.114 & 4080.618 \\
\hline 2 & 8 & 548.142 & 4080.627 & 548.713 & 4080.815 \\
\hline 2 & 4 & 548.872 & 4080.868 & 549.610 & 4081.110 \\
\hline 2 & 5 & 549.563 & 4081.009 & 548.831 & 4080.769 \\
\hline 2 & 9 & 548.671 & 4080.716 & 548.101 & 4080.528 \\
\hline 3 & 9 & 548.073 & 4080.519 & 547.503 & 4080.332 \\
\hline 3 & 10 & 547.446 & 4080.228 & 548.032 & 4080.421 \\
\hline 2 & 10 & 548.061 & 4080.430 & 548.626 & 4080.616 \\
\hline 2 & 6 & 548.770 & 4080.664 & 549.511 & 4080.907 \\
\hline 2 & 7 & 549.459 & 4080.805 & 548.738 & 4080.567 \\
\hline 2 & 11 & 548.622 & 4080.529 & 548.046 & 4080.340 \\
\hline 3 & 11 & 547.994 & 4080.323 & 547.425 & 4080.136 \\
\hline 3 & 12 & 547.421 & 4080.049 & 547.990 & 4080.236 \\
\hline 2 & 12 & 548.042 & 4080.253 & 548.618 & 4080.443 \\
\hline 2 & 8 & 548.735 & 4080.481 & 549.408 & 4080.703 \\
\hline 2 & 9 & 549.356 & 4080.601 & 548.730 & 4080.394 \\
\hline 2 & 13 & 548.613 & 4080.356 & 548.038 & 4080.167 \\
\hline 3 & 13 & 547.986 & 4080.150 & 547.417 & 4079.963 \\
\hline 3 & 14 & 547.412 & 4079.876 & 547.981 & 4080.063 \\
\hline 2 & 14 & 548.033 & 4080.080 & 548.609 & 4080.269 \\
\hline 2 & 10 & 548.726 & 4080.307 & 549.304 & 4080.498 \\
\hline 2 & 11 & 549.253 & 4080.395 & 548.722 & 4080.221 \\
\hline 2 & 15 & 548.605 & 4080.183 & 548.030 & 4079.993 \\
\hline 3 & 15 & 547.978 & 4079.977 & 547.407 & 4079.789 \\
\hline 3 & 16 & 547.404 & 4079.703 & 547.973 & 4079.890 \\
\hline
\end{tabular}


Table B-1. Proposed Repository Drift Coordinates for License Application Design (Continued)

\begin{tabular}{|c|c|c|c|c|c|}
\hline \multirow[b]{2}{*}{ Panel } & \multirow[b]{2}{*}{ Drift } & \multicolumn{2}{|c|}{ East Side } & \multicolumn{2}{|c|}{ West Side } \\
\hline & & $\begin{array}{c}\text { UTM } \\
\text { Easting } \\
(\mathrm{km})\end{array}$ & $\begin{array}{c}\text { UTM } \\
\text { Northing } \\
(\mathrm{km})\end{array}$ & $\begin{array}{c}\text { UTM } \\
\text { Easting } \\
(\mathrm{km})\end{array}$ & $\begin{array}{c}\text { UTM } \\
\text { Northing } \\
(\mathrm{km})\end{array}$ \\
\hline 2 & 16 & 548.025 & 4079.907 & 548.601 & 4080.096 \\
\hline 2 & 12 & 548.718 & 4080.134 & 549.201 & 4080.293 \\
\hline 2 & 13 & 549.164 & 4080.196 & 548.713 & 4080.048 \\
\hline 2 & 17 & 548.596 & 4080.009 & 548.021 & 4079.820 \\
\hline 3 & 17 & 547.969 & 4079.803 & 547.399 & 4079.616 \\
\hline 3 & 18 & 547.395 & 4079.529 & 547.965 & 4079.717 \\
\hline 2 & 18 & 548.016 & 4079.733 & 548.593 & 4079.923 \\
\hline 2 & 14 & 548.710 & 4079.962 & 549.142 & 4080.104 \\
\hline 2 & 15 & 549.115 & 4080.010 & 548.705 & 4079.875 \\
\hline 2 & 19 & 548.588 & 4079.836 & 548.012 & 4079.647 \\
\hline 3 & 19 & 547.961 & 4079.630 & 547.391 & 4079.443 \\
\hline 3 & 20 & 547.387 & 4079.356 & 547.956 & 4079.543 \\
\hline 2 & 20 & 548.008 & 4079.560 & 548.584 & 4079.750 \\
\hline 2 & 16 & 548.701 & 4079.789 & 549.106 & 4079.921 \\
\hline 2 & 17 & 549.087 & 4079.830 & 548.696 & 4079.702 \\
\hline 2 & 21 & 548.580 & 4079.663 & 548.003 & 4079.474 \\
\hline 3 & 21 & 547.951 & 4079.457 & 547.382 & 4079.269 \\
\hline 3 & 22 & 547.381 & 4079.184 & 547.948 & 4079.370 \\
\hline 2 & 22 & 548.000 & 4079.387 & 548.575 & 4079.576 \\
\hline 2 & 18 & 548.693 & 4079.615 & 549.067 & 4079.738 \\
\hline 2 & 19 & 549.049 & 4079.647 & 548.688 & 4079.529 \\
\hline 2 & 23 & 548.571 & 4079.490 & 547.995 & 4079.300 \\
\hline 3 & 23 & 547.946 & 4079.284 & 547.389 & 4079.101 \\
\hline 3 & 24 & 547.396 & 4079.018 & 547.962 & 4079.204 \\
\hline 1 & 1 & 548.112 & 4079.254 & 548.566 & 4079.403 \\
\hline 1 & 2 & 548.563 & 4079.316 & 548.012 & 4079.135 \\
\hline 3 & 25 & 547.959 & 4079.118 & 547.403 & 4078.935 \\
\hline 3 & 26 & 547.411 & 4078.852 & 547.954 & 4079.031 \\
\hline 1 & 3 & 548.006 & 4079.048 & 548.558 & 4079.230 \\
\hline 1 & 4 & 548.554 & 4079.143 & 548.002 & 4078.961 \\
\hline 3 & 27 & 547.950 & 4078.944 & 547.419 & 4078.770 \\
\hline 3 & 28 & 547.426 & 4078.687 & 547.946 & 4078.858 \\
\hline 1 & 5 & 548.003 & 4078.877 & 548.550 & 4079.056 \\
\hline 1 & 6 & 548.546 & 4078.970 & 548.044 & 4078.805 \\
\hline 3 & 29 & 547.944 & 4078.772 & 547.437 & 4078.605 \\
\hline 3 & 30 & 547.470 & 4078.531 & 547.977 & 4078.697 \\
\hline 1 & 7 & 548.541 & 4078.883 & 548.128 & 4078.747 \\
\hline 3 & 31 & 548.074 & 4078.645 & 547.528 & 4078.465 \\
\hline 1 & 8 & 548.538 & 4078.796 & 548.215 & 4078.691 \\
\hline 5 & 1 & 548.525 & 4078.537 & 547.794 & 4078.297 \\
\hline 5 & 2 & 547.793 & 4078.211 & 548.520 & 4078.450 \\
\hline 5 & 3 & 548.516 & 4078.363 & 547.791 & 4078.125 \\
\hline
\end{tabular}


Table B-1. Proposed Repository Drift Coordinates for License Application Design (Continued)

\begin{tabular}{|c|c|c|c|c|c|}
\hline \multirow[b]{2}{*}{ Panel } & \multirow[b]{2}{*}{ Drift } & \multicolumn{2}{|c|}{ East Side } & \multicolumn{2}{|c|}{ West Side } \\
\hline & & $\begin{array}{c}\text { UTM } \\
\text { Easting } \\
(\mathbf{k m})\end{array}$ & $\begin{array}{c}\text { UTM } \\
\begin{array}{c}\text { Northing } \\
(\mathrm{km})\end{array} \\
\end{array}$ & $\begin{array}{c}\text { UTM } \\
\text { Easting } \\
(\mathbf{k m})\end{array}$ & $\begin{array}{c}\text { UTM } \\
\text { Northing } \\
\text { (km) }\end{array}$ \\
\hline 5 & 4 & 547.790 & 4078.040 & 548.511 & 4078.277 \\
\hline 5 & 5 & 548.508 & 4078.190 & 547.789 & 4077.954 \\
\hline 5 & 6 & 547.788 & 4077.869 & 548.503 & 4078.103 \\
\hline 5 & 7 & 548.499 & 4078.017 & 547.786 & 4077.783 \\
\hline 5 & 8 & 547.786 & 4077.697 & 548.495 & 4077.930 \\
\hline 5 & 9 & 548.491 & 4077.843 & 547.784 & 4077.612 \\
\hline 5 & 10 & 547.783 & 4077.526 & 548.486 & 4077.757 \\
\hline 5 & 11 & 548.483 & 4077.670 & 547.785 & 4077.441 \\
\hline 5 & 12 & 547.787 & 4077.356 & 548.478 & 4077.583 \\
\hline 5 & 13 & 548.473 & 4077.497 & 547.788 & 4077.272 \\
\hline 5 & 14 & 547.789 & 4077.187 & 548.469 & 4077.410 \\
\hline 5 & 15 & 548.465 & 4077.324 & 547.792 & 4077.102 \\
\hline 5 & 16 & 547.793 & 4077.018 & 548.461 & 4077.237 \\
\hline 5 & 17 & 548.456 & 4077.150 & 547.795 & 4076.933 \\
\hline 5 & 18 & 547.800 & 4076.849 & 548.453 & 4077.064 \\
\hline 5 & 19 & 548.448 & 4076.977 & 547.805 & 4076.766 \\
\hline 5 & 20 & 547.807 & 4076.681 & 548.444 & 4076.890 \\
\hline 5 & 21 & 548.440 & 4076.804 & 547.807 & 4076.596 \\
\hline 5 & 22 & 547.805 & 4076.510 & 548.436 & 4076.717 \\
\hline 5 & 23 & 548.431 & 4076.630 & 547.806 & 4076.425 \\
\hline 5 & 24 & 547.807 & 4076.340 & 548.428 & 4076.544 \\
\hline 5 & 25 & 548.416 & 4076.455 & 547.815 & 4076.257 \\
\hline 5 & 26 & 547.843 & 4076.181 & 548.381 & 4076.358 \\
\hline 5 & 27 & 548.337 & 4076.259 & 547.892 & 4076.113 \\
\hline
\end{tabular}

Output DTN: LA0303BY831811.001. 
APPENDIX C

DEVELOPMENT OF DISTRIBUTIONS FOR NUMBER OF ERUPTIVE CENTERS PER VOLCANIC EVENT AND AVERAGE SPACING BETWEEN ERUPTIVE CENTERS 


\section{C1 INTRODUCTION}

This appendix presents the derivation of discrete distributions for the number of eruptive centers per volcanic event, $n^{E C}$, and the average spacing between eruptive centers. These assessments are derived from the PVHA experts' assessments of the number of volcanic events at the three Quaternary volcanic centers in the site region, Lathrop Wells (LW), Sleeping Butte (SB), and Northwest Crater Flat (NWCF) using the first two assumptions described in Section 5. As defined in the PVHA (CRWMS M\&O 1996 [DIRS 100116]), the number of eruptive centers at each of these sites is: two at Sleeping Butte (Little Black Peak and Hidden Cone); five at Crater Flat (Little Cones southwest, Little Cones northeast, Red Cone, Black Cone, and Makani Cone); and one at Lathrop Wells.

\section{C2 ILLUSTRATION OF THE PROCESS}

The process is illustrated using the assessments of Alex McBirney (AM) (from Table AM-1, p. AM-13 of Appendix E in Probabilistic Volcanic Hazard Analysis for Yucca Mountain, Nevada (CRWMS M\&O 1996 [DIRS 100116])). For Lathrop Wells (LW), AM assigned probabilities of $0.3,0.2,0.4$, and 0.1 , for possible volcanic events $1,2,3$, and 4 , respectively. If only one event occurred, then the data from LW are one event with one eruptive center per event $\left(n^{E C}=1\right)$. If there were two events, then the data are two events with $n^{E C}=1$. For the three and four volcanic event scenarios the data are three events with $n^{E C}=1$ and four events with $n^{E C}=1$, respectively. These assessments are summarized in Table $\mathrm{C}-1$.

For Sleeping Butte (SB), AM assigned probabilities of $0.05,0.8$, and 0.15 to there being 1,2 , or 3 volcanic events, respectively. For the one event scenario, the data are one event with $n^{E C}=2$ (Hidden Cone and Little Black Peak). For the two-event scenario, the data are two events with $n^{E C}=1$. For the three-event scenario, the data are three events with $n^{E C}=1$.

For Northwest Crater Flat (NWCF), AM assigned probabilities of 0.9, 0.05, 0.025, 0.015, and 0.01 , because there were $1,2,3,4$, or 5 volcanic events, respectively. For the one event scenario, the data are one event with $n^{E C}=5$ (Little Cones SW, Little Cones NE, Red Cone, Black Cone, and Makani Cone). For the two-event scenario, AM linked Little Cones (SW and NE), Red Cone, and Black Cone into one event and considered Makani Cone to be the second event. Thus, the data are one event with $n^{E C}=4$ and one event with $n^{E C}=1$. For the three-event scenario, AM considered Red Cone and Black Cone to be one event, Little Cones SW and NE to be one event, and Makani Cone to be the third event. Thus, the data are two events with $n^{E C}=2$ and one event with $n^{E C}=1$. For the four-event scenario, AM considered Little Cones SW and NE to be one event, and Red Cone, Black Cone, and Makani Cone to each be separate events. Thus, the data are one event with $n^{E C}=2$ and four events with $n^{E C}=1$. Finally, for the five-event scenario, the data are five events with $n^{E C}=1$.

The PVHA experts defined their assessments at each of the volcanic centers to be independent of the assessments at the other centers. As a result, for the assessments from Alex McBirney, there are $4 \times 3 \times 5=60$ possible combined scenarios for the number of Quaternary volcanic events. Each of these combined scenarios represents a possible empirical data set for evaluating the distribution for $n^{E C}$. For example, if LW scenario 1, SB scenario 1, and NWCF scenario 1 are the correct assessments for the number of events, then the combined data set consists of one 
event with $n^{E C}=1$, one event with $n^{E C}=2$, and one event with $n^{E C}=5$. The resulting empirical distribution defining the relative frequency for various values of $n^{E C}$ is:

$$
\begin{gathered}
P\left(n^{E C}=1\right)=1 / 3=0.333 \\
P\left(n^{E C}=2\right)=1 / 3=0.333 \\
P\left(n^{E C}=3\right)=0 / 3=0 \\
P\left(n^{E C}=4\right)=0 / 3=0 \\
P\left(n^{E C}=5\right)=1 / 3=0.333
\end{gathered}
$$

The joint probability that this combined scenario represents the correct data is the product of the three independent probabilities for each scenario and is equal to $0.3 \times 0.05 \times 0.9=0.0135$. There are 59 other possible combined data sets, each resulting in an empirical distribution for $n^{E C}$. The weighted average of these distributions is used to represent the expected distribution for $n^{E C}$ based on the assessments of Alex McBirney.

A similar process is followed to compute the average spacing between eruptive centers. Whenever a volcanic event is defined to contain more than one of the eruptive centers, then the assessment provides a data point that can be used to evaluate the average spacing between eruptive centers. In the above combined scenario, there are two volcanic events with multiple eruptive centers. The single event at Sleeping Butte consists of eruptive centers at Little Black Peak and Hidden Cone. These cones are located $2.45 \mathrm{~km}$ apart. The single event at Crater Flat consists of five eruptive centers. The distance between Makani Cone and Little Cones SW is $11.19 \mathrm{~km}$. Dividing this distance by 4 , which is the number of intervals between eruptive centers, gives an average spacing of $2.80 \mathrm{~km}$. Thus the empirical distribution consists of a sample of two points, $2.45 \mathrm{~km}$ with a probability of 0.5 and $2.80 \mathrm{~km}$, with a probability of 0.5 . This distribution is weighted by the probability for the scenario of 0.0135 . Repeating the process for the 59 other scenarios, weighting each empirical distribution by its scenario probability provides a composite empirical distribution for the average spacing between eruptive centers in future volcanic events. In performing this calculation, those scenarios that result in only volcanic events with no multiple eruptive centers are removed from the weighting process.

\section{C3 CALCULATION INPUT AND RESULTS}

The inputs to the calculation are the distributions for the number of volcanic events represented by the mapped Quaternary volcanoes defined by the PVHA experts and the locations of the volcanoes. Tables $\mathrm{C}-1$ through $\mathrm{C}-10$ summarize the interpretations of the assessments made by the 10 PVHA experts. 
Table C-1. Assessments from Alex McBirney's Volcanic Hazard Model

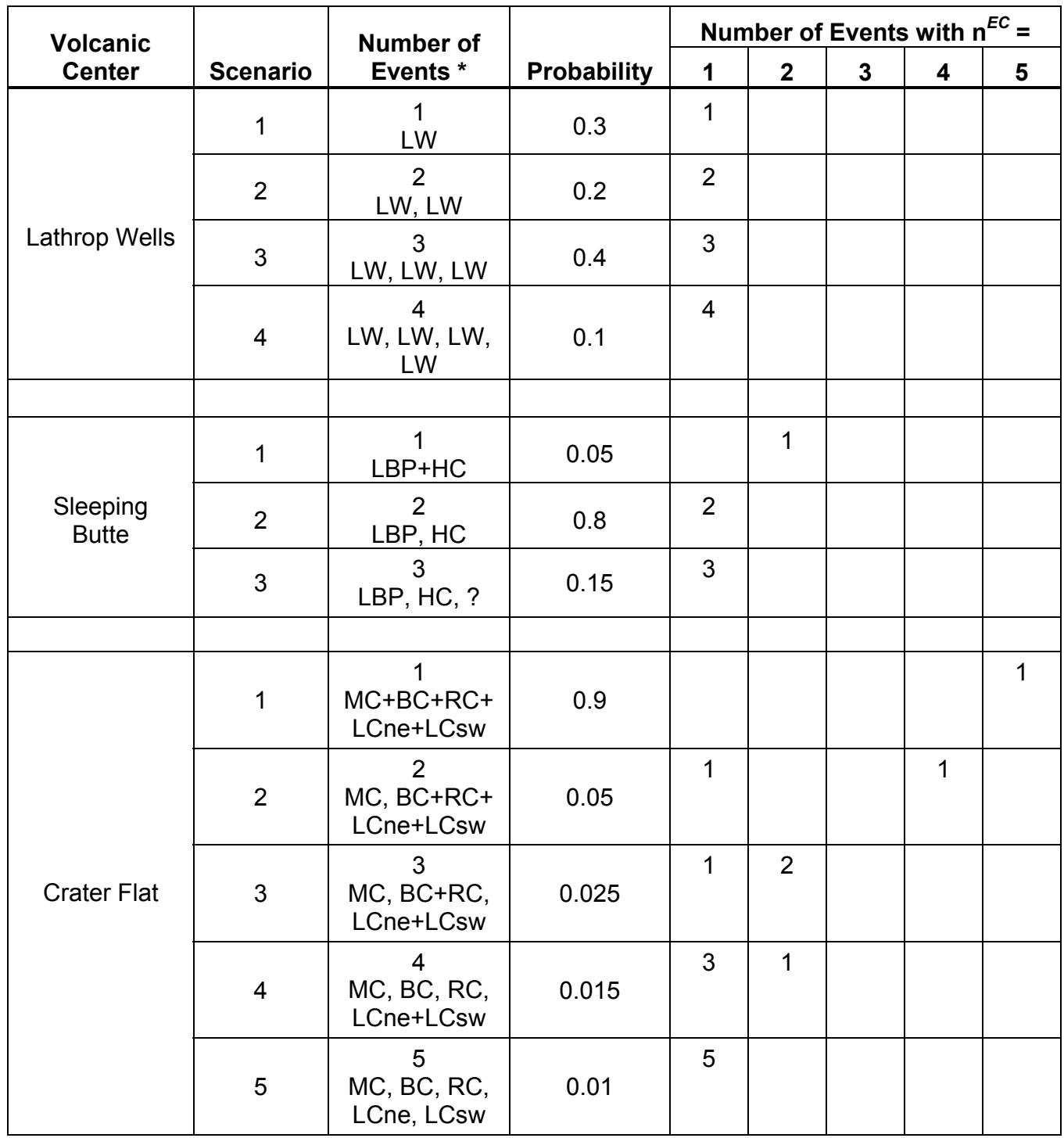

DTN: MO0002PVHA0082.000 [DIRS 148234].

Source: CRWMS M\&O (1996 [DIRS 100116], Appendix E, Table AM-1, p. AM-13).

NOTE: * LW = Lathrop Wells; HC = Hidden Cone; LBP = Little Black Peak; MC = Makani Cone; $\mathrm{BC}=$ Black Cone; $\mathrm{RC}=$ Red Cone; Lcne = Little Cones North East; LCsw = Little Cones southwest, undetected. A + indicates eruptive centers considered to be part of a single volcanic event. 
Table C-2. Assessments from Bruce Crowe's Volcanic Hazard Model

\begin{tabular}{|c|c|c|c|c|c|c|c|c|}
\hline \multirow{2}{*}{$\begin{array}{c}\text { Volcanic } \\
\text { Center }\end{array}$} & \multirow[b]{2}{*}{ Scenario } & \multirow{2}{*}{$\begin{array}{c}\text { Number of } \\
\text { Events * }\end{array}$} & \multirow[b]{2}{*}{ Probability } & \multicolumn{5}{|c|}{ Number of Events with $n^{E C}=$} \\
\hline & & & & 1 & 2 & 3 & 4 & 5 \\
\hline \multirow{4}{*}{ Lathrop Wells } & 1 & $\begin{array}{c}1 \\
\text { LW }\end{array}$ & 0.9 & 1 & & & & \\
\hline & 2 & $\begin{array}{c}2 \\
\text { LW, LW }\end{array}$ & 0.06 & 2 & & & & \\
\hline & 3 & $\begin{array}{c}3 \\
\text { LW, LW, LW }\end{array}$ & 0.03 & 3 & & & & \\
\hline & 4 & $\begin{array}{c}4 \\
\text { LW, LW, LW, } \\
\text { LW }\end{array}$ & 0.01 & 4 & & & & \\
\hline \multirow{3}{*}{ Sleeping Butte } & 1 & $\begin{array}{c}1 \\
\mathrm{LBP}+\mathrm{HC}\end{array}$ & 0.35 & & 1 & & & \\
\hline & 2 & $\begin{array}{c}2 \\
\text { LBP, } \mathrm{HC}\end{array}$ & 0.45 & 2 & & & & \\
\hline & 3 & $\begin{array}{c}3 \\
\text { LBP, } \mathrm{HC}, ?\end{array}$ & 0.2 & 3 & & & & \\
\hline \multirow{7}{*}{ Crater Flat } & 1 & $\begin{array}{c}1 \\
\text { MC+BC+RC+ } \\
\text { LCne+LCsw }\end{array}$ & 0.1 & & & & & 1 \\
\hline & 2 & $\begin{array}{c}2 \\
M C+B C, \\
R C+L C n e+L C \\
\text { sw }\end{array}$ & 0.1 & & 1 & 1 & & \\
\hline & 3 & $\begin{array}{c}3 \\
M C, B C+R C, \\
L C n e+L C s w\end{array}$ & 0.45 & 1 & 2 & & & \\
\hline & 4 & $\begin{array}{c}4 \\
M C, B C, R C, \\
\text { LCne+LCsw }\end{array}$ & 0.2 & 3 & 1 & & & \\
\hline & 5 & $\begin{array}{c}5 \\
\text { MC, BC, RC, } \\
\text { Lcne, LCsw }\end{array}$ & 0.1 & 5 & & & & \\
\hline & 6 & $\begin{array}{c}6 \\
\text { MC, BC, RC, } \\
\text { Lcne, LCsw, ? }\end{array}$ & 0.025 & 6 & & & & \\
\hline & 7 & $\begin{array}{c}7 \\
\text { MC, BC, RC, } \\
\text { Lcne, LCsw, } \\
?, ?\end{array}$ & 0.025 & 7 & & & & \\
\hline
\end{tabular}

DTN: MO0002PVHA0082.000 [DIRS 148234].

Source: CRWMS M\&O (1996 [DIRS 100116], Appendix E, Table BC-3, p. BC-39).

NOTE: * LW = Lathrop Wells; HC = Hidden Cone; LBP = Little Black Peak; MC = Makani Cone; $\mathrm{BC}=$ Black Cone; RC = Red Cone; Lcne = Little Cones North East; LCsw = Little Cones southwest, undetected. A + indicates eruptive centers considered to be part of a single volcanic event. 
Table C-3. Assessments from George Thompson's Volcanic Hazard Model

\begin{tabular}{|c|c|c|c|c|c|c|c|c|}
\hline \multirow{2}{*}{$\begin{array}{c}\text { Volcanic } \\
\text { Center }\end{array}$} & \multirow[b]{2}{*}{ Scenario } & \multirow{2}{*}{$\begin{array}{c}\text { Number of } \\
\text { Events* }\end{array}$} & \multirow[b]{2}{*}{ Probability } & \multicolumn{5}{|c|}{ Number of Events with $n^{E C}=$} \\
\hline & & & & 1 & 2 & 3 & 4 & 5 \\
\hline \multirow{4}{*}{ Lathrop Wells } & 1 & $\begin{array}{c}1 \\
\mathrm{LW}\end{array}$ & 0.75 & 1 & & & & \\
\hline & 2 & $\begin{array}{c}2 \\
L W, L W\end{array}$ & 0.09 & 2 & & & & \\
\hline & 3 & $\begin{array}{c}3 \\
\mathrm{LW}, \mathrm{LW}, \mathrm{LW}\end{array}$ & 0.08 & 3 & & & & \\
\hline & 4 & $\begin{array}{c}4 \\
\text { LW, LW, LW, } \\
\text { LW }\end{array}$ & 0.08 & 4 & & & & \\
\hline \multirow{2}{*}{ Sleeping Butte } & 1 & $\begin{array}{c}1 \\
\mathrm{LBP}+\mathrm{HC}\end{array}$ & 0.35 & & 1 & & & \\
\hline & 2 & $\begin{array}{c}2 \\
\text { LBP, } \mathrm{HC}\end{array}$ & 0.65 & 2 & & & & \\
\hline \multirow{5}{*}{ Crater Flat } & 1 & $\begin{array}{c}1 \\
M C+B C+R C+ \\
\text { LCne+LCsw }\end{array}$ & 0.2 & & & & & 1 \\
\hline & 2 & $\begin{array}{c}2 \\
M C, B C+R C+ \\
\text { LCne+LCsw }\end{array}$ & 0.15 & 1 & & & 1 & \\
\hline & 3 & $\begin{array}{c}3 \\
M C, B C+R C, \\
\text { LCne+LCsw }\end{array}$ & 0.1 & 1 & 2 & & & \\
\hline & 4 & $\begin{array}{c}4 \\
M C, B C, R C, \\
\text { LCne+LCsw }\end{array}$ & 0.5 & 3 & 1 & & & \\
\hline & 5 & $\begin{array}{c}5 \\
\text { MC, BC, RC, } \\
\text { Lcne, LCsw }\end{array}$ & 0.05 & 5 & & & & \\
\hline
\end{tabular}

DTN: MO0002PVHA0082.000 [DIRS 148234].

Source: CRWMS M\&O (1996 [DIRS 100116], Appendix E, Table GT-1, p. GT-11).

NOTE: * LW = Lathrop Wells; $\mathrm{HC}=$ Hidden Cone; LBP = Little Black Peak; MC = Makani Cone; $\mathrm{BC}=$ Black Cone; $\mathrm{RC}=$ Red Cone $;$ Lcne = Little Cones North East $;$ LCsw = Little Cones southwest, undetected. A + indicates eruptive centers considered to be part of a single volcanic event. 
Table C-4. Assessments from George Walker's Volcanic Hazard Model

\begin{tabular}{|c|c|c|c|c|c|c|c|c|}
\hline \multirow{2}{*}{$\begin{array}{c}\text { Volcanic } \\
\text { Center }\end{array}$} & \multirow[b]{2}{*}{ Scenario } & \multirow{2}{*}{$\begin{array}{c}\text { Number of } \\
\text { Events* }^{*}\end{array}$} & \multirow[b]{2}{*}{ Probability } & \multicolumn{5}{|c|}{ Number of Events with $n^{E C}=$} \\
\hline & & & & 1 & 2 & 3 & 4 & 5 \\
\hline \multirow{4}{*}{ Lathrop Wells } & 1 & $\begin{array}{c}1 \\
\mathrm{LW}\end{array}$ & 0.9 & 1 & & & & \\
\hline & 2 & $\begin{array}{c}2 \\
\mathrm{LW}, \mathrm{LW}\end{array}$ & 0.07 & 2 & & & & \\
\hline & 3 & $\begin{array}{c}3 \\
\text { LW, LW, LW }\end{array}$ & 0.02 & 3 & & & & \\
\hline & 4 & $\begin{array}{c}4 \\
\text { LW, LW, LW, } \\
\text { LW }\end{array}$ & 0.01 & 4 & & & & \\
\hline \multirow{2}{*}{ Sleeping Butte } & 1 & $\begin{array}{c}1 \\
\mathrm{LBP}+\mathrm{HC}\end{array}$ & 0.4 & & 1 & & & \\
\hline & 2 & $\begin{array}{c}2 \\
\mathrm{LBP}, \mathrm{HC}\end{array}$ & 0.6 & 2 & & & & \\
\hline \multirow{3}{*}{ Crater Flat } & 1 & $\begin{array}{c}1 \\
\text { MC+BC+RC+ } \\
\text { LCne+LCsw }\end{array}$ & 0.1 & & & & & 1 \\
\hline & 3 & $\begin{array}{c}3 \\
M C, B C+R C, \\
\text { LCne+LCsw }\end{array}$ & 0.35 & 1 & 2 & & & \\
\hline & 4 & $\begin{array}{c}4 \\
\text { MC, BC, RC, } \\
\text { LCne+LCsw }\end{array}$ & 0.55 & 3 & 1 & & & \\
\hline
\end{tabular}

DTN: MO0002PVHA0082.000 [DIRS 148234].

Source: CRWMS M\&O (1996 [DIRS 100116], Appendix E, Table GW-1, p. GW-11).

NOTE: $\quad$ * LW = Lathrop Wells; HC = Hidden Cone; LBP = Little Black Peak; MC = Makani Cone; $\mathrm{BC}=$ Black Cone; $\mathrm{RC}=$ Red Cone; Lcne = Little Cones North East; LCsw $=$ Little Cones southwest, undetected. A + indicates eruptive centers considered to be part of a single volcanic event. 
Table C-5. Assessments from Mel Kuntz's Volcanic Hazard Model

\begin{tabular}{|c|c|c|c|c|c|c|c|c|}
\hline \multirow{2}{*}{$\begin{array}{l}\text { Volcanic } \\
\text { Center }\end{array}$} & \multirow[b]{2}{*}{ Scenario } & \multirow{2}{*}{$\begin{array}{c}\text { Number of } \\
\text { Events * }\end{array}$} & \multirow[b]{2}{*}{ Probability } & \multicolumn{5}{|c|}{ Number of Events with $\mathrm{n}^{E C}=$} \\
\hline & & & & 1 & 2 & 3 & 4 & 5 \\
\hline \multirow{4}{*}{ Lathrop Wells } & 1 & $\begin{array}{c}1 \\
\text { LW }\end{array}$ & 0.95 & 1 & & & & \\
\hline & 2 & $\stackrel{2}{L W}$, LW & 0.03 & 2 & & & & \\
\hline & 3 & $\begin{array}{c}3 \\
\mathrm{LW}, \mathrm{LW}, \mathrm{LW}\end{array}$ & 0.019 & 3 & & & & \\
\hline & 4 & $\begin{array}{c}4 \\
\text { LW, LW, LW, } \\
\text { LW }\end{array}$ & 0.001 & 4 & & & & \\
\hline \multirow{3}{*}{$\begin{array}{l}\text { Sleeping } \\
\text { Butte }\end{array}$} & 1 & $\begin{array}{c}1 \\
\mathrm{LBP}+\mathrm{HC}\end{array}$ & 0.6 & & 1 & & & \\
\hline & 2 & $\begin{array}{c}2 \\
\text { LBP, }, H C\end{array}$ & 0.3 & 2 & & & & \\
\hline & 3 & $\begin{array}{c}3 \\
\mathrm{LBP}, \mathrm{HC}, ?\end{array}$ & 0.1 & 3 & & & & \\
\hline \multirow{4}{*}{ Crater Flat } & 1 & $\begin{array}{c}1 \\
M C+B C+R C+ \\
\text { LCne+LCsw }\end{array}$ & 0.6 & & & & & 1 \\
\hline & 2 & $\begin{array}{c}2 \\
\text { MC, BC+RC+ } \\
\text { LCne+LCsw }\end{array}$ & 0.3 & 1 & & & 1 & \\
\hline & 3 & $\begin{array}{c}3 \\
M C, B C+R C \\
L C n e+L C s w\end{array}$ & 0.05 & 1 & 2 & & & \\
\hline & 4 & $\begin{array}{c}4 \\
M C, B C, R C, \\
\text { LCne+LCsw }\end{array}$ & 0.05 & 3 & 1 & & & \\
\hline
\end{tabular}

DTN: MO0002PVHA0082.000 [DIRS 148234].

Source: CRWMS M\&O (1996 [DIRS 100116], Appendix E, Table MK-1, p. MK-18).

NOTE: * LW = Lathrop Wells; $\mathrm{HC}=$ Hidden Cone; LBP = Little Black Peak; $M=$ Makani Cone; $\mathrm{BC}=$ Black Cone; $\mathrm{RC}=$ Red Cone; Lcne = Little Cones North East; LCsw $=$ Little Cones southwest, undetected. $A+$ indicates eruptive centers considered to be part of a single volcanic event. 
Table C-6. Assessments from Michael Sheridan's Volcanic Hazard Model

\begin{tabular}{|c|c|c|c|c|c|c|c|c|}
\hline \multirow{2}{*}{$\begin{array}{c}\text { Volcanic } \\
\text { Center }\end{array}$} & \multirow[b]{2}{*}{ Scenario } & \multirow{2}{*}{$\begin{array}{c}\text { Number of } \\
\text { Events * }\end{array}$} & \multirow[b]{2}{*}{ Probability } & \multicolumn{5}{|c|}{ Number of Events with $\mathbf{n}^{E C}=$} \\
\hline & & & & 1 & 2 & 3 & 4 & 5 \\
\hline \multirow{2}{*}{ Lathrop Wells } & 1 & $\begin{array}{c}1 \\
\mathrm{LW}\end{array}$ & 0.9 & 1 & & & & \\
\hline & 2 & $\stackrel{2}{\text { LW, LW }}$ & 0.1 & 2 & & & & \\
\hline \multirow{2}{*}{ Sleeping Butte } & 1 & $\begin{array}{c}1 \\
\mathrm{LBP}+\mathrm{HC}\end{array}$ & 0.67 & & 1 & & & \\
\hline & 2 & $\begin{array}{c}2 \\
\text { LBP, }, H C\end{array}$ & 0.33 & 2 & & & & \\
\hline \multirow{3}{*}{ Crater Flat } & 1 & $\begin{array}{c}1 \\
\mathrm{MC}+\mathrm{BC}+\mathrm{RC} \\
+ \\
\text { LCne+LCsw }\end{array}$ & 0.7 & & & & & 1 \\
\hline & 2 & $\begin{array}{c}2 \\
M C \\
B C+R C+ \\
\text { LCne+LCsw }\end{array}$ & 0.2 & 1 & & & 4 & \\
\hline & 3 & $\begin{array}{c}3 \\
M C \\
B C+R C \\
\text { LCne+LCsw }\end{array}$ & 0.1 & 1 & 2 & 2 & & \\
\hline
\end{tabular}

DTN: MO0002PVHA0082.000 [DIRS 148234].

Source: CRWMS M\&O (1996 [DIRS 100116], Appendix E, Table MS-1, p. MS-16 and from text on pages MS-6 to MS-7).

NOTE: $\quad$ *LW $=$ Lathrop Wells; $\mathrm{HC}=$ Hidden Cone; $\mathrm{LBP}=$ Little Black Peak; $\mathrm{MC}=$ Makani Cone; $\mathrm{BC}=$ Black Cone; RC = Red Cone; Lcne = Little Cones North East; LCsw $=$ Little Cones southwest, undetected. A + indicates eruptive centers considered to be part of a single volcanic event. 
Table C-7. Assessments from Richard Carlson's Volcanic Hazard Model

\begin{tabular}{|c|c|c|c|c|c|c|c|c|}
\hline \multirow{2}{*}{$\begin{array}{c}\text { Volcanic } \\
\text { Center }\end{array}$} & \multirow[b]{2}{*}{ Scenario } & \multirow{2}{*}{$\begin{array}{c}\text { Number of } \\
\text { Events * }\end{array}$} & \multirow[b]{2}{*}{ Probability } & \multicolumn{5}{|c|}{ Number of Events with $n^{E C}=$} \\
\hline & & & & 1 & 2 & 3 & 4 & 5 \\
\hline \multirow{2}{*}{ Lathrop Wells } & 1 & $\begin{array}{c}1 \\
L W\end{array}$ & 0.95 & 1 & & & & \\
\hline & 2 & $\begin{array}{c}2 \\
L W, L W\end{array}$ & 0.05 & 2 & & & & \\
\hline \multirow{3}{*}{$\begin{array}{l}\text { Sleeping } \\
\text { Butte }\end{array}$} & 1 & $\begin{array}{c}1 \\
\mathrm{LBP}+\mathrm{HC}\end{array}$ & 0.7 & & 1 & & & \\
\hline & 2 & $\begin{array}{c}2 \\
\text { LBP, } \mathrm{HC}\end{array}$ & 0.2 & 2 & & & & \\
\hline & 3 & $\begin{array}{c}3 \\
\text { LBP, } \mathrm{HC}, ?\end{array}$ & 0.1 & 3 & & & & \\
\hline \multirow{3}{*}{ Crater Flat } & 1 & $\begin{array}{c}1 \\
M C+B C+R C+ \\
L C n e+L C s w\end{array}$ & 0.6 & & & & & 1 \\
\hline & 3 & $\begin{array}{c}3 \\
M C, B C+R C, \\
\text { LCne+LCsw }\end{array}$ & 0.3 & 1 & 2 & & & \\
\hline & 5 & $\begin{array}{c}5 \\
\text { MC, BC, RC, } \\
\text { Lcne, LCsw }\end{array}$ & 0.01 & 5 & & & & \\
\hline
\end{tabular}

DTN: MO0002PVHA0082.000 [DIRS 148234].

Source: CRWMS M\&O (1996 [DIRS 100116], Appendix E, Table RC-1, p. RC-16).

NOTE: ${ }^{*} \mathrm{LW}=$ Lathrop Wells; $\mathrm{HC}=$ Hidden Cone; $\mathrm{LBP}=$ Little Black Peak $\mathrm{MC}=$ Makani Cone; $\mathrm{BC}=$ Black Cone; RC = Red Cone; Lcne = Little Cones North East; LCsw $=$ Little Cones southwest, undetected. $A+$ indicates eruptive centers considered to be part of a single volcanic event. 
Table C-8. Assessments from Richard Fisher's Volcanic Hazard Model

\begin{tabular}{|c|c|c|c|c|c|c|c|c|}
\hline \multirow{2}{*}{$\begin{array}{l}\text { Volcanic } \\
\text { Center }\end{array}$} & \multirow[b]{2}{*}{ Scenario } & \multirow{2}{*}{$\begin{array}{c}\text { Number of } \\
\text { Events * }\end{array}$} & \multirow{2}{*}{$\begin{array}{c}\text { Probabilit } \\
y\end{array}$} & \multicolumn{5}{|c|}{ Number of Events with $n^{E C}=$} \\
\hline & & & & 1 & 2 & 3 & 4 & 5 \\
\hline \multirow{4}{*}{ Lathrop Wells } & 1 & $\begin{array}{c}1 \\
\text { LW }\end{array}$ & 0.6 & 1 & & & & \\
\hline & 2 & $\begin{array}{c}2 \\
\text { LW, LW }\end{array}$ & 0.3 & 2 & & & & \\
\hline & 3 & 3 & 0.05 & 3 & & & & \\
\hline & 4 & 4 & 0.05 & 4 & & & & \\
\hline \multirow{3}{*}{ Sleeping Butte } & 1 & $\begin{array}{c}1 \\
\mathrm{LBP}+\mathrm{HC}\end{array}$ & 0.7 & & 1 & & & \\
\hline & 2 & $\begin{array}{c}2 \\
\text { LBP, } \mathrm{HC}\end{array}$ & 0.25 & 2 & & & & \\
\hline & 3 & $\begin{array}{c}3 \\
\mathrm{LBP}, \mathrm{HC}, \mathrm{HC}\end{array}$ & 0.05 & 3 & & & & \\
\hline \multirow{4}{*}{ Crater Flat } & 1 & $\begin{array}{c}1 \\
M C+B C+R C+ \\
L C n e+L C s w \\
\end{array}$ & 0.8 & & & & & 1 \\
\hline & 2 & $\begin{array}{c}2 \\
M C+B C, \\
R C+L C n e+L C s \\
w \\
\end{array}$ & 0.05 & & 1 & 1 & & \\
\hline & 3 & $\begin{array}{c}3 \\
M C, B C+R C \\
L C n e+L C s w\end{array}$ & 0.05 & 1 & 2 & & & \\
\hline & 4 & $\begin{array}{c}4 \\
M C, B C, R C, \\
\text { LCne+LCsw }\end{array}$ & 0.1 & 3 & 1 & & & \\
\hline
\end{tabular}

DTN: MO0002PVHA0082.000 [DIRS 148234].

Source: CRWMS M\&O (1996 [DIRS 100116], Appendix E, Table RF-1, p. RF-12).

NOTE: ${ }^{*} \mathrm{LW}=$ Lathrop Wells; $\mathrm{HC}=$ Hidden Cone; $\mathrm{LBP}=$ Little Black Peak; $\mathrm{MC}=$ Makani Cone; $\mathrm{BC}=$ Black Cone; RC = Red Cone; $\mathrm{LCne}=$ Little Cones North East; LCsw $=$ Little Cones southwest, undetected. A + indicates eruptive centers considered to be part of a single volcanic event. 
Table C-9. Assessments from Wendell Duffield's Volcanic Hazard Model

\begin{tabular}{|c|c|c|c|c|c|c|c|c|}
\hline \multirow{2}{*}{$\begin{array}{c}\text { Volcanic } \\
\text { Center }\end{array}$} & \multirow[b]{2}{*}{ Scenario } & \multirow{2}{*}{$\begin{array}{c}\text { Number of } \\
\text { Events* }\end{array}$} & \multirow[b]{2}{*}{ Probability } & \multicolumn{5}{|c|}{ Number of Events with $n^{E C}=$} \\
\hline & & & & 1 & 2 & 3 & 4 & 5 \\
\hline \multirow{2}{*}{ Lathrop Wells } & 1 & $\begin{array}{c}1 \\
L W\end{array}$ & 0.9 & 1 & & & & \\
\hline & 2 & $\begin{array}{c}2 \\
L W, L W\end{array}$ & 0.1 & 2 & & & & \\
\hline \multirow{2}{*}{$\begin{array}{l}\text { Sleeping } \\
\text { Butte }\end{array}$} & 1 & $\begin{array}{c}1 \\
\mathrm{LBP}+\mathrm{HC}\end{array}$ & 0.05 & & 1 & & & \\
\hline & 2 & $\begin{array}{c}2 \\
\text { LBP, } \mathrm{HC}\end{array}$ & 0.95 & 2 & & & & \\
\hline \multirow{5}{*}{ Crater Flat } & 1 & $\begin{array}{c}1 \\
\text { MC+BC+RC+ } \\
\text { LCne+LCsw }\end{array}$ & 0.07 & & & & & 1 \\
\hline & 2 & $\begin{array}{c}2 \\
M C+B C+R C, \\
L C n e+L C s w\end{array}$ & 0.14 & & 1 & 1 & & \\
\hline & 3 & $\begin{array}{c}3 \\
M C, B C+R C, \\
\text { LCne+LCsw }\end{array}$ & 0.26 & 1 & 2 & & & \\
\hline & 4 & $\begin{array}{c}4 \\
\text { MC, BC, RC, } \\
\text { LCne+LCsw }\end{array}$ & 0.34 & 3 & 1 & & & \\
\hline & 5 & $\begin{array}{c}5 \\
\text { MC, BC, RC, } \\
\text { Lcne, LCsw }\end{array}$ & 0.19 & 5 & & & & \\
\hline
\end{tabular}

DTN: MO0002PVHA0082.000 [DIRS 148234].

Source: CRWMS M\&O (1996 [DIRS 100116], Appendix E, Table WD-1, pp. WD-11 and page WD-5).

NOTE: $\quad{ }^{*} \mathrm{LW}=$ Lathrop Wells; $\mathrm{HC}=$ Hidden Cone; $\mathrm{LBP}=$ Little Black Peak $\mathrm{MC}=$ Makani Cone; $\mathrm{BC}=$ Black Cone; RC = Red Cone; Lcne = Little Cones North East; LCsw $=$ Little Cones southwest, undetected. A + indicates eruptive centers considered to be part of a single volcanic event. 
Table C-10. Assessments from William Hackett's Volcanic Hazard Model

\begin{tabular}{|c|c|c|c|c|c|c|c|c|}
\hline \multirow{2}{*}{$\begin{array}{c}\text { Volcanic } \\
\text { Center }\end{array}$} & \multirow[b]{2}{*}{ Scenario } & \multirow{2}{*}{$\begin{array}{c}\text { Number of } \\
\text { Events* }\end{array}$} & \multirow[b]{2}{*}{ Probability } & \multicolumn{5}{|c|}{ Number of Events with $n^{E C}=$} \\
\hline & & & & 1 & 2 & 3 & 4 & 5 \\
\hline \multirow{5}{*}{ Lathrop Wells } & 1 & $\begin{array}{c}1 \\
\text { LW }\end{array}$ & 0.4 & 1 & & & & \\
\hline & 2 & $\begin{array}{c}2 \\
\text { LW, LW }\end{array}$ & 0.1 & 2 & & & & \\
\hline & 3 & $\begin{array}{c}3 \\
\mathrm{LW}, \mathrm{LW}, \mathrm{LW}\end{array}$ & 0.4 & 3 & & & & \\
\hline & 4 & $\begin{array}{c}4 \\
\text { LW, LW, LW, } \\
\text { LW }\end{array}$ & 0.05 & 4 & & & & \\
\hline & 5 & $\begin{array}{c}5 \\
\text { LW, LW, LW, } \\
\text { LW, LW }\end{array}$ & 0.05 & 5 & & & & \\
\hline \multirow{3}{*}{$\begin{array}{l}\text { Sleeping } \\
\text { Butte }\end{array}$} & 1 & $\begin{array}{c}1 \\
\mathrm{LBP}+\mathrm{HC}\end{array}$ & 0.4 & & 1 & & & \\
\hline & 2 & $\begin{array}{c}2 \\
\mathrm{LBP}, \mathrm{HC}\end{array}$ & 0.5 & 2 & & & & \\
\hline & 3 & $\begin{array}{c}3 \\
\text { LBP, } \mathrm{HC}, ?\end{array}$ & 0.1 & 3 & & & & \\
\hline \multirow{6}{*}{ Crater Flat } & 1 & $\begin{array}{c}1 \\
\text { MC+BC+RC+ } \\
\text { LCne+LCsw }\end{array}$ & 0.1 & & & & & 1 \\
\hline & 2 & $\begin{array}{c}2 \\
M C+B C+R C, \\
L C n e+L C s w\end{array}$ & 0.3 & & 1 & 1 & & \\
\hline & 3 & $\begin{array}{c}3 \\
M C, B C+R C, \\
\text { LCne+LCsw }\end{array}$ & 0.4 & 1 & 2 & & & \\
\hline & 4 & $\begin{array}{c}4 \\
\text { MC, BC, RC, } \\
\text { LCne+LCsw }\end{array}$ & 0.1 & 3 & 1 & & & \\
\hline & 5 & $\begin{array}{c}5 \\
\text { MC, BC, RC, } \\
\text { Lcne, LCsw }\end{array}$ & 0.05 & 5 & & & & \\
\hline & 6 & $\begin{array}{c}6 \\
M C, B C, R C, \\
\text { Lcne, LCsw, ? }\end{array}$ & 0.05 & 6 & & & & \\
\hline
\end{tabular}

DTN: MO0002PVHA0082.000 [DIRS 148234].

Source: CRWMS M\&O (1996 [DIRS 100116], Appendix E, Table WH-1, pp. WH-16).

NOTE: * LW $=$ Lathrop Wells; $\mathrm{HC}=$ Hidden Cone; LBP = Little Black Peak; MC = Makani Cone; $\mathrm{BC}=$ Black Cone; $\mathrm{RC}=$ Red Cone; Lcne = Little Cones North East LCsw = Little Cones southwest, undetected. A + indicates eruptive centers considered to be part of a single volcanic event. 
The locations of the Quaternary volcanoes are listed in Table C-11. These values were used in the PVHA calculation (CRWMS M\&O 1996 [DIRS 100116]) and were taken from Connor and Hill (1995 [DIRS 102646]).

Table C-11. Volcano Locations

\begin{tabular}{|c|c|l|}
\hline UTM East $(\mathbf{k m})$ & UTM North $(\mathbf{k m})$ & \multicolumn{1}{c|}{ Volcano } \\
\hline 543.780 & 4060.380 & Lathrop Wells \\
\hline 523.230 & 4112.530 & Hidden Cone \\
\hline 522.130 & 4110.340 & Little Black Peak Cone \\
\hline 540.330 & 4079.130 & Makani Cone (North Cone) \\
\hline 538.840 & 4073.990 & Black Cone \\
\hline 537.450 & 4071.470 & Red Cone \\
\hline 535.500 & 4069.490 & Little Cone northwest \\
\hline 535.131 & 4069.220 & Little Cone southeast \\
\hline
\end{tabular}

Source: DTN: MO0002PVHA0082.000 [DIRS 148234].

The calculation of the distribution for the number of eruptive centers per volcanic event and the average spacing between eruptive centers was performed using the software routine NECPDS (BSC 2000 [DIRS 168238]). The data in Tables C-1 through C-11 were used to create the following input files. The resulting output files are listed after each input file.

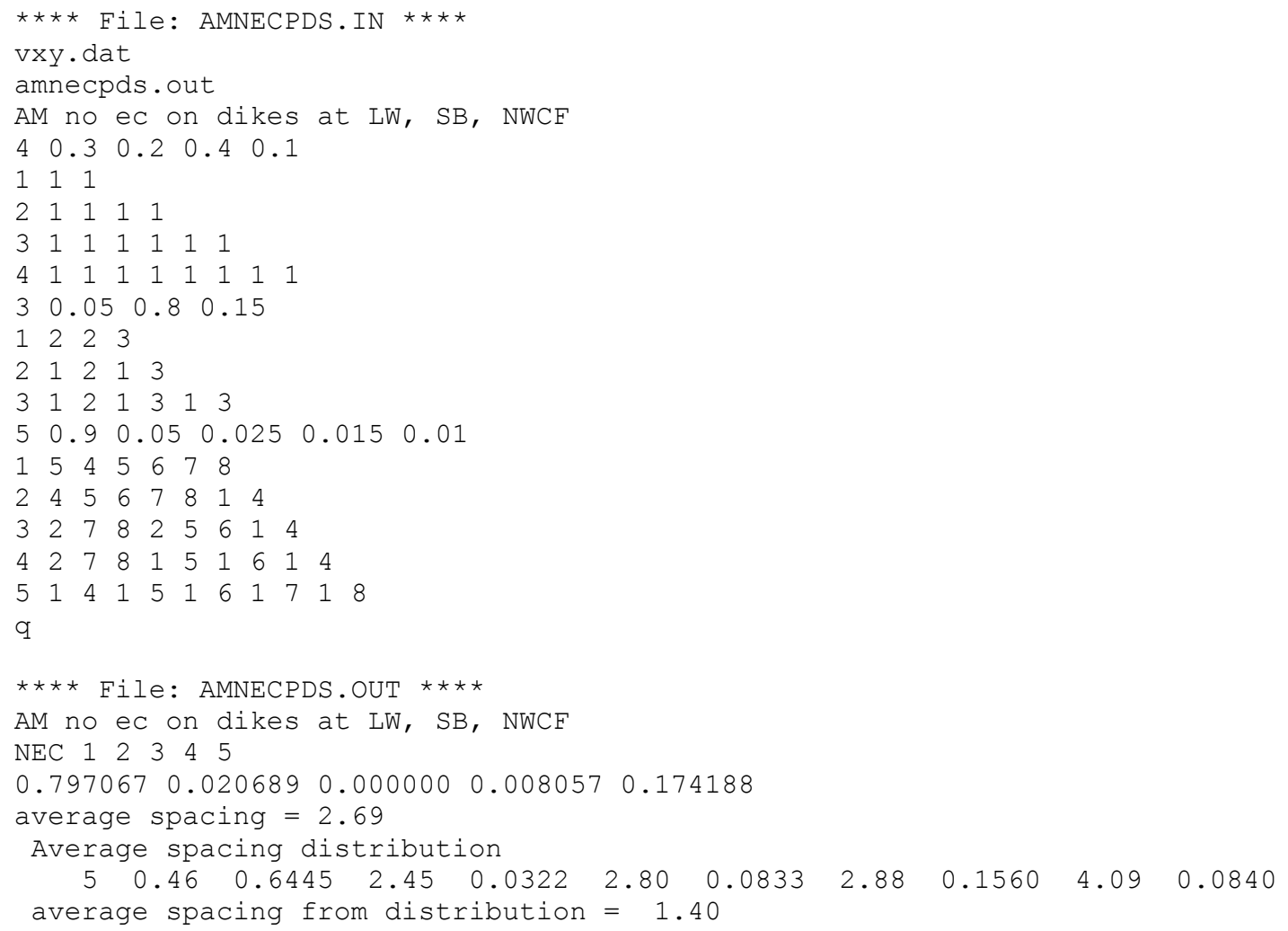




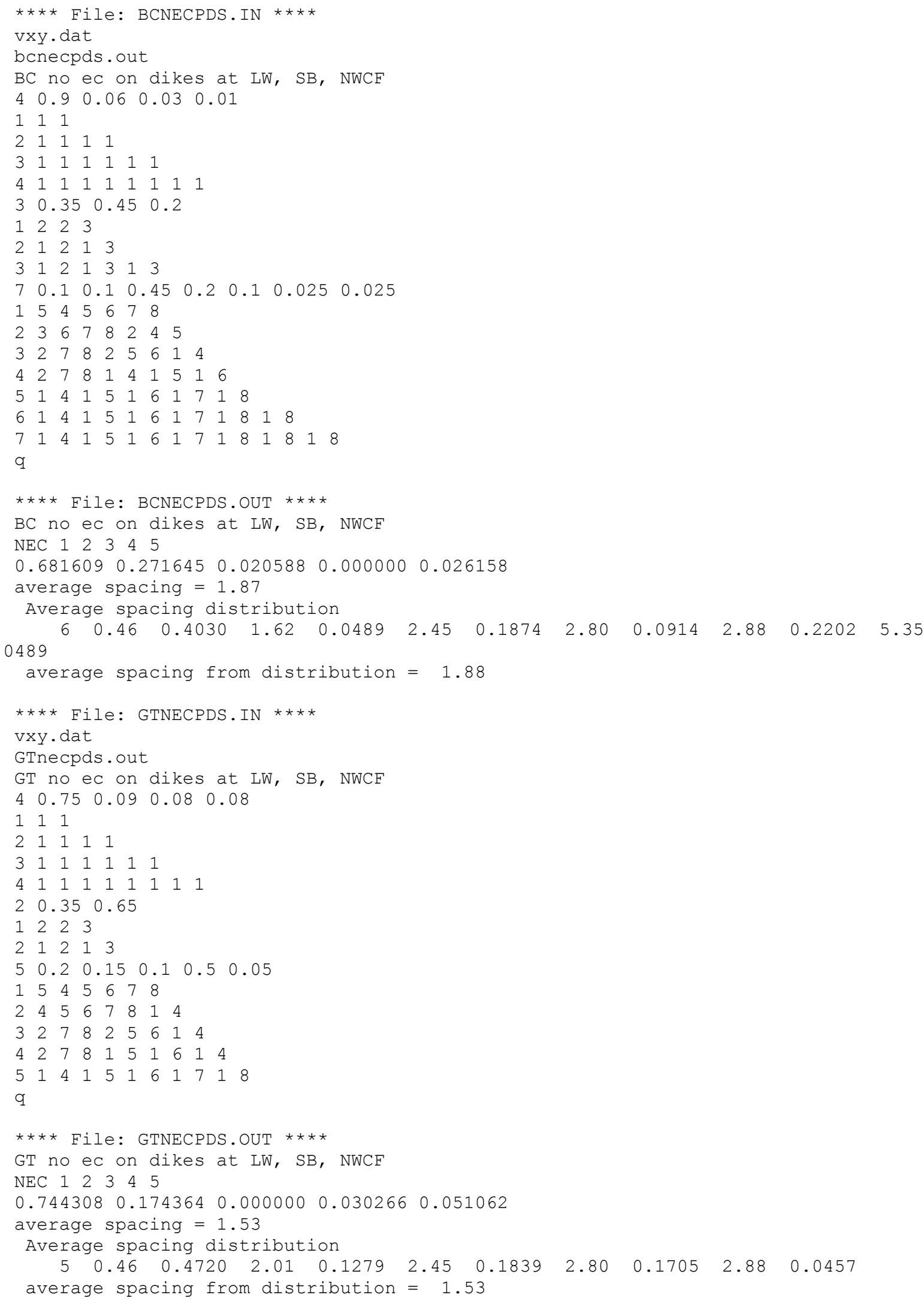




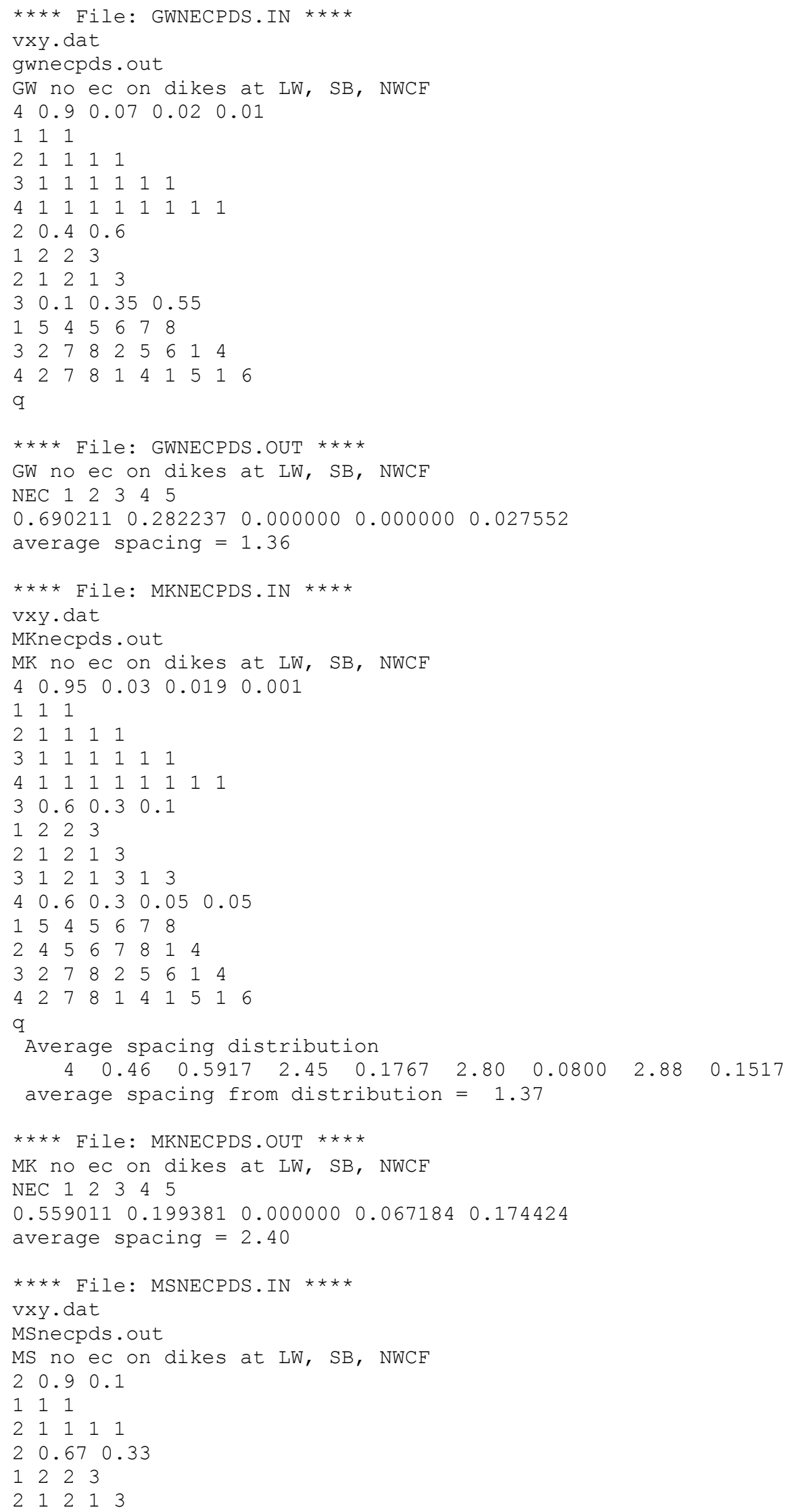




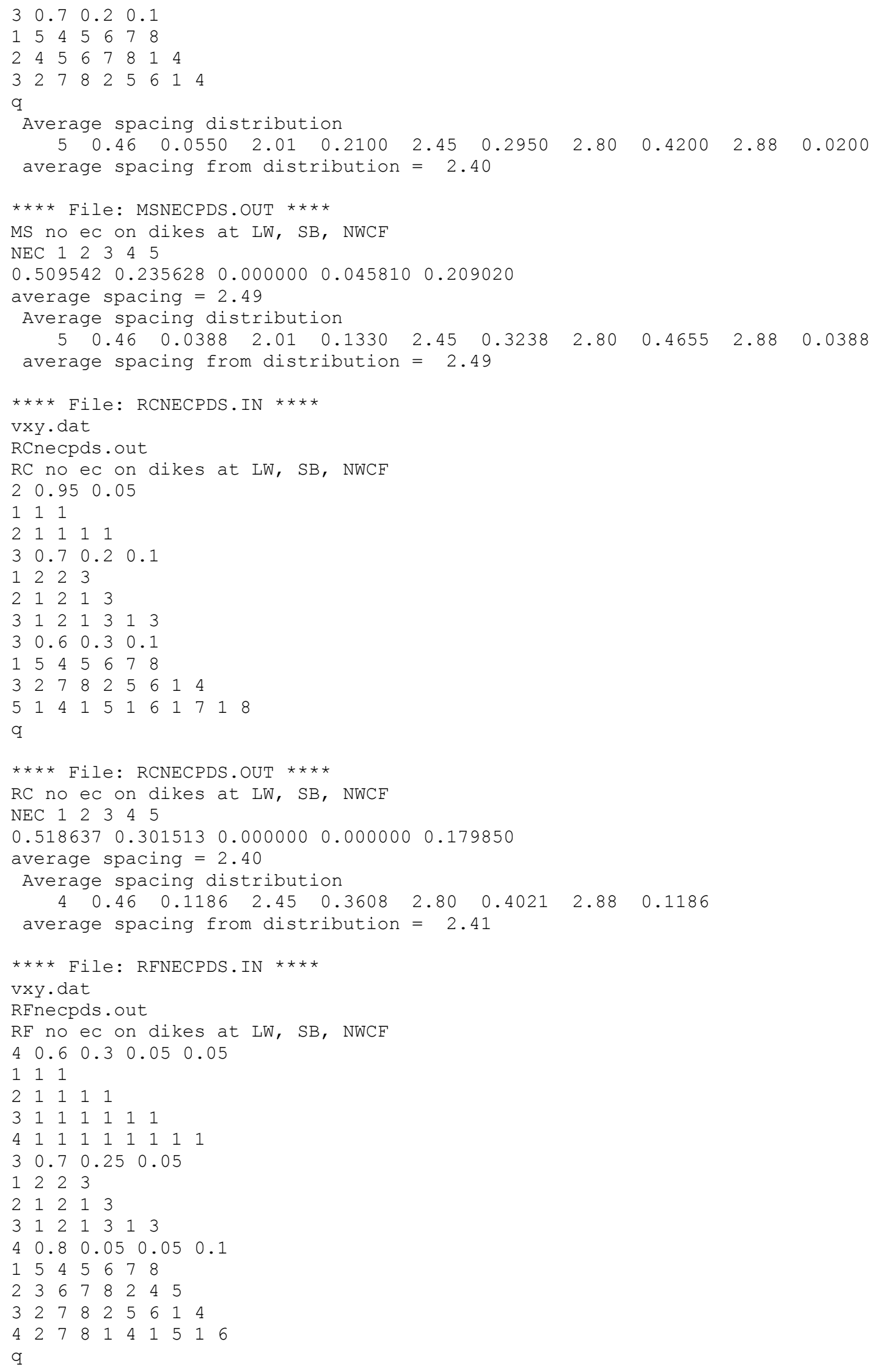




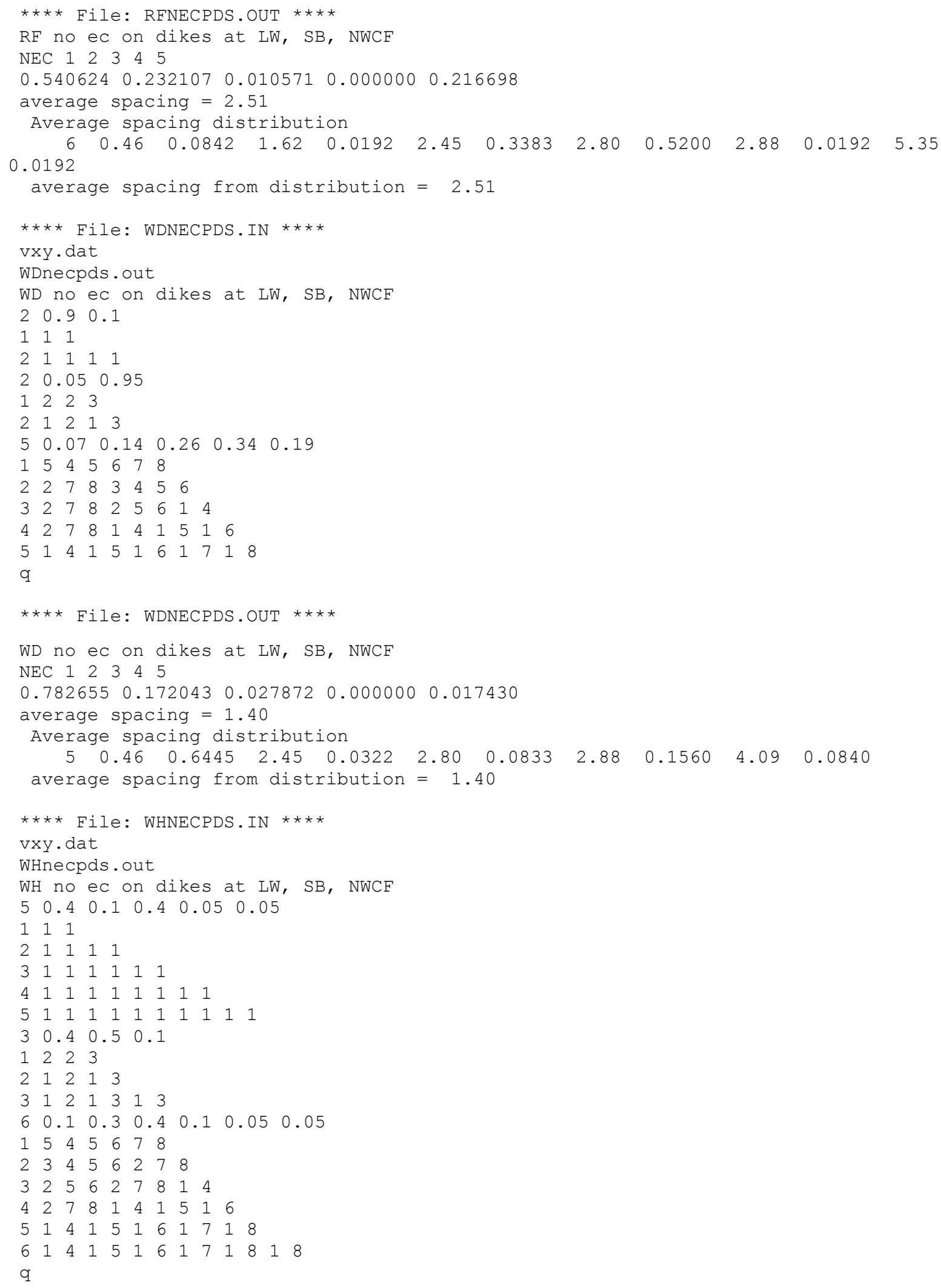




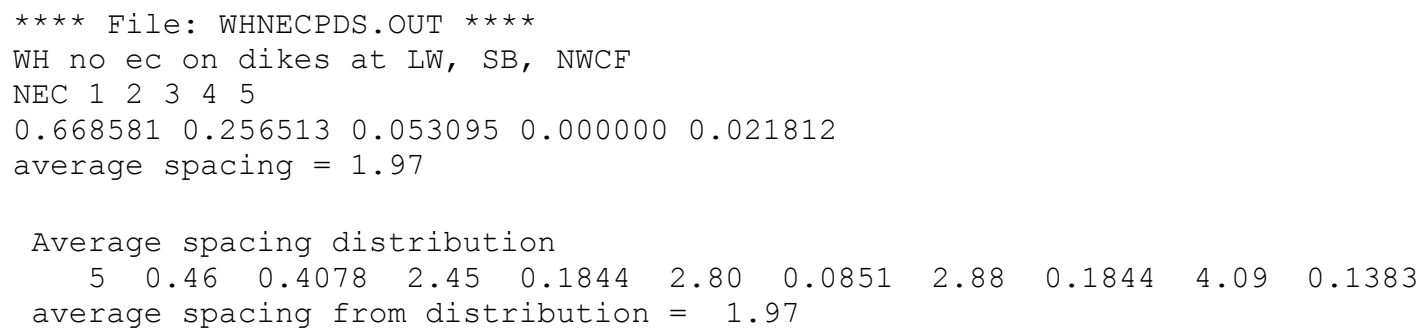

The distributions for $\mathrm{nEC}$ for each expert are plotted in Figure $\mathrm{C}-1$. The expected value for the average spacing between eruptive centers computed from each PVHA expert's hazard model is listed in Table $\mathrm{C}-12$ and the empirical distributions for the average spacing between eruptive centers are listed in Table C-13.

Table C-12. Summary of Expected Average Spacing Between Eruptive Centers Calculation Results

\begin{tabular}{|l|c|}
\hline \multicolumn{1}{|c|}{ PVHA Expert } & $\begin{array}{c}\text { Expected Average Spacing } \\
\text { Between Eruptive Centers (km) }\end{array}$ \\
\hline Alex McBirney (AM) & 2.7 \\
\hline Bruce Crowe (BC) & 1.9 \\
\hline George Thompson (GT) & 1.5 \\
\hline George Walker (GW) & 1.4 \\
\hline Mel Kuntz (MK) & 2.4 \\
\hline Michael Sheridan (MS) & 2.5 \\
\hline Richard Carlson (RC) & 2.4 \\
\hline Richard Fisher (RF) & 2.5 \\
\hline Wendell Duffield (WD) & 1.4 \\
\hline William Hackett (WH) & 2.0 \\
\hline
\end{tabular}

Output DTN: LA0009FP831811.001. 
Table C-13. Empirical Distribution for Average Spacing Between Eruptive Centers Calculation Results

\begin{tabular}{|c|c|}
\hline PVHA Expert & $\begin{array}{l}\text { Empirical Distribution for Average Spacing between } \\
\text { Eruptive Centers (km) }\end{array}$ \\
\hline Alex McBirney (AM) & $\begin{array}{l}0.46(0.0272), 2.01(0.0492), 2.45(0.0253), 2.80 \text { (0.8859), } \\
2.88(0.0124)\end{array}$ \\
\hline Bruce Crowe (BC) & $\begin{array}{l}0.46(0.4031), 1.62(0.0489), 2.45(0.1874), 2.80(0.0914), \\
2.88(0.2203), 5.35(0.0489)\end{array}$ \\
\hline George Thompson (GT) & $\begin{array}{l}0.46(0.4720), 2.01(0.1279), 2.45(0.1839), 2.80(0.1705) \text {, } \\
2.88(0.0457)\end{array}$ \\
\hline George Walker (GW) & $0.46(0.5916), 2.45(0.1767), 2.80(0.0800), 2.88(0.1517)$ \\
\hline Mel Kuntz (MK) & $\begin{array}{l}0.46(0.0550), 2.01(0.2100), 2.45(0.2950), 2.80(0.4200) \text {, } \\
2.88(0.0200)\end{array}$ \\
\hline Michael Sheridan (MS) & $\begin{array}{l}0.46(0.0388), 2.01(0.1330), 2.45(0.3238), 2.80(0.4656), \\
2.88(0.0388)\end{array}$ \\
\hline Richard Carlson (RC) & $0.46(0.1186), 2.45(0.3608), 2.80(0.4020), 2.88(0.1186)$ \\
\hline Richard Fisher (RF) & $\begin{array}{l}0.46(0.0842), 1.62(0.0192), 2.45(0.3383), 2.80 \text { (0.5199), } \\
2.88(0.0192), 5.35(0.0192)\end{array}$ \\
\hline Wendell Duffield (WD) & $\begin{array}{l}0.46(0.6445), 2.45(0.0322), 2.80(0.0833), 2.88(0.1560) \\
4.09(0.0840)\end{array}$ \\
\hline William Hackett (WH) & $\begin{array}{l}0.46(0.4078), 2.45(0.1844), 2.80(0.0851), 2.88(0.1844), \\
4.09(0.1383)\end{array}$ \\
\hline
\end{tabular}

Output DTN: LA0009FP831811.004.

NOTE: The values in ( ) are the empirical probability for the preceding value of average spacing.

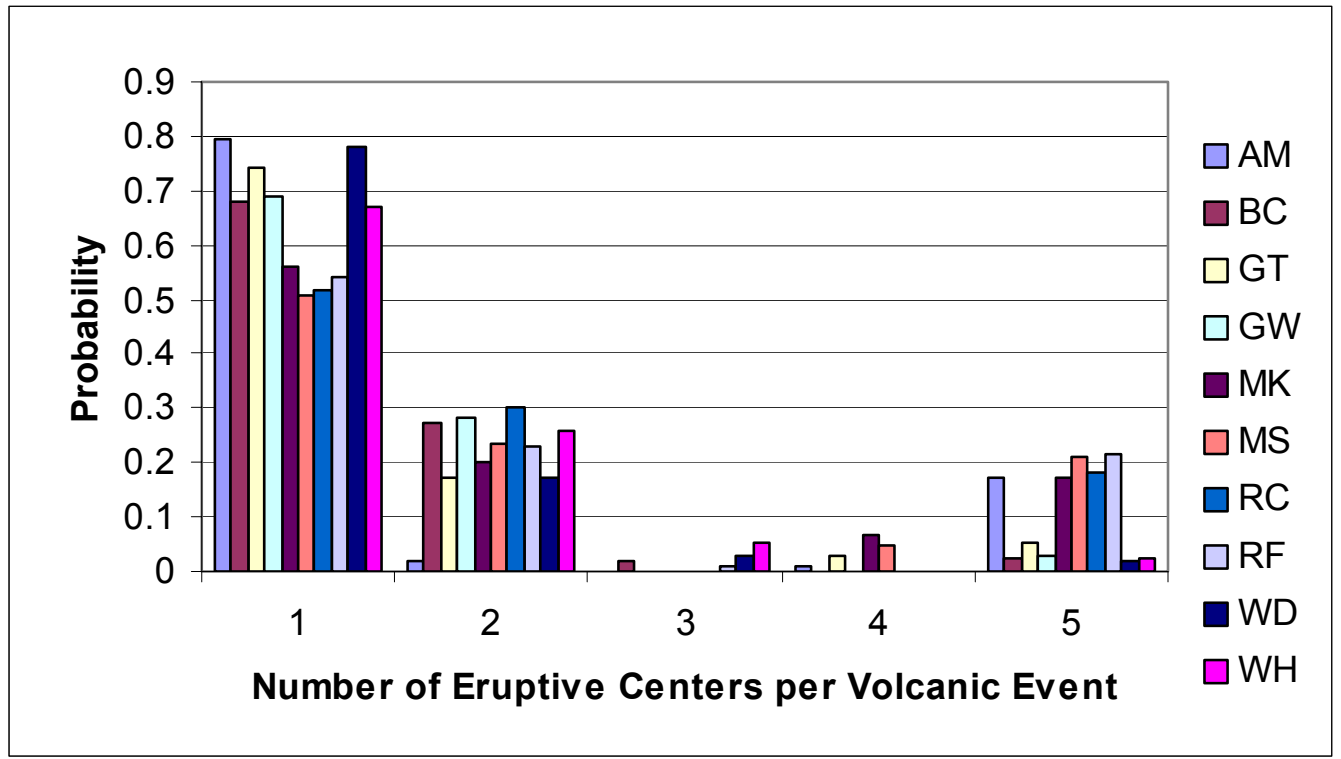

Output DTN: LA0009FP831811.001.

NOTE: The two-letter code indicates the PVHA expert's initials from Table C-12.

Figure C-1. Distributions for Number of Eruptive Centers per Volcanic Event, $\mathrm{n}^{\mathrm{EC}}$, Derived from the Probabilistic Volcanic Hazard Analysis Experts' Interpretations 


\section{INTENTIONALLY LEFT BLANK}




\section{APPENDIX D}

ADDRESSING YUCCA MOUNTAIN REVIEW PLAN, FINAL REPORT ACCEPTANCE CRITERIA RELATED TO SITE CHARACTERIZATION, IDENTIFICATION OF EVENTS WITH PROBABILITIES GREATER THAN $10^{-8}$ PER YEAR, AND VOLCANIC DISRUPTION OF WASTE PACKAGES 
The probability of intersection of the repository by an ascending basaltic dike has been estimated to be $1.7 \times 10^{-8}$ per year. Therefore, to meet the requirements of $10 \mathrm{CFR} 63.114(\mathrm{~d})$, the probability of intersection has been identified as an event that must be evaluated as part of the analysis of repository postclosure performance. Section 1.5.2 of the Yucca Mountain Review Plan, Final Report, and Section 1.5.3 of NUREG-1804 (NRC 2003 [DIRS 163274]) provides the acceptance criteria that apply to the description of site characterization activities. NUREG-1804, Section 2.2.1.2.2.3 contains Acceptance Criteria related to the integrated subissue of identification of events with probabilities greater than $10^{-8}$ per year. NUREG-1804, Section 2.2.1.3.2.3 contains the acceptance criteria related to the integrated subissue of mechanical disruption of waste packages. NUREG-1804, Section 2.2.1.3.10.3 contains the acceptance criteria related to the integrated subissue of volcanic disruption of waste packages. The following information identifies sections of this report that contain information relevant to future igneous events at Yucca Mountain. The applicable acceptance criteria may also be addressed in other analysis and model reports and are considered fully addressed when this report is considered in conjunction with those reports.

\section{Section 1.5.3 Acceptance Criterion 1: The "General Information" section of the License Application contains an adequate description of site characterization activities}

1. An adequate overview is provided of the site characterization activities related to geology; hydrology; geochemistry; geotechnical properties and conditions of the host rock; climatology, meteorology, and other environmental sciences; and the reference biosphere.

Section 6.1.1 describes the conceptual model for igneous activity, and Section 6.2 describes the volcanic history of the Yucca Mountain region. Section 6.3 describes the PVHA (CRWMS M\&O 1996 [DIRS 100116]), including the process used (Section 6.3.1), the definition of a volcanic event, and the technical basis for the definition (6.3.2). Section 6.4 describes the Crater Flat structural domain and its relationship to volcanism.

Section 1.5.3 Acceptance Criterion 2: The "General Information" section of the License Application contains an adequate description of site characterization results.

2. A sufficient understanding is provided of current features and processes present in the Yucca Mountain region.

FEPs associated with igneous activity and addressed by information in this report are identified in Section 6.1.2. The analysis report describes the volcanic history of the YMR and separates the Miocene eruptions of huge volumes of silicic tephra from the Pliocene and Quaternary eruptions of very modest amounts of basalt that ended with the eruption(s) at the Lathrop Wells cone about 80,000 years ago. Internal structure and boundaries of the Crater Flat structural domain are described in Section 6.4.1. The correlation of volcanism with features of the structural domain is described in Section 6.4.1.5. The relationship of volcanic source zones described in the PVHA) to the structural domain is described in Section 6.4.2. 
The PVHA established that the annual probability of intersection of the repository by a basaltic dike is very low but still large enough that volcanism must be considered in the TSPA-LA. The estimate of the annual probability of intersection of the repository by an ascending basaltic dike was done using an expert elicitation process described in the PVHA. Topics of special interest include (a) discussion of PVHA results and uncertainty (Section 6.3.1.5), (b) consideration of alternative conceptual models (Section 6.3.1.6), (c) discussion of the significance of buried volcanic centers on PVHA results (Section 6.3.1.7), (d) discussion of alternative estimates of intersection probabilities, (e) discussion of the definitions and parameters of a volcanic event and implications for alternative probability calculations (Section 6.3.2), and (f) discussion of conceptual models of volcanism and formulation of probability models (Section 6.3.3).

3. An adequate understanding is provided of future events and processes likely to be present in the Yucca Mountain region that could affect repository safety.

The PVHA established that the annual probability of intersection of the repository by a basaltic dike is very low but still large enough that volcanism must be considered in the TSPA-LA. The estimate of the annual probability of intersection of the repository by an ascending basaltic dike was done using an expert elicitation process described in the PVHA. Topics of special interest include (a) discussion of PVHA results and uncertainty (Section 6.3.1.5), (b) consideration of alternative conceptual models (Section 6.3.1.6), (c) discussion of the significance of buried volcanic centers on PVHA results (Section 6.3.1.7), (d) discussion of alternative estimates of intersection probabilities, (e) discussion of the definitions and parameters of a volcanic event and implications for alternative probability calculations (Section 6.3.2), and (f) discussion of conceptual models of volcanism and formulation of probability models (Section 6.3.3).

For TSPA-LA, volcanic disruption of the repository will be modeled by two disruption scenarios. The first is a direct release scenario, which features a basaltic eruption through the repository and ejection and dispersal of contaminated ash to the location of the RMEI. The second is an indirect release scenario, which features intrusion of a basaltic dike into the repository without eruption, damage to waste packages, and exposure of the waste to transport by normal groundwater mechanisms. In each case, the dose is multiplied by the annual probability to provide a probability-weighted mean annual dose. The annual probability is documented in this report and other reports document the other parameters needed to complete the models for the two scenarios.

4. The description of the reference biosphere is consistent with present knowledge of natural processes in and around the Yucca Mountain site, including the location of the RMEI.

This report does not address the characteristics of the reference biosphere or the location of the RMEI. 


\section{Section 2.2.1.2.2.3, Identification of Events with Probabilities Greater Than $10^{-8}$ Per Year}

\section{Acceptance Criterion 1: Events Are Adequately Defined}

5. Events or event classes are defined without ambiguity and used consistently in probability models, so that probabilities for each event or event class are estimated separately.

For the PVHA (CRWMS M\&) 1996 [DIRS 100116]), an expert panel was convened in 1995 to review all pertinent data relating to volcanism at Yucca Mountain and, based on these data, to quantify both the annual probability and associated uncertainty of a volcanic event intersecting a proposed repository sited at Yucca Mountain. The data the experts reviewed was comprehensive, consisting of two decades of data collected by volcanologists who conducted studies to quantify the probability that a future volcanic eruption would disrupt the proposed repository. PVHA results and uncertainties are summarized in Section 6.3.1.5. Section 6.3.2 describes how the experts defined a volcanic event and the implications of the definition for alternative probability calculations. Based on the description in Section 6.3.2, although the experts defined a volcanic event differently, the product of the expert elicitation process was an unambiguous definition of a volcanic event and the descriptions in Sections 6.3.2 and 6.3.3 show how the definitions were consistently used in the development and evaluation of probability models that supported the estimate of the probability of intersection of the proposed repository by a future igneous event.

6. Probabilities of intrusive and extrusive igneous events are calculated separately.

Section 6.5.3 describes the results of the estimation of the probability of intersection of the repository footprint by an ascending basaltic dike. The section also describes the results of the estimation of the number of eruptive centers that could occur within the repository footprint. Probability values, presented in Table 6-14, show the annual frequency of intersection of the repository by a dike, the conditional probability of at least one eruptive center (given intersection), and the annual frequency of occurrence of one or more eruptive centers within the proposed repository.

\section{Acceptance Criterion 2: Probability Estimates For Future Events Are Supported By Appropriate Technical Bases}

1. Probabilities for future natural events have considered past patterns of the natural events in the Yucca Mountain region considering the likely future conditions and interactions of the natural and engineered system. These probability estimates have specifically included igneous events.

Section 6.2 describes the volcanic history of the YMR. Section 6.3.1 describes the PVHA process and includes documentation of the measures used to include information about past patterns of igneous activity in the YMR were incorporated into alternative spatial and temporal distributions of potential future volcanic activity in the region (Section 6.3.1.3). Section 6.3.1.7 describes the methods used to evaluate the significance of buried volcanic centers on the PVHA results, and Section 6.3.1.8 
describes the measures used to include alternative estimates of the intersection probability. Section 6.3.2 includes examples of how information about vents and vent alignments in the YMR was incorporated into the probability calculations.

\section{Acceptance Criterion 3: Probability Model Support Is Adequate}

(1) Probability models are justified through comparison with output from detailed process-level models and/or empirical observations (e.g., laboratory testing, field measurements, or natural analogs, including Yucca Mountain site data). Specifically:

(a) For infrequent events, the U.S. Department of Energy justifies, to the extent appropriate, proposed probability models with data from reasonably analogous systems. Analog systems should contain significantly more events that the Yucca Mountain system, to provide reasonable evaluations of probability model performance.

Section 6.3.1.3 describes the temporal and spatial aspects of probability models and the methods that were used to ensure that alternative spatial and temporal models were considered by the experts and included in the development of probability models. Section 6.3.1.6 describes the consideration of alternative conceptual models of the tectonic environment of Yucca Mountain that have emerged since the PVHA was completed. Section 6.3.1.7 describes the methods used to consider the significance of buried volcanic centers on the PVHA results. Section 6.3.1.8 describes the alternative estimates of intersection probability and provides comments about the relevance of each of the models to estimating the probability of intersection. Section 6.3.2 describes definitions and parameters of a volcanic event and describes implications of these elements for alternative probability calculations. Section 6.3.2.1 specifically addresses use of analogue information and describes evidence from analogue sites related to determining whether dikes or dike systems can reach the near-surface without any portion of the system erupting. Data from the analogue systems shows that field observations do not support the multipliers assigned for undetected intrusive events by the NRC. Rather, the analogue information supports the interpretation that the intrusion/extrusion ratio is close to 1 .

(b) The U.S. Department of Energy justifies, to the extent appropriate, the ability of probability models to produce results consistent with the timing and characteristics (e.g., location and magnitude) of successive past events in the Yucca Mountain system.

The DOE probability estimate for intersection of the proposed repository by a basaltic dike is a combined estimate developed from inputs of 10 experts but modified to reflect a more current repository design. The experts' models were based on the igneous characteristics of the YMR; hence, the probability models they developed were consistent with the timing and characteristics of past events in the YMR. The information used by the experts and the results of their deliberations are extensively documented in the PVHA (CRWMS M\&O 1996 [DIRS 100116]). The ability of the 
probability model to produce results consistent with timing and characteristics of past events is described in detail in Section 6.5.3, and the effects of new aeromagnetic information on the hazard estimate is evaluated in Section 6.5.4.

Based on structural arguments and the past patterns of the close association of volcanism and extension, the eastern boundaries of local volcanic source zones defined in the PVHA separate more tectonically active and less tectonically active portions of the Crater Flat basin and may be reasonable predictors of the eastern extent of volcanism expected in the future (Section 6.4.2). The correlation between volcanism and internal structures and boundaries of the Crater Flat basin is described in Section 6.4.1.4. The relationship between the probability of dike intersection and structural features of Crater Flat is described in Section 6.4.2. The area of most likely future volcanism is not at the repository but rather is in the southwest part of the Crater Flat basin in the area with the most extension (Section 6.4.2).

(c) The U.S. Department of Energy probability models for natural events use underlying geologic bases (e.g., tectonic models) that are consistent with other relevant features, events, and processes evaluated, using Section 2.2.1.2.1

Consistency of experts' models with tectonic models is discussed in Section 6.4, which presents a detailed description of the Crater Flat structural domain. Consideration of relevant FEPs is discussed in Section 6.1.2.

\section{Acceptance Criterion 4: Probability Model Parameters Have Been Adequately Established}

(1) Parameters used in probability models are technically justified and documented by the U.S. Department of Energy. Specifically:

(a) Parameters for probability models are constrained by data from the Yucca Mountain region and engineered repository system to the extent practical.

Section 6.2 describes the volcanic history of the YMR. Section 6.3.1 describes the PVHA process and includes documentation of the measures used to include information about past patterns of igneous activity in the YMR were incorporated into alternative spatial and temporal distributions of potential future volcanic activity in the region (Section 6.3.1.3). Section 6.3.1.7 describes the methods used to evaluate the significance of buried volcanic centers on the PVHA results, and Section 6.3.1.8 describes the measures used to include alternative estimates of the intersection probability. Section 6.3.2 includes examples of how information about vents and vent alignments in the YMR was incorporated into the probability calculations.

(b) The U.S. Department of Energy appropriately establishes reasonable and consistent correlations between parameters. 
The volcanic history of the YMR is described in Section 6.2. The correlations between volcanism and the internal structure and boundaries of the Crater Flat basin are described in Section 6.4.1.5, and the relationship between Crater Flat structural features and the probability of dike intersection with the repository is described in Section 6.4.2. The reasonableness and consistency of the relationship between intrusive and extrusive event, and the effects of consideration of alternative models of the relationship based on analogue information, is described in detail in Section 6.3.2.1. Alternative event (dike) lengths and their consistency with data from the YMR and with data from analogues are considered in Section 6.3.2.2. Conceptual models of volcanism and the use of these models in the development of probability models are described in Section 6.3.3.

(c) Where sufficient data do not exist, the definition of parameter values and conceptual models is based on appropriate use of other sources, such as expert elicitation conducted in accordance with appropriate guidance.

The DOE probability estimate is based on the results of formal elicitations of ten experts (Section 6.3.1.1). The data considered by the experts was described in detail in the PVHA report (CRWMS M\&O 1996 [DIRS 100116], e.g., Table 3-1). The development of the probability estimate is summarized in Section 6.3 of this report, and the elicitation process is summarized in Section 6.3.1.4. Elicitation results are extensively documented in the PVHA report (CRWMS M\&O 1996 [DIRS 100116], Sections 4.1 and 4.2) and are summarized in this report in Section 6.3.1.5. DOE and $\mathrm{NRC}$ guidance relevant to the elicitation process and adherence to that guidance during the elicitation process was described in the PVHA (CRWMS M\&O 1996 [DIRS 100116], Section 2.1.1).

\section{Acceptance Criterion 5: Uncertainty In Event Probability Is Adequately Evaluated}

(1) Probability values appropriately reflect uncertainties. Specifically:

(a) The U.S. Department of Energy provides a technical basis for probability values used, and the values account for the uncertainty in the probability estimates.

The technical basis for the probability values described in this report are extensively documented in Sections 6.3.2 and 6.4, and the PVHA process is summarized in Section 6.3.1. The formulations and methods used to recalculate the frequency of intersection, develop distributions for length and orientation of dikes, and estimate the number of eruptive centers within the repository footprint are described in Sections 6.5.1 and 6.5.2. The results of the calculations are described in Section 6.5.3.

Uncertainties in the PVHA elicitation process are summarized in Section 6.3.1.5, and uncertainties in the technical basis supporting the probability values calculated in this report are described in Sections 6.3.2 and 6.3.3. The correlation of volcanism in the YMR with the Crater Flat structural domain is discussed in Section 6.4.1.5, and the relationship of the PVHA volcanic source zones to Crater Flat structural features and 
the probability of dike intersection is described in Section 6.4.2. Propagation of uncertainties in the analyses is specifically described in Section 6.5.3 and is shown, for example, in Figure 6-18.

(b) The uncertainty for reported probability values adequately reflects the influence of parameter uncertainty on the range of model results (i.e., precision) and the model uncertainty, as it affects the timing and magnitude of past events (i.e., accuracy).

Propagation of uncertainties in the analyses is specifically described in Section 6.5.3 and shown, for example, in Figure 6-18. Methods to include uncertainties associated with specific parameter are described in the formulation of the probability models in Section 6.5.1.

\section{Integrated Subissue: Mechanical Disruption of Engineered Barriers}

Acceptance criteria related to mechanical disruption of engineered barriers are presented in Section 2.2.1.3.2.3 of NUREG-1804 (NRC 2003 [DIRS 163274]). Because this section of NUREG-1804 addresses the consequences of an igneous event intersecting the repository, the applicability of the information in this report to the acceptance criteria is limited. Information in this report about the segment lengths and orientations of dikes that intersect the repository and the spacing between dikes is needed to evaluate the effects of igneous intrusion on the repository. However, this report does not address issues related to the nature of the possible interactions between a dike and repository drifts; nor does this report address waste package damage caused by exposure to magmatic conditions or the incorporation of such damage models into TSPA-LA.

\section{Acceptance Criterion 1: System Description and Model Integration Are Adequate}

1. Total System Performance Assessment (TSPA) adequately incorporates important design features, physical phenomena, and couplings, and uses consistent and appropriate assumptions throughout the mechanical disruption of engineered barrier abstraction process.

The subjects identified in this acceptance criterion are not addressed by information in this report.

2. The description of geological and engineering aspects of design features, physical phenomena, and couplings that may affect mechanical disruption of engineered barriers, is adequate. For example, the description may include materials used in the construction of engineered barrier components, environmental effects (e.g., temperature, water chemistry, humidity, radiation, etc.) on these materials, and mechanical failure processes and concomitant failure criteria used to assess the performance capabilities of these materials. Conditions and assumptions in the abstraction of mechanical disruption of engineered barriers are readily identified and consistent with the body of data presented in the description.

The subjects identified in this acceptance criterion are not addressed by information in this report. 
3. The abstraction of mechanical disruption of engineered barriers uses assumptions, technical bases, data, and models that are appropriate and consistent with other related U.S. Department of Energy abstractions. For example, assumptions used for mechanical disruption of engineered barriers are consistent with the abstraction of degradation of engineered barriers (Section 2.2.1.3.1 of the Yucca Mountain Review Plan). The descriptions and technical bases provide transparent and traceable support for the abstraction of mechanical disruption of engineered barriers.

The subjects identified in this acceptance criterion are not addressed by information in this report.

4. Boundary and initial conditions used in the TSPA abstraction of mechanical disruption of engineered barriers are propagated throughout the abstraction approaches.

The subjects identified in this acceptance criterion are not addressed by information in this report.

5. Sufficient data and technical bases to assess the degree to which features, events, and processes have been included in this abstraction are provided.

This report provides the mean annual frequency of intersection of the repository footprint by an igneous event (Section 6.5.3.1). The report also provides the conditional distributions for one or more eruptive centers forming within the repository, and distributions for dike length and azimuth (Section 6.5.3.2).

6. The conclusion, with respect to the impact of transient criticality on the integrity of the engineered barriers, is defensible.

Transient criticality is not addressed in this report.

7. Guidance in NUREG-1297 (Altman et al. 1988 [DIRS 103597]) and NUREG-1298 (Altman et al. 1988 [DIRS 103750]) or other acceptable approaches, is followed.

NUREG-1297 describes the generic technical position with respect to the use of peer reviews on high-level waste repository programs. Peer review was not used in the development of this report. NUREG-1298 describes the generic technical position with respect to qualification of existing data. When external sources have provided unqualified data that have been used as direct input to this document, the inputs from those sources are qualified for intended use within the document using the criteria found in AP-SIII.9Q, Scientific Analyses. These criteria represent a subset of the methods and attributes required for qualification of data per AP-SIII.2Q, Qualification of Unqualified Data. These methods and attributes are based on those that are presented in NUREG 1298, which are meant to provide "the level of confidence in the data ... commensurate with their intended use. 


\section{Acceptance Criterion 2: Data Are Sufficient for Model Justification}

1. Geological and engineering values used in the license application to evaluate mechanical disruption of engineered barriers, are adequately justified. Adequate descriptions of how the data were used, and appropriately synthesized into the parameters, are provided.

This report provides the mean annual frequency of intersection of the repository footprint by an igneous event (Section 6.5.3.1). The report also provides the conditional distributions for one or more eruptive centers forming within the repository, and distributions for dike length and azimuth (Section 6.5.3.2).

2. Sufficient data have been collected on the geology of the natural system, engineering materials, and initial manufacturing defects, to establish initial and boundary conditions for the TSPA abstraction of mechanical disruption of engineered barriers.

This report provides the mean annual frequency of intersection of the repository footprint by an igneous event (Section 6.5.3.1). The report also provides the conditional distributions for one or more eruptive centers forming within the repository, and distributions for dike length and azimuth (Section 6.5.3.2). The volcanic history of the region is described in Section 6.2, and the characteristics of the Crater Flat Structural Domain are described in Section 6.4. Other inputs needed to establish initial and boundary conditions for the TSPA abstraction of mechanical disruption of engineered barriers are beyond the scope of this report.

3. Data on geology of the natural system, engineering materials, and initial manufacturing defects used in the TSPA abstraction, are based on appropriate techniques. These techniques may include laboratory experiments, site-specific field measurements, natural analogue research, and process-level modeling studies. As appropriate, sensitivity or uncertainty analyses used to support the U.S. Department of Energy TSPA abstraction are adequate to determine the possible need for additional data.

This report provides the mean annual frequency of intersection of the repository footprint by an igneous event (Section 6.5.3.1). The report also provides the conditional distributions for one or more eruptive centers forming within the repository, and distributions for dike length and azimuth (Section 6.5.3.2). The volcanic history of the region is described in Section 6.2, and the characteristics of the Crater Flat Structural Domain are described in Section 6.4. Use of analogue data for differentiation of intrusive and extrusive events is described in Section 6.3.2.1. Analyses examining the sensitivity of the volcanic hazard estimate to potential buried volcanic centers are described in Section 6.5.4. Other inputs needed to support the TSPA abstraction of mechanical disruption of engineered barriers are beyond the scope of this report. 
4. Engineered barrier mechanical failure models for disruption events are adequate. For example, these models may consider effects of prolonged exposure to the expected emplacement drift environment, material test results not specifically designed or performed for the Yucca Mountain site, and engineered barrier component fabrication flaws.

Analysis of mechanical failure models for disruption events is beyond the scope of this report.

\section{Acceptance Criterion 3: Data Uncertainty Is Characterized and Propagated Through the Model Abstraction}

1. Models use parameter values, assumed ranges, probability distributions, and bounding assumptions that are technically defensible, reasonably account for uncertainties, and variabilities, and do not result in an under-representation of risk.

This report provides the mean annual frequency of intersection of the repository footprint by an igneous event (Section 6.5.3.1). The report also provides the conditional distributions for one or more eruptive centers forming within the repository, and distributions for dike length and azimuth (Section 6.5.3.2). Analyses examining the sensitivity of the volcanic hazard estimate to potential buried volcanic centers are described in Section 6.5.4.

2. Process-level models used to represent mechanically disruptive events, within the emplacement drifts at the proposed Yucca Mountain repository, are adequate. Parameter values are adequately constrained by Yucca Mountain site data, such that the estimates of mechanically disruptive events on engineered barrier integrity are not underestimated. Parameters within conceptual models for mechanically disruptive events are consistent with the range of characteristics observed at Yucca Mountain.

This report provides the mean annual frequency of intersection of the repository footprint by an igneous event (Section 6.5.3.1). The report also provides the conditional distributions for one or more eruptive centers forming within the repository, and distributions for dike length and azimuth (Section 6.5.3.2). Analyses examining the sensitivity of the volcanic hazard estimate to potential buried volcanic centers are described in Section 6.5.4. The analyses described in this report do not include development of parameters for conceptual models of mechanically disruptive events.

3. Uncertainty is adequately represented in parameter development for conceptual models, process-level models, and alternative conceptual models considered in developing the TSPA abstraction of mechanical disruption of engineered barriers. This parameter development may be done either through sensitivity analyses or use of conservative limits.

Uncertainties associated with the PVHA results are described in Section 6.3.1.5. The frequency of intersection of repository footprint by a dike is described in Section 6.5.3.1, and the conditional distributions for intersection length and azimuth 
and number of eruptive centers within the repository footprint are described in Section 6.5.3.2. These distributions include uncertainties associated with each parameter.

4. Where sufficient data do not exist, the definitions of parameter values and conceptual models are based on appropriate use of expert elicitation, conducted in accordance with NUREG-1563 (Kotra et al. 1996 [DIRS 100909]). If other approaches are used, the U.S. Department of Energy adequately justifies their use.

The volcanic hazard estimate (frequency of intersection of the repository by an igneous event) documented in the PVHA is based on an expert elicitation (Section 6.3.1). The elicitation was done in accordance with the DOE procedure for expert elicitation and was consistent with NRC draft guidance for expert elicitations that was the basis for NUREG-1563.

\section{Acceptance Criterion 4: Model Uncertainty Is Characterized and Propagated Through the Model Abstraction}

1. Alternative modeling approaches of features, events, and processes are considered and are consistent with available data and current scientific understanding, and the results and limitations are appropriately considered in the abstraction.

Definitions and parameters of a volcanic event and implications for alternative probability calculations are described in Section 6.3.2, and alternative estimates of the intersection probability are described in Section 6.3.1.8. Consistency of the frequency of intersection estimates with volcanic source zones defined by the PVHA experts is described in Section 6.4.2, and the correlation of internal structures and boundaries of the Crater Flat structural domain with volcanism are described in Section 6.4.1.5. Propagation of uncertainties associated with the frequency of intersection is described in Section 6.5.3.1, and with dike lengths, azimuths, and the number of eruptive centers is described in Section 6.5.3.2. Sensitivity studies that examined the effects of buried volcanic centers (variations in the number of events) on the volcanic hazard estimate are described in Section 6.5.4.

2. Consideration of conceptual model uncertainty is consistent with available site characterization data, laboratory experiments, field measurements, natural analogue information and process-level modeling studies; and the treatment of conceptual model uncertainty does not result in an under-representation of the risk estimate.

As described in Section 6.1.1, the results of the PVHA are a set of alternative models for assessing the volcanic hazard at Yucca Mountain, probabilities that each model is the appropriate model, and probability distributions for the parameters of the models. As such, the PVHA defines the scientific uncertainty in applying models to assess the volcanic hazard. The PVHA experts documented the basis for their assessments of the validity of the alternative models in Probabilistic Volcanic Hazard Analysis for Yucca Mountain, Nevada (CRWMS M\&O 1996 [DIRS 100116], Appendix E). Therefore, 
the results of the PVHA are considered valid for assessing the uncertainty in the volcanic hazard at Yucca Mountain.

In the context of the PVHA the volcanic hazard is defined as the annual frequency of intersection of the repository by a volcanic event. A volcanic event was defined in the PVHA to be a spatially and temporally distinct batch of magma ascending from the mantle through the crust as a dike or system of dikes (CRWMS M\&O 1996 [DIRS 100116], Appendix E). For the purposes of the probability models developed in the PVHA and discussed in this report, a volcanic event is defined as a point $(x, y)$ in space representing the expected midpoint of the dike system involved in the magma ascent. The dike system associated with the volcanic event is represented in probability model by a line element defined in terms of a length, azimuth, and location relative to the point event. The term "dike length" used in the PVHA and in this report when discussing volcanic events, refers to the total length of the dike system associated with the volcanic event. The phrase "intersection of the repository footprint by a dike" refers to intersection of the emplacement area of the repository by the line element representing the dike system associated with the volcanic event. The possibility that a dike system (e.g., multiple dikes) has width or consists of multiple parallel dikes does not significantly affect the intersection probability and is not part of the calculations in this report. The width of the dikes and the number of parallel dikes does affect the consequences of an intersection and is included in the consequence analyses presented in Number of Waste Packages Hit by Igneous Intrusion (BSC 2004 [DIRS 170001]).

Based on the PVHA outputs and assumptions in Section 5 of this report, probability distributions are developed for the length and orientation of intersecting dikes within the repository footprint and for the number of eruptive centers located within the repository footprint (conditional on a dike intersecting the repository). These distributions provide estimates of the uncertainties associated with the parameters.

3. Appropriate alternative modeling approaches are investigated that are consistent with available data and current scientific knowledge and that appropriately consider their results and limitations using tests and analyses that are sensitive to the processes modeled.

Section 6.3.2 describes the definitions and parameters of a volcanic event and implications for alternative probability calculations. In addition, Section 6.3.1 explains that the PVHA resulted in the development of alternative models for volcanism by each expert. The alternatives were combined in the PVHA to produce a composite mean annual frequency of intersection as well as $5^{\text {th }}$ and $95^{\text {th }}$ percentile frequencies. Finally Section 6.5.4 describes studies of the sensitivity of the hazard estimate to variations in the number of buried volcanic centers near Yucca Mountain. 


\section{Acceptance Criterion 5: Model Abstraction Output Is Supported by Objective Comparisons}

1. Models implemented in this TSPA abstraction provide results consistent with output from detailed process-level models and/or empirical observations (laboratory and field testing and/or natural analogues).

The direct input provided to TSPA by the analysis described in this report is the volcanic hazard or the mean annual frequency of intersection of the repository by a basaltic dike. The hazard was determined during the PVHA (Section 6.3.1.5), and the methods selected for the PVHA were used specifically to ensure that uncertainties associated with the hazard estimate were quantified. The PVHA estimate has been updated to consider the 2003 repository footprint (BSC 2003 [DIRS 162289]), and the hazard magnitude has increased from $1.5 \times 10^{-8}$ per year to $1.7 \times 10^{-8}$ per year because of the area of the 2003 footprint is greater than the area of the footprint used for the PVHA (Section 6.5.3). Consistency of the volcanic hazard analysis with detailed process-level models is described in Section 6.4.2, and use of information from natural analogue sites is described in Section 6.3.2.1.

2. Outputs of mechanical disruption of engineered barrier abstractions reasonably produce or bound the results of corresponding process-level models, empirical observations, or both.

This report does not address the effects of disruption of the engineered barriers. Such effects are described in analysis report Number of Waste Packages Hit by Igneous Intrusion (BSC 2004 [DIRS 170001]) and model reports Dike/Drift Interactions (BSC 2004 [DIRS 170028]) and Atmospheric Dispersal and Deposition of Tephra from a Potential Volcanic Eruption at Yucca Mountain, Nevada (BSC 2004 [DIRS 170026]).

3. Well-documented procedures that have been accepted by the scientific community to construct and test the mathematical and numerical models are used to simulate mechanical disruption of engineered barriers.

This report does not describe simulations used to evaluate mechanical disruption of engineered barriers or the results of such simulations. See previous item.

4. Sensitivity analyses or bounding analyses are provided to support the TSPA abstraction of mechanical disruption of engineered barriers that cover ranges consistent with site data, field or laboratory experiments and tests, and natural analogue research.

This report does not describe analyses used to evaluate mechanical disruption of engineered barriers or the results of such simulations. Studies to evaluate the sensitivity of the mean annual frequency of intersection are described in Section 6.5.4. 


\section{Integrated Subissue: Volcanic Disruption of Waste Packages}

Acceptance criteria related to the volcanic disruption of waste packages are presented in Section 2.2.1.3.10.3 of NUREG-1804 (NRC 2003 [DIRS 163274] NUREG-1804). Because this section of NUREG-1804 addresses the consequences of an igneous event intersecting the repository, the applicability of the information in this report to the acceptance criteria is limited. Information in this report about the segment lengths and orientations of dikes that intersect the repository, the number of eruptive centers that could form along a dike segment within the repository footprint, and the spacing between centers is needed to evaluate eruptive processes. However, this report does not address issues related to the nature of the possible interactions between a dike and repository drifts; nor does this report address waste package damage caused by exposure to magmatic conditions or the incorporation of such damage models into TSPA-LA.

\section{Acceptance Criterion 1: System Description And Model Integration Are Adequate}

1. Total system performance assessment adequately incorporates important design features, physical phenomena, and couplings, and uses consistent and appropriate assumptions throughout the volcanic disruption of waste packages abstraction process.

The element is not addressed by information in this report. Information about the effects of exposure of waste packages to the environmental conditions attending intersection of the repository by a basaltic dike is provided in the model report, Dike/Drift Interactions [DIRS 170028].

2. Models used to assess volcanic disruption of waste packages are consistent with physical processes generally interpreted from igneous features in the Yucca Mountain region and/or observed at active igneous systems.

Information in this report addresses the relationship between an ascending dike and the number of eruptive centers that could occur within the repository footprint (Section 6.5.3.2). The formulations and implementation methods needed to support the analyses are described in Sections 6.5.1.2 and 6.5.2.2, respectively. Models that are used to support the analysis of the effects of exposure of waste packages to the environmental conditions attending intersection of the repository by a basaltic dike will be described in the report, Dike/Drift Interactions [DIRS 170028].

3. Models account for changes in igneous processes that may occur from interaction with engineered repository systems.

Changes in igneous processes that may occur from interactions with the engineered repository systems are not addressed in this report. Changes in igneous processes will be addressed in the update of the report, Dike/Drift Interactions [DIRS 170028]. 
4. Guidance in NUREG-1297 and NUREG-1298 (Altman et al. 1998 a, b) or other acceptable approaches is followed.

NUREG-1297 provides guidance for the use of peer review. Peer review was not used in the development or evaluation of this report; so the guidance in NUREG-1297 is not relevant.

External sources have provided unqualified data that have been used as direct inputs to the analyses described in this report. The inputs from these sources are qualified for intended use within the document using the criteria found in AP-SIII.9Q, Scientific Analyses. These criteria represent a subset of the methods and attributes required for qualification of data per AP-SIII.2Q, Qualification of Unqualified Data. These methods and attributes are meant to provide "the level of confidence in the data ... commensurate with their intended use."

\section{Acceptance Criterion 2: Data Are Sufficient For Model Justification}

1. Parameter values used in the license application to evaluate volcanic disruption of waste packages are sufficient and adequately justified. Adequate descriptions of how the data were used, interpreted, and appropriately synthesized into the parameters are provided.

The parameters developed in this report and needed in the analysis of volcanic disruption of waste packages are the results of calculations of the length and orientation of dikes and the number of eruptive centers within the repository. These parameters are documented in Section 6.5.3.

2. Data used to model processes affecting volcanic disruption of waste packages are derived from appropriate techniques. These techniques may include site-specific field measurements, natural analogue investigations, and laboratory experiments.

This report does not provide information about processes affecting volcanic disruption of waste packages, except for the frequency of intersection (Section 6.5.3.1), and conditional distributions for intersection length, azimuth, and number of eruptive centers within the license application footprint (Section 6.5.3.2). Information about and descriptions of the modeling of, processes affecting volcanic disruption of waste packages will be provided in the following analysis reports:

- Characterize Eruptive Processes and Ash Redistribution at Yucca Mountain, Nevada (BSC 2004 [DIRS 169980])

- Dike/Drift Interactions (BSC 2004 [DIRS 170028])

- Number of Waste Packages Hit by Igneous Intrusion (BSC 2004 [DIRS 170001])

- Atmospheric Dispersal and Deposition of Tephra from a Potential Volcanic Eruption at Yucca Mountain, Nevada (BSC 2004 [DIRS 170026]) 
3. Sufficient data are available to integrate features, events, and processes, relevant to volcanic disruption of waste packages into process-level models, including determination of appropriate interrelationships and parameter correlations.

This report does not provide information about processes affecting volcanic disruption of waste packages, except for the frequency of intersection (Section 6.5.3.1), and conditional distributions for intersection length, azimuth, and number of eruptive centers within the license application footprint (Section 6.5.3.2). Table 6-1 identifies the FEPs that are included in this analysis report. However, this report does not provide that FEPs disposition documentation. That documentation will be provided in the update of the disruptive events FEPs analysis report (BSC 2004 [DIRS 170017]).

4. Where sufficient data do not exist, the definition of parameter values and associated conceptual models is based on appropriate use of expert elicitation, conducted in accordance with NUREG-1563 (Kotra et al 1996 [DIRS 100909]). If other approaches are used, the U.S. Department of Energy adequately justifies their use.

The DOE probability estimate is based on the results of formal elicitations of 10 experts (Section 6.3.1). The data considered by the experts was described in detail in the PVHA report (CRWMS M\&O 1996 [DIRS 100116], e.g., Table 3-1). The identification of the technical issues considered in the PVHA is summarized in Section 6.3.1.2 of this report, and the elicitation process is summarized in Section 6.3.1.4. Elicitation results are extensively documented in the PVHA report (CRWMS M\&O 1996 [DIRS 100116], Sections 4.1 and 4.2) and are summarized in this report in Section 6.3.1.5. DOE and NRC guidance relevant to the elicitation process and adherence to that guidance during the elicitation process was described in the PVHA (CRWMS M\&O 1996 [DIRS 100116], Section 2.1.1).

\section{Acceptance Criterion 3: Data Uncertainty Is Characterized And Propagated Through The Model Abstraction}

1. Models use parameter values, assumed ranges, probability distributions, and bounding assumptions that are technically defensible, and reasonably account for uncertainties and variabilities, and do not result in an under-representation of the risk estimate.

The formulations support the probability estimate and propagate parameter uncertainties, methods used to implement the analyses, and results of the analyses are described in detail in Sections 6.5.1, 6.5.2, and 6.5.3, respectively, of this report. In addition, the definitions and parameters of a volcanic event and their implications for alternative probability calculations are described in Section 6.3.2. PVHA results and associated uncertainties are discussed in Section 6.3.1.5. Consideration of alternative probability models in the PVHA process is described in Section 6.3.1.6, and the significance of buried volcanic centers on the PVHA results is described in Section 6.5.4. Alternative estimates of the intersection probability are described in Section 6.3.1.8. The robustness of the estimate of the probability of intersection has been demonstrated through sensitivity analyses (e.g., Brocoum 1997 [DIRS 147772]), 
and some published estimates of the probability of intersection of the repository by a dike are presented in Table 6-5.

2. Parameter uncertainty accounts quantitatively for the uncertainty in parameter values observed in site data and the available literature (i.e., data precision), and the uncertainty in abstracting parameter values to process-level models (i.e., data accuracy).

The uncertainties associated with the temporal and spatial aspects of models of the probability of intersection are described in Section 6.3.1.3. PVHA results and uncertainty are described in Section 6.3.1.5. Similarly, the formulations, implementation, and results of the recalculation of the frequency of intersection and the development of distributions for length and orientation of dikes are explained in Sections 6.5.1, 6.5.2, and 6.5.3, respectively. These sections also explain the development of the probability distributions for the number of eruptive center that could occur within the repository. The process for abstracting the recalculated values is not addressed in this report.

3. Where sufficient data do not exist, the definition of parameter values and associated uncertainty is based on appropriate use of expert elicitation, conducted in accordance with NUREG-1563 (Kotra et al 1996 [DIRS 100909]). If other approaches are used, the U.S. Department of Energy adequately justifies their use.

The DOE probability estimate is based on the results of formal elicitations of 10 experts (Section 6.3.1.1). The data considered by the experts was described in detail in the PVHA report (CRWMS M\&O 1996 [DIRS 100116], Table 3-1). The development of the probability estimate is summarized in Section 6.3.1 of this report, and the elicitation process is summarized in Section 6.3.1.4. Elicitation results are extensively documented in the PVHA report (CRWMS M\&O 1996 [DIRS 100116], Sections 4.1 and 4.2) and are summarized in this report in Section 6.3.1.5. DOE and NRC guidance relevant to the elicitation process and adherence to that guidance during the elicitation process was described in the PVHA (CRWMS M\&O 1996 [DIRS 100116], Section 2.1.1).

\section{Acceptance Criterion 4: Model Uncertainty Is Characterized And Propagated Through The Model Abstraction}

1. Alternative modeling approaches to volcanic disruption of the waste package are considered and are consistent with available data and current scientific understandings, and the results and limitations are appropriately considered in the abstraction.

This report does not address modeling of the volcanic disruption of waste packages. Modeling of the volcanic disruption of waste packages is addressed in Number of Waste Packages Hit [DIRS 170001] and Atmospheric Dispersal and Deposition of Tephra from a Potential Volcanic Eruption at Yucca Mountain, Nevada [DIRS 170026]. 
2. Consideration of conceptual model uncertainty is consistent with available site characterization data, laboratory experiments, field measurements, natural analogue information and process-level modeling studies; and the treatment of conceptual model uncertainty does not result in an under-representation of the risk estimate.

This report does not directly address the processes and associated models of volcanic disruption of waste packages. Modeling of the volcanic disruption of waste packages is addressed in Number of Waste Packages Hit by Igneous Intrusion (BSC 2004 [DIRS 170001]) and Atmospheric Dispersal and Deposition of Tephra from a Potential Volcanic Eruption at Yucca Mountain, Nevada (BSC 2004 [DIRS 170026]).

Uncertainties in conceptual models used to estimate the probability of intersection of the repository, distributions of dike length and orientation, and the number of eruptive centers within the proposed repository are explained in Section 6.5.1, which describes the formulation of the analyses and 6.5.4, which describes studies of the sensitivity of the frequency of intersection to increases in the number of buried volcanic centers.

\section{Acceptance Criterion 5: Model Abstraction Output Is Supported By Objective Comparisons}

This report does not address model abstraction. Analysis outputs consist of the frequency of intersection of the repository (Section 6.5.3.1), and conditional distributions for intersection length, azimuth, and number of eruptive centers within the repository footprint (Section 6.5.3.2). 